\title{
PROFESSIONAL DEVELOPMENT OF ENGLISH LANGUAGE \\ TEACHERS IN MALANG, INDONESIA: \\ INSTITUTIONAL AND INDIVIDUAL PERSPECTIVES
}

Anik Nunuk Wulyani

A thesis submitted for the degree of

Doctor of Philosophy in Applied Linguistics

School of Linguistics and Applied Language Studies

Victoria University of Wellington

2017 

This page is intentionally left blank 



\section{ABSTRACT \\ Professional development of English language teachers in Malang, Indonesia: Institutional and individual perspectives}

Two important areas of professional development for teachers of English as a foreign language (EFL) in Indonesia identified in the 2003 Law on National Education System and 2005 Law on Teachers and Lecturers are disciplinary knowledge and ICT skills. The present thesis investigates institutional and individual aspects of EFL teacher professional development (TPD) in Indonesia in relation to the development of these two areas of expertise.

Three studies were carried out. The first study measured Indonesian EFL teachers' target language (English) proficiency as a core component of their professional knowledge and how it is maintained and developed by the teachers. EFL teachers' language proficiency in this study was operationalised as their lexical, reading and writing proficiency and measured using the Vocabulary Levels Test (VLT), IELTS-like reading comprehension test and IELTS-like academic writing test, respectively. The results showed that the teachers' length of service correlated negatively with their knowledge of academic vocabulary, as well as reading and writing proficiency, indicating issues with the outcomes of the TPD in this area. To triangulate the test results, teacher perceptions data were also gathered using questionnaires and interviews. It was found that the EFL teachers tended to overestimate their own overall English language proficiency.

The second study used a longitudinal blogging activity with the EFL teachers as a form of personal professional development that targeted their English language and ICT skills while reflecting on topics related to their professional (teaching) activities. Qualitative analysis of the blog entries of three EFL teachers suggested that the individual teachers' blogging, critical reading and reflective writing skills were very uneven. Interviews with nine teachers and 11 educational stakeholders were then conducted to understand their views on blogging as a form of professional development. The results revealed that the perceived obstacles and 
drawbacks outweighed the perceived benefits of blogging as a form of personal professional development.

The third study examined Indonesian national TPD policy documents, how these policies were translated into local professional development programmes in Malang district. It was found that the needs for EFL teachers to maintain their English proficiency and ICT skills were only partially addressed in TPD policy and implementation. In addition, the interviewed teachers and stakeholders perceived the definitions, goals, administration, evaluation, benefits, and challenges of TPD differently.

Taken as a whole, the present findings show that institutional implementation of TPD policies in Indonesia needs to better target individual EFL teachers' English proficiency and ICT skills, and that opportunities for better professional development need to be sought at both personal and institutional levels. At the individual level, self-motivation to continue learning is crucial for English language teachers who want to keep up with change and innovation in English language teaching. At the institutional level, needs analyses and environmental analyses are essential in designing programs for maintaining and developing teacher professional competency. 


\section{ACKNOWLEDGEMENTS}

My $\mathrm{PhD}$ journey has been amazing in many different ways and I come to realise that the journey is manageable and workable because I received assistance from many people and significant others. First of all, I would like to thank Allah for giving me the chance to pursue one of my dreams, studying for a $\mathrm{PhD}$ in Aotearoa, New Zealand.

My gratitude goes to my main supervisor Dr Irina Elgort and my secondary supervisor Dr Averil Coxhead. I am truly grateful for having them as my supervisors because I learn so much about thinking, reading and writing critically. They also provided support and encouragement throughout my thesis writing process. Their feedback and comments about the subjects I investigated, my writing style, the organisation of the thesis and life in academia have enriched my personal professional development. I am very fortunate and grateful to have both of you during my ups and downs and throughout my thesis writing process.

I also would like to thank Directorate of Higher Education of Indonesia (DIKTI) and Victoria University of Wellington, the sponsors of my $\mathrm{PhD}$ study in the Land of the Long White Cloud. The scholarships have allowed me to start my study, experience the Four Strands (Nation, 2007) first hand through English Proficiency Programme (EPP), participate in conferences, and finish my study.

My heartfelt appreciation goes to my informants who had spent some of their precious time and shared their knowledge, experiences and opinions in the study. I do hope that the results of this study would benefit personal and institutional professionalism of EFL teachers in Indonesia and other countries with similar setting.

I also thank my institution, Universitas Negeri Malang (UM), for allowing me to pursue my $\mathrm{PhD}$. Special thank yous are extended to the former Dean of Faculty of the Letters of UM, Professor Dawud and to the present Dean, Professor Utami Widiati for their full support of my study. I thank the Head of School and my colleagues in Jurusan Sastra Inggris, Fakultas Sastra, UM for the encouragement 
and support. For Evi, Inayatul, Maya, Nabhan, Niamika, Nurenzia, Nur Hayati and Pak Yazid, thank you for being there to listen to my rants. Stay fantastic! My gratitude also goes to the staff of the Linguistics and Applied Language Studies (LALS), Language Learning Centre (LLC), Student Learning, and Victoria International. Thank you for being very supportive of international students like me. I love being part of the Victoria Family. Thank you to Perhimpunan Pelajar Indonesia Wellington (PPIW), Umat Muslim Indonesia (UMI) and KAMASI in Wellington, New Zealand. Thank you for allowing me to participate and be an active member.

I am also grateful that I am surrounded by beautiful, supportive, and helpful people: Fenty, Rini, Marko, Dwi Purwestri, Ubay, Ghif, Ningsih, Tenri, Lilik, Dwi Agustina, Avi, Sani, Rike, TJ, Tareeq, Ha, Diego, Pim, Yen, Mark, Shota, Melanie, Paweena, Khadij, and Emily. It was great to know you all. Stay in touch! My gratitude also goes to my family and relatives. I thank my Mom, Dad, sisters, brothers, in-laws, and my munchkins for the encouragement and prayers. I love you all! Finally, I thank my husband, Setyo Utomo, for his companionship through my $\mathrm{PhD}$ journey. I think you should receive a title of $\mathrm{S} . \mathrm{PhD}$, spouse of a doctor of philosophy, eh? I love you to the moon and back and what about jumping into more adventures soon? 


\section{TABLE OF CONTENTS}

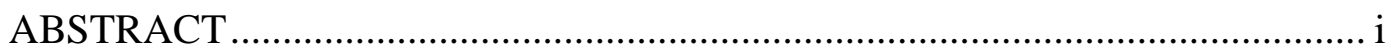

ACKNOWLEDGEMENTS .....................................................................

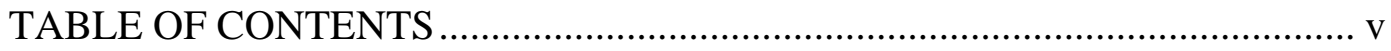

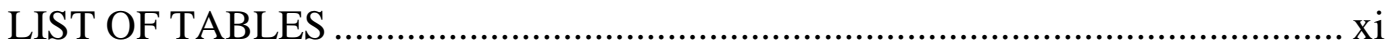

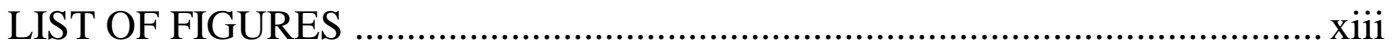

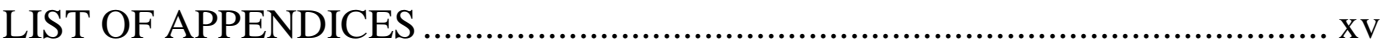

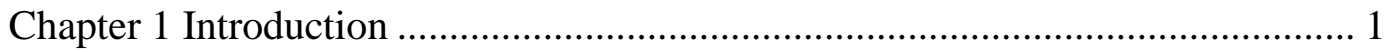

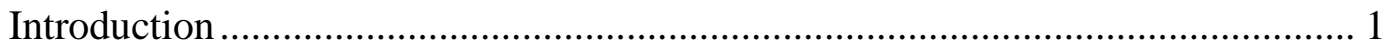

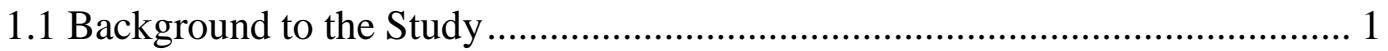

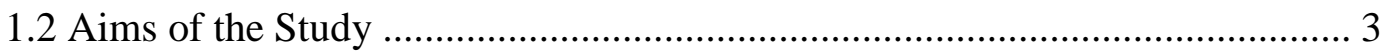

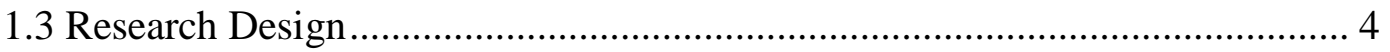

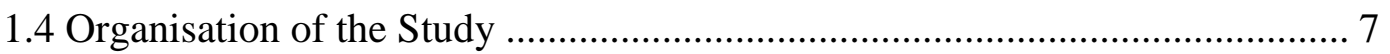

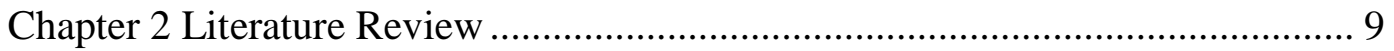

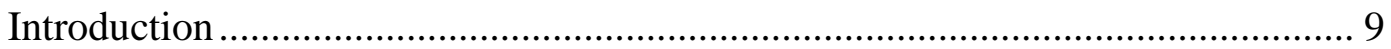

2.1 Teacher professional development (TPD) and its socio-cultural context ....... 10

2.2 What aspects characterise effective TPD programmes? ............................... 15

2.2.1 Institutional perspectives of teacher development .................................. 18

2.2.2 Individual perspectives of teacher development..................................... 20

2.2.3 Environment analyses, needs analyses and evaluation in teacher

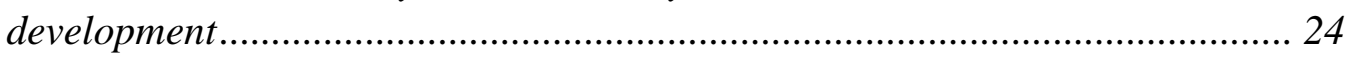

2.2.4 Studies on TPD practice in Indonesia .................................................. 26

2.3 Why is target language proficiency maintenance an essential component of

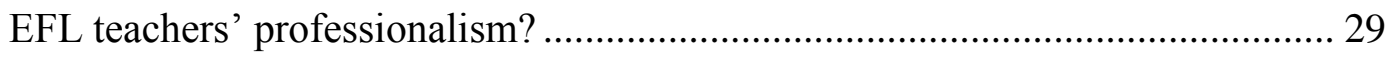

2.3.1 The status of English in Indonesian educational policy........................... 29

2.3.2 Language attrition among second or foreign language users ................. 30

2.3.3 Studies on foreign language teachers ' L2 proficiency ........................... 32

2.4 What potential does blogging-integrated professional development hold for EFL TPD?

2.4.1 Mastering ICT is an integral part of Indonesian National Education

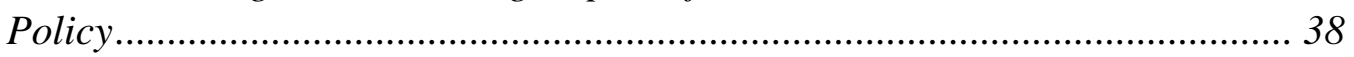

2.4.2 Information and communication technology is a useful teaching aid...... 39

2.4.3 Blogging offers benefits for teaching and learning ............................... 42 
2.5 Summary

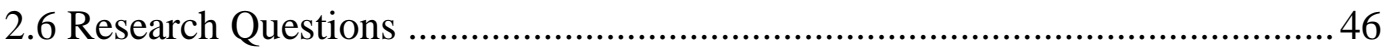

Chapter 3 Teacher L2 Proficiency Study ........................................................ 51

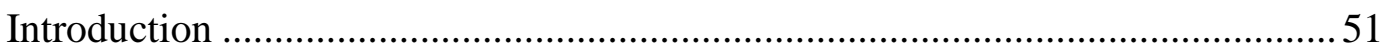

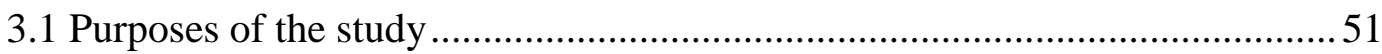

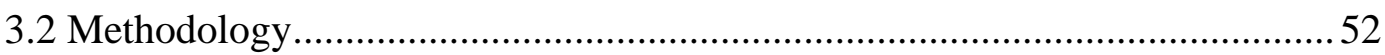

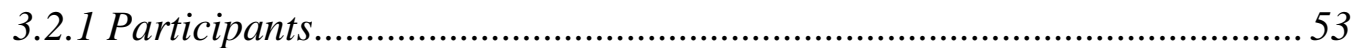

3.2.2 Data collection instruments ....................................................................... 55

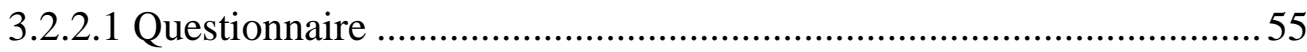

3.2.2.2 Language proficiency tests ............................................................... 57

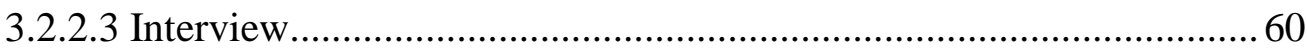

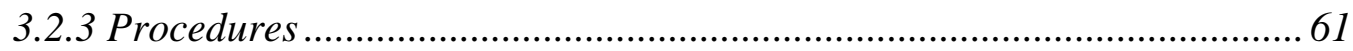

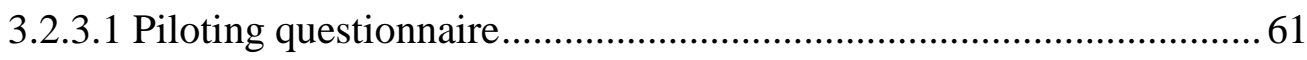

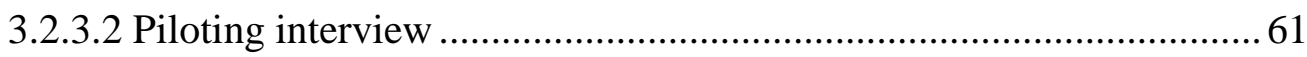

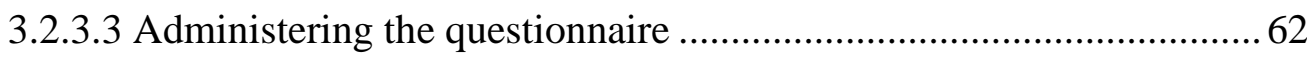

3.2.3.4 Administering L2 proficiency tests .................................................... 63

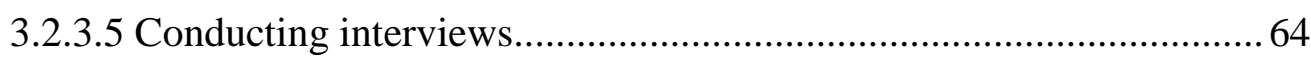

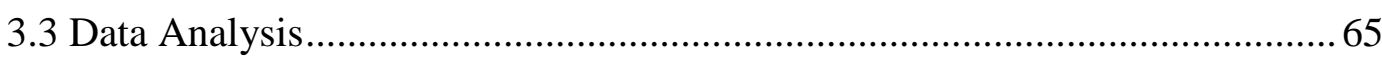

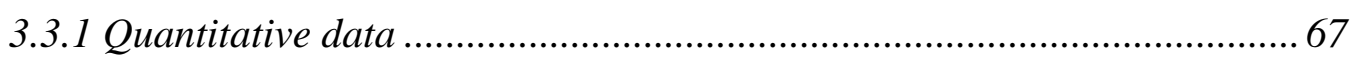

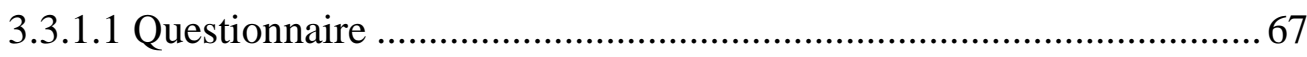

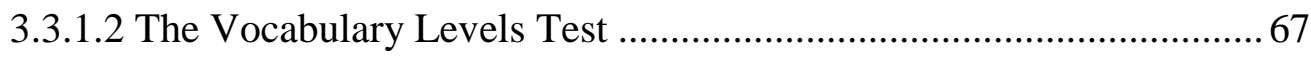

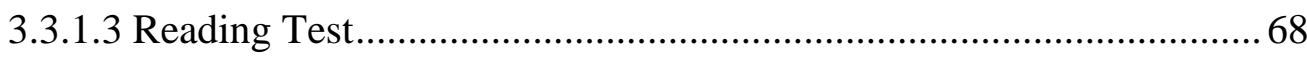

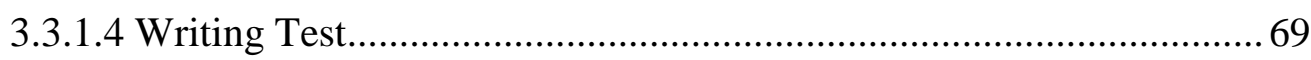

3.3.1.5 Analysis of the relationship between test scores and teachers' length

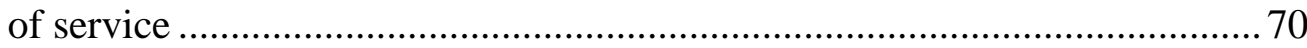

3.3.2 Qualitative data: Interview ................................................................... 71

3.4 Results and Discussion of the Findings on EFL Teachers' L2 Proficiency ....73

3.4.1 L2 vocabulary knowledge …………………………………………... 73

3.4.2 L2 reading proficiency..................................................................... 76

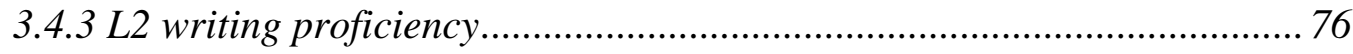

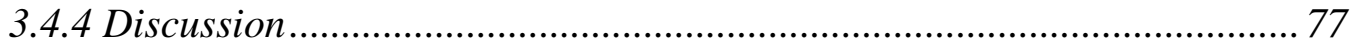

3.5 Relationship between the EFL Teachers' Years of Service and Their English

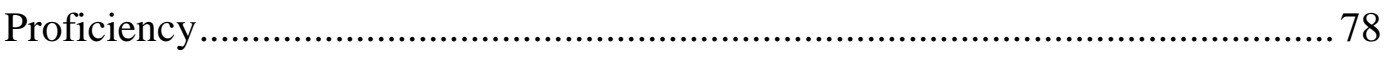

3.5.1 Years of service and teachers' academic vocabulary level ...................... 78 
3.5.2 Years of service and teachers' reading proficiency ............................... 79

3.5.3 Years of service and teachers ' writing proficiency ............................... 79

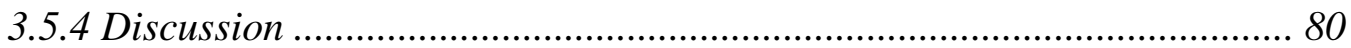

3.6 Perceived English Proficiency and its Supporting Factors and Constraints ... 81

3.6.1 Overestimating English proficiency ....................................................... 81

3.6.2 Overestimating efforts to maintain teachers' L2 proficiency................... 84

3.6.3 Understating the extent of teachers' overall L2 proficiency improvement

3.6.4 Supporting factors and constraints in maintaining L2 proficiency......... 87

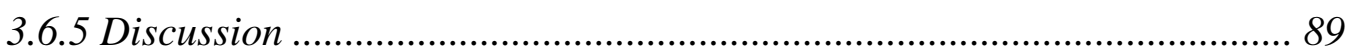

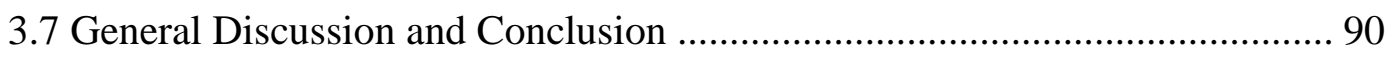

3.7.1 EFL teachers' L2 proficiency does not fully meet expected professional

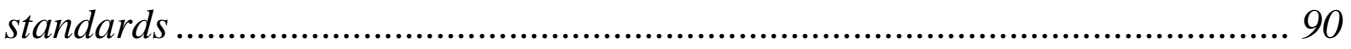

3.7.2 L2 proficiency of the EFL teachers appears to diminish over time ........ 91

3.7.3 Disparity between perceived and actual L2 proficiency ......................... 91

3.7.4 EFL teachers' efforts to sustain or improve their L2 proficiency ............ 92

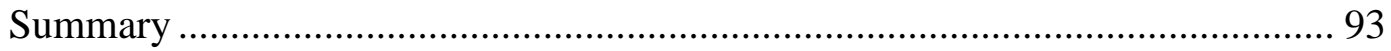

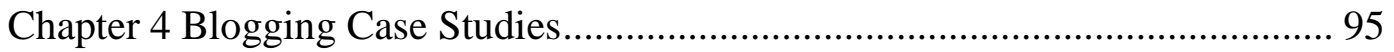

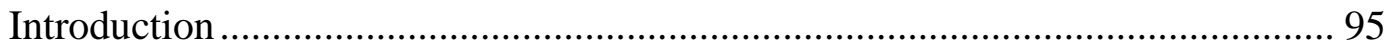

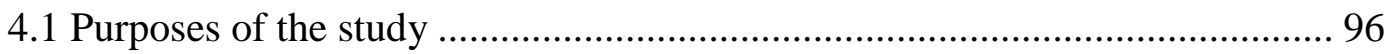

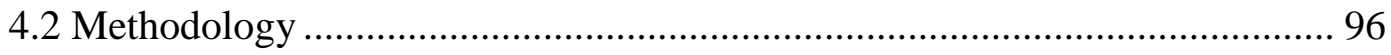

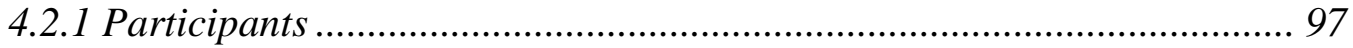

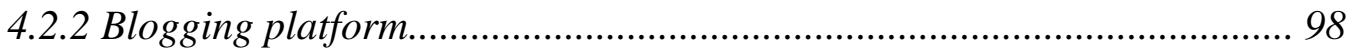

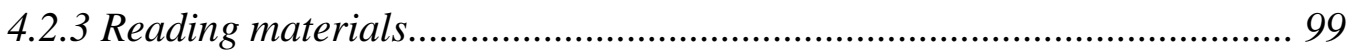

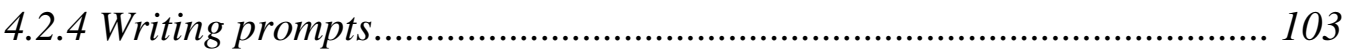

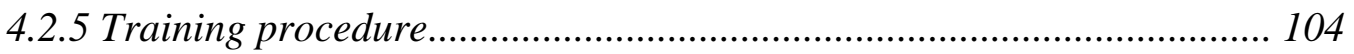

4.2.6 Collection of the blogging data ............................................................ 105

4.2.7 Approach to the data analysis .................................................................. 107

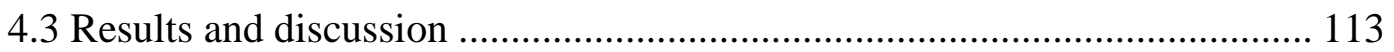

4.3.1 What language and blogging features did bloggers use when writing blog

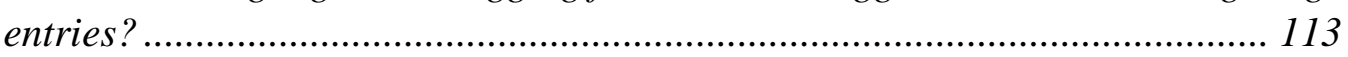

4.3.1.1 Language features ................................................................. 113

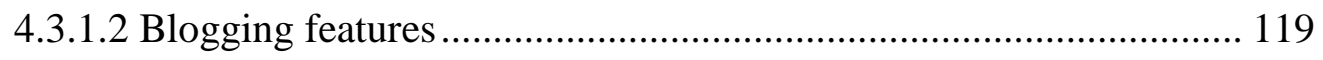

4.3.2 How did the teachers engage in critical thinking and reflective writing

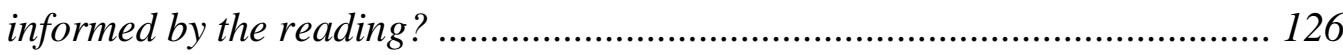




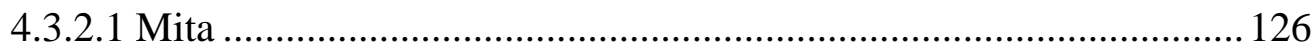

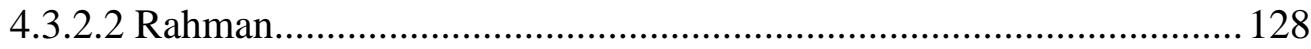

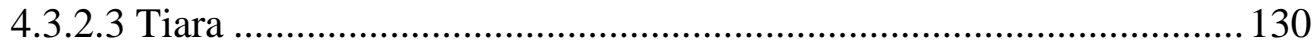

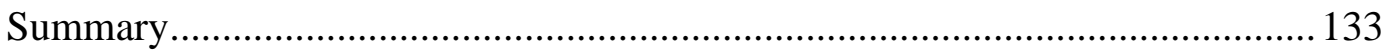

Chapter 5 Blogging as a Form of Professional Development ............................... 135

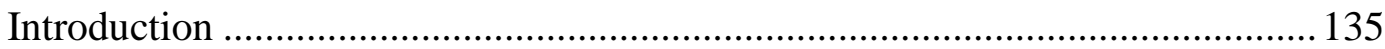

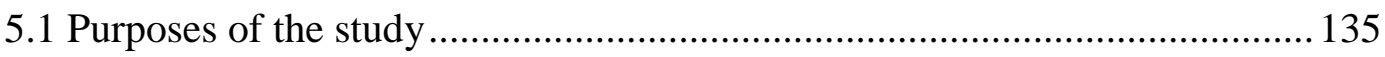

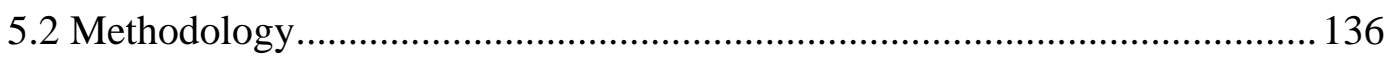

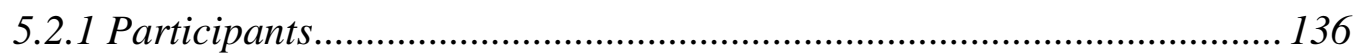

5.2.2 Data collection instruments ................................................................. 141

5.2.2.1 Questionnaire .................................................................................. 141

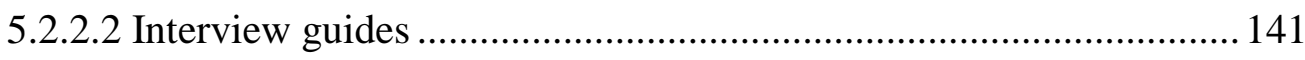

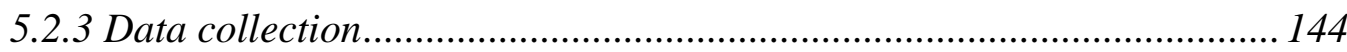

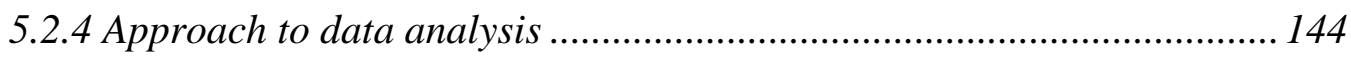

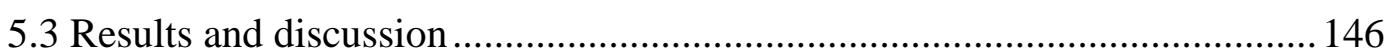

5.3.1 EFL high school teachers' blogging experiences and behaviors........... 146

5.3.2 Perceived benefits of blogging.............................................................. 149

5.3.3 Perceived barriers to blogging .............................................................. 152

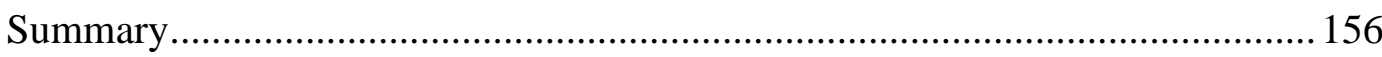

Chapter 6 Policies and Perceptions of Teacher Development............................. 159

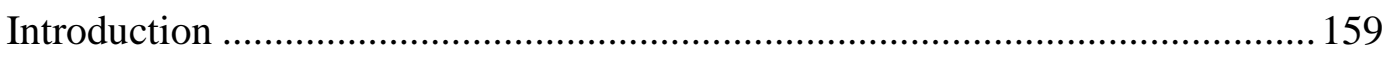

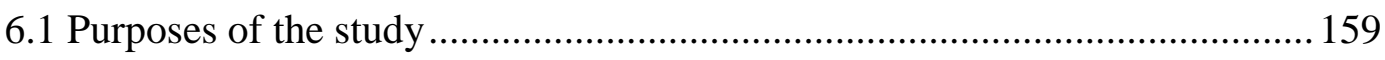

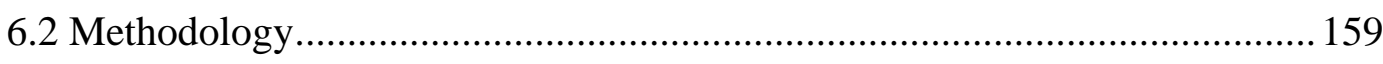

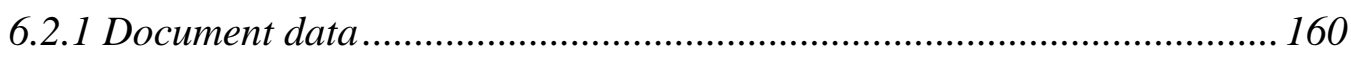

6.2.1.1 Teacher professional development policy documents ...................... 161

6.2.1.2 Implementation documents of TPD ................................................ 162

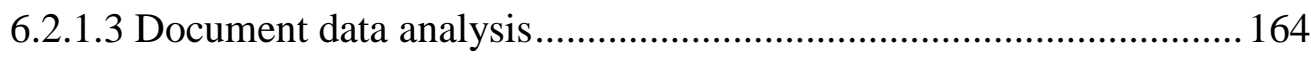

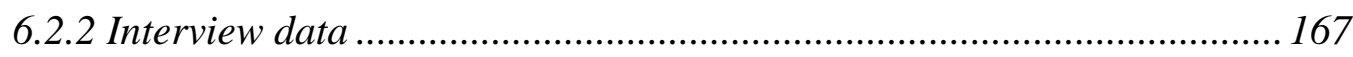

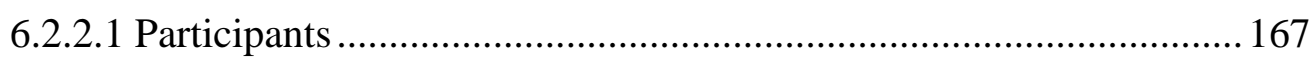

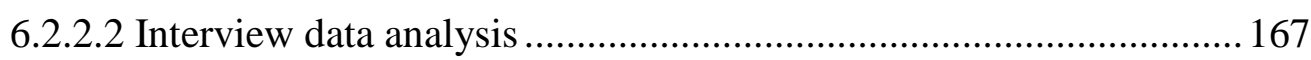

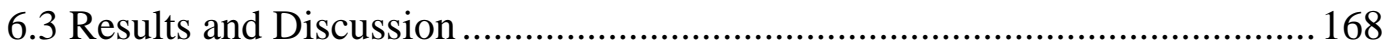

6.3.1 Maintaining L2 proficiency and improving ICT skills in the TPD

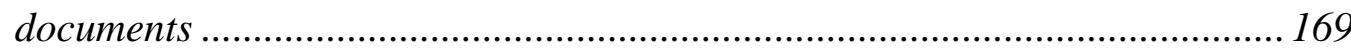

6.3.1.1 Unspecific discussion of EFL teachers' L2 proficiency ................... 169 
6.3.1.2 Specific discussion of ICT skills in the documentation. 174

6.3.2 Ineffectiveness of the TPD policies and implementation documents ..... 176

6.3.2.1 Unacknowledged environment analyses...................................... 176

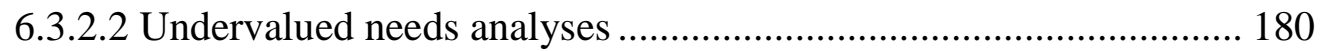

6.3.2.3 Unrecognised TPD monitoring and evaluation ............................. 181

6.3.3 Uneven knowledge about concepts, policies and practice of TPD ........ 182

6.3.3.1 Mixed concepts of teacher development's goals and definition...... 182

6.3.3.2 Various ideas of administering TPD............................................. 190

6.3.3.3 Unclear concept of TPD evaluation ............................................... 202

6.3.3.4 Imbalance benefits and challenges of TPD..................................... 205

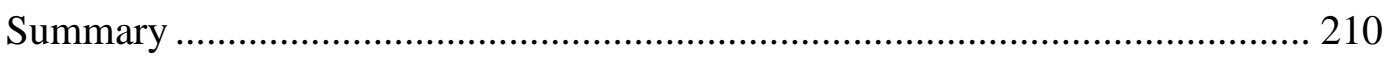

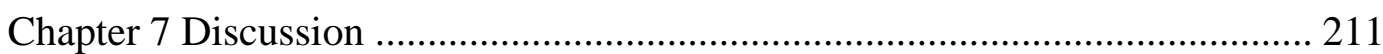

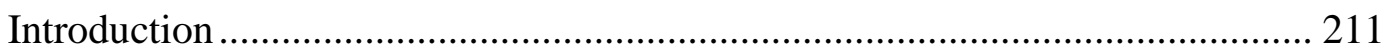

7.1 Issue One: EFL Teachers' L2 Proficiency ................................................. 211

7.1.1 Dissonance between the EFL teachers' perceived and actual L2

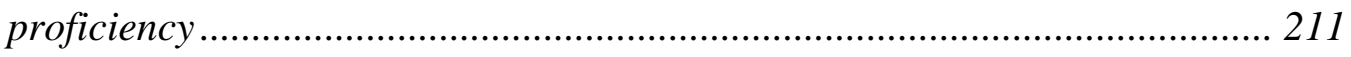

7.1.2 Negative correlation between EFL teachers' years of service and L2

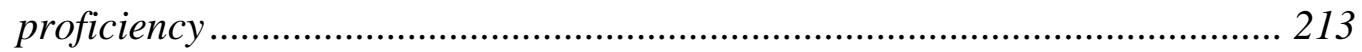

7.2 Issue Two: EFL Teachers' ICT and Blogging Skills ................................. 214

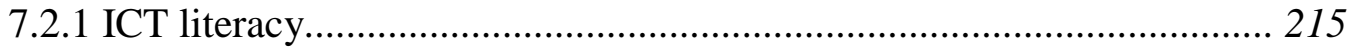

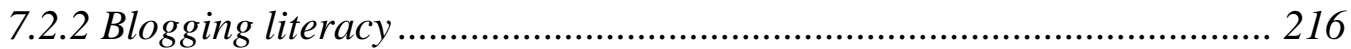

7.3 Issue Three: Institutional and Individual Teacher Development among EFL

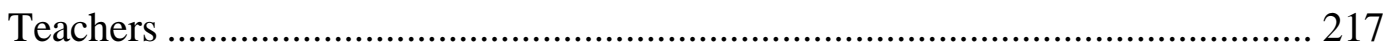

7.3.1 Institutional teacher development .................................................... 218

7.3.1.1 Keeping up with changes and innovations in subject matter

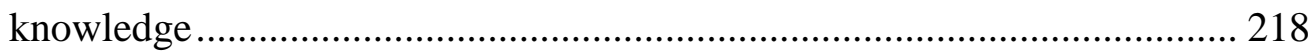

7.3.1.2 Answering the increasing demand for competent English teachers 220

7.3.2 Individual teacher development ........................................................ 222

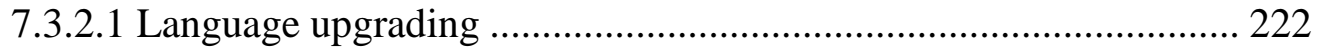

7.3.2.2 Maintaining subject matter knowledge .......................................... 223

7.3.2.3 Maintaining pedagogical expertise …........................................... 225

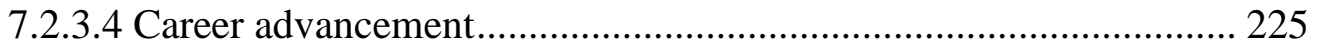

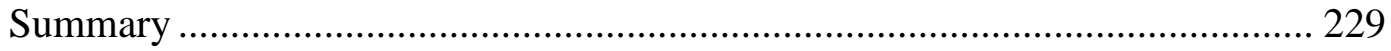

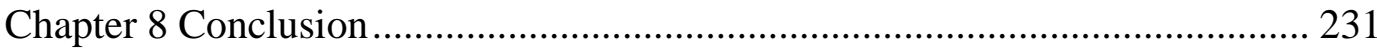

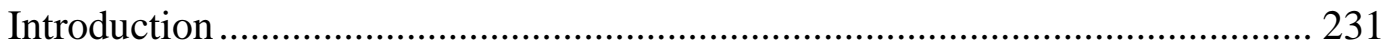


8.1 Implications and Recommendations

8.1.1 Implications for TPD targeting EFL teachers' L2 proficiency

8.1.2 Implications for TPD targeting ICT-related issues

8.1.3 Implications for the TPD policy and implementation

8.2 Limitations and Suggestions for Future Research.... 237

8.3 Conclusion 241

References 243

Appendices 261

Appendix 1 Information Sheet for Participants 262

Appendix 2 Consent form .265

Appendix 3 Survey for Indonesian EFL Teachers 267

Appendix 4 Interview guides 272

Appendix 5 The Vocabulary Levels Test 277

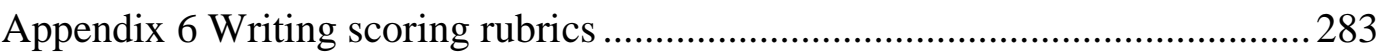

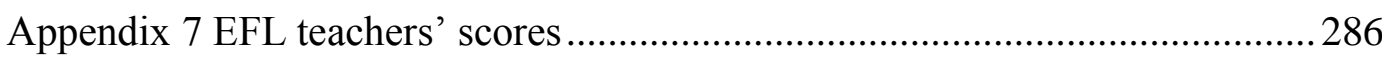

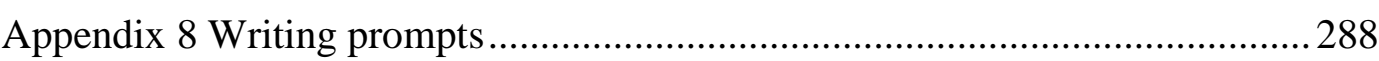

Appendix 9 Seven guidelines for second language teacher institutional professional development. 300

Appendix 10 Seven guidelines for second language teacher personal professional developmen 302

Appendix 11 Questions on teacher development for teachers 304 Appendix 12 Ethics Approval 306 


\section{LIST OF TABLES}

Table 2.1 Purposes and areas of institutional professional development 19

Table 2.2 Seven areas of individual professional development

(Farrell, 2015: 7-8; Richards \& Farrell, 2005: 9-10) 22

Table 3.1 Number of participants $\quad 54$

Table 3.2 Information of nine teachers interviewed on their L2 proficiency 54

Table 3.3 Lexical profile of the reading texts 59

Table 3.4 Questions on L2 proficiency in the interview guides for teachers 60

Table 3.5 Data types and analyses $\quad 66$

Table 3.6 IELTS Academic Reading marking scheme 68

Table 3.7 Phases of thematic analysis $\quad 71$

Table 3.8 Data extract with codes $\quad 72$

Table 3.9 Means on each level of VLT 74

Table 3.10 Mean of reading test $\quad 76$

Table 3.11 Mean of writing test $\quad 76$

Table 3.12 Pearson's correlations of length of service and VLT 78

Table 3.13 Pearson's correlations of length of service and reading test $\quad 79$

Table 3.14 Pearson's correlations of length of service and writing test $\quad 80$

Table 3.15 EFL teachers' perceived and actual proficiency 83

Table 4.1 Information about the three teachers who completed the blogging $\begin{array}{ll}\text { task } & 98\end{array}$

Table 4.2 Topics for blogging $\quad 100$

Table 4.3 Academic word coverage in the reading 102

Table 4.4 Content of writing prompts 103

Table 4.5 Observation sheet for the EFL teachers' use of language and blogging features 106

Table 4.6 Observation sheet of participants' engagement analysis $\quad 109$

Table 4.7 Observation sheet of participants' reflection analysis 111

Table 4.8 Total entries and words written and analysed 113

Table 4.9 Academic words coverage in blog entries, by participants 115 
Table 4.10 Observation sheet for the use of blogging features, by participant

Table 5.1 Characteristics of the EFL teachers interviewed about blogging 137

Table 5.2 Characteristics of the educational stakeholders 138

Table 5.3 Summary of interview participants 140

Table 5.4 Questions from the interview guide used with the teachers 142

Table 5.5 Questions from the interview guide used with the stakeholders 143

Table 6.1 Data extract with codes 168

Table 6.2 Summary of documents analysis $\quad 171$

Table 6.3 Summary of documents analysis: Environment and $\begin{array}{ll}\text { needs analyses } & 177\end{array}$

Table 6.4 Goals and definitions of TPD 189 


\section{LIST OF FIGURES}

Figure 1.1 Relationship between three studies 5

Figure 1.2 Design of the study 6

Figure 2.1 Framework for analysing the effectiveness of professional learning experiences (Timperley et al., 2007: 24)

Figure 2.2 A model of the parts of the curriculum design process

(Nation \& Macalister, 2010: 3)

Figure 3.1 Example of adjustment in the questionnaire 56

Figure 3.2 Boxplots of each word level 75

Figure 3.3 Questionnaire responses to the questions, 'Since you have received your teaching qualification, how will you describe your overall English proficiency?'

Figure 3.4 At present, how would you describe your vocabulary, reading and writing proficiency? $\quad 82$

Figure 3.5 I frequently seek opportunities to read and write in English $\quad 84$

Figure 3.6 Thinking outside the school settings, how often have you had time to engage in the following activities during the last three school years (since July 2010)?

Figure 4.1 Blogging platform 99

$\begin{array}{ll}\text { Figure 4.2 Data cleaning and analysis } & 107\end{array}$

$\begin{array}{ll}\text { Figure 4.3 Mita's blog entry } & 121\end{array}$

Figure 4.4 Rahman's blog entry 122

Figure 4.5 Tiara's blog entry 123

$\begin{array}{ll}\text { Figure 4.6 Mita's use of picture } & 124\end{array}$

Figure 4.7 Rahman's simple blog entry 124

Figure 5.1 Teacher ICT literacy $(n=68$, varied missing value in each data set)

Figure 5.2 Teacher engagement with ICT and blogging-related activities

( $\mathrm{n}=68$, varied missing value in each data set) 147

Figure 6.1 Hierarchy of four policy documents 162

Figure 6.2 Comparing and summarizing document data 166 
Figure 6.3 Resources of Continuous TPD

Figure 6.4 Stages of Continuous TPD

Figure 6.5 Layers of authorities

195

Figure 6.6 Components of continuous TPD

200 


\section{LIST OF APPENDICES}

Appendix 1 Information Sheet for Participants

Appendix 2 Consent form

Appendix 3 Survey for Indonesian EFL Teachers

Appendix 4 Interview guides

Appendix 5 The Vocabulary Levels Test

Appendix 6 Writing scoring rubrics

Appendix 7 EFL teachers' scores

Appendix 8 Writing prompts

Appendix 9 Seven guidelines for second language teacher institutional professional development

Appendix 10 Seven guidelines for second language teacher individual professional development

Appendix 11 Questions on teacher development for teachers 


This page is intentionally left blank 


\section{Chapter 1 Introduction}

\section{Introduction}

This chapter provides the background of the study by situating the context within teacher development among teachers of English as a foreign language (EFL) at the lower secondary, higher secondary and vocational secondary schools in Indonesia. This chapter also describe the aims, research questions, research design, and organisation of the study.

\subsection{Background to the Study}

To be able to keep up with change and innovation in second language education and to answer the increasing demand for competent English teachers worldwide, teachers of English as a foreign language (EFL) have to constantly maintain and improve their professional and pedagogical competency. They should actively participate in some institutional and individual teacher professional development (TPD) programmes. Indonesian English teachers are no exception to such TPD programmes.

Reflecting upon my professional life as an educator in a teacher training institute, I started my service as a junior lecturer and I did not deal very much with university students and their expectations. I kept my motivation and interest alive by participating in conferences, seminars or informal chats with my seniors. Some institutional initiatives to improve my professionalism, i.e. International Action Research in Education, Workshop on Classroom Reading Training Programme, Workshop on The ABC's of the $21^{\text {st }}$ Century, were also available. However, I could not see how my institutional teacher development assisted me in dealing with issues in my day-to-day teaching activity. I also could not see how my personal teacher development helped my institution to reach its institutional goals. Reflecting on this situation caused me to think about the personal and institutional teacher development among teachers of English as a foreign language (EFL) in Indonesia. 
Two events, my personal involvement in an online distance course and my observation of EFL teachers' L2 proficiency, navigate the direction of my present study. As part of my personal teacher development, I participated in a distance online course in 2011 through a scholarship. This scholarship had allowed me to work with other English lecturers from distant places, such as other provinces in Indonesia, the US, and the Republic of China. The 12-week online course allowed me to communicate with people from different cultures and to improve my teaching and English language competency too. In addition, my duty as a lecturer has allowed me to work with English language teachers from different levels of education. During my interaction with them, I observed that they lacked confidence because they struggled to read, listen, speak and write well in English. I believed that I could help teachers to maintain their second language proficiency through writing critical reflective posts in a blog platform. I saw some potential in blogging to help EFL teachers in Malang district to maintain and improve their institutional and individual professionalism.

Leung (2009: 49) suggests that institutional professionalism or institutional teacher development should be called sponsored professionalism. He maintains:

Sponsored professionalism is usually proclaimed on behalf of teachers as a collectivity; therefore, it does not necessarily coincide with individual teachers' views on professionalism, as often as not because it is promoted by regulatory bodies to introduce reform and/or by professional associations to advocate change.

Richards and Farrell (2005) define individual or personal teacher development as the efforts by the teachers to add up their professional knowledge, to keep up with theory and practice in their fields, to improve their teaching skills so that they are more confident and their students reach better learning outcomes, and to clarify and understand their teaching and school principals, beliefs, and values (for further explanation of institutional and individual teacher development, refer to Sections 2.1.1 and 2.1.2, Chapter Two).

There are several published and unpublished studies dedicated to investigating the teachers' professional development in Indonesian high schools (Abdullah, 2015; Aritonang, 2016; Korompot, 2012; Silvia, 2015; Tantri, 2014; Thamrin, 2011). 
Most of these studies are unpublished Masters or $\mathrm{PhD}$ theses. There are also several studies which have investigated EFL teachers' second language (L2) proficiency (Lengkanawati, 2005; Lie, 2007; Marcellino, 2005) and teacher ICT skills (Silvia, 2015; Son, Robb, \& Charismiadji, 2011) and a number of studies investigated the utilization of technology for TPD (Sari, 2012; Silvia, 2015; Widodo \& Riandi, 2013). To ensure the reliability of the literature review, I will particularly explore the peer-reviewed articles or studies.

Recognizing the context of institutional and individual TPD in Indonesia in general helps me to understand what EFL teachers and the institutions (government of Indonesia and schools) have done to maintain and to improve two areas of expertise of EFL teachers: L2 proficiency and ICT skills.

\subsection{Aims of the Study}

The purposes of this thesis are threefold: to investigate (1) whether teachers of English as a foreign language (EFL) in Indonesia are able to maintain their L2 proficiency and remain competent after graduating from their formal teaching education, (2) whether teacher blogging (i.e. a regular activity of writing short reflective pieces and sharing them online with other teachers) would facilitate the development and maintenance of two aspects of teacher professional competency: target language proficiency and the subject matter teaching expertise, and (3) what institutional and personal aspects of teacher development are established in maintaining and improving their second language competency and ICT skills. To achieve these goals, I need to look into the TPD policy and implementation documents and their individual professional development aspects (English language proficiency and blogging skill).

To investigate the EFL teachers' ability to maintain their target language proficiency, I examined the EFL teachers' individual perceived and actual L2 proficiency in terms of vocabulary knowledge, reading proficiency, writing proficiency. To explore whether they remain competent after their formal teacher training, I looked in to the correlation between the EFL teachers' length of service and their L2 proficiency. I investigated the teachers' perceptions of ICT and blogging and their individual participation in an online professional development 
programme to understand: (1) whether they have sufficient ICT skills to blog, (2) how familiar they are with ICT skills and blogging, (3) how reflective they were when writing their blog posts, (4) whether their ICT skills and L2 proficiency were reflected in their blog posts, and (5) what benefits and shortcomings of blogging they perceived.

For the purpose of the study, I set up a blogging platform for the EFL teachers. I created a group blog where I was the sole administrator. All participating teachers were able to access reading materials and to draft, write and post their blog items in the platform (see 4.1.1.2, Chapter Four, for a detailed explanation of the platform). The platform was targeted to provide a place for EFL teachers to express their ideas and to maintain or to improve their English proficiency through reading, writing and the interaction of both language skills.

I looked into the TPD policy documents that the government created and TPD implementation documents that EFL teachers created to investigate: (1) what the documents say about teacher development in general, (2) what the documents say about institutional teacher development and individual teacher development for English language teachers in particular, (3) how the documents address the EFL teacher institutional goals to keep up with the development of technology in their field and career advancement, (4) and how the documents address the EFL teacher individual goals to maintain their L2 proficiency and ICT skills.

\subsection{Research Design}

Figure 1.1 describes the research design of the present study. Study 1 investigated the teachers' perceived and actual English language proficiency. This data provides information of the EFL teachers' English proficiency before they embark upon Study 2 which demands reading and writing in English.

Study 2 explored EFL teachers' blogging and perceptions of blogging. Study 2 draws on case study data and on questionnaire and interview data from teachers and stakeholders. The blogging case studies investigated three EFL teachers' reading engagement and reflective writing. The study of blogging as a form of professional development for EFL teachers looked into EFL teachers and 
stakeholders' views of blogging and factors that support and inhibit blogging among teachers. Together, Study 1 and Study 2 investigated the EFL teachers' L2 proficiency in terms of lexical, reading and writing proficiency and their individual TPD by exploring the teachers' their engagement in reading and blogging writing.

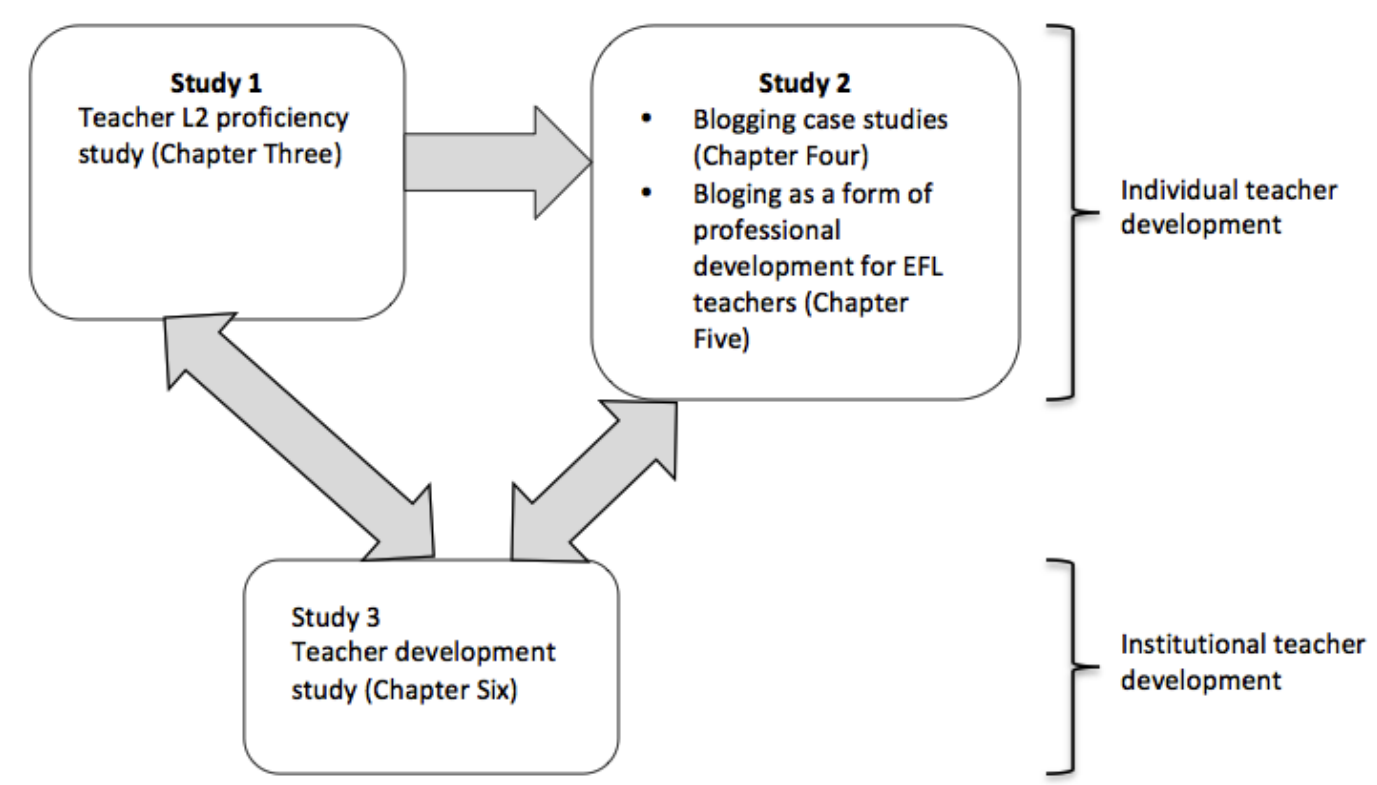

\section{Figure 1.1 Relationship between three studies}

Study 3 investigates policies and implementation documents of teacher development in Indonesia (the institutional aspects of teacher development among EFL teachers in high schools in Indonesia.) Study 3 is also used to understand the emerging issues on individual aspect of teacher development observed in Study 1 and Study 2.

The design of the thesis follows a "sequential explanatory strategy" (Creswell, 2014; Creswell \& Clark, 2007). Creswell states:

"The quantitative results typically inform the types of participants to be purposefully selected for the qualitative phase and the types of questions that will be asked of the participants." (2014: 274).

Creswell further explains that this strategy is typically used to explain and interpret surprising results in the first phase of the study (quantitative phase) in more detail. Figure 1.2 details the design of the present study. 


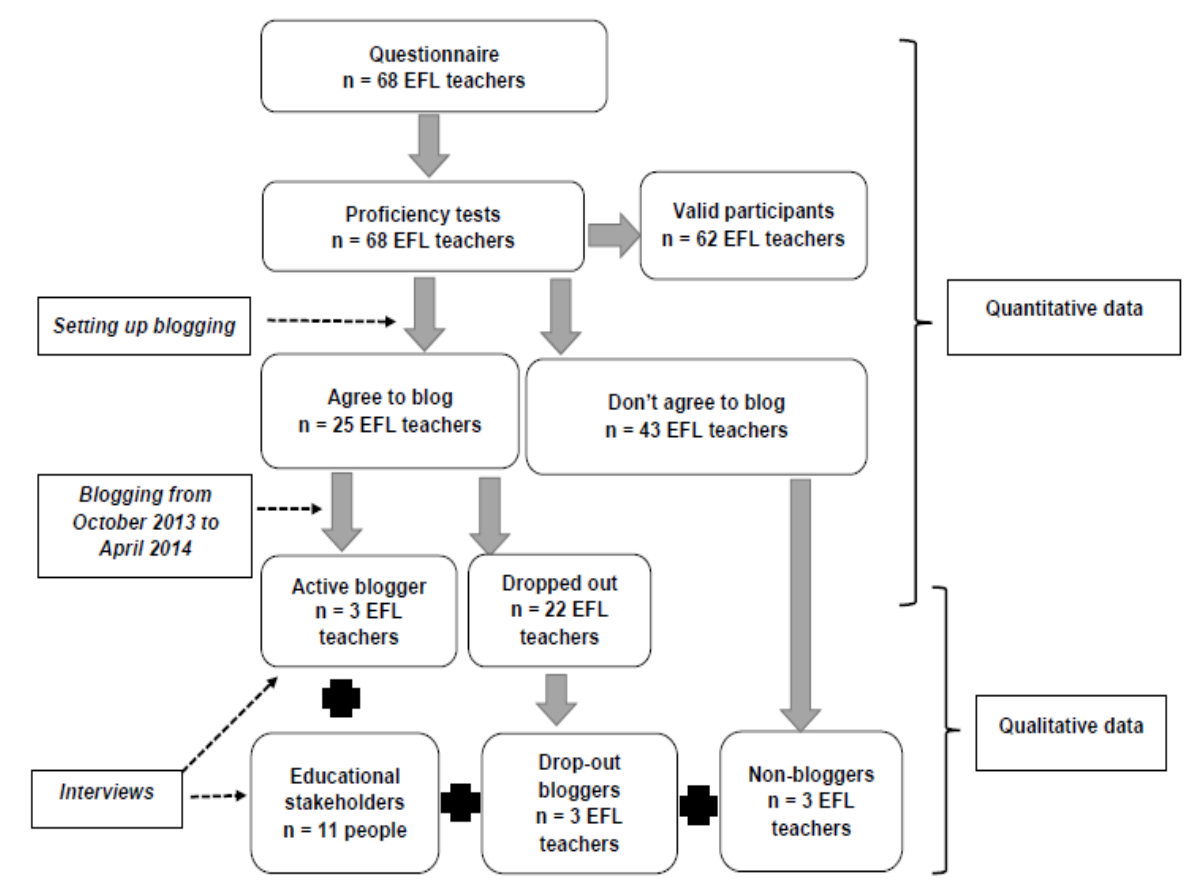

\section{Figure 1.2 Design of the study}

The thesis started with L2 proficiency study (Chapter Three) that explored quantitative data of the EFL teachers' demographic information ( $n=68$ teachers) and their views on their English proficiency. It was followed with the L2 proficiency tests that also gathered quantitative data about the EFL teachers' lexical, reading and writing proficiency ( $\mathrm{n}=62$ teachers). To have a better understanding of the results of the questionnaire and L2 proficiency tests, some teachers were interviewed (qualitative data).

The L2 proficiency study was followed by Study Two, blogging case studies (Chapter Four) that explored quantitative and qualitative data from the teachers' blog posts and blogging as a form of TPD study (Chapter Five) that investigated the EFL teachers' critical and reflective writings. Finally, the thesis was wrapped up by professional development study (Chapter Six). Figure 1.2 shows how the overall thesis was built on the analysis of quantitative data and the analysis was completed by qualitative data. Thus, sequential explanatory strategy (Creswell, 2014; Creswell \& Clark, 2007) is appropriate for the purpose of the present thesis. 


\subsection{Organisation of the Study}

This chapter (Chapter One) serves as an entry point to the topic of personal and institutional teacher professional development (TPD) programme among secondary school EFL teachers.

Chapter Two reviews literature on effective teacher professional development (TPD) and the existing TPD studies in Indonesia. The chapter also considers the reasons why the present study seeks to investigate EFL teachers' target language proficiency and ICT skills, especially their blogging skills. The chapter also considers research on supporting and inhibiting factors of TPD, English language teaching in Indonesia, and change and innovation in second language teaching. Chapters Three, Four, Five, and Six describe the findings of the study. Chapter Three explains the details of the EFL teachers' L2 proficiency study. Chapter Four describe the data and findings of three teachers' engagement with reading and reflective writing. Chapter Five reports on blogging as a form of professional development of EFL teachers. Chapter Six focuses on TPD policy and implementation documents and the teachers' TPD practices.

Chapter Seven discusses findings and emerging issues from Chapters Three, Four, Five, and Six. Three key issues which surfaces from these chapters are: issues (1) of EFL teachers' L2 proficiency, (2) on EFL teachers' ICT literacy, and (3) on institutional and individual teacher development among EFL teachers.

Chapter Eight focuses on recommendations on improving policy and implementation documents, implications for EFL teachers' professional development, theoretical implications, and methodological implications. It also describes limitations of this study, and suggestions for future research. 
This page is intentionally left blank 


\section{Chapter 2 Literature Review}

\section{Introduction}

In 2009, Indonesia and nine other countries in Southeast Asia that are under the Association of Southeast Asian Nations (ASEAN) collaborated to build the ASEAN Community 2015. One of the frameworks that has become the focus of ASEAN Community 2015 is improving the quality of education in Southeast Asia (ASEAN Secretariat, 2009). Indeed, there is a demand for all ASEAN members to conform to their national and ASEAN educational standard.

Motivated by my personal professional development and a desire to help EFL teachers to maintain and improve their professionalism, I investigated whether personal and institutional aspects of teacher development of EFL teachers in Indonesia are effective in maintaining and improving the teachers' disciplinary knowledge and ICT skills. For the purpose of the study, disciplinary knowledge is defined as the EFL teachers' target language (English) proficiency; a core component of their professional knowledge, and was operationalised as their lexical, reading and writing proficiency. ICT skills in this study refer to the EFL teachers' web-based skills when using email, internet, blogging, voice chatting, or video conferencing. A key focus of my research was to explore whether blogging could help the teachers in maintaining and improving their second language proficiency and subject matter expertise.

Thus, this chapter explores four important issues: how teacher professional development (TPD) programmes are shaped by the socio-cultural contexts in which they are embedded, what aspects characterise effective TPD programmes, why target language proficiency maintenance is an essential component of EFL teachers' professionalism, and what potential blogging-integrated professional development holds for EFL TPD? 


\subsection{Teacher professional development (TPD) and its socio-cultural context}

TPD has been defined differently based on the socio-cultural contexts where it is implemented. The context of TPD is significant because it provides 'the medium in which the professional learning activities occur and strongly influences how teachers may understand and react to the learning opportunities' (Timperley, Wilson, Barrar, \& Fung, 2007: 25).

A growing body of literature has investigated professional learning opportunities for teachers and the socio-cultural contexts where they take place (Avalos, 2004; Grundy \& Robison, 2004; Timperley et al., 2007). Avalos (2004) looked into the TPD policies and practices in the Latin American region. Grundy and Robison (2004) investigated the recent themes and trends in TPD in Australia. Timperley et.al. (2007) reported the best evidence synthesis iteration of teacher professional learning and development in New Zealand.

In Latin America, it is common to refer TPD to as capacitation (skill training), perfeccionamiento (improvement), actualizacion (upgrading or refreshing) or as in-service preparation and the concept of 'permanent' or 'continuing' teacher education (Avalos, 2004: 121). This study highlights the eclectic concept and fragmented practices of teacher development in south American countries, i.e. Chile, Argentina, Uruguay, Brazil, Cuba and Peru. Avalos (2004) further explained that in the 1990s, the TPD policies and reforms in Latin America were aimed to develop the teachers' professionalism. The activities followed what international experiences as good practice of TPD as shown by the teachers' initiative for changes and collaboration. Using the international and local financial and human resources, these countries aimed to reform their educational system, including the teacher personal, social and professional development. A number of good TPD programmes were introduced and institutions were embraced to improve the teacher professionalism including national and state or provincial government activities, supervisor-facilitated teacher workshops, and nongovernmental (i.e. religious groups) activities. The programmes showed effects on learning indicators, including increased learning for average, rural and indigenous 
students as well as lower repetition and drop-out rates. The teachers were also reported to gain capacity to teach and develop curricular materials. However, Avalos also noted that the implementation of the policies and reforms were done in traditional way where the possibility of innovations were truncated by norms and regulations. The programmes were challenged by the teachers' inadequate initial trainings and reliance to school supervisors and principals. Teachers were also reported to be challenged by heavy teaching loads, lack of time for teaching preparation, and little time for their own improvements.

Avalos' report on TPD policies and practices in Latin American region is thorough and comprehensive. She is also critical of the tendency of the stakeholders to start a new programme to solve TPD problems, rather than review the issues as a whole and decide on a more comprehensive and flexible policies with middle-term and longer-term ends in view.

In Australia, professional development is seen as a part of growth and development cycle of a professional career. The definition refers to three key functions of TPD: 'extension through educational innovation, growth through the development of greater levels of expertise and renewal through transformation and change of knowledge and practice' (Grundy \& Robison, 2004: 159). They reported that the themes and trends in TPD in Australia shifted from time to time. They reported that between the 1960s/1970s, TPD aimed to keep individuals up to date with current changes and development in discipline, content and pedagogy. In the 1980s, the trend was school-based TPD and that education was carried out based on business and market principles. An educational reform took place in the 1990s and PD was placed in wider social and industrial contexts. This reform aimed to address the individual teacher's professional growth and enhancement as well as the school and systemic context. The report also indicates a shift back to the 1960s/1970s trends starting from the beginning of the new millennium to the present days where TPD becomes the responsibility of the individuals. The changes of trends in the implementation of TPD in Australia indicate that teachers' autonomy and motivation to improve themselves are experiencing a revival. The support from the government and other parties are important but the teachers' own initiatives in TPD cannot be underestimated. 
The term professional development in New Zealand context is described as 'delivering some kind of information to teachers in order to influence practice'; professional learning is described as 'an internal process through which individuals create professional knowledge' (Timperley et al., 2007: 3). The best evidence synthesis iteration was written by gathering and analysing studies in New Zealand and other countries (i.e. the US, Canada and the UK) on how to promote teacher learning in ways that impact on outcomes for the diversity of students in classrooms. The report defines professional learning as the umbrella term and professional development is just one part of professional learning. Timperley et al. (2007: xlvi) argued that, a number of requirements (i.e. consistency with wider policy trend and research, an extended time for teachers to engage with new ideas and their implications for practice, opportunities to engage in a range of learning activities, a catalyst to participate and the engagement of existing theories of practice) were necessary but not sufficient to promote professional learning, unless they were focused on students' better learning achievements.

A closer study on the report of the New Zealand's Ministry of Education, one will promptly notice the framework for analysing the effectiveness of professional learning experiences for teachers proposed in the study (see Figure 2.1). The professional learning is placed in a wider social context where formal educational policies or curriculum, prevailing discourses and social organisations exist. The learning is aimed to impact on the learners, and the teachers are exposed to focused opportunities and meaningful activities that promote their learning. The synthesis was written in sections: mathematics, science, and literacy; teachers' social construction of students; and the topical issues of leadership, multiple roles of assessment, engaging teachers' theories, and professional learning communities. Although, the number of the studies and countries analysed and reported in the synthesis was impressive, English as a foreign language and TPD policies and practices in developing countries were not the focus in the iteration.

Even though the iteration was focused on the developed countries, the framework (Figure 2.1) provides Indonesian TPD with a benchmark to investigate its 
effectiveness and an international context to explore the policies and practices of TPD for EFL teachers.

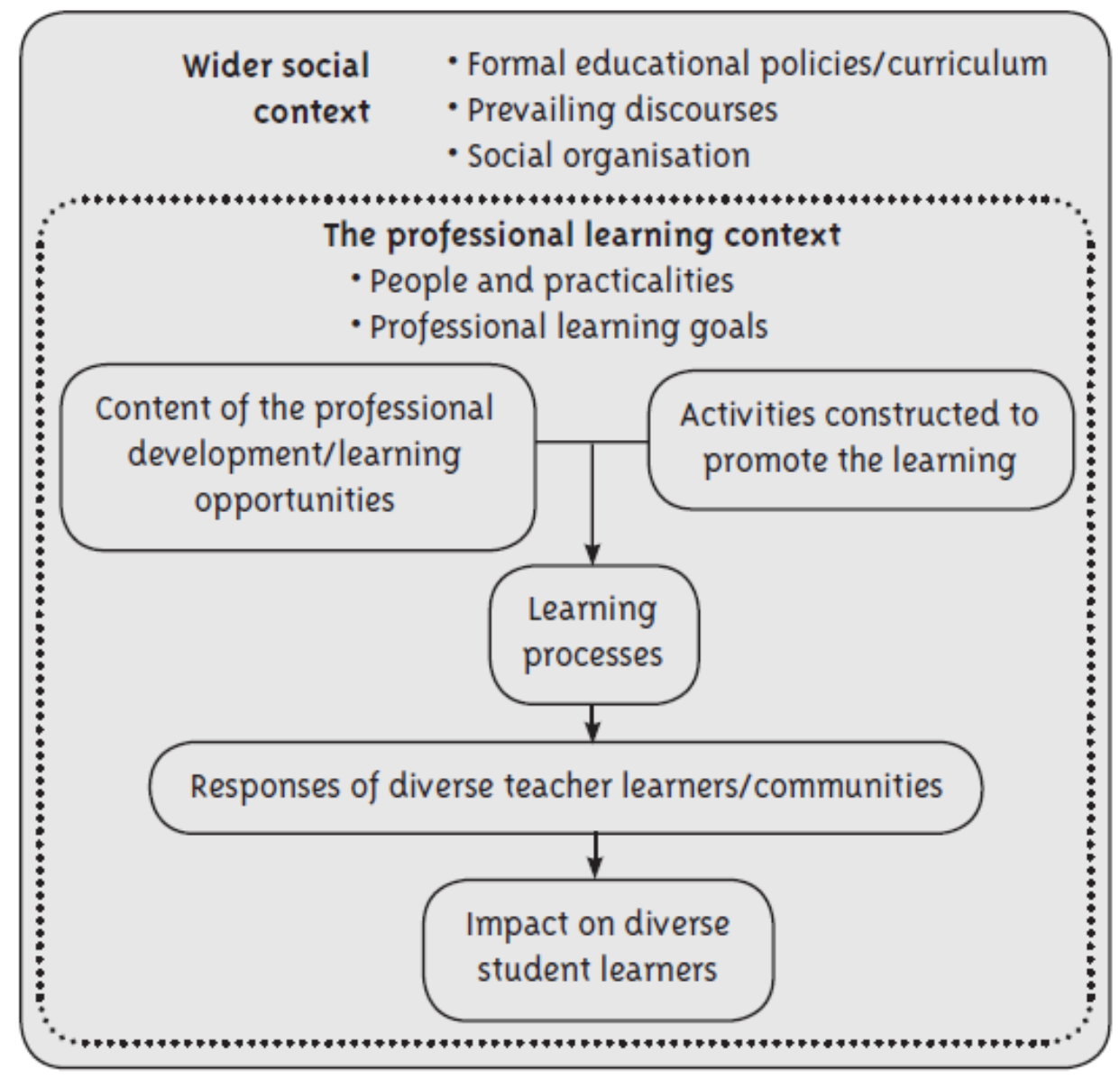

Figure 2.1 Framework for analysing the effectiveness of professional learning experiences (Timperley et al., 2007: 24)

The key categories of the framework are wider social context, professional learning context, content of professional development or learning opportunities, activities to promote learning, learning processes, response of diverse teacher learners/communities, and impact on diverse student learners.

Timperley et al. (2007) highlight two contexts for professional learning. The first is the wider social context that includes formal educational policies that initiate the professional learning opportunities, and whether the professional learning opportunities are voluntary or mandated. Prevailing discourses include discourses prior to and after the professional learning opportunities. Social organisation may refer to school organisation that includes school structure, culture and practices. 
The second is the context of professional learning, i.e. length, frequency, allocation of funding, and mode of delivery of the programme.

Timperley et al. (2007) further argue that the next key factors for professional learning are its content and activities. The content includes conceptual understandings and skills that can be used to inform practice and are related to teachers' own practice, and methods of inquiry that challenged teacher practice. The activities include listening, watching, being observed and receiving feedback, engaging with professional readings, and discussing practice with someone more expert.

The last three key aspects of professional learning are the process, the teacher learners' response and the students' learning outcomes. The learning process encompasses three processes: cueing and retrieving prior knowledge, becoming aware of new information/skills and integrating them into current values and belief system, and creating dissonance with current position (values and beliefs). The response of diverse teacher learners/communities include six responses: (1) reject/ignore new theory and practice and continue with prior practice, (2) continue with prior practice and believing that it is new practice, (3) select parts of new theory and practice an adapt to current practices, (4) implement as required, (5) actively engage and change practice substantively or (6) demonstrate enhanced regulation of own and others' learning. Finally, impact on diverse student learners may include no improvement (or decline) in outcomes, limited improvement in a narrow range of outcomes, and substantive improvement in a broad range of outcomes.

In the Indonesian situation, the wider social context of professional learning for EFL teachers in Indonesia is situated where English language is part of the national educational curriculum (State Secretariat of the Republic of Indonesia, 2003) and professional development is mandated institutionally and individually initiated (Direktorat Jenderal Peningkatan Mutu Pendidik dan Tenaga Kependidikan, 2010). Some typical contents of professional development for teachers include curriculum and planning a lesson, teaching model/strategies, assessment, teaching media, and e-learning and some common professional 
learning activities include seminars, training of trainers (ToT), courses, and Japanese-based lesson study (Widodo \& Riandi, 2013). All these efforts are aimed to impact positively to the students' learning outcomes (Direktorat Jenderal Peningkatan Mutu Pendidik dan Tenaga Kependidikan, 2010; State Secretariat of the Republic of Indonesia, 2003). In other words, the context for EFL teachers' professional learning (wider social context and professional learning context) exist in Indonesia. The contents and activities of professional learning are also available for teachers to improve the students' learning outcomes. It appears that the learning processes, the response of teacher learners, and more importantly, chances for EFL teachers to maintain and improve their professionalism to teach English in English are missing from the current TPD policies and programmes in Indonesia. Thus, it is important to explore them.

Together, the three studies (Avalos, 2004; Grundy \& Robison, 2004; Timperley et al., 2007) show that socio-cultural backgrounds of the teachers, stakeholders, students, and institutions play important roles in the teachers' and stakeholders' understanding and practice of TPD. TPD does not exist in a vacuum. In the next sub-section, various aspects that characterise effective TPD is investigated and analysed. The discussion is aimed to better understand the aspects that encourage and discourage the practice of TPD among teachers in general and among English language teachers in particular.

\subsection{What aspects characterise effective TPD programmes?}

Richards and Farrell (2005) state that an on-going professional development is not a sign of insufficient training but an answer to the fact that not everything teachers need to know is offered in their pre-service education, as well as the fact that teaching knowledge changes and innovations are introduced to improve teaching strategies. They write:

"Teacher education is a process that takes place over time rather than an event that starts and ends with formal training or graduate education. This process can be supported both at the institutional level and through teachers' individual efforts".

Similarly, Grundy and Robison (2004) describe that teaching is a never ending enterprise because changes naturally take place not only in the content of what the 
teachers teach but also in the methods of teaching, in the students and teachers, and many other aspects of teaching and learning itself.

Harwell (2003) argues that the most effective TPD programmes were characterised by an ideal environment for interaction among participants, opportunities for teachers to practice what they learn over relatively extended periods of time, and contents that were relevant to the curricular and instructional strategies for students to have better learning outcomes. Harwell (2003) explains that TPD should be a continuing endeavour and be well planned. TPD should also focus and serve school or institutional long-term goals and acknowledge and embrace the teachers' personal goals.

Richards and Farrell (2005) point out that the success of on-going TPD can be achieved if it addressed the language teachers' personal growth or individual perspective and departmental performance or institutional perspective. They further explain that TPD needs to address seven individual key issues: subject matter knowledge, pedagogical expertise, self-awareness, understanding learners, understanding curriculum and materials, career advancement, and language upgrading. Richards and Farrell (2005) also explain that TPD needs to address three areas of institutional goals: institutional development, career development and enhanced levels of students learning. Harwell (2003) and Richards and Farrell (2005) agree that in response to keeping up with development in sciences, technology, and educational fields, it is important that TPD programmes acknowledge and address relevant issues on second language teaching and integration of technology in teaching.

In addition to the recognition of institutional and individual goals, Nation and Macalister (2010) highlight the importance for teachers and other stakeholders, i.e. school principals, school supervisors, and school committees to carry out needs analyses and environmental analyses at the beginning of the programme and an evaluation at the end of the programme to ensure the effectiveness of the on-going TPD programmes. This idea is in line with that of Richards and Farrell (2005: 17):

A strategic approach to professional development starts with needs analysis. 
Needs analysis here refers to both the institution's needs and the perceived needs of teachers....

Needs analysis should include the needs of both the individual and the institution as a whole....

Richards and Farrell (2005:17\&20) also add that EFL teachers need to evaluate what they been learned during their institutional and individual TPD and later decide if the findings are worth sharing and recommending to others.

However, the administration of TPD is not always without any challenges. Evans, Tate, Navarro, and Nicolls (2009: 21) find that TPD for in-service teachers in Indonesia was challenged by different issues such as the absence of a needs analysis, lack of monitoring and evaluation, and little coordination among institutions that administer in-service teacher training programmes such as MoEC, Centre for Development and Empowerment of Teachers and Educational Personnel, Educational Quality Assurance Institution, Teacher Professional Associations, teacher training colleges and universities, and donor institutions (i.e. AusAID, USAID, JICA, the World Bank). In addition, Jalal, Samani, Chang, Stevenson, Ragatz, and Negara (2009) agree that time and measures of outcomes may pose some problems to the administration of TPD if they are not sufficiently met.

The review of literature on effective on-going TPD above indicates that continuing professional development is important for in-service EFL teachers in particular and for teachers in general. Additionally, for teacher development to be effective, it is not sufficient for EFL teachers to participate in sporadic, random, and unplanned teacher development programmes. They have to participate in effective TPD for EFL teachers. Thus, if there are gaps between the knowledge and skills gained during their formal teachers training, they can fill the gaps in by participating in the programme.

To conclude, Harwell (2003) and Richards and Farrell, (2005)suggest that an effective on-going TPD should take account of the schools, educational institutions, or the nation's perspectives and the teachers' individual perspectives. In addition, Richards and Farrell (2005) and Nation and Macalister (2010) suggest that the effectives of TPD is also partly depended upon the administration of 
environment analysis and needs analysis in the beginning of the programme and evaluation in the end of the programme. Now, let us discuss these three aspects one by one.

\subsubsection{Institutional perspectives of teacher development}

A first key aspect to effective TPD is taking into account the objectives of the educational institutions. In this section, I review Day and Sachs (2004) and Richards and Farrell (2005) ideas on institutional aspects of professional development.

Richards and Farrell (2005) explain that teacher education may not address all subjects that student teachers need to know when they start their service as novice teachers. Teacher education may prepare student teachers to navigate through their first or second year of teaching because they tend to be given "basic" teaching responsibility. However, the knowledge base of teaching changes and novice teachers may have to be responsible for bigger tasks, i.e. coordinating teachers of the same subject matter from the same school or from the same district or substituting senior teachers who have to take new assignments. What teachers learned in their teacher education may become outdated and less relevant to their new tasks at schools. Hence, it is critical for teachers to update their knowledge and skills.

In a chapter about the purposes of continuing professional development (CPD), Day and Sachs (2004: 22) state:

"Broadly speaking the function of professional development may be seen to be one of three imperatives: to align teachers' practice with educational policies, to improve the learning outcomes of the students by improving the performance of the teachers, or to enhance the status and profile of the teaching professional.

These three purposes of on-going professional development appear to be sufficient and complete because other authors also discuss similar ideas to those of Day and Sachs (2004). Richards and Farrell (2005: 10) argue that the schools must provide the following three areas of staff development for EFL teachers, so that teachers can acquire the knowledge and skills they need: institutional development, career development, and enhanced levels of student learning (see 
Table 2.1). These three areas of staff development appear to be compatible with the three purposes of TPD articulate by Day and Sachs (2004).

Table 2.1 Purposes and areas of institutional professional development

\begin{tabular}{ll}
\hline $\begin{array}{l}\text { Three purposes of continuing professional } \\
\text { development/CPD (Day \& Sachs, 2004) }\end{array}$ & $\begin{array}{l}\text { Three areas of staff development } \\
\text { (Richards \& Farrell, 2005: 10-11) }\end{array}$ \\
\hline $\begin{array}{l}\text { To align teachers' practice with } \\
\text { educational policies }\end{array}$ & Institutional development \\
\hline
\end{tabular}

To enhance the status and profile of the Career development

teaching professional

To improve the learning outcomes of the Enhanced levels of student

students by improving the performance of learning

the teachers

Richards and Farrell (2005: 10-11) explain that institutional development refers to the efforts to enhance the performance of school as a whole, i.e. attract more students or gain a higher accreditation score. Career development refers to the availability of opportunities for teachers to advance their professional position to a more senior position and to learn necessary knowledge and skills. It is hoped that these efforts increase the job satisfaction and in turns improve teacher performance and retention. Finally, staff development aims to raise the students' learning outcomes. The students' good learning outcomes provide a boost for the reputation of the school and its teachers. At a national level, government (i.e. through Ministry of Education and Culture) and teacher education institutions must be aware of and provide support to the three areas of institutional TPD. Richards and Farrell (2005: 17-21) suggest guidelines to administer institutional teacher development (see Appendix 9).

Richards and Farrell (2005: 10) claim that institutional teacher development refers to the initiatives undertaken by schools to achieve teacher personal and institutional goals. While envisaging a school as an institution is reasonable, I argue that in the Indonesian teaching and learning context, a more comprehensive understanding will be achieved if the meaning of institution is extended from school level to district, provincial, and state levels. That is to say that the teacher 
personal improvement has to be supported by the school as well as by the district, provincial and central government and MoEC of Indonesia. This is because professional development programmes and activities for language teachers are intended not merely to improve the performance of teachers but also to benefit the school, and to address strategic educational goals set by provincial and central governments.

\subsubsection{Individual perspectives of teacher development}

Another important aspect of effective TPD is taking into account the EFL teachers' individual goals. For the purpose of this study, I review two seminal ideas on individual perspectives of teacher development (Leung, 2009; Richards $\&$ Farrell, 2005). At the end of the section, I will discuss the implications of these ideas and study in the present study.

Leung (2009) contrasts two dimensions of teacher development: independent professionalism or individual TPD (Richards \& Farrell, 2005) and institutionally prescribed professionalism (sponsored professionalism) or institutional TPD (Richards \& Farrell, 2005). Independent professionalism in Leung's (2009: 53) perspective refers to EFL teachers' personal engagement in reflexive examination of their own beliefs and actions. He argues that:

"Engaging in reflexive examination is an important element of independent professionalism, or a commitment to careful and critical examination of the assumptions and practices embedded in sponsored professionalism with reference to discipline-based knowledge and wider social values, and to take action to effect change where appropriate".

According to Richards and Farrell (2005: 9) individual perspectives of teacher development refer to teachers' views on how to build on their professional knowledge and keep up with theory and practice in their field, in order to improve their teaching skills and feel more confident about what they teach and what they can do to improve their students' learning outcome. Richards and Farrell introduced seven areas of individual professional development (see Table 2.2).

Richards and Farrell (2005) suggest that the subject matter knowledge area is commonly learned through formal education (i.e. teacher training) as part of the requirements for the EFL teacher professional qualification, while language 
upgrading can be done through teacher development. They urge EFL teachers to extend their subject matter knowledge by increasing their basis of TESOL through various activities including teaching portfolios, action research, self-monitoring, and journal writing (2005: 14).

Self-awareness is important because it helps EFL teachers to reflect on the principles and values they believe in and strengths and weaknesses they have. EFL teachers have quite a few activities to be explored including: (1) selfmonitoring, i.e. making a video-taped record of their teaching activities journal writing, (2) teaching portfolio, i.e. compiling evidence of the teachers' competency and development, and (3) teaching journal, i.e. keeping a journal to record of classroom events and observations to reflect back and find inspirations from what have or have not carried out in the classrooms.

Farrell and Richards (2007: 60) also explore the general goals for language improvement opportunities for language teachers. The goals include improving teachers' proficiency in reading, writing, speaking and listening, developing their confidence in English, further developing their knowledge about English, developing an awareness of the nature of classroom discourse, developing strategies for carrying out common classroom functions in English, and developing less of a dependence on the textbook as a primary teaching source. Farrell (2015) and Richards and Farrell (2005) did not explained whether these seven areas of individual professional development are equally important for EFL teachers. They also recommend that EFL teachers follow seven guidelines of individual TPD (see Appendix 10).

From the way the authors wrote the seven areas, I assumed that they are equally significant. However, I argue that the first and seventh areas, subject matter knowledge and language upgrading, are the basis for the other five areas of individual teacher development. Without having solid English proficiency and sufficient mastery of English as their subject matter knowledge, it will be difficult for them to proceed to the other five areas of individual TPD. To illustrate my argument, let us look carefully at the third area of TPD (self-awareness), the seventh area of TPD (language upgrading), and one of the activities that EFL 
teachers can carry out to nurture their self-awareness, writing a teaching journal. While journal writing may allow EFL teachers to express their thoughts and emotions and to capture or records their experiences, carrying it in the target language elevates the level of the challenge. Coupled with the request to step back from their teaching and learning experiences to understand what the experiences mean, the teaching journal writing moves from social/psychological dimension of expressing oneself to cognitive dimension of communication of making selfreflection (Deng \& Yuen, 2011). Thus, without having sufficient linguistic skills and subject matter knowledge, making some conscious efforts to critically examine and write teaching and learning practices in English would be less likely to happen.

Table 2.2 Seven areas of individual professional development (Farrell, 2015; Richards \& Farrell, 2005)

\begin{tabular}{|c|c|c|}
\hline No & $\begin{array}{l}\text { Areas of individual } \\
\text { professional development }\end{array}$ & Description \\
\hline 1 & Subject matter knowledge & $\begin{array}{l}\text { Increasing knowledge of the disciplinary basis of } \\
\text { TESOL - that is, English grammar, discourse } \\
\text { analysis, phonology, testing, second language } \\
\text { acquisition research, methodology, curriculum } \\
\text { development, and the other areas that define the } \\
\text { professional knowledge base of language } \\
\text { teaching. }\end{array}$ \\
\hline 2 & Pedagogical expertise & $\begin{array}{l}\text { Mastery of new areas of teaching, adding to one's } \\
\text { repertoire of teaching specializations, improving } \\
\text { ability to teach different skill areas to learners of } \\
\text { different ages and backgrounds. }\end{array}$ \\
\hline 3 & Self-awareness & $\begin{array}{l}\text { Knowledge of oneself as a teacher, of one's } \\
\text { principles and values, strengths and weaknesses. }\end{array}$ \\
\hline 4 & Understanding learners & $\begin{array}{l}\text { Deepening understanding of learners, learning } \\
\text { styles, learners' problems and difficulties, ways of } \\
\text { making content more accessible to learners. }\end{array}$ \\
\hline 5 & $\begin{array}{l}\text { Understanding of } \\
\text { curriculum and materials }\end{array}$ & $\begin{array}{l}\text { Deepening one's understanding of curriculum and } \\
\text { curriculum alternatives, use and development of }\end{array}$ \\
\hline
\end{tabular}




\begin{tabular}{ll}
\hline & instructional materials. \\
\hline $6 \quad$ Career advancement & Acquisition of the knowledge and expertise \\
& necessary for personal advancement and \\
& promotion, including supervisory and mentoring \\
& skills. \\
\hline $7 \quad$ Language upgrading & A fundamental component of a language teacher's \\
& professional competency is his or her proficiency \\
& in the language he or she teachers. The \\
& proficiency level of a language teacher will in \\
& many cases determine the extent to which the \\
& teacher is able to use many current teaching \\
& methods appropriately and whether the teacher is \\
& able to provide reliable model of target language \\
& input for his or her students (Farrell \& Richards, \\
& 2007: 60). \\
\hline
\end{tabular}

In this study, I use Richards and Farrell's (2005) ideas about individual perspectives of TPD and associated aspects and values. Leung's (2009) ideas on independent professionalism can be mapped onto Richards and Farrell's (2005) self-awareness and understanding of curriculum and materials.

Furthermore, there are five similarities between the guidelines of institutional and individual perspectives of teacher development: carry out needs analysis, set goals, provide support, evaluate what has been learned and share the results (see Appendices $9 \& 10$ ). These similarities suggest that institutional and individual teacher development share common values about the importance of those five aspects. One limitation of the guidelines for the institutional development perspectives is that Richards and Farrell (2005) do not identify the need to select teacher trainers or instructors for the TPD programmes.

This review concludes that institutional and personal aspects of teacher development are both important. However, further guidance is needed on how institutional efforts should be allocated to maintain and improve EFL teachers' subject matter knowledge and ICT skills in Indonesia. In response to the gap, the 
present study explores both personal and institutional aspects of EFL teacher development in Malang, Indonesia.

\subsubsection{Environment analyses, needs analyses and evaluation in teacher development}

The last aspect that is also important for the success of TPD is the administration of environment analysis, needs analysis and evaluation of teacher development (see Figure 2.2). I used a model of curriculum design process introduced by Nation and Macalister (2010). The model was used because of its relevance. I adopted this model from the original context (where it was design for developing curriculum for teaching English as a second language, and not professional development for teachers), and that I only used the parts that are relevant and applicable in the TPD context.

Nation and Macalister (2010) define environment analysis as the analysis of three important factors - teachers as learners, teacher trainers and situation - of any curriculum design, because they ensure that the design will be feasible.

Nation and Macalister, (2010: 24) describe needs analysis as the analysis of "what the teacher learners know already and what they need to know'. They further divide the needs into three: necessities, lacks, and wants. Necessities refers to required knowledge. Lacks refers to what the EFL teachers are lacking. Wants refer to things the teachers wish to learn. These aspects are all essential considerations prior to the commencement of the professional development programme. 


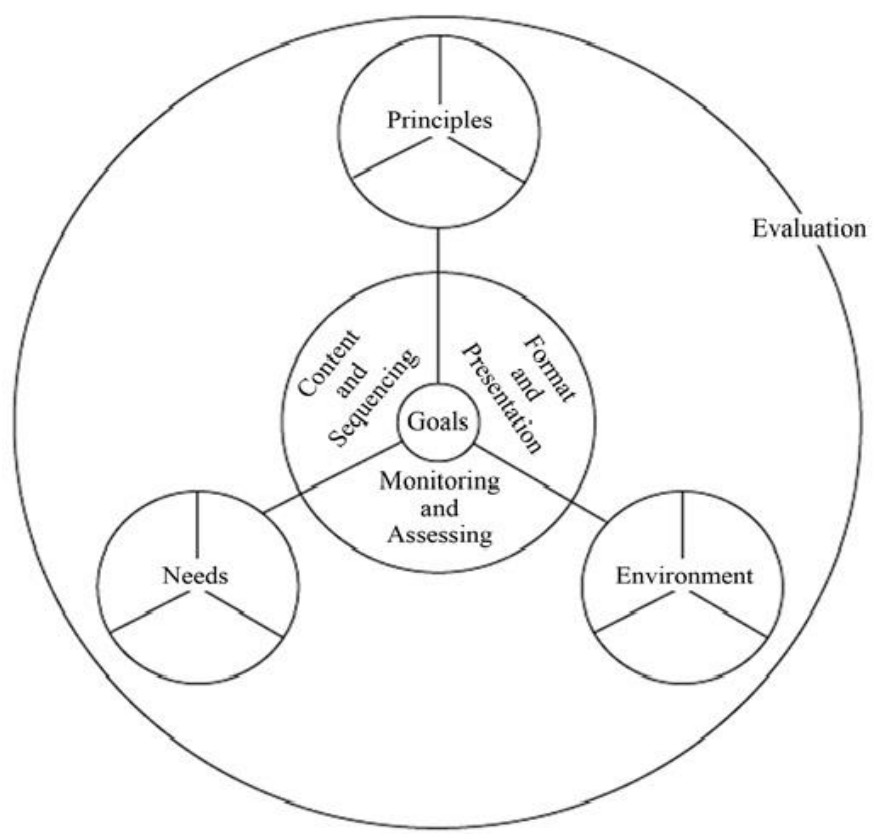

Figure 2.2 A model of the parts of the curriculum design process (Nation \& Macalister, 2010: 3)

Nation and Macalister (2010: 38-39) suggest 20 principles of successful language teaching that encompass three main threads: content and sequencing, format and presentation, and monitoring and assessment to success a language course. They also acknowledge and explain the 20 principles of language teaching that would help second language teachers to teach the target language to their learners.

However, not all aspects of the model are equally applicable for EFL teacher development. The model of language curriculum design presented in Nation and Macalister (2010) specifically considers the curriculum design only for language learners (i.e. students at schools, universities, or undertaking courses), but not for EFL teachers who need to maintain and improve their English language proficiency. While I argue that general aspects in the model are applicable for EFL teachers' professional development, more specific examples and explanation are needed for a teacher development programme. The principles are essential for second language learners.

Together, the review shows that recognising personal and institutional goals of teacher development, administering environment and needs analyses as well as 
carrying out evaluation are crucial in the administration of professional development for EFL teachers.

\subsubsection{Studies on TPD practice in Indonesia}

Studies have been done to investigate TPD practices among teachers in Indonesia (Sari, 2012; Widiati \& Hayati, 2015; Widodo \& Riandi, 2013). Sari (2012) investigated the implementation of online learning community (OLC) for TPD in Indonesia. The study aimed to explore the feasibility of OLC with Indonesian teachers and teacher educators between 2009 and 2010. The participants of the study were teachers, teacher educators, education leaders and the researcher. The researcher played important roles as Design-Based Research (DBR) designer and eModerator for the OLC. There were four phases in the DBR: problem analysis, design and development, iterative testing and refinement, and documentation and reflection. The first and the fourth phases appear to be similar to the environment and needs analysis and evaluation that are discussed by Nation and Macalister, (2010) and Richards and Farrell (2005). The findings of her study showed that there were three benefits of OLC. OLC allows teachers, school leaders and teacher educators to work together and reflect upon their professions. OLC helps also these participants to overcome the issues in finance, human resources and geographical limitations. Lastly, OLC encourages the creation of new knowledge to solve authentic professional issues.

However, some challenges were identified including the participants' lack of ICT access and literacy. Considering Indonesia with its archipelagic area as the site of the study, Sari was systematic and thorough in preparing and executing this threeyear study. However, because of its wide coverage, this study seems not to be able to see what actually happened among the teachers.

A study on institutional teacher development in Indonesia was carried out by Widiati and Hayati (2015). The study purposes of the study were threefold: (1) to investigate the historical changes in the policies of English language teacher education in Indonesia, (2) to describe the objectives, administration, curriculum and implementation of Pendidikan Profesi Guru (PPG) at Universitas Negeri Malang (State University of Malang/UM, and (3) to analyse the supporting factors 
and constraints of the PPG programme. The data were obtained from two groups of respondents, the programme lecturers and the participants. The data from the programme lecturers were gathered through coordination meetings with them. The data from the participants were gathered through discussion throughout the programme and the written reflective journals that was composed at the end of the programme. In the journals, the participants described their perceived development, constraints, and teaching aspects that they would like to improve. The findings show that the goals of PPG are improving the EFL teacher teaching competencies: pedagogical, professional (i.e. subject matter knowledge), social, and personal competencies and providing participants with the knowledge and skills to carry out classroom action research. However, the programme was challenged by various issues, including (1) the participants' insufficient English language proficiency and knowledge of pedagogical concepts, (2) the discords between the content of the PPG curriculum and the students' abilities and needs, and (3) the fact that the ASEAN curriculum has not been explicitly integrated in the curriculum of Indonesian teacher education.

Widodo and Riandi (2013) investigated the results of a two-year research project aimed at developing TPD model in Indonesia. The participants of the study were 102 science teachers from Bandung and Sumedang, West Java, Indonesia. A needs analysis assessment was administered to identify the teachers' professional needs. As a result, a dual-mode TPD that combined face-to-face and online sessions was developed. The data came from questionnaires, field notes, internet access records and interviews. The needs assessment was administered in the first year and the questionnaires were used to gather the teachers' ideas of what they needed in their professional development programme. The assessment revealed that $59.8 \%$ of teachers were interested in eLearning, $45.1 \%$ expected to have online training, $89.2 \%$ expected to have face-to-face training, $14.7 \%$ did not have computer skills, and $46.1 \%$ did not have skills to use internet. Thus, a pre-TPD programme was administered to provide teachers with basic computer and internet skills training and a combination of face-to-face and online training was designed. Based on the assessment of the teachers' interest and needs, the dual-mode programme was designed to cater the needs for teachers to have face-to-face and 
online trainings. The administration of the dual-mode TPD programme was done in the second year. The study showed that regardless of the teachers' interest in eLearning and in online learning training mode, their participation in online sessions was low. Only 5 out of 102 teachers participated in the online session. In response to this limitation, Widodo and Riandi (2013) suggest that administrators of TPD (in this case the Indonesian government) look into teachers' motivation to keep on learning, encourage the integration of bottom-up (based on teachers' individual needs) and top-down (based on institutional goals) teacher development and be more open to collaborating with universities and other training centres. While Widodo and Riandi had reported the results of the questionnaire (the needs analysis instrument), they did not discuss the findings from the field notes, internet access records, and interviews. They reported the supporting and inhibiting factors of the administration of the dual-mode TPD programme but they did not explain why only five teachers participated actively in the programme. They also did not probe why most of them discontinued their participation. Overall, the report seems to only partially report the whole study. It is important to see the whole picture of the study so that precise suggestions can be proffered to better the administration of the TPD programme. In view of the gaps in Widodo and Riandi's (2013) study, the present study has the potential to investigate whether there have been some changes in the administration of institutional and individual aspects of TPD in Indonesia. There is also a potential to investigate detrimental factors that might be responsible for the participants dropping out from TPD programmes.

Taken together, the review has looked into the three key aspects to effective TPD, taking into account (1) institutional goals, (2) individual goals and (3) environment and needs analysis (and evaluation). The review also shows that there are few studies, which explored the administration of TPD in the Indonesian teaching and learning context. The studies being reviewed include the use of online learning community in TPD, the administration of PPG and its benefits and challenges, and the use of dual-mode TPD model. Thus far, previous studies have reported the administration of TPD. However, there is a little research on the policy and implementation documents of TPD in Indonesia, the EFL teachers and 
stakeholders' views on TPD policies and practices, and importance of environment and needs analysis and evaluation in TPD administration. As such, the present study investigates those three issues and uses institutional and individual aspects of TPD and needs and environmental analysis to frame its discussion.

\subsection{Why is target language proficiency maintenance an essential component of EFL teachers' professionalism?}

Farrell (2015) states that two out of seven areas of individual teacher development for EFL teachers are subject matter knowledge improvement and language upgrading. So, why is target language proficiency maintenance essential for the EFL teachers' professionalism? An extensive literature on second language proficiency maintenance suggests that the status of English and the possibility of language attrition are key reasons why L2 proficiency maintenance should be administered in a context where English is confined in classrooms or academic forums.

\subsubsection{The status of English in Indonesian educational policy}

The Indonesian national language policies are: (1) Bahasa Indonesia as a national language is used to communicate with people from various language backgrounds in Indonesia, (2) English or other foreign languages are used to communicate with people from other countries, and (3) English is a compulsory subject for secondary school students and students of higher education, universities and institutes (Dardjowidjojo, 2000; Jazadi, 2000; Lauder, 2008).

Dardjowidjojo (2000: 23) states that English became a foreign language in Indonesia alongside French, German, Arabic, Chinese and Japanese after the Indonesian Independence Day in 1945. Likewise, (Lauder, 2008: 12-13) claims that English has become a medium for accessing information, knowledge and technology, a source of vocabulary of Indonesian language, and a means of expanding ones intellectual horizons. Later, (ASEAN Secretariat, 2009: 68) declares that English serves as a means of regional communication among Southeast Asian nations. The status of English as a foreign language in Indonesia 
and as a lingua franca in the Southeast Asian countries affects the EFL teachers' professional development, i.e. it creates a need for EFL teachers in Indonesia to meet the professional teacher standards accepted among ASEAN members, increasing the expectation for the English teacher professional education. Widiati and Hayati (2015) indicate that if Indonesian EFL teachers benchmark their standard to the ASEAN EFL teachers' standard, they would be able to communicate well in English with their students or other fellow teachers in the regional and international levels. Furthermore, Dardjowidjojo (2000), Jazadi (2000), and Lauder (2008) argue that the status of English as a compulsory subject in secondary high schools and tertiary education has created the need for a great number of qualified EFL teachers in Indonesia.

Hence, the review reveals that the EFL teachers in Indonesia are obliged to have good command of English language skills to access information, to keep up with the development of science and technology, to share knowledge, ideas and skills, and to answer the growing demand of proficient EFL teachers in the national, regional, and international levels.

\subsubsection{Language attrition among second or foreign language users}

Another reason why second or foreign language users have to maintain their target language proficiency is because a second/foreign language proficiency may attrite over time (Bardovi-Harlig \& Stringer, 2010; Schmid, 2011; Schmid \& Mehotcheva, 2012). In this subsection, I review variables that may contribute to second or foreign language attrition and how these variables relate to the present study.

In their critical review article of language attrition research from the 1980s to 2010s, Bardovi-Harlig and Stringer (2010: 2) defines language attrition as "loss of language as a result of contact with majority languages, loss of language by communities, or loss of language by individuals in both pathological and nonpathological settings". Based on their critical review, they described several first language (L1) and second language (L2) attrition theories and variables that are pertinent to L1 and L2 attrition. They find that linguistic and extra linguistic 
variables may play significant roles in the attrition of one's L2. Bardovi-Harlig and Stringer (2010: 25) describe:

The linguistic variables include level of attainment, area of the grammar investigated, sociolinguistic competence, receptive versus productive language use, development of L2 literacy skills, and typical of lexical items. Under the extra linguistic variables are age (at time of acquisition, cessation of acquisition, and period of attrition), factors of language knowledge and use, factors of input, motivation, instruction (intensive/distributed, formal/contact learning), and attitude.

While Bardovi-Harlig and Stringer's (2010) review is important to provide basic knowledge of L1 and L2 attrition theories and variables of language attrition, it is not sufficient because the authors mostly discussed the learning of L2 and how to establish baseline for attainment so that people can measure attrition. Thus, I explore Schmid (2011) and Schmid and Mehotcheva (2012) to find more relevant theories on second/foreign language attrition.

In general, Schmid (2011: i) defines language attrition as "a loss of, or changes to, grammatical and other features of a language as a result of declining use by speakers who have changed their linguistic environment and language habits'. However, this definition is also not sufficient to explain the second or foreign language attrition. In their review of development and directions in the language attrition, Schmid and Mehotcheva (2012: 2-3) suggest that within the field of language attrition, there are two distinct areas: L1 attrition or the attrition of a native language associated with immigrants and L2 or foreign language (FL) attrition, the attrition of language acquired later in life. Furthermore, they argue that L2 and FL attrition have some substantial differences which may be caused by the amount of instructed and immersed language learning input, exposure to and use of the language. The difference may also be attributed to the representation of the linguistic structures in memory between the instructed or immersed language. Based on their review, Schmid and Mehotcheva (2012: 11) argue that unlike L1 and L2, foreign language acquisition (and presumably foreign language attrition) is not a linear process. There are many factors involved 
in the acquisition (and attrition) including the learners' linguistic and extra linguistic factors. Within the extra linguistic factors are personal (age, age at the onset of attrition, attained proficiency, and attitude and motivation) and external (time since onset of attrition, language contact and use and/or length of exposure to the language) (Schmid \& Mehotcheva, 2012: 13).

Up to now, the review has mostly investigated the theories of language attrition for language learners and not much has been discussed on adult learners or EFL teachers' language maintenance. However, one of the external factors, contact with and/or use of the language (Schmid \& Mehotcheva, 2012: 15) is particularly relevant in the context of EFL teachers in Indonesia. It is pertinent because EFL teachers in the Indonesian teaching and learning context learned and used the target language during their formal teacher training. However, when they graduated, it were as if they had been removed from a supportive environment to a less supportive environment where English was less likely to be used or if they did use the target language, the frequency of usage was rather low (Lengkanawati, 2005; Lie, 2007; Marcellino, 2005). I will discuss each of these studies and other relevant studies in the next section.

\subsubsection{Studies on foreign language teachers' L2 proficiency}

The issues of foreign language teachers' proficiency have received significant attention in Asia, Southeast Asian nations and/or in a more global context (Aiello, Di Martino, \& Di Sabato, 2015; Best, 2014; Butler, 2005; Dudzik \& Nguyen, 2015; Eslami \& Fatahi, 2008; Ghasemboland \& Hashim, 2013; Harvey, Conway, Richards, \& Roskvist, 2010; Lengkanawati, 2005; Lie, 2007; Mai, 2014; Marcellino, 2005; Mori, Ming, Nor, Suppiah, \& Imm, 2011; Musthafa, 2001; Richards, 2017). However, only a few of them specifically explore the EFL teachers' actual and perceived L2 proficiency (Aiello et al., 2015; Mori et al., 2011). Most studies maintain that teachers' actual proficiency in the target language refers to one's language proficiency and is commonly measured using performance-based tests (i.e. oral and written language assessment). These authors also maintain "perceived L2 proficiency refers to the extent to which a person thinks that she is competent at communicating and is commonly assessed by 
soliciting her self-report data (i.e. questionnaire or survey)". Unlike most of the studies, Richards (2017: 22) argues that language proficiency and teaching ability is not the same thing. Thus, he maintains that the EFL teachers' ability to answer standardised English tests is not sufficient for these teachers to teach effectively in English. He also argues that EFL teachers need suitable training and resources within realisable timeframe to be able to use English as both the medium and target of instruction.

While Aiello et al. (2015) and Mori et al.'s (2011) studies explored teachers' actual and perceived productive skills (oral and written language skills), the present study explored the EFL teachers' actual and perceived vocabulary, reading and writing proficiency. In the present study, actual proficiency refers to the EFL teachers' ability to answer three language proficiency tests (vocabulary, reading and writing tests). In addition, perceived L2 proficiency refers to the belief that one has on particular levels of vocabulary, reading and writing proficiency.

Review of two previous studies on EFL teachers' English proficiency in Indonesia showed that actual or perceived L2 proficiency were usually examined independently from each other (Lengkanawati, 2005; Marcellino, 2005). Test of English as a Foreign Language (TOEFL) or equivalents is commonly used as an objective measure of L2 proficiency (Lengkanawati, 2005). Other methods of assessment, such as self-report or self-assessment of one's perceived L2 proficiency is also common prevalent (Marcellino, 2005). The correlation between the EFL teachers' length of service and their English language proficiency, however, has not been explored. In a more specific manner, studies on teachers' L2 (especially in English) proficiency in Indonesia show that EFL teachers are challenged by their low English proficiency (Lengkanawati, 2005) and tendency to use first language (Bahasa Indonesia) to communicate with others in academic forums (Lie, 2007) and to communicate with their students in the classrooms (Marcellino, 2005).

In the absence of effective professional development targeting the maintenance of L2 proficiency, in the EFL setting, EFL teachers' length of service may be associated with second/foreign language attrition (Bardovi-Harlig \& Stringer, 
2010; Schmid, 2011; Schmid \& Mehotcheva, 2012). Thus, in this section, I review studies on both teachers' second or foreign language proficiency in Indonesia and beyond and discuss their implications to my present studies.

A study on Teacher Professional Development Languages (TPDL) in years 7 to 10 was done in New Zealand in 2008 (Harvey et al., 2010). It aimed to understand the impact of TPDL programme on the development of teachers' fluency in the teaching language, on teacher second language teaching knowledge, on teachers' knowledge of the Learning Languages strand of the New Zealand Curriculum (2007) and specific curriculum guidelines, on student learning outcomes, and how sustainable and replicable the TPDL programme is. The team of researchers in the study used questionnaire, interview, and observation to gather data. The study was divided into three stages and involved 34 participants in the first stage, 29 participants in the second phase and 25 participants in the third stage. The declining numbers of the participants was due to the nature of the voluntary participation. The teaching languages or the languages investigated in the study were the teachers' second language: French, Spanish, Chinese, Germany, and Japanese. The study reveals some significant findings including (1) the importance of sitting and passing an internationally recognized language examination for the teachers' pride and motivation and (2) four key factors for successful and sustainable professional development that changes teachers' practices. The success and sustainability of the TPD programme rely on the teachers' strong foundation of deep principled knowledge, given opportunities to develop their inquiry skills, support from schools, and their active participation as members of knowledge community. This study was thorough and the findings were significant for similar research on the field of second or foreign language TPD. However, the report does not engage in the current investigation on the TPD programme for teachers of English as a second or foreign language. Thus, I will look into the issue of EFL teachers' English proficiency in one of the Southeast Asian nations, Vietnam.

Similar to Indonesia, the Socialist Republic of Vietnam is a member of Association of Southeast Asian Nations (ASEAN) and the working language of ASEAN is English (ASEAN Secretariat, 2009). Dudzik and Nguyen (2015) 
reported that Vietnam has done relevant changes in education policy to foster regional and international integration. The changes focus on foreign language proficiency and teaching competency in English and are realized into a number of national initiatives that are aimed to build national foreign language capacity. One of the initiatives is providing a benchmark for EFL teachers' English proficiency using the Common European Framework of Reference (CEFR) (Dudzik \& Nguyen, 2015: 47-48). The initiative was followed by a massive language assessment of the teachers all over Vietnam. Dudzik and Nguyen (2015) believe that the CEFR provides EFL teachers in Vietnam with some ground to benchmark their foreign language proficiency with international framework. However, Richards (2017) argues that the benchmark only reflects teachers' general language proficiency in English rather than their ability to teach through English. While the findings of the study done by Dudzik and Nguyen provide a number of significant lessons and recommendations for Vietnamese and other southeast Asian nations including Indonesia, perhaps the most serious issue is the missing explanation of what data were investigated, how the data were gathered and analyzed, and who the subjects of the study were.

Turning now to the Indonesian context, Lengkanawati (2005) carried out a study about EFL teachers' competency in West Java, Indonesia. It aimed to investigate the EFL teachers' readiness in facing the implementation of the 2004 English Curriculum and its implications for teacher education by assessing their English proficiency. The subjects of the study were the 66 EFL junior and high school teachers in West Java, Indonesia. The test instruments used to measure the teachers' English proficiency were a TOEFL equivalent test and a writing test. Only 38 out of 66 data sets were analysed because only 38 teachers managed to finish both proficiency tests. The rest of the data were excluded because they were not complete. The study also used interviews to gain information on the teachers' teaching challenges, perception of the new curriculum, and expectations for future in-service training. The findings showed that with 500 band-scale of TOEFL score as a baseline, $42.10 \%$ of 38 teachers scored below $500(n=16), 28.95 \%$ scored 500 $(n=11)$ and $28.95 \%$ scored above $500(n=11)$. The study also identified that most of the teachers' essays contained issues in almost all aspects of their writing: 
content, organisation, vocabulary, grammar, and mechanics. The essays showed little substance and the topics were not developed adequately. Their writing lacked logical sequencing and development. They also frequently made errors of word forms, choice of words and usage, grammar, and mechanics (i.e. capitalisation, paragraphing)

The evidence appears to be moderately robust because Lengkanawati used a standardised test, a TOEFL-equivalent test, as a tool to gather the participants' English proficiency. However, she did not provide a robust explanation about how she selected the study participants. Her study would have been more convincing if she had discussed how the participants were recruited, how they were selected from the population, and how her sample of the subjects represented EFL teachers in West Java, Indonesia. There were no reports on whether the essays were double marked by different raters to ensure the reliability of the scores. She also did not report the data analysis and the results of the study in a detailed manner. Hence, it is hard to have a reasonable confidence in the findings of the study.

Another paper that investigated the need for EFL teachers to have good command of English in relation to the education policy and EFL curriculum in Indonesia was carried out by Lie (2007). The study aimed to "describe the gap between the commitment to competency as promised in the 2004 Curriculum and the English classroom practices" and "look into the possibilities of how an organisation such as TEFLIN (association of Teachers of English as a Foreign Language in Indonesia) may help shape the language policy and practices". Lie reported that only a few junior high school English teachers were able to present their action research (CAR) papers in English and none wrote in English in an event that took place in Yogyakarta on 18-20 November 2002. The event was part of a World Bank project to improve the quality of teachers in six areas of class subjects (English, Indonesia, geography, math, physics, and biology) through an institutional initiative that helped teachers to conduct CAR and write a paper based on the CAR. Four hundred papers that were written by different subject teacher were submitted and the best 80 papers from different areas in Indonesia were selected at the provincial level. Her role was as one of the expert reviewers whose duties were to read the papers, listen to the presentation, and choose the 
papers to be presented in the symposium. From the 80 papers, there were 45 papers that were written by EFL teachers. The EFL teachers were given an opportunity to present their paper in Indonesian or English. Lie (2007) found none of their action research reports were written in English and less than 10 of them delivered the papers in English. The findings of the study indicate that the author overlooked the fact that the project did not provide teachers with skills to speak in public and present papers in academic settings. Apparently, the issue of teachers' lack of confidence to speak in English was persistent but improving the teachers' public speaking skills was not one of the main purposes of the project.

Marcellino's (2005) study aimed to explore and evaluate the extent to which Competency-Based Language Teaching (CBLT) was used in Indonesia. To achieve the purposes of the study, Marcellino video recorded the classroom interaction between EFL teachers with their students in six classrooms at five outstanding senior high schools in the capital city of Indonesia, Jakarta. However, Marcellino did not provide explanation of how many teachers were being observed and what "outstanding senior high schools" was supposed to mean. The interview was conducted with a representative sample of the respondents. Once again, he did not provide explanation of what he described as representative sample of the respondents. He claimed that CBLT could not be implemented well in the five schools because of several factors, and one of those being the teachers' insufficient English competency to communicate and teach. One major drawback of Marcellino's claim is the insufficient explanation he provided about why and how he gathered the data and how he analysed it.

Reviewing the literature, the second or foreign language teachers' proficiency of the language they are teaching has received significant attention. However, Indonesian EFL teachers lacked necessary language proficiency to carry out meaningful communication in and outside the classroom (Lengkanawati, 2005; Lie, 2007; Marcellino, 2005).

This review provides an ample support on why EFL teachers have to maintain their English language proficiency after graduating from their formal teaching training. The review also reveals that existing research on TPD among EFL 
teachers in Indonesia has not explored why English language maintenance is importance for them. What we know about research on EFL teachers' L2 proficiency in the Indonesian context is largely based upon studies that investigate the implementation of particular curricula in Indonesia and how they affected teachers, students and classroom practices. The present study allows the investigation of the EFL teachers' current L2 proficiency (lexical, reading and writing proficiency) and the correlation between periods of decreased opportunity to use their second language (represented by the teachers' length of service) and their actual and perceived L2 proficiency.

\subsection{What potential does blogging-integrated professional development hold for EFL TPD?}

In the introduction chapter of this study, I state that it is important for EFL teachers to constantly upgrade their English proficiency and ICT skills by keeping up with the changes and innovations in English language teaching (ELT) and technology-based ELT teaching and learning approaches. In this section of the literature review I consider what blogging (and ICT, more generally) is able to contribute to the EFL teachers' professional development in high schools in Malang, Indonesia?

This section consists of three parts and implications of each part to the present study will be discussed.

\subsubsection{Mastering ICT is an integral part of Indonesian National}

\section{Education Policy}

The Indonesian National Education Policy requires teachers to be proficient in ICT skills. In the 2003 Law on National Education System, pedagogically and professionally, teachers are advised to integrate information and technology for teaching. Teachers are also urged to participate in individual or institutional professional development programmes to keep up with new developments in science, technology and arts. While learning how to use ICT in teaching is essential for teachers because they can keep up with their students' ICT literacy and gear the students' learning potentials, the 2003 Law does not provide detailed 
explanation on how institutions such as schools, MoEC, and government should support the teachers to learn, maintain or improve their ICT skills. Neither is an explanation available for teachers in general and EFL teachers in particular on how to integrate ICT in their teaching. In response to this gap, the present study explores the 2003 Law and other professional development policies and implementation documents of TPD among EFL teachers in Malang, Indonesia. It particularly seeks to investigate whether the documentation discusses institutional and individual aspects of teacher development and the EFL teachers' needs to maintain their disciplinary knowledge and ICT skills.

\subsubsection{Information and communication technology is a useful teaching aid}

The second reason that encourages the present study to look into the significance of ICT and blogging in English language teaching, is a growing body of literature that discusses how the ICT and internet have made it possible to both educators to teach and learn better (Silvia, 2015; Son, Robb, \& Charismiadji, 2011). These studies were administered and reported at the institutional level and none of them addressed teachers' individual professional development in ICT. In the order of importance from the most to the least important, I will review these three articles and other relevant articles. Then, I link them to my present study.

Silvia (2015) investigated the integration of ICT in a professional development programme for EFL teachers that was run by Coursera, a virtual online platform of Massive Open Online Courses (MOOC). The purpose of the study was to examine the extent to which online EFL teacher development administered through Coursera (https://www.coursera.org/) benefited the participating teachers. The participants were 24 teachers from different countries: Brazil, India, Indonesia, Italy, Turkey, the US, and Russia. They came from different educational levels, from primary to tertiary, and private language schools. Using a survey that investigated the teachers' attitude towards five evaluative elements, the data were gathered. The survey explored the participant reaction, professional learning, use of new skills, organisational culture, and student learning outcomes. Silvia found that relevancy to teachers' professional development needs, sufficient 
learning time, and content are three crucial elements of online TPD. She also found that the platform helped English language teachers to have meaningful and vibrant TPD, although they were challenged by lack of support from their institution and policy makers. Silvia's (2015) study showed that the integration of ICT in TPD had freed teachers from the constraints of time and space to develop themselves professionally. However, her approach does involve a limitation, especially to the answer of the fifth evaluative element: students learning outcomes. While the survey showed that there was a strong positive idea that Coursera helped teachers to boost their students learning outcomes, she did not provide explanation of what particular learning outcomes were affected by the teachers' participation in Coursera. She believed that her study would be more meaningful if she also looked into the issues longitudinally so that she could provide robust justification of her claim. Considering the identified strengths in Silvia's study, the present study has the potential to substantiate that ICT and help EFL teachers' professional development. Given the identified limitation in Silvia's study, the present study does not look into the extent to which teachers' participation in blogging may affect the students' learning outcomes, but rather focuses only on the EFL TPD.

Son et.al. (2009) investigated the perceived levels of ICT skills of teachers in Indonesia and the internal and external factors that affect the teachers' use of computers in the classrooms. The respondents were a total of 73 in-service EFL primary teachers, secondary teachers, private language tutors and university lecturers from Jakarta ( $n=28$ teachers) and Yogyakarta $(n=45$ teachers). Son et al. (2011) investigated EFL teachers' computer literacy and competency through a survey question. The survey was administered during a pre-conference workshop at the Globalization and Localization in Computer-Assisted Language Learning (GLoCALL) 2008 Conference held on separated days in Jakarta and Yogyakarta, Indonesia. The study found that most teachers perceived their level of computer literacy and internet literacy as adequate or good. The regular users of computer applications such as word processing, email, web and multimedia were mostly non-primary school teachers. However, other applications such as blogs, video conferencing, databases, concordances or online discussion groups were rarely or 
never used. The results also showed that the teachers considered technology a useful teaching aid because it helped them to enhance their teaching approaches such as providing students chances to learn by having various language inputs and real language experiences. Son et al. (2011) noted that because of the size of the participant group and the condition of the data collection, the generalisability of the study had to be considered carefully. They believed that the results could not be used to predict the computer literacy and competency level of all EFL teachers in Indonesia. While I agree with their idea about the generalisability of the study, I would like to add that Jakarta and Yogyakarta are two different cities in terms of availability of size, facilities and supports for teachers, and characteristic of the teachers. Besides the size of the participant group and the condition of the data collection, the characteristics of the two cities and the teachers from those two cities might have created biases. In other words, primary school EFL teachers from Jakarta might have used computers and internet extensively because they were parts of the school and household facilities. However, the same case might not be true in Yogyakarta because computer and internet were not parts of their school or household facilities.

However, studies also reveal that integration of ICT in the teacher development may be challenged by various issues. Widodo and Riandi (2013: 388-389) find that TPD in Indonesia needs to be reframed because of five issues: absence of formal consequences for teachers when not participating, inadequate supporting infrastructure, i.e. internet access and participants' preference for direct personal interaction than for virtual interaction, lack of time, and lack of computer and/or internet skills. Another study also finds that lack of ICT access and ICT literacy challenged the use of online learning community for TPD (Sari, 2012: 71). Still another study also finds that teachers' workloads and administrative work at schools has challenged the teachers' efforts to foster their professional development (Silvia, 2015: 229).

There is a growing interest in using ICT in classrooms for TPD. Until recently, research on the integration of ICT for EFL teacher development in Indonesia has focused on how to integrate ICT for teaching in the classroom. However, not much existing research focused on the integration of ICT to maintain or improve 
their second language proficiency. The present study offers to explore how EFL teachers' ICT skills and English language proficiency can be maintained or improved through web-based integrated professional development; that is through blogging.

\subsubsection{Blogging offers benefits for teaching and learning}

In this subsection, I provide a brief historical account of blogging, review studies on the affordances of and barriers to blogging, and link them to the present study. During the past 15 years, much more information has become available on blogging. Historically, blogs were known as weblogs in 1999 (Blood, 2000). Web 2.0 replaced Web 1.0 at the end of 1990s and has allowed computer users to create their own public spaces (O'Reilly, 2005). Campbell (2003) stated that blogging as a Web 2.0 platform had developed a lot since it was introduced in 1999.

Blogs had received a lot of recognition as a tool for teaching, including for teaching English as a second language. Blogging also serves as a personal online journal and a group publishing space for students or for English language teachers. Several studies have investigated the affordance of blogging for teaching at the institutional level. The word affordance was coined by Gibson (2015) and was reintroduced by van Lier (2000). Affordance refers to "a reciprocal relationship between an organism and a particular feature of its environment" (van Lier, 2000: 252). Van Lier further explains that:

An affordance affords further action (but does not cause or trigger it). An affordance depends on what the organism does, what it wants, and what is useful for it.

With regards to its affordances, blogging plays its role as an online journal (Blood, 2000) but it may also allow its users to share knowledge, feelings and thoughts with people around the globe (de Almeida Soares, 2008), without space and time constraints (Vurdien, 2013; 127) and to reflect on their teaching (Brescia \& Miller, 2006; Deng \& Yuen, 2011; Luehmann, 2008).

Sun (2010) aimed to examine the effects that blogging had on the development of students' writing ability in English as a foreign language (EFL). The research 
questions that guide her study are as follows: (1) Does writing extensively on a blog affect writing performance? (2) What are learners' writing processes in blogging? (3) What are learners' perceptions of blogging? The participants of her study were 23 undergraduate students (males $=20$, females $=3$ ) who were taking an academic writing course to write thesis or journal articles at a university in Taiwan. They came from different levels of tertiary education (freshman to seniors). The students were asked to publish 30 blog entries and 10 response entries in a semester (18 weeks). One of the findings is the indication that blogging had a potential to constitute an effective task-based environment that prompted students to use language authentically and purposefully and enhanced their writing proficiency in foreign languages.

Deng and Yuen (2011) investigated the educational affordances of blogs among 37 students of Bachelor of English language education at a university in Hong Kong. Two classes participated in the study: Class A $(n=15$ students $)$ and Class B ( $\mathrm{n}=22$ students). Questionnaires and interviews were used as the main instruments for the data collection. The secondary data came from the blog posts and comments of the students. During a ten-week teaching practicum the students were teaching in different schools and the blog was used to connect them with their fellow student teachers. The study found that blogging helped student teachers to express themselves and reflect on what they did in the past, what they were doing in the present and what they would do in the future. Deng and Yuen (2011: 443) explained:

Self-expression and self-reflection fall into the individual dimension that centre on the individual processes of exploration, description, examination, and deliberation. Self-expression involves expressing one's thought and emotions, as well as capturing or recording one's experiences. Selfreflection, on the other hand, moves beyond just recording experiences and events, towards a cognitive level of extracting meaning from them. Social interaction and reflective dialogue constitute the community dimension that is concerned with the social processes of exchanging ideas, care and support.

Deng and Yuen (2011) show that blogging affords students the ability to express themselves and reflect on the experiences they have been through. This affordance of blogging provides a basis for the present study to explore the affordance of 
blogging for EFL teachers as a way to maintain and improve their English proficiency.

Luehmann (2008) investigated teacher personal blogging experience. This study aimed to report a case study on the use of blogging to support teacher's professional identity development. The subject of the study was Ms. Frizzle (pseudonym) who was a science teacher at an urban middle school and a remarkable blogger. The author has three main research questions: (1) how Ms. Frizzle used her blog over the period of one school year, (2) how blogging helped her address specific issues she faced as an urban reform-minded science teacher, and (3) how Ms. Frizzle herself perceived the effects of blogging on her practice and development as a teacher. Luehmann (2008) argued that blogging empirically supported teachers' professional identity development for several reasons. Blogging as a tool of learning provides teachers the opportunities to be selfdirected, to reflect and engage in meta-cognition, to further develop one's thinking because of interaction with an audience, to play the role of knowledgebroker, and to engage in identity work. Specifically for the affordance of blogging to knowledge brokering, she mentioned that the teachers' ability to use blogging features, i.e. hyperlinks, pictures, and multimedia effectively showed that these teachers were able to "select and connect their own work and thoughts to those of others, to a wider community and to professional discourse" (Luehmann, 2008: 290).

The findings of her study confirm her claim that blogging provide Ms. Frizzle with great chances to deal with key issues in her teaching practice and to develop her professional identity as a teacher. It was found that blogging allowed Ms. Frizzle to recognise and support her identity development because she invested significant time and energy in the blog. In other words, different teachers with different time and effort investment may reap different results too. The results are subject to the time and effort invested by teachers. Given the benefits of blogging and the caution that Luehmann (2008) raised, the present study might be challenged by both issues because it takes a half-time of Luehmann's study, six months. 
Brescia and Miller's study (2006) aimed to describe the elements or characteristics of blogging that make it an effective tool for supporting college level instruction. A descriptive, exploratory study using the Delphi-survey method was used to collect data from a panel of 24 experts who came from 18 different states and 22 different universities in the United States. The study found that two of the greatest instructional benefits of blogging were the opportunities for self-expression and self-reflection. While Brescia and Miller (2006) carefully and systematically recruited their participants through snowballing sampling procedures, they generated ideas using the top-down approach. The elements that made blogging distinctive and effective in supporting instruction were gathered from individuals who had published academic articles about blogging.

The review of the studies reveals that there are at least four benefits of blogging: to build positive language awareness, express ideas, reflect on their teaching, and to do both without the constraints of time and space. However, studies also show that the integration of blogging in the teaching and learning context has been challenged by a few issues including: lack of time and technical problems. De Almeida Soares (2008) explored whether her students saw class blog as a learning tool ( $\mathrm{n}=9$ students age 14 to15 year old) and what blogging like in other language teaching contexts was ( $\mathrm{n}=16$ language teachers). She carried out some Exploratory Practice for three months to investigate her students' perception of blogging. She asked 16 volunteer members of a group of language professionals to answer an online survey on what blogging like in different language teaching context. The findings reveal that students were challenged by issues such as lack of time to blog and technical problems to post blog entries. Regarding the technical problem, De Almeida Soares' students (2008) sent her emails and asked her to post the emails as blog entries in the class blog. The survey showed that the other teachers also integrated blog in their classrooms.

Together, the review shows that blogging has more to offer to EFL teachers. The review also indicates that the studies appear to focus more on the benefits of blogging rather than the barriers to blogging. Furthermore, review of literature on the use of blogging shows not much attention has been paid to the idea of blogging to facilitate the development and maintenance of EFL teachers' target 
language proficiency and subject matter teaching expertise. Thus, the present study explores issues on EFL teachers' professional development, L2 proficiency, benefits and barriers to blogging, and self-reflection of their teaching and learning experiences through a blogging platform that I specifically designed for the study.

\subsection{Summary}

The studies presented thus far elicit three related issues on what professional development offers language teachers, why target language proficiency maintenance is essential for EFL teachers' professionalism, and why ICT and blogging skills should be part of TPD. The first section of this chapter showed that: (1) on-going professional development offers important benefits to EFL teachers, (2) there are institutional and individual aspects of professional development, and (3) the environment analysis, needs analysis, and evaluation are critical to administer effective TPD. The second section revealed that the existing research on Indonesian EFL teachers' L2 proficiency is, at best, a partial examination of the teachers' L2 proficiency. They also showed that, personally and institutionally, the maintenance of teachers' disciplinary knowledge was overlooked. In the third section, several studies have been done to integrate ICT and TPD in Indonesia. It was found that there were some blogging affordances offered for teachers to reflect upon their teaching experiences. However, the studies did not elicit how EFL teachers could personally and institutionally use blogs to maintain their L2 proficiency and improve their ICT skills. What we understand from the literature review is that quite a few ICT-integrated activities had been introduced for teaching and institutional TPD. However, not much is known about the use of ICT to maintain EFL teachers' L2 competency in Indonesia or the use of blogs for TPD in Indonesia.

\subsection{Research Questions}

This research investigates the issue of L2 proficiency among EFL teachers in Indonesia and using blogging to assist EFL teachers to maintain or improve their L2 proficiency through ICT mediated TPD. I seek to answer the following questions: 
1. Are EFL teachers able to maintain their L2 proficiency after graduating from their formal teaching training?

The first question addresses the EFL teachers' actual and perceived proficiency in the target language and factors that support or inhibit their L2 proficiency maintenance. This research question is subdivided into three subquestions:

a. What is the state of the EFL teachers' L2 proficiency in vocabulary knowledge, reading and writing?

b. Are EFL teachers able to maintain their target language in terms of vocabulary knowledge, reading and writing after their formal teaching training?

c. What are the EFL teachers' views on their own English proficiency and perception of factors that support or inhibit their L2 proficiency?

To investigate whether EFL teachers are able to maintain their L2 proficiency, I consider the possibility of a correlation between the EFL teachers' years of service and their English proficiency in vocabulary knowledge, reading and writing.

Taking into account the need for EFL teachers to master ICT in their teaching and learning practice and the potential of blogging as a TPD tool, I investigate if EFL teachers' professionalism can be supported through blogging. Thus my second research question investigates the practice of using blogging to (1) maintain the EFL teachers' L2 proficiency and (2) facilitate teacher reflection on their teaching and learning experiences (i.e. as a form of TPD).

2. Can EFL teacher professionalism be supported through blogging as a form of TPD?

The second question is subdivided into six questions. The first two subquestions (a.i and a.ii) are used to analyse blogging case studies of three teacher bloggers. The last four subquestions (b.i - b.iv) examine the EFL teachers' familiarity with blogging, frequency of their use, and perceived benefits and barriers to blogging.

a. Blogging case studies:

i. What language and blogging features did teachers use when writing in a blog? 
ii. How did the teachers engage in critical thinking and reflection in their blog entries informed by the readings?

b. Blogging as a form of TPD:

i. To what degree are EFL teachers familiar with blogging?

ii. How frequently do teachers engage in blogging?

iii. What are the perceived benefits of blogging?

iv. What are the perceived barriers to blogging?

My third research question focuses on the existing Indonesian TPD policy and implementation documents, and EFL teachers' and stakeholders' views of TPD policies and practice. I attempt to answer the third question using Farrell (2015) and Richards and Farrell (2005) framework of institutional and individual TPD.

3. What institutional and individual teacher development initiatives are established to maintain and improve EFL teachers' L2 proficiency and ICT skills in Indonesia?

The third question can be subdivided into three subquestions:

a. To what extent do Indonesian TPD policy and implementation documents discuss institutional and individual teacher development for EFL teachers to maintain or improve their subject matter knowledge and ICT skills?

b. To what extent are the TPD policy and implementation documents effective in respect to the maintenance and improvement of EFL teachers' L2 proficiency and ICT skills?

c. What do Indonesian teachers and stakeholders know and think about TPD policies and practice?

The third question wraps up the present study by situating the previous two questions in the contexts of EFL teachers' professional development in Indonesia. Chapter Three combines quantitative (questionnaire and L2 proficiency tests) data and interview data. Chapter Four, this chapter, quantifies the blogging data by analysing the language and special blogging feature data. Chapter Five combines quantitative (questionnaire) and qualitative (interview) data. Finally, Chapter Six that combines quantitative (document) and qualitative (interview) data. 
The next four chapters, Chapters Three, Four, Five and Six, are organized in similar sections: introduction, purposes of the study, methodology, findings and discussion sections. Chapter Three used mixed-method approach to answer the first research question (RQ1) on teachers' English proficiency and its three subquestions. Chapters Four and Five also used mixed-methods approach to answer the second research question (RQ2) on blogging case studies and on Blogging as a form of TPD. Finally, Chapter Six used qualitative approach to the document and interview data to answer the third research question (RQ3) on teacher professional development and its three subquestions. Further methodological details are included in each individual study.

The next chapter describes the purposes, methodology, findings and general discussion of the first study, EFL teachers' L2 proficiency study. 
This page is intentionally left blank 


\section{Chapter 3 Teacher L2 Proficiency Study}

\section{Introduction}

This chapter seeks to explore teachers' actual and perceived L2 proficiency as well as the correlation of teachers' length of service and their actual L2 proficiency.

\subsection{Purposes of the study}

L2 proficiency of EFL teachers is a key component of their professionalism. The present study aims to investigate whether or not EFL teachers in Malang District, East Java, Indonesia are able to maintain their target language proficiency and remain competent after graduating from their teaching training.

To be able to answer the research questions I investigated (1) the current English language proficiency of EFL teachers in Malang District, East Java, Indonesia in terms of vocabulary, reading and writing proficiency, (2) the relationship between their years of service and their current English proficiency, and (3) the perceived levels of their proficiency and the perceived supporting and inhibiting factors to sustain the teachers' L2 proficiency.

The teachers' estimated English proficiency, their self-reported English proficiency (gathered using a questionnaire), and extended self-reports (gathered using an interview) play a critical role in the second (blogging) study. In the second study, the teachers were required to read materials relevant to their teaching and learning practice, reflect on them, and write reflective blog posts based on these readings. The relationship between the EFL teachers' years of service and their L2 proficiency is relevant to the third study, in which the relationship between TPD policies, their implementation documents, and practice are considered.

The research question investigated in the teacher L2 proficiency study is "Are EFL teachers able to maintain their L2 proficiency and remain competent after 
graduating from their formal teaching training?" This research question can be subdivided into three research questions:

1. What is the current state of the EFL teachers' L2 proficiency in vocabulary knowledge, reading and writing?

2. Is there a relationship between the EFL teachers' years of service and their English proficiency in vocabulary knowledge, reading and writing?

3. What are the EFL teachers' evaluations of their own English proficiency and perception of factors that support or inhibit their L2 proficiency?

In the following section, the details of the participants, instruments, and data collection procedures are explained.

\subsection{Methodology}

The present study used two types of data, quantitative and qualitative data. The quantitative data includes the questionnaire data on EFL teachers' English language proficiency and the teachers' English proficiency test scores. The qualitative data includes the teachers' interview data gathered on their perceived English competency. The quantitative data, which is mostly about the EFL teachers' personal information from the questionnaire and the results of the L2 proficiency test, was used to answer subquestions 1 and 2. Some quantitative data (the teachers' perceptions on their vocabulary, reading, writing and overall English proficiency, frequency to read and write in English and to engage in ICT and blogging-based activities in English) from the questionnaire and all qualitative data from the interview were used to answer subquestion 3. To explore the quantitative and qualitative data, a mixed-methods data approach (Creswell, 2014; Creswell \& Clark, 2007; Creswell, Plano Clark, Gutmann, \& Hanson, 2003; Riazi \& Candlin, 2014) was used. With regards to the definition of a mixedmethods study, Creswell et al. (2003: 165) suggest:

A mixed methods study involves the collection or analysis of both quantitative and/or qualitative data in a single study in which the data are collected concurrently or sequentially, are given a priority, and involve the integration of the data at one or more stages in the process of research.

They also suggest that some of the perceived advantages of a mixed-methods approach are having more robust, detailed and contextualized studies rather than 
using only one approach (quantitative or qualitative approach). In other words, the use of mixed-methods in the present study is aimed to validate results from the quantitative data set with those from qualitative data set. However, Riazi and Candlin (2014: 158) remind that a careful consideration has to be done in using the mixed-methods approach because researchers "might be tempted to cherrypick for their research designs to gain benefit of the perceived strengths of the two methodologies (i.e. quantitative and qualitative methodologies)".

\subsubsection{Participants}

The participants of the study were English language teachers. They taught junior high school, senior high school or vocational high school in Malang District, East Java, Indonesia. The teachers were recruited as study participants to provide some insights into their current English competency in terms of vocabulary, reading and writing. The participants were all gathered through convenience sampling because the data collection relied upon the attendance of the EFL teachers in the Musyawarah Guru Mata Pelajaran or School-Cluster Subject Teacher Working Group (MGMP) meetings. These meetings became the vehicles that I used to meet the teachers and administer the study.

Sixty-eight EFL teachers participated in the questionnaire session. Sixty participants were in-service high school teachers and eight participants were preservice teachers who had just received their bachelor degree qualifications. The number of male and female participants was not balanced (males, $\mathrm{n}=13$ and females, $n=55)$. Fifty-six EFL teachers voluntarily agreed to complete in the questionnaire. The other four teachers and eight fresh graduate participants were approached personally and they agreed to participate in it.

Sixty-two of these teachers participated in the L2 proficiency tests. There were 53 females and nine males (see Table 3.1). Fifty-four of them were in-service EFL teachers and the rest were pre-service teachers. While it is important to know the variant between the two groups of teachers (in the questionnaire and English proficiency test sessions), it was not possible to differentiate who participated in both sessions and who participated in one of them. This issue was caused by the fact that the questionnaire used an anonymous approach and the attendance record 
from the same session was managed by the MGMP and was not an accurate document to be used as a reference.

Table 3.1 Number of participants

\begin{tabular}{lllllll}
\hline Session & Female & Male & Total & $\begin{array}{l}\text { In-service } \\
\text { teachers }\end{array}$ & $\begin{array}{l}\text { Pre-service } \\
\text { teachers }\end{array}$ & $\begin{array}{l}\Sigma \text { service } \\
\text { years }\end{array}$ \\
\hline $\begin{array}{l}\text { L2 proficiency } \\
\text { tests }\end{array}$ & 53 & 9 & 62 & 54 & 8 & 12.21 \\
Questionnaire & 55 & 13 & 68 & 60 & 8 & 12.71 \\
Interview & 6 & 3 & 9 & 8 & 1 & 9.56 \\
\hline
\end{tabular}

Nine EFL teachers from this group were also interviewed. These teachers also answered questions relevant to the blogging study (Chapters Four \& Five) and to the teacher professional development study (Chapter Six). The decision to interview the same teachers for the three studies was made to obtain a coherent picture of the views held by these teachers on all three components of this research project. Overall, each teacher was interviewed for 30 to 60 minutes.

Table 3.2 summarises the information of the nine teachers being interviewed about their L2 proficiency. The average age of the teachers is 34.11 years and the average length of service is 9.55 years. The nine participants of the interviews (see Table 3.2) were a sample of convenience because they were accessible to be interviewed through long distance phone calls using Skype or Facebook Chat.

Table 3.2 Information of nine teachers interviewed on their $\mathrm{L} 2$ proficiency

\begin{tabular}{lccccc}
\hline Pseudonym & Gender & $\begin{array}{c}\text { Age } \\
\text { (by 2013) }\end{array}$ & $\begin{array}{c}\text { Started } \\
\text { teaching }\end{array}$ & $\begin{array}{c}\text { Length of } \\
\text { service (to } \\
\text { 2013) }\end{array}$ & $\begin{array}{c}\text { Teaching } \\
\text { context/School }\end{array}$ \\
\hline Tiara & F & 54 years & 1995 & 29 years & Senior high \\
Mita & F & 37 years & 2004 & 9 years & Senior high \\
Rahman & M & 28 years & 2011 & 2 years & Senior high \\
\hline Arum & F & 41 years & 1998 & 15 years & Junior high \\
Bintang & F & 30 years & 2006 & 7 years & Junior high \\
Waskito & M & 24 years & 2011 & 2 years & Senior high \\
\hline Agni & F & 43 years & 1994 & 19 years & Junior high
\end{tabular}




\begin{tabular}{cccccc} 
Adya & F & 28 years & 2010 & 3 years & Junior high \\
Wulan & F & 22 years & n/a & 0 year & Pre-service \\
\hline & Average & 34.11 & Average & 9.55 &
\end{tabular}

They were also selected because of their participation in the second study, the blogging study. Three teachers who blogged actively were gathered as the first group. They are Tiara, Mita and Rahman (see Table 3.2). The second group consisted of three teachers who dropped out from the blogging: Arum, Bintang and Waskito. The third group consisted of three teachers who did not agree to blog: Agni, Adya and Wulan. Attempts had been made to ensure that the participants of the proficiency tests, the questionnaire, and interviews were representative of the EFL teacher population in Malang district. However, the vocational high school teachers were not represented in the interview because I could not reach them to participate in the interview session.

\subsubsection{Data collection instruments}

\subsubsection{Questionnaire}

The questionnaire consists of five sections: individual information, professional development, professional characteristics and skills, use of English and miscellaneous (see Appendix 3). The sections that are relevant to the present study are Section 1 (individual information), Section 3 (professional characteristics and skills) and Section 4 (use of English). However, there is one question in Section 2 (professional development) that asks the teachers' overall L2 proficiency after they received their teaching qualification (Question 2.1, Appendix 3). Some parts of Sections 3 and 4 require EFL teachers to self-assess their L2 proficiency and some others require them to self-assess their ICT and blogging skills. Only the data related to the teachers' L2 proficiency were analysed in this chapter. The questionnaire data related to the blogging study and teacher professional study are discussed in Chapters Four and Five respectively.

The participants rated different aspects of their L2 proficiency in the questionnaire. Each section consisted of one or more questions. Altogether there were 54 items in the questionnaire. Forty-five out of 54 items in the 
questionnaires were closed-ended questions and nine items were open-ended questions (see Appendix 3). Most of the questions used in the study are adapted from Fraga-Cañadas' study (2010). The questions have passed through some adjustment so that they can appropriately address the subjects of the present study, EFL teachers in Indonesia (see Figure 3.1).

The questionnaire was written in English and had to be answered in English too because the target respondents are EFL teachers. Requiring the respondent to answer in English, has a goal of making them aware of their English proficiency. The mixed scales and items are used to "create a sense of variety and to prevent respondents from simply repeating previous answers" (Dörnyei \& Csizér, 2011: 78).

Q. 1. 1.1 How long have you been teaching Spanish(SPN) English (ENG) (in years)?

Q.2. 1.2 What is your first (native) language?

Q. 3. 1. 3 What your primary second language other language(s) do you speak or know?

Q.4. 1. 4 What is your gender? Female $\square$ Male $\square$

\section{Figure 3.1 Example of adjustment in the questionnaire}

Fraga-Cañadas (2010) investigated the maintenance and improvement of teachers' second language proficiency in Spanish and I investigated the EFL teachers' English language proficiency. Thus, I changed 'Spanish (SPN)' to 'English (ENG)'. I decided to use and adapt questions from Fraga-Cañadas's study (2010) because the themes discussed in the studies are relevant to my study of (1) teacher professional development, (2) maintaining teacher L2 proficiency, and (3) improving teachers' ICT skills. The questionnaire used some closed and openended questions and was written in English. The closed-ended items used the Likert Scale that consists of a characteristic statement or question accompanied by four or five response options. The use of the Likert Scale and close-ended forms was relevant because they helped me to gather information on particular issues 
without having respondents provide their own answers. The open-ended questions were used to collect information on the respondents' length of service, date of birth and other relevant issues they wanted to share with me (see Appendix 3). The teachers' lengths of service data were obtained through the attendance record list where teachers had to write down not only their name but also their length of service.

\subsubsection{Language proficiency tests}

This study investigated the EFL teachers' L2 proficiency in three areas: knowledge of vocabulary, reading comprehension ability, and writing ability. The scores of the Vocabulary Levels Test (Nation, 1983; Schmitt, Schmitt, \& Clapham, 2001), Reading test, and Writing test are used to estimate the participants' English language competency at the time of the study.

To estimate the Indonesian EFL teachers' vocabulary knowledge, the present study uses the VLT (Nation, 1983; Schmitt et al., 2001) Version 2 (see Appendix 5). The VLT was used to measure the EFL teachers' lexical proficiency because it is the most researched and reliable VLT (Beglar \& Hunt, 1999; Cobb, 1999; Nurhemida, 2007; Schmitt et al., 2001; Webb \& Chang, 2012).

The first version of the VLT was constructed by (Nation, 1983). This version consisted of five levels: 2000, 3000, 5000, 10.000 word levels, and the university word list (UWL). There were 18 test items in each of the level. The VLT uses word family units in grouping vocabulary into the levels. The words that were used in the first version of the VLT were selected based on frequency counts and other criteria including ease of learning, coverage of useful concepts and stylistic level (Coxhead, 2000; Nation, 1990; Schmitt et al., 2001). The words included in the VLT were selected using frequency criteria that compared the Thorndike \& Lorge's (1944) list against the General Service List (West, 1953), and against the Computational Analysis of Present-Day American English (Kučera \& Francis, 1967; Nation, 1990: 263-264).

In 1993, the test was revised by Norbert Schmitt and colleagues who also wrote three additional versions (Versions B, C and D) (Schmitt et al., 2001). The new versions consist of five levels but each section has 30 items. The UWL section in 
the test was replaced with the AWL (Coxhead, 2000).. The replacement of the UWL with the AWL is justified because the AWL was gathered from a larger and well-designed corpus of academic words than the UWL, which was created by combining previous available lists (Coxhead, 2000).

The VLT consists of four word frequency levels: the 2000-word level, 3000-word level, 5000-word level, 10,000-word level and the level of academic vocabulary (see Appendix 5) (Schmitt et al., 2001; Webb \& Chang, 2012)). Webb and Chang (2012) state that "the participants must choose the right word to go with each meaning and write the number of the word next to its meaning". There are three distractor words in each set of the items. The participants are not allowed to guess the meaning if they do not have any idea of the meaning of the words. However, if they think they know the meaning, they should try to find the answer.

The reading texts and the questions were taken from one reading section of the Cambridge IELTS 6 (Cambridge IELTS 6, 2007). The Cambridge IELTS 6 is a collection of past examination papers from University of Cambridge English for Speakers of Other Languages examinations. There are three texts used to test the EFL teachers' reading skills. The first text, entitled Australia's Sporting Success, contained 888 words. The second text, Delivering Goods, had 859 words, and the third text, Climate Change and the Inuit, had 937 words. Table 3.3 provides the details of how many words come from the first thousand, second thousand, Academic Word List (AWL), and the off-list words that are categorised into their word family, types and tokens in the reading passages. The definition of these three categories can be found in Coxhead (2000). A word family refers to a stem plus all closely related affixed forms, i.e. stem word: indicate, family words: indicated, indicates, indicating, indication, indications, indicative, indicator, and indicators. The term type refers to each different word in a text, irrespective of how many times it occurs. The term tokens or running words refers to the total number of words in a text.

To estimate the EFL teachers' reading and writing skills, past IELTS Reading and Writing Tests were used in the study. The IELTS Academic Reading and Writing tests were used for two reasons. First, the IELTS score was one of the test scores 
used as a benchmark for bachelor degree graduates in one state university in Malang, East Java, Indonesia. Second, the IELTS test is a standardised test that is reliable and valid to measure second language learners' English proficiency skills. The Academic Reading and Writing tests are designed to measure the test-takers' academic readiness to study or receive training in English at the undergraduate or graduate level as described in Chalhoub-Deville \& Turner (2000) and 'IELTS:

Test Takers Home Page' (n.d.).

Table 3.3 Lexical profile of the reading texts

\begin{tabular}{llccccc}
\hline Title & Measure & $\begin{array}{c}\text { K1* } \\
(\%)\end{array}$ & $\begin{array}{c}\text { K2 } * \\
(\%)\end{array}$ & $\begin{array}{c}\text { AWL* } \\
(\%)\end{array}$ & $\begin{array}{c}\text { Off-list } \\
(\%)\end{array}$ & $\begin{array}{c}\text { Total words } \\
(\mathrm{n})\end{array}$ \\
\hline Australia's & Word Families & 72.22 & 6.13 & 11.46 & $?$ & $288+?$ \\
Sporting & Types & 59.58 & 13.16 & 8.55 & 18.7 & 433 \\
Success & Tokens & 72.4 & 8.55 & $\mathbf{5 . 5 2}$ & 13.51 & $\mathbf{8 8 8}$ \\
\hline Delivering & Word Families & 70.46 & 13.42 & 16.11 & $?$ & $298+?$ \\
Goods & Types & 61.07 & 10.02 & 14.45 & 14.45 & 429 \\
& Tokens & 74.50 & 6.63 & $\mathbf{8 . 6 1}$ & 10.24 & $\mathbf{8 5 9}$ \\
\hline Climate & Word Families & 75.39 & 11.67 & 12.93 & $?$ & $317+?$ \\
Change and & Types & 65.70 & 8.62 & 10.18 & 15.48 & 452 \\
the Inuit & Tokens & 78.12 & 5.33 & $\mathbf{5 . 7 6}$ & 10.77 & $\mathbf{9 3 7}$ \\
\hline
\end{tabular}

* Note: K1=1-1000 words, K2 = 1001-2000 words, AWL = Academic Word List

The AWL coverage of the first, second and third reading texts is $5.52 \%, 8.61 \%$, and $5.76 \%$, respectively. Table 3.3 also shows that the coverage of the academic vocabulary in the three texts is lower than 9.40 for arts sub-corpora (Coxhead, 2000). This means that although the reading texts are categorised into the IELTS Academic Reading, they are actually more narrative than academic in nature.

The topics of the writing tests were taken from the online IELTS writing topic specimens that had been used in past IELTS tests and were available online (http://www.goodluckielts.com/IELTS-essay-topics.html). The writing prompts used in the writing test of the present study were from the academic version of the IELTS because (1) the study aims to evaluate teachers' writing proficiency in academic (teaching) contexts and (2) the participants were asked to write blog posts on academic topics. In the writing test, the participants had to express their 
ideas in argumentative essays on given topics. They were asked to write at least 250 words. They were given approximately 40 minutes to finish the task. The topic of age of retirement was chosen in the present study because it is an issue the teachers face in real life. The prompt used in the test was "Should retirement be compulsory at 65 years of age?"

\subsubsection{Interview}

The EFL teachers' L2 proficiency was also addressed in the interview with the three teachers who completed the blogging study, as well as three teachers who started but did not complete the blogging study, and three teachers who did not agree to participate in the blogging study (see Appendix 4).

Table 3.4 shows which interview questions for each group of teachers are relevant to the investigation of the EFL teachers' second language competency. The questions that are related to the blogging study and teacher professional development study are discussed in the relevant chapters.

Table 3.4 Questions on L2 proficiency in the interview guides for teachers

\begin{tabular}{llccc}
\hline & & \multicolumn{3}{c}{ Teachers } \\
\cline { 2 - 4 } & Bloggers & $\begin{array}{c}\text { Drop-out } \\
\text { bloggers }\end{array}$ & $\begin{array}{c}\text { Non- } \\
\text { bloggers }\end{array}$ \\
\hline 1. & When did you start your service? & $\mathrm{n} / \mathrm{a}$ & $\sqrt{ }$ & $\mathrm{n} / \mathrm{a}$ \\
\hline 2. & You mentioned in the & $\sqrt{ }$ & \\
& questionnaire that your language \\
& proficiency was (improved, stay \\
the same or declined). Why did & & \\
& you think that your language \\
proficiency was (improved, stay \\
the same or declined)?
\end{tabular}


proficiency is (improved, stay the

same or declined)?

4. What do you do outside school to maintain your English proficiency?

5. Now look at the results of your $\mathrm{n} / \mathrm{a}$ $\mathrm{n} / \mathrm{a}$ tests. The one that I have sent you. Please tell me what you understand about the scores you have here.

\subsubsection{Procedures}

All research instruments (i.e. the questionnaire, interview guideline, information sheet, and consent form) were reviewed and approved by the Human Ethics Committee of Victoria University of Wellington (see Appendix 12).

\subsubsection{Piloting questionnaire}

To check whether the instructions were comprehensible and unambiguous, the questionnaire was piloted prior to its use with the study participants. The questionnaire was sent to five English language teachers in Indonesia via email, but only three teachers returned the questionnaires. I also asked two Indonesian EFL high school teachers (at the time of the pilot was carried out they were $\mathrm{PhD}$ candidates living in Wellington) to pilot this questionnaire.

The feedback from the respondents was used to improve the instructions and wording of the questionnaire used in the main study. The pilot version of the questionnaire did not contain the objectives, which were later added to the questionnaire used in the main study. Two statements in Section 5 Blogging which were identified as potentially confusing were taken out. The Likert Scales were also modified to include a no opinion option, to ensure that respondents who were not familiar with blogging prior to the study could choose a "no opinion" option.

\subsubsection{Piloting interview}

I piloted the interview guides for teachers (used in the L2 proficiency study, blogging study and teacher professional development study) and for teacher 
educators (used in the blogging study and teacher professional development study) at the end of July 2014 to identify some potential problems. Piloting the interview guide is as important as the interview itself as it helps me to understand what questions are not clear to the interviewees, what answers I am looking for from the respondents and if some points might need to be added in the interview guide. Friedman (2012) stated that it is recommended that researchers pilot the interview guide to identify potential problems and to revise the questions before the commencement of the data collection. The practice aimed to ensure fast feedback of the interview guide so that, if needed, I could revise the guides if needed as soon as possible.

The practice interview to test the interview guide for teachers was done with two Indonesian EFL teachers who were taking their PhDs in a Faculty of Education in Wellington. They were chosen because they were high school English teachers in Indonesia and they had similar characteristics with the participants of the present study. The interview guide pilot for teacher educators was done with a teacher educator from Malang district, who was teaching English to pre-service teachers at a public university. The choice was made because she had the characteristics of the target respondents. The pilot interview was carried out online via Skype, the same means of communication as the main interviews. The practices were administered to ensure that the long distance phone call was feasible and reliable to collect the data. The results show that the questions were clear and understandable and that the means of communication turned out to be viable and reliable. The practice interviews showed that there was a need to provide some information about the aims of the study and the need to record the interviews.

\subsubsection{Administering the questionnaire}

Using a paper and pencil approach, the questionnaire was administered in person to ensure that the questionnaire would reach the sufficient number of respondents. An online questionnaire was initially going to be used in the study. However, due to the current slow speed of the internet in Indonesia and potential reluctance of teachers to participate online, the questionnaire was distributed in a direct face-toface meeting. It took participants between 20 to 30 minutes to complete the 
questionnaire. The questionnaire used in this L2 proficiency study was also used in the blogging study (Chapters Four \& Five) and teacher professional development study (Chapter Six). The questionnaire was administered between August and October 2013 to 60 EFL high school teachers and eight pre-service teachers in Malang district. To maintain the confidentiality in reporting the data pseudonyms were used in the discussion.

To be able to do my study with English language teachers and stakeholders I had to ask for a permission letter from the Head of the District Ministry of Education and Culture in Malang. I had to work with three teacher coordinators who supervised three groups of teachers: those in senior high schools, junior high schools and vocational high schools. These three teacher coordinators acted as mediators so that I could recruit participants in those three groups of schools. Because each group of these schools administered their own MGMP meeting schedule, I had to arrange three initial meetings with these three groups of teachers. These initial meetings aimed to introduce the study, give the information sheet, hand out the consent form to the potential participants, and hand out the questionnaire. The first questionnaire session was with the junior high school teachers, the second with the senior high school teachers, and the third with the EFL teachers from vocational high schools in Malang District. The same procedure was used for all three groups. I also held individual sessions with preservice teachers and other in-service teachers who were not able to attend the first or the second data collection, following the same procedure. Most teachers filled in the questionnaires on the day of the initial meetings. However, fourteen teachers were unable to complete the questionnaire face-to-face, and therefore submitted their questionnaires via email.

\subsubsection{Administering $L 2$ proficiency tests}

The junior and senior high school teachers agreed to have the VLT, reading test and writing test in the same venue, one of junior high schools in Malang District. The senior and junior high school teachers who were not able to attend this testing session were invited to attend the next tests, in one of the vocational high schools in Malang District. In both sessions, the teachers were individually seated when 
answering the test. In the third test session, the test was carried out by appointment with each of the participants and over three different days because the participants had various personal reasons for not being able to sit on the test on the same day.

The order of the tests was vocabulary, reading, and finally writing. The VLT was conducted first because it was less challenging than the reading test. The VLT requires test-takers to match the provided descriptions to the targets words, while minimising guessing (Schmitt et al., 2001).

The reading comprehension tasks in the IELTS reading test vary, and may include labelling a diagram, identifying information, identifying the writer's view, matching features, matching headings, answering multiple-choice questions, or completing a table ('IELTS: Test Takers Home Page', n.d.). This format is more demanding than the VLT because the VLT only requires test takers to write corresponding numbers of test items. The IELTS reading test I used in the present study consists of three reading passages: Australia's Sporting Success (has 13 test items), Delivering Goods (has 13 test items), and Climate Change and the Inuit (has 14 test items). All together there are 40 questions in the reading test. The participants should complete each reading passage in 20 minutes. Altogether the participants were given 60 minutes to complete the three reading passages.

The writing test was administered last. Unlike the VLT and the reading test, the writing test demands the productive skills of the participants. The participants were only given a topic on retirement age. They had to make use of their lexical, grammatical and other linguistic knowledge to write an essay on the age of retirement. This order of increasing difficulty is believed to moderate the strength of the relationship between test anxiety and test performance (Chen, 2012).

\subsubsection{Conducting interviews}

The interviews with the EFL teachers were carried out over a long-distance phone call via Skype to home phones, mobile phones, or via Facebook + Skype video chat. The interviews with the EFL teachers took place from August to September 2014. I had to contact them individually and arrange the best time for the participants to participate in the interview. The prior arrangement was important 
because there is a five-hour time difference between Wellington, New Zealand (Greenwich Mean Time or GMT+12) and Malang, Indonesia (GMT+7).

The interviews were mostly carried out in Bahasa Indonesia. This was done to ensure that the teachers understood the questions well and were comfortable in answering them. All nine EFL teachers answered the interview in Indonesian. The consent from each interviewee was given orally and was recorded. The interviews were recorded and transcribed. The transcription was done using the standard orthography to ensure that the message was clear and understandable. The transcription does not include the non-verbal features such as eye gaze, gestures and tone of the voice, because those features were not captured through audio recording. In other words, I am more interested in what the interviewees were saying than how they were saying it. In addition, the audio recording was seen as the most appropriate option because video calling is not feasible with the current Indonesian internet connection. The chance of losing the internet connection could be minimised if the interviews were administered using audio call only. Skype and Facebook were used to contact each teacher through long distance phone calls.

The interviews aimed to verify the teachers' perceptions of their English ability. The questions asked were whether or not they remembered what they reported in the questionnaire, "Do you remember what you reported in the questionnaire regarding your current English proficiency?" "Has it improved, declined or stayed the same compared to your ability when you just graduated from your Bachelor Degree in English?" The interviews also probed the reasons why the teachers felt that their English had improved, declined or stayed the same. Each of the nine teachers was interviewed once.

\subsection{Data Analysis}

Two types of data were gathered from the three data collection methods. The quantitative data were gathered from the questionnaire and the L2 proficiency tests. The qualitative data were gathered from the interviews with the nine teachers. Table 3.5 provides an overview of how the data were collected and 
analysed. The types of the data determined how they were scored and what type of data analysis was used to understand them.

Table 3.5 Data types and analyses

\begin{tabular}{|c|c|c|}
\hline Data & $\begin{array}{l}\text { Data collection } \\
\text { methods }\end{array}$ & Data analysis methods \\
\hline \multirow[t]{4}{*}{ Quantitative } & Questionnaire & - Descriptive statistics, frequency \\
\hline & $\begin{array}{l}\text { The Vocabulary } \\
\text { Levels Test } \\
\text { (VLT) }\end{array}$ & $\begin{array}{l}\text { - } \\
\text { Marking scheme as suggested by (I. S. P. } \\
\text { Nation, 1983; Schmitt et al., 2001) } \\
\text { - Inferential statistics, multiple regression } \\
\text { analysis (Field, 2013; Pallant, 2011) }\end{array}$ \\
\hline & Reading Test & 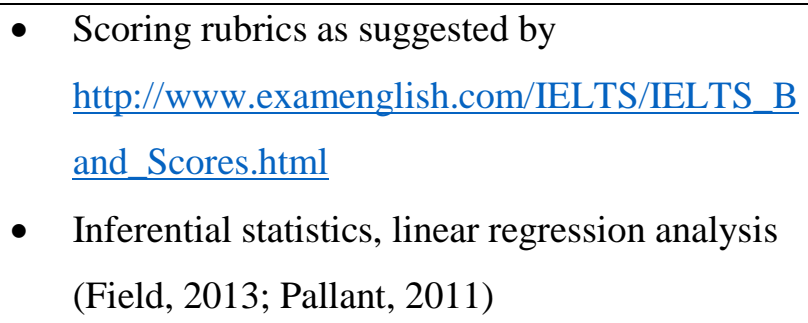 \\
\hline & Writing Test & $\begin{array}{ll}\text { - } & \text { Scoring rubrics as suggested by } \\
\text { http://www.ielts.org/pdf/uobds writingt2.pdf } \\
\text { - Inferential statistics, linear regression analysis } \\
\text { (Field, 2013; Pallant, 2011) }\end{array}$ \\
\hline Qualitative & Interviews & $\begin{array}{l}\text { - Thematic analysis (Braun \& Clarke, 2006, } \\
\text { 2012) }\end{array}$ \\
\hline
\end{tabular}

The first research question on the state of the EFL teachers' lexical, reading and writing proficiency is answered using the quantitative data from the VLT, reading test and writing test. The second research question on the relationship between the EFL teachers' years of service and their lexical, reading and writing proficiency, is answered using the quantitative data from the questionnaire (years of service) and L2 proficiency tests (lexical, reading and writing scores). A multiple regression analysis was used to analyse the correlation between the teachers' length of service and their lexical proficiency because the VLT consists of five aspects (four word levels and one AWL). A regression analysis was used to analyse the correlation between the teachers' length of service and their reading and writing proficiency (see Subsection 3.3.1.5, this chapter). The third research 
question (RQ3), the teachers' perceptions of their English proficiency and of inhibiting and supporting factors to maintain their L2 proficiency, is answered using the quantitative data from the questionnaire and the qualitative data from the interviews.

\subsubsection{Quantitative data}

\subsubsection{Questionnaire}

The questionnaire data was coded and analysed using the data analysis programme 'SPSS 20'. The data from the questionnaire was grouped into the following themes relevant to the proficiency study: teachers' demographic information, teachers' L2 proficiency, and teachers' effort to maintain their English proficiency outside classroom. For example, question number 2.1 in the questionnaire asked the teachers to self-assess their overall English proficiency, "Since you received your teaching qualification, do you think your overall ENG proficiency has ? [improved, stayed the same, declined, not sure]" (Appendix 3). This question was categorised as part of the L2 proficiency theme. The responses were coded as follows: declined $=1$, not sure $=2$, stayed the same state $=3$ and improved $=4$. SPSS 20 generated a summary of the questionnaire's results.

There were some missing data in each question of the questionnaire. Furthermore, although the number of the test participants is approximately the same as the number of the participants in the questionnaire session, these two groups do not contain exactly the same participants: a few of them were different teachers because the school principals appointed different teachers to participate in these two data collection sessions. However, all teachers were from the same population sample.

\subsubsection{The Vocabulary Levels Test}

The VLT is scored by giving one mark for each correct matching of a word and its definition (Nation, 1983). Each section (level 2000, 3000, 5000, 10,000 and AWL) was scored independently. For example, if some test-takers score 14 correct answers out of 30 on the 5000 level, it indicates that they have mastered just under $50 \%$ of the word families at that particular frequency band. Nation 
(1983) explained that the scores for each section should be recorded separately because it is more useful to interpret the scores independently, for each word frequency level, than to have the total scores for all levels together.

Investigating the EFL teachers' vocabulary level is essential for three reasons. First, the study helps to understand the breadth of the EFL teachers' receptive vocabulary. Second, it aims to fill the gap in estimating Indonesian EFL teachers' lexical knowledge. Third, as indicated above, estimation of the EFL teachers' vocabulary levels prior to blogging study, which required the teachers to read and write in the group blog, was needed for the selection and development of the materials for the blogging task.

\subsubsection{Reading Test}

Because the present study used an IELTS Academic Reading test, an IELTS Academic Reading marking rubric was used to score the EFL teachers' reading test (Table 3.6).

Table 3.6 IELTS Academic Reading marking scheme

\begin{tabular}{cc}
\hline Band Score & Score \\
\hline 9 & $39-40$ \\
\hline 8.5 & $37-38$ \\
\hline 8 & $35-36$ \\
\hline 7.5 & $33-34$ \\
\hline 7 & $30-32$ \\
\hline 6.5 & $27-29$ \\
\hline 6 & $23-26$
\end{tabular}

\begin{tabular}{cc}
\hline Band score & Score \\
\hline 5.5 & $19-22$ \\
\hline 5 & $15-18$ \\
\hline 4.5 & $13-14$ \\
\hline 4 & $10-12$ \\
\hline 3.5 & $8-9$ \\
\hline 3 & $6-7$ \\
\hline 2.5 & $4-5$ \\
\hline
\end{tabular}

The test was scored by giving one mark for each correct answer. The correct answers were converted to an overall band score. The IELTS test does not dichotomise their test-takers into fail and pass categories, so neither does the present study. The teachers' reading proficiency was estimated from the number of their correct answers and the equivalent band of their scores. 


\subsubsection{Writing Test}

The writing test was scored using the IELTS (academic) Task 2 Writing rubric on a 10 point scale ( 0 to 9 , with 9 representing the highest possible score), on four different criteria: task response, coherence and cohesion, lexical resources, and grammatical range and accuracy. A full description of the writing scoring rubric can be accessed in Appendix 6.

The teachers' writing compositions were analysed by two raters using the IELTS scoring rubric. In this analysis, the researcher acted as the first rater, because of her familiarity with the test and experience of scoring the institutional IELTS writing test. The second rater was a PhD student from the Faculty of Education, Victoria University of Wellington. She had experience of taking the IELTS test, but was not familiar with the writing scoring system. Below I explain how I trained her in using the rubric for essay scoring.

Two training sessions were conducted. In the first meeting, I introduced her to the IELTS task 2 Writing scoring rubric, including the band descriptors, and gave her examples of marked paragraphs or essays. I explained the four categories in the marking rubric: task response, coherence and cohesion, lexical resource, and grammatical range and accuracy. At the second meeting I prepared three samples of the teachers' essays. I asked the second rater to mark the three essays based on the descriptors independently. I also marked the essays independently using the rubric. Then, we compared the results of the scoring. From the scoring of the samples, we agreed that the score my second rater and I provided should not differ by more than 1 point. If we had more than 1 point difference, we had to discuss why they were different and attempt to arrive at an agreement for the final scores. This was done to ensure that both raters provided equal and balanced scoring.

This approach was also used in the marking of the IELTS writing test in the proficiency study. After all the essays were marked and scores were ready, a test of Interrater Reliability (IRR) was administered to see the consistency of both first and second raters. IRR refers to the degree to which different raters or observers make consistent estimates of the same phenomenon (Multon, 2010; Mackey \& Gass, 2005: 129). Graham and Miller (2012) define IRR as 'the measurement of 
the consistency between evaluators in the ordering or relative standing of performance ratings, regardless of the absolute value of each evaluator's rating.' The present study adopts the later definition of the term.

Multon (2010) explains that there are three most common statistical analyses to investigate the IRR: correlation coefficients (i.e. Pearson correlation and Spearman correlation), Cronbach's alpha, and intraclass correlation or R value. The present study used the intraclass correlation (ICC) because it is 'the best measure of interrater reliability available for ordinal and interval data' (Multon, 2010: 6). With 62 participants, Rater $1(\mathrm{M}=5.169, \mathrm{SD}=1.130)$ and Rater $2(\mathrm{M}=$ $5.349, \mathrm{SD}=.973$ ) had Cronbach's Alpha of .852 , where an acceptable coefficient level is .700. The .852 coefficient level means that most of the variance in the total composite score is a result of true score variance and not the result of error variance. In other words, both raters were consistent in scoring the teachers' essays and the scores were reliable to be analysed further.

The scores of the VLT (2000/General Service List or GSL, 3000, 5000, 10,000, and AWL), the reading test, writing test, and the teachers' length of service were analysed using SPSS 20.

\subsubsection{Analysis of the relationship between test scores and teachers' length of service}

To understand the relationship between the independent variable (the teachers' years of service) and the dependent variable (their L2 proficiency) and to describe the strength and direction of the relationship between two variables, two regression analyses were used. A multiple regression analysis was used to see the correlation between the teachers' years of service and their vocabulary that consisted of five aspects. A linear regression analysis was used to see the correlation between the teachers' years of service and their reading and writing proficiency (Field, 2013; Pallant, 2011).

Due to insufficient access to English language input, paucity of engagement in activities using English as a primary means of communication, and absence of English from the EFL classroom, I hypothesised that EFL teachers' length of service may negatively correlate with their English language proficiency. A 
regression analysis was used to investigate this hypothesis. The regression analysis examined the relationship between the scores of the teachers' VLT, reading and writing tests (the dependent variables) and their length of service (the independent variable). It allows one to statistically model the relationship between a dependent (outcome) variable and a set of independent (predictor) variables However, with the convenience sampling method used in this study, the results must be interpreted with caution, because the findings might not be as robust as random sampling method.

\subsubsection{Qualitative data: Interview}

Thematic analysis was used to analyse the qualitative data from the interviews with the nine EFL teachers. Thematic analysis (TA) refers to 'a method for identifying, analysing and reporting patterns (themes) within data' (Braun \& Clarke, 2006: 79). TA was chosen because it offers two benefits: accessibility and flexibility (Braun \& Clarke, 2006, 2012). TA as a method of data analysis is accessible because it allows me to code and analyse qualitative data systematically and link the codes to broader theoretical or conceptual issues (Braun \& Clarke, 2012: 58). TA is flexible because it can be conducted in a number of different ways: inductive or deductive, experiential or critical orientation of data, or essential or constructionist theoretical perspective (Braun \& Clarke, 2012: 58). There are six phases in TA and the following table, Table 3.7, summarises the phases (Braun \& Clarke, 2006: 87).

Table 3.7 Phases of thematic analysis

\begin{tabular}{lll}
\hline \multicolumn{1}{c}{ Phase } & \multicolumn{1}{c}{ Description of the process } \\
1. $\begin{array}{l}\text { Fourself } \\
\text { with your data: }\end{array}$ & $\begin{array}{l}\text { Transcribing data (if necessary), reading and re-reading } \\
\text { the data, noting down initial ideas. }\end{array}$ \\
\hline 2. & Generating initial \\
codes: & $\begin{array}{l}\text { Coding interesting features of the data in a systematic } \\
\text { fashion across the entire data set, collating data relevant } \\
\text { to each code. }\end{array}$ \\
\hline 3. & $\begin{array}{l}\text { Searching for } \\
\text { themes: }\end{array}$ & $\begin{array}{l}\text { Collating codes into potential themes, gathering all data } \\
\text { relevant to each potential theme. }\end{array}$ \\
\hline 4. & Reviewing themes: & Checking if the themes work in relation to the coded \\
\hline
\end{tabular}




\begin{tabular}{|c|c|}
\hline & $\begin{array}{l}\text { extracts (Level 1) and the entire data set (Level 2), } \\
\text { generating a thematic 'map' of the analysis. }\end{array}$ \\
\hline $\begin{array}{l}\text { 5. Defining and } \\
\text { naming } \\
\text { themes: }\end{array}$ & $\begin{array}{l}\text { On-going analysis to refine the specifics of each theme, } \\
\text { and the overall story the analysis tells, generating clear } \\
\text { definitions and names for each theme. }\end{array}$ \\
\hline $\begin{array}{l}\text { 6. Producing the } \\
\text { report: }\end{array}$ & $\begin{array}{l}\text { The final opportunity for analysis. Selection of vivid, } \\
\text { compelling extract examples, final analysis of selected } \\
\text { extracts, relating back of the analysis to the research } \\
\text { question and literature, producing a scholarly report of } \\
\text { the analysis. }\end{array}$ \\
\hline
\end{tabular}

During the first phase of the data analysis, familiarising myself with my data, I transcribed the interview data. I also read and re-read the data and noted down some initial ideas. In the second phase, generating initial codes, I produced my initial codes that came from the semantic content of the interviews.

In the third phase, searching for themes, I sorted the different codes into potential themes. I used mind maps to organise the codes and to see relationships between codes, themes, and/or sub-themes. Phase 4, reviewing themes, involves two levels: reviewing at the level of coded data extracts and reviewing at the level of the entire data set (Braun \& Clarke, 2006: 91-92). At the first level, I examined and re-examined the codes and candidate themes to see if they formed coherent patterns. At the second level, I used a similar process by considering the whole data set and came up with some ideas of how to narrate a story from the data. In the fifth phase of the study, defining and naming themes, I identified what I believed significant, and determined which aspect of the data each of the themes captured. Phase 6, producing the report, started when I did my final analysis and wrote up the report. I also provided some examples that would be able to capture the points I argued. Table 3.8 shows examples of coding applied to an excerpt of the interviews with the teachers.

\section{Table 3.8 Data extract with codes}

\begin{tabular}{ll}
\hline Data extract & Codes \\
\hline I think it [my English proficiency] is a little bit declined & 1. Perceived L2 proficiency: \\
\hline
\end{tabular}


compares to [my proficiency] when I was in college. Skills, especially writing skills. I think the other skills are fine. Because not much time is available to write, writing skills declined (Waskito) declined

2. Writing skills: declined

3. Reasons of declined writing skills

In the present study I used a deductive approach to data coding and analysis. I brought into the data some concepts of teachers' L2 proficiency, effects of years of service to teachers' L2 proficiency, and teacher self-reported L2 proficiency that I used to code and interpret the data. The data from the interviews with teachers were categorised and coded according to themes on the teachers' L2 proficiency and teachers' effort to maintain their English proficiency outside classroom (see Table 3.8). When analysing the interview data from the nine teachers, I paid special attention to the similar themes and patterns across the data set. I interpreted the themes or codes by reading and re-reading them and checking and re-checking relevant literature on sustaining and improving teacher language proficiency. The themes or codes were reviewed and refined during the data analysis. After robust themes and extract examples were identified and analysed, I related back the analysis to the research questions and literature and finally reported the analysis.

\subsection{Results and Discussion of the Findings on EFL}

\section{Teachers' L2 Proficiency}

\subsubsection{L2 vocabulary knowledge}

The mean scores of the VLT are shown in Table 3.9. The teachers' complete vocabulary scores are available in Appendix 7. In terms of individual levels of vocabulary, the results reveal a gradual decline of the EFL teacher vocabulary knowledge as the word frequency decreased. The teachers received higher scores for the low-frequency words and lower scores for higher-frequency words. As expected, the mean scores on the high frequency words (2000 and 3000 word levels) are higher than those on the mid-frequency (5000 word level) and low frequency (10,000 word level) words. The greatest decline was observed from the 5000 to the 10,000 -word level, from $66 \%$ to $23 \%$. This finding shows that there is 
a big gap between the EFL teachers' knowledge of mid-frequency words and their knowledge of low frequency words.

The mean scores show that the EFL teachers mastered the basic 2000-word level, as indicated by the mean score of 27.40. A score of 26 or higher for a particular level indicates that the participants have mastered that level (Schmitt et al., 2001; Webb \& Chang, 2012). The mean scores on the 3000-word level, academic vocabulary, and 5000-word level (see Table 3.9) show substantial words knowledge. These relatively high results may be due to a number of the L2 cognates/loan words in the VLT (Webb \& Chang, 2012), especially in the academic vocabulary list. The words contract, method schedule, scheme, option, accumulation, guarantee, estimate, final, negative are kontrak, metode, skema, opsi, akumulasi, garansi, estimasi, final, negatif in Indonesian.

Table 3.9 Means on each level of VLT $(n=62)$

\begin{tabular}{lcccc}
\hline & Minimum & Maximum & Mean & Std. Deviation \\
\hline $2000 \mathrm{WL} / \mathrm{GSL}$ & 13 & 30 & 27.40 & 3.564 \\
\hline $3000 \mathrm{WL}$ & 8 & 30 & 24.42 & 5.065 \\
\hline $5000 \mathrm{WL}$ & 3 & 29 & 19.74 & 6.319 \\
\hline $10000 \mathrm{WL}$ & 0 & 27 & 6.95 & 6.542 \\
\hline AWL & 0 & 30 & 23.37 & 7.751 \\
\hline
\end{tabular}

The standard deviation of each word frequency level demonstrates an increase in the variability of the teachers' scores from high frequency (the 2000-word level) to the low frequency words (the 10,000-word level). It indicates the uniformity of the EFL teachers' high frequency word knowledge (see Figure 3.2). The figure also shows that the 2000 and 3000 word levels had moderate variability (see Table 3.9) indicating that the EFL teachers had quite robust knowledge of the 2,000 and 3,000 levels. These findings indicate that high frequency words are likely to be known and used by the EFL teachers (Webb and Chan, 2012: 114). 


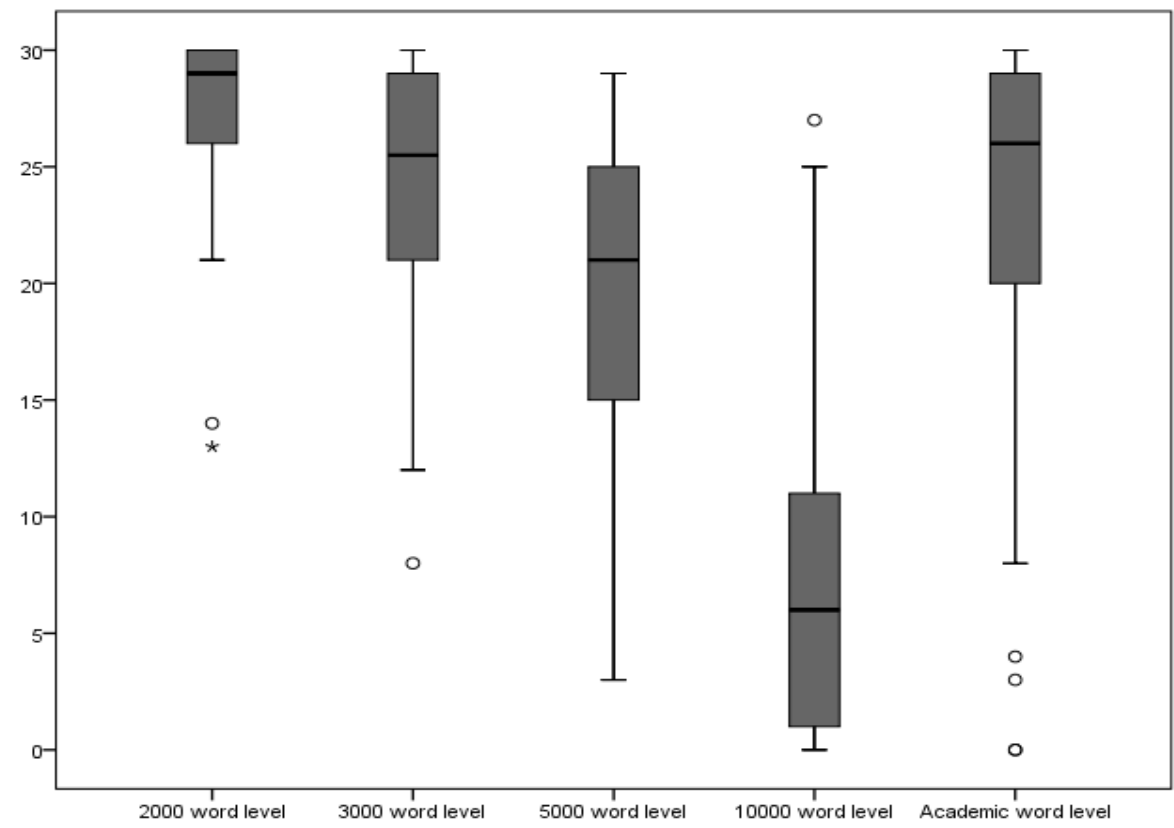

Figure 3.2 Boxplots of each word level

The 5,000 and 10,000 word levels had greater variability than the 2000 and 3000 word levels, but had less variability than the AWL. At the 5000WL, most of the teachers could answer the receptive VLT well. A few of them could do very well and some others could not do well (see Figure 3.2). At the 10,000WL, only a few teachers could do well and most of them could not do well. An investigation of the individual distribution of the teachers' scores, only one out of 62 teachers was able to achieve a high score (27 correct answers) on the 10.000 word level. The highest variability was observed on the academic words test, indicating uneven level of knowledge of academic vocabulary in this group, as shown by the AWL scores range ( 0 to 30 correct answers). This variability indicates that the teachers' knowledge of the academic words varied substantially between the teachers, from having advanced knowledge of academic vocabulary to not knowing it at all. These findings point to uneven EFL teachers' knowledge of the academic vocabulary, mid-frequency and low-frequency words. This suggests that less frequent vocabulary used in subject-specific topics or themes (i.e. in specialist academic texts) are less likely to be known or used by the EFL teachers', in and outside the classrooms.

Overall, two important conclusions can be drawn from the results of the VLT. First, the EFL teachers' vocabulary knowledge is adequate at high-frequency 
word levels, but suffers a dramatic decline at the low-frequency level. Second, there is a gradual increase of the variability of VLT score from high to low frequency words (as shown in the boxplots in Figure 3.2), with the highest variability observed in the knowledge of academic words.

\subsection{2 $L 2$ reading proficiency}

Twenty-one out of 62 teachers (33\%) scored $\geq 5.5$ IELTS band-scale and 41 teachers scored $\leq 5$ IELTS band-scale (see Appendix 7). These findings indicate that most of the teachers were below the expected level of proficiency in academic reading.

Table 3.10 Mean of reading test

\begin{tabular}{lccccc}
\hline & $\mathrm{n}$ & Minimum & Maximum & Mean & Std. Deviation \\
\hline Reading scores & 62 & 1.0 & 8.5 & 4.823 & 1.420 \\
\hline
\end{tabular}

The mean score of the EFL teachers on the reading test was 4.823 (see Table 3.10), confirming that their reading proficiency was lower than the expected baseline of 5.5 IELTS band-scale. The results of the reading test also show that variability of the scores is high among the teachers (see minimum and maximum scores in Table, 3.10).

\subsubsection{L2 writing proficiency}

Twenty-three out of 62 teachers $(37 \%)$ scored $\leq 5$ IELTS band-scale and 39 out of 62 teachers scored $\geq 5.5$ IELTS band-scale (see Appendix 7). These findings indicate that $63 \%$ teachers were able to write academic essay well.

Table 3.11 Writing Test

\begin{tabular}{lccccc}
\hline & $\mathrm{n}$ & Minimum & Maximum & Mean & Std. Deviation \\
\hline Writing scores & 62 & 2.5 & 7.5 & 5.363 & .972 \\
\hline
\end{tabular}

The EFL teachers' mean writing score was 5.363 (see Table 3.11), close to the expected baseline of 5.5 IELTS band scale. This means that the EFL teachers' writing proficiency appeared to be close to the expected writing proficiency for a graduate of ELT teacher training institute. The writing test results also reveal that 
the variability of the scores is not as great as the variability of the EFL teachers' vocabulary and reading tests.

\subsubsection{Discussion}

The first research question asked about the current state of the EFL teachers' L2 proficiency in vocabulary, reading, and writing. The results showed that, in general, the Indonesian EFL teachers' lexical and reading proficiency was below the baseline of 5.5 IELTS band score.

The results of the present study show that the EFL teachers mastered the 2000word level only. This situation was unexpected and suggests that the EFL teachers' knowledge of the mid-frequency vocabulary, academic words and low frequency words was somewhat sub-standard. Similar to the results of the vocabulary test, the reading results show that, in general, the teachers' proficiency is lower than the expected baseline. Because EFL teachers have to use English to communicate with their students and model language use for their students, I have argued that EFL teacher English language proficiency is a core part of their professionalism. The results of the proficiency tests indicate that professional development of the EFL teachers in Indonesia needs to be adjusted to better help them achieve and maintain the required level of professionalism in terms of their L2 proficiency.

Several questions remain unanswered at this point: (1) whether or not there is a relationship between the teachers' years of service and their lexical, reading and writing proficiency, (2) if yes, whether this relationship is positive or negative, (3) how the teachers perceive (self-evaluate) their overall L2 proficiency, and (4) what factors support or constrain the teachers' maintenance of their English language competency. To answer these four key questions, not only quantitative data but also qualitative data were required. The first two questions are answered in the next section that considers the relationship between the teachers' English proficiency and years of service. The last two questions are answered and discussed in Section 3.6. 


\subsection{Relationship between the EFL Teachers' Years of Service and Their English Proficiency}

\subsubsection{Years of service and teachers' academic vocabulary level}

The multiple regression analysis showed that there was a reliable (but weak), negative correlation between years of service and their knowledge of the AWL vocabulary. The Pearson's $r$ showed that the teachers with longer service time scored lower on the academic word level, $r=-.298, \mathrm{n}=62, \mathrm{p}<.01$ (1-tailed). However, there were no significant correlations between the years of service and participants' vocabulary knowledge at the 2000, 3000, and 10,000 word frequency levels. A trend in the predicted direction was observed at the 5000-word frequency level $(r=-.168, \mathrm{n}=62, \mathrm{p}=.095,1$-tailed $)$. Table 3.12 summarises the statistical results.

Table 3.12 Pearson's Correlations of Length of Service and VLT

\begin{tabular}{llccccc}
\hline & & $2000 \mathrm{WL}$ & $3000 \mathrm{WL}$ & $5000 \mathrm{WL}$ & $10000 \mathrm{WL}$ & AWL \\
\hline \multirow{2}{*}{$\begin{array}{l}\text { Length of } \\
\text { Service }\end{array}$} & Pearson correlation & -.086 & -.160 & -.168 & -.127 & $-.298^{* *}$ \\
\cline { 2 - 7 } & Sig. (1-tailed) & .253 & .107 & .095 & .162 & .009 \\
\cline { 2 - 7 } & $\mathrm{N}$ & 62 & 62 & 62 & 62 & 62
\end{tabular}

** Correlation is significant at the 0.01 level (1-tailed).

The presence of the weak negative correlation at the AWL level indicates that the longer the EFL teachers had been teaching, the lower their academic vocabulary knowledge was (and, to a lesser extent, this trend was also present at the 5000word frequency level). In other words, teachers who recently completed their qualification (e.g. pre-service teachers) were likely to have higher academic word knowledge than those with more years of service (e.g. in-service teachers with more than 10 years of experience). Together with the VLT scores distributions discussion in section 3.4.1, this finding suggests that the EFL teachers' experience in its present form (represented by their length of service) does not appear to improve their mastery of the AWL that, in fact, may decline as they continue teaching. 


\subsubsection{Years of service and teachers' reading proficiency}

There was a medium negative correlation between the EFL teachers' years of service and reading proficiency, $r=-.341, \mathrm{n}=62, \mathrm{p}<.01$, with longer years of service associated with lower reading proficiency (see Table 3.13).

Table 3.13 Pearson's Correlations of Length of Service and Reading Test

\begin{tabular}{llc}
\hline & \multicolumn{1}{l}{ Reading scores } \\
\hline \multirow{2}{*}{ Length of Service } & Pearson Correlation & $-.341^{* *}$ \\
\cline { 2 - 3 } & Sig. (1-tailed) & .003 \\
\cline { 2 - 3 } & $\mathrm{N}$ & 62 \\
\hline
\end{tabular}

**. Correlation is significant at the 0.01 level (1-tailed).

The negative correlation shows that the EFL teachers who have been teaching in high schools for a longer period of time were liable to have lower reading ability than those who had shorter teaching experience or those who had just graduated. This finding is in the same direction as the previous finding about the teacher lexical proficiency.

An investigation of the distribution of individual scores of the reading test showed that 40 out of 62 teachers scored $\leq 5$ IELTS band-scale and 22 teachers scored $\geq$ 5.5 IELTS band-scale (see Appendix 7; Section 3.4.2). The lowest score of band 1 on the IELTS scale was achieved by a teacher of a junior high school with 23 years of service. Only one teacher's score was in the maximum 8.5 on the IELTS scale. She was a pre-service teacher with no teaching experience. For the eight pre-service teachers, however, the reading scores ranged from 5.5 to 8.5 , i.e., at or above the expected baseline. These results suggest that the practicing teachers' reading proficiency was lower than that of the ELT Bachelor Degree graduates.

\subsubsection{Years of service and teachers' writing proficiency}

There was a medium negative correlation between the EFL teachers' years of service and writing proficiency, $r=-.369, n=62, p<.01$, with longer years of service associated with lower writing proficiency (see Table 3.14). 
Table 3.14 Pearson's Correlations of Length of Service and Writing Test

\begin{tabular}{llc}
\hline & & Writing scores \\
\hline \multirow{3}{*}{ Length of Service } & Pearson Correlation & $-.369^{* *}$ \\
\cline { 2 - 3 } & Sig. (1-tailed) & .002 \\
\cline { 2 - 3 } & $\mathrm{N}$ & 62 \\
\hline
\end{tabular}

**. Correlation is significant at the 0.01 level (1-tailed).

The results of the correlation test showed that the longer the teachers taught, the lower their writing proficiency was. This finding is similar to the results obtained in the analyses of the teachers' lexical and reading proficiency. A further investigation of the scores revealed that the minimum score for the teachers' writing test was 2.5 and only one teacher scored 2.5. She was a junior high school teacher who had been teaching 33 years at the time the study was administered. The highest score was 7.5. The score was awarded to a vocational high school teacher who had been teaching for 13 years. The 23 teachers with low writing scores were all in-service teachers. All pre-service teachers $(n=8)$ scored above 5.5 IELTS band-scale. Together with the results of the correlation analysis, these findings suggest that the writing proficiency of longer serving teacher was lower than that of recent graduates.

\subsubsection{Discussion}

The second research question (RQ2) was "Is there a relationship between the EFL teachers' years of service and their English proficiency in terms of vocabulary, reading and writing proficiency?" The finding confirmed my prediction that the teachers' proficiency would decline over years of service if actions were not taken to maintain it. The teachers' length of service correlated negatively with the teachers' knowledge of the academic word list, and with their reading and writing proficiency.

Together, the findings in response to RQ1 and RQ2 indicate that a minimum threshold level of professionalism expected of all school teachers was not maintained, with a decline in L2 proficiency observed over time. However, it is important to treat these findings with caution because of the rather restricted participant recruitment process. 
There are three RQs in the present proficiency study. RQ1 and RQ2 have been answered using the quantitative data from the questionnaire and three proficiency tests. However, as indicated earlier, the third research question calls for both quantitative and qualitative data, as it pertains to understanding the teachers' perceptions of their overall L2 proficiency and factors that support or limit the maintenance of their English language competency. The following section describes and discusses the two issues.

\subsection{Perceived English Proficiency and its Supporting Factors and Constraints}

This section describes four important findings from the questionnaire and interview data related to the EFL teachers' English proficiency and its supporting factors and constraints.

\subsubsection{Overestimating English proficiency}

The questionnaire data show that most EFL teachers overestimated their English proficiency. For the first question asked about the teachers' English proficiency: 'Since you have received your teaching qualification, how would you describe your overall English proficiency?', the findings show that $64.1 \%$ of the teachers believed that their overall English language proficiency improved after they graduated from their Bachelor Degree in ELT (see Figure 3.3). Only a few of them perceived that their English proficiency declined or was not as good as when they were still studying. In other words, most of the teachers were confident that they could maintain and improve their English proficiency. 


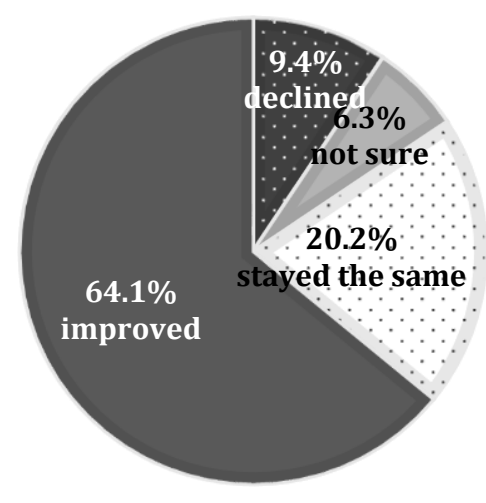

Figure 3.3 Questionnaire responses to the questions, 'Since you have received your teaching qualification, how would you describe your overall English proficiency?'

The second question asks about the participants' lexical proficiency: 'At present, how will you describe your lexical proficiency?' The vocabulary bar chart in Figure 3.4 shows that a total of $36(57.14 \%)$ out of 63 teachers perceived that their lexical knowledge was rather poor or poor. Only three teachers $(4.76 \%)$ reported that their vocabulary proficiency were excellent.

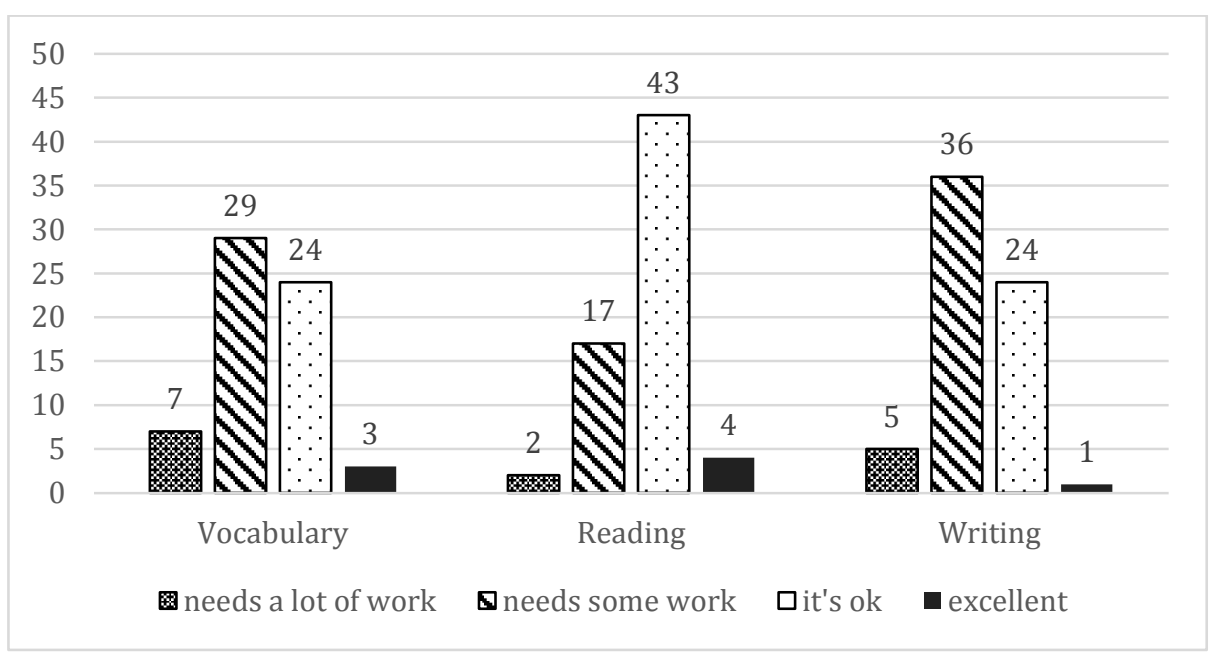

Figure 3.4 At present, how would you describe your vocabulary, reading and writing proficiency?

The reading bar chart in Figure 3.4 shows that a total of $47(71.21 \%)$ out of 66 teachers believed that their reading proficiency was fine, with four teachers $(6 \%)$ reporting that their reading skills were excellent. Nineteen teachers $(28.78 \%)$ 
perceived that their reading skills needed to be improved. The writing bar chart in Figure 3.4 shows that $41(62.12 \%)$ out of 66 teachers thought that they had poor writing skills. Only one teacher $(1.5 \%)$ believed her writing skills were excellent. These findings suggest that there is some dissonance between the participants perceived and actual proficiency (see Table 3.15).

Table 3.15 EFL teachers' perceived and actual proficiency

\begin{tabular}{lll}
\hline & $\begin{array}{l}\text { Perceived proficiency } \\
\text { (questionnaire) }\end{array}$ & $\begin{array}{l}\text { Actual proficiency } \\
\text { (L2 proficiency tests) }\end{array}$ \\
\hline Vocabulary & Generally poor & $\begin{array}{l}\text { Good at 2K, acceptable at 3K and AWL, } \\
\text { weak at 5K and very poor at 10K levels }\end{array}$ \\
\hline Reading & Generally good & $\begin{array}{l}\text { The mean score is between 4 and 5 on the } \\
\text { IELTS band-scale (M=4.82), i.e. below the } \\
\text { threshold of 5.5 }\end{array}$ \\
\hline Writing & Generally poor & $\begin{array}{l}\text { Between 5 and } 6 \text { on the IELTS band-scale } \\
(\mathrm{M}=5.36), \text { i.e. close to the threshold of 5.5 }\end{array}$ \\
\hline $\begin{array}{l}\text { Overall } \\
\text { proficiency } \\
\text { and change } \\
\text { over time }\end{array}$ & $\begin{array}{l}\text { Improved since } \\
\text { of ELT }(64.1 \%)\end{array}$ & $\begin{array}{l}\text { Lower than the expected standards, and } \\
\text { there's a tendency for proficiency to be } \\
\text { lower, across all measures, for the longer }\end{array}$ \\
\hline
\end{tabular}

First, the participants tended to believe that they had poor lexical proficiency. However, the results of the VLT showed that they mastered the high-frequency word family, and their mastery of the mid-frequency word families and academic words was satisfactory. Thus, the VLT showed that they had moderate lexical English proficiency. Second, the participants believed that their reading proficiency was satisfactory. This view contrasts with that of the English proficiency tests' results. Their average reading score was lower than 5.5 IELTS band-scale. Lastly, whereas the participants believed that their writing proficiency was not satisfactory, the writing test showed that their average writing score was satisfactory. 


\subsubsection{Overestimating efforts to maintain teachers' L2 proficiency}

The questionnaire shows that EFL teachers tended to overestimate their efforts to maintain their L2 proficiency when asked a general question. The questionnaire data show that most teachers frequently seek opportunities to read and write in English (see Figure 3.5). A total of 65 (98.48\%) teachers frequently looked for chances to read in English and a total of 59 (92.18\%) teachers frequently sought chances to write in English.

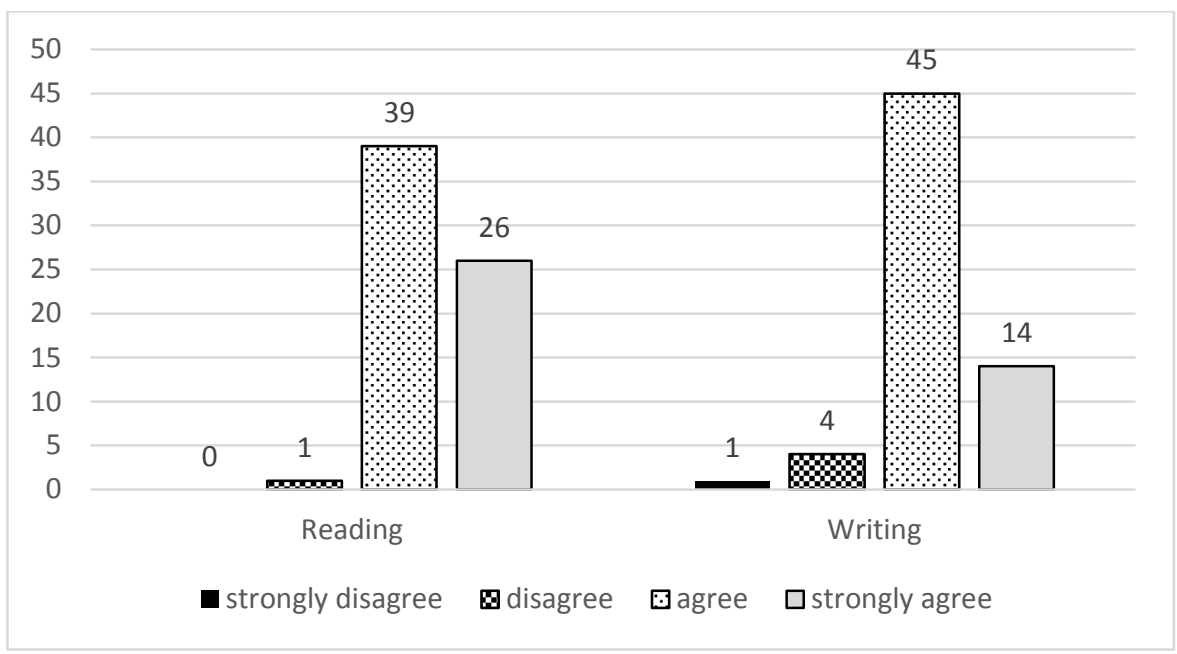

Figure 3.5 I frequently seek opportunities to read and write in English

Although the teachers reported looking for opportunities to maintain their reading and writing skills, their answers on detailed questions of the issue did not show their consistency (see Figure 3.6). The EFL teachers were asked to indicate if they "almost always or always, frequently, occasionally, and never or rarely engaged" in the following activities: reading books, reading magazines, chatting online, writing emails or letters, and writing in blogs. The findings show that the teachers appeared to be hesitant. Compared to the previous general questions on how they describe their vocabulary, reading and writing proficiency (see Figures 3.4) and whether they frequently seek opportunities to read and write in English which asked about the frequency of the teachers' reading and writing habit in English (see Figures 3.6), different patterns of answers emerged.

Figure 3.6 reveals that $36(56.25 \%)$ out of 64 EFL teachers stated that they read books in English to maintain sustain their English proficiency and only twentyfive $(37.31 \%)$ out of 67 teachers frequently read English magazines. In relation to 
their writing practice, not many teachers reported chatting online, writing letters or emails, or blogging in English. Twenty-three (37.09\%) out of 62 teachers chatted online in English. Eighteen (28.12\%) out of 64 teachers wrote letters or emails in English, and only five (8.06\%) out of 62 teachers wrote blogs. Indeed, while they reported that they frequently seek opportunities to read and write in English, their reading and writing activities did not consistently show the same patterns.

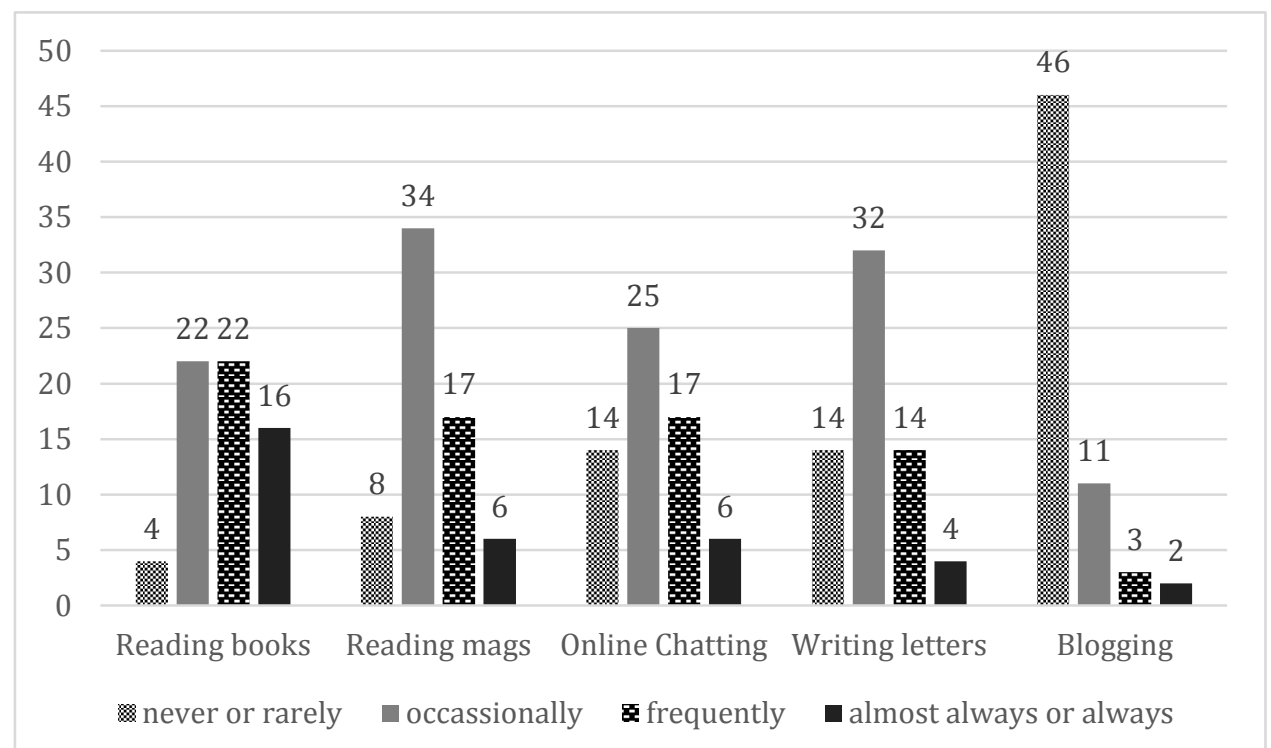

Figure 3.6 Thinking outside the school setting, how often have you had time to engage in the following activities during the last three school years (since July 2010)?

The questionnaire shows that most EFL teachers seek opportunities to read and write in English. However, the questionnaire also shows that there were inconsistencies between their perceived efforts and frequency of engaging in reading and writing activities. Together, the findings suggest that the EFL teachers might overrate the efforts they make to maintain their English proficiency.

\subsubsection{Understating the extent of teachers' overall L2 proficiency improvement}

Turning now to the interview data with the nine teachers, the findings show that some EFL teachers understated the extent of their overall L2 proficiency 
improvement. Four out of nine teachers stated that their overall English proficiency had improved since they graduated with their Bachelor Degree in ELT. Three of them perceived that their overall English proficiency declined and two of them perceived that it stayed the same. Only a few of them supported the claims they made about their overall English proficiency by providing examples of activities to maintain it. The explanation that the teachers offered in the interviews indicated that their overall English proficiency might improve, decline or stay the same because of the frequency of use of the target language. On her declined overall English proficiency, Tiara said:

When I am teaching again, my overall proficiency declines again because I don't use it. It declines again. To maintain it, I write academic papers so that I can participate in TEFLIN conferences and other activities.

The interview data showed that only two teachers (Mita and Bintang) perceived that their vocabulary mastery had improved since they graduated. On her overall proficiency, vocabulary mastery and reading proficiency, Bintang said:

"From my personal perspective, my vocabulary mastery improved. That's for sure. Teachers are demanded to read a lot. I taught junior high school students. The vocabulary is easy. I believe I was very passionate to learn vocabulary when I was studying. Now I read less. If it is about the internet, I learn a lot. I think my overall English proficiency stays the same."

There was only one explicit mention of whether or not the EFL teachers' reading proficiency improved, declined or stayed the same compared to their reading proficiency when they were studying. Mita, a keen reader and teacher, said that her reading had improved. She explained that she could read novels with understanding faster than in her college years. She recalled needing a semester to understand a novel back in her college days, and now she just needed three to four days to finish similar popular novels. The other teachers did not mention about their current reading proficiency explicitly.

During the interviews, four teachers explicitly mentioned that their writing proficiency had declined since they graduated from their teaching training institutes. Five teachers expressed the need to improve their writing skills. Waskito, one of the teachers said:

I think my English language proficiency is not as good as my [English language] proficiency when I was still studying. My skills, especially my 
writing skills. Well, the other skills might not decline. I think I didn't have enough time to write, that is why my writing skills declined.

However, this finding has to be interpreted with caution for two reasons. First, the nine teachers' lexical, reading and writing proficiency were not explored well in the interviews because the question asked in the interviews was about EFL teachers' overall English proficiency. Second, the participants of the interviews were a sample of convenience.

\subsubsection{Supporting factors and constraints in maintaining L2 proficiency}

The interview data revealed some factors that supported and obstructed EFL teachers' efforts to maintain their L2 proficiency. First, the supporting factors were sharing knowledge, participating in the professional development programmes to maintain their L2 proficiency, i.e. trainings, conferences, seminars or workshops, using various media and platforms, and reading and writing in English. On sharing knowledge and participating in professional development programmes, Rahman explained,

First, I participated at the teacher monthly meeting. Second, I always want to participate in any workshops or trainings. Third, I can share my knowledge with other teachers from others schools. During school competition and we discussed a lot of things. Fourth, I hope there are some scholarships or funds to continue my study postgraduate.

Two teachers, Tiara and Wulan, were particularly keen on writing papers and presented them at international conferences. Wulan did not only write but also integrated her reading and writing skills to write papers that she could present in academic forums, such as seminars, workshops, or conferences. Wulan, explained:

I continue reading and writing. I like reading theories of ELT. My goal is to develop my subject-matter knowledge. I read theories on teaching that I want to understand and I express them in my writing. Then, I present the paper in an academic forum.

Some teachers also frequently seek opportunities to use different media and platform, such as emails, online chats, or blogs to maintain their English proficiency. 
On the significance of reading to maintain their English proficiency outside the classrooms, four teachers (Mita, Arum, Wulan and Agni) believed that reading was significant. Agni said:

Well, I browsed the internet, read news written in English, listened to the music too. I believe it is related to the vocabulary. If there are words that I don't know, I will guess the meaning based on the contexts of the sentences and consult the dictionary. Well, about writing, that's the most difficult one and I have never participated in seminars, not as a presenter.

Second, the constraints were lack of time, use of Bahasa Indonesia (L1) in the classroom, and lack of exposure to the target language, English. Five EFL teachers admitted that they did not read or write much in English. One teacher, Adya, confessed that she just did not have the time to read or write because of the many duties that she had at school. This lack of time issue is further complicated by the teachers' heavy teaching loads and additional administrative tasks. She explained,

That's the problem. I don't know if I am too naïve or what but in my school, teachers' duties are not only teaching their subject matters. Take me as an example, I am not only a subject matter teacher of English but also a supervisor for student intra-curricular activities as well as English language laboratory manager. It means that the time I should use to improve my quality as an English teacher is taken by those administrative tasks. That's why there is no sufficient time left for me to read and write to friends or colleagues in English.

Thus, the workloads and the administrative duties have left the teachers with very little or no time to think about or make some efforts to sustain their L2 proficiency.

On the use of L1 and her lack of exposure to the target language, Adya explained:

To me, I think my English proficiency declined. It declined because when I am in the field, I didn't use English. My students rejected the idea of using it. They rejected because when they were in primary schools they were not accustomed to use it. They just can't. I had not used English from 2009 to 2013. I used Bahasa Indonesia in the classrooms and with friends. I felt ashamed of meeting my friends who also graduates from ELT programme because my using Bahasa Indonesia. I have forced myself to use English in the classrooms since 2013. I rarely read English literature too.

Comparing the findings of the interviews on perceived supporting factors and constraints to maintain EFL teachers' L2 proficiency and of the regression 
analyses, two key ideas emerge. First, the negative correlations between the EFL years of service and their academic words, reading proficiency and writing proficiency might be explained by the teachers' lack of exposure to the target language. They appeared to experience periods of declined use of the target language and it might have caused their language to attrite (Bardovi-Harlig \& Stringer, 2010). Second, to improve their L2 proficiency could be carried out by considering the supporting factors explained in this subsection. The integration of EFL teachers' English language maintenance in the teachers' personal or institutional professional development (Richards \& Farrell, 2005) that allow them to share knowledge, read in English, write in English and make use of available media and technology might need to be considered in the near future. One source of weakness of the research design, which could affect the validity, and reliability of the findings was the participants' recruitment process. While nine teachers being interviewed were selected from 62 teachers who took the L2 proficiency tests, they were a convenience sample. Regardless of their limitation, the two key ideas are persistent and each of them is an important issue for future research.

\subsubsection{Discussion}

The study showed that there were some discrepancies between the EFL teachers' perceived and actual English language proficiency. The study also showed that there was discord between the EFL teachers' perceived efforts to maintain their L2 proficiency. The study also found some understatements about the extent of the EFL teachers' overall proficiency improvement. Finally, there were some factors that support and hamper the EFL teachers' efforts to maintain their L2 proficiency. These findings suggest that there are some contradictions between what the teachers' perceived about their disciplinary knowledge (in this case, their L2 proficiency in terms of lexical, reading and writing proficiency), the efforts they made to maintain their L2 proficiency, the extent of their L2 proficiency improvement and what they actually mastered, did and understood. In general, therefore, it seems that investigating the institutional and individual aspects of EFL teachers' professional development in relation to the development of their disciplinary knowledge and other teaching skills is essential. 


\subsection{General Discussion and Conclusion}

Four key issues emerge from the findings of the present study: (1) the EFL teachers' L2 proficiency does not fully meet set professional standards, (2) the L2 proficiency of the EFL teachers appears to diminish over time, (3) the EFL teachers' L2 perceptions of their overall L2 proficiency are at odds with the results of proficiency analysis conducted in this study, and (4) teachers identify actions and factors that support or impede their efforts to maintain L2 proficiency.

\subsubsection{EFL teachers' L2 proficiency does not fully meet expected professional standards}

Using Schmitt et al. (2001) as a baseline for the EFL teachers' vocabulary levels and 5.5 IELTS Scoring Band as a baseline for the teachers' reading and writing proficiency, several conclusions were made. First, the teachers were proficient at the 2000-word level. Second, their ability at the 3000, 5000 word levels and academic word was not as satisfactory as their first 2000-word level. The teacher 10,000-word level was the lowest compared to the other levels. Their reading proficiency was also lower than the expected baseline, but their writing proficiency was, on average, close to being satisfactory compare to the standard of ELT Bachelor degree graduates (5.5 IELTS band-scale).

Unlike other Southeast Asian nations, such as Vietnam (Dudzik \& Nguyen, 2015), Indonesia has not agreed on a national standard of their EFL teachers. Vietnam, for example, uses CEFR as a benchmark for their EFL teachers' proficiency (Dudzik \& Nguyen, 2015: 47-48). The claim that the Indonesian EFL teachers L2 proficiency does not fully meet Indonesian professional standards appears to be supported by the results of the study. However, the claim should be made with caution for two reasons. Firstly, Indonesia has not agreed on common standards. The standards proposed in the present study are the ones used in one of a few distinguished teacher-training institutes in Indonesia. Secondly, the EFL teachers' proficiency as measured by the IELTS test (or other standardised tests) may not adequately represent their ability to teach English (Richards, 2017). 


\subsubsection{L2 proficiency of the EFL teachers appears to diminish over}

time

A significant negative correlation was observed between the teachers' length of service and their academic word knowledge. There were also significant negative correlations between the teachers' length of service and their reading and writing proficiency. These findings are in accords with the point made by Schmid and Mehotcheva (2012: 15), who suggest that one key external factor that affects foreign language maintenance is contact with and/or use of the target language. Thus, it behoves EFL teachers to actively maintain their L2 proficiency achieved at the time of their graduation from teacher training institutions, or it may decrease over time. To reiterate, on-going efforts to maintain L2 proficiency are essential for in-service teachers.

\subsubsection{Disparity between perceived and actual L2 proficiency}

Most teachers believed that their English proficiency had improved after their graduation from teacher training institutions. However, these beliefs are at odds with the results obtained in the present study.

The teachers' estimations of their overall L2 proficiency were higher than those for specific language skills. Judging proficiency, as a whole, could be associated with the participants' feeling of self-worth as EFL teachers. Questions about skills, on the other hand, are less value-laden and are easier to evaluate objectively, without viewing responses as judgements of a character or professional competency. This suggests that it may be better to ask more specific questions in participants' self-evaluation of proficiency in future research.

Furthermore, when specific questions were asked, the teachers began to consider whether or not they were able to use English receptively (reading and listening) and productively (speaking and writing), which then made them think about the use of English in and outside the classrooms in a more objective way. 


\subsubsection{EFL teachers' efforts to sustain or improve their L2 proficiency}

The participating teachers shared suggestions to improve their L2 proficiency individually and institutionally. Individually, teachers believed that sharing knowledge with others during non-formal meetings could help them improve their English. They also mentioned that visiting English web pages, listening to music or watching television programmes or films would help them improve their L2 proficiency. Some teachers also planned to continue their studies at the postgraduate level. They also thought that the postgraduate study would be more appealing if they could get scholarships. Some teachers suggested writing submissions for national or international conferences as a means to improve their L2 proficiency.

Institutionally, teachers were under the regulation of local and regional teacher association, such as MGMP. Under a teacher coordinator's supervision, the EFL teachers held a meeting once every month. At school, the headmasters also sometimes provided teachers with opportunities to take English courses or practise English at school.

Nevertheless, these institutional and individual efforts to improve the teachers' L2 proficiency were mostly done without reflection, feedback or follow-up activities. Critical reflection helps teachers to understand their own strengths, weaknesses, opportunities and threats with regards to improving their English proficiency, and can contribute to the development of their language learner autonomy. Feedback helps teachers to stay motivated and experience a sense of achievement. Followup activities help teachers perceive their English language practice as an on-going endeavour.

Some inconsistency was found between what the teachers believed and what they did. While they perceived themselves as looking for opportunities to use English outside class, the data showed that they rarely used the possibilities they had. The interviews revealed possible reasons for this discrepancy, namely the students' rejections of using English in the classroom and lack of time to read, write, and communicate in English. The existing classroom practices and contextual factors 
hindered the teachers' ability to practise what they believed were effective ways to maintain and improve their English. One teacher, for example, reported having to use English only once in a while in the classroom because students did not have the expected level of English to understand her. The teachers' heavy teaching and administrative workloads also prevented them from practising English outside the classroom.

Taken together, the qualitative data on the EFL teachers' perceived English proficiency and the supporting factors and constraints of the teachers' L2 proficiency (see Section 3.6) complements the quantitative data that are discussed in Sections 3.4 and 3.5 of this chapter. The qualitative data provide more insights on how to explain and interpret the quantitative data on the EFL teachers' English proficiency and how it correlates to their years of service.

\section{Summary}

This chapter has detailed the findings from the L2 proficiency tests and described the relationship between the teachers' years of service and their L2 proficiency. The combination of these findings confirms my prediction on the urgency of Indonesian EFL teachers to actively maintain and continue improving their L2 proficiency after their graduation from teacher training institutions.

In the next chapter, I will present an in-depth study of the writing outputs produced by three EFL teachers who actively participated in the blogging task. I will describe their language use and the content of their blog entries, and relate them to the issues of L2 proficiency and professional development programmes. 
This page is intentionally left blank 


\section{Chapter 4 Blogging Case Studies}

\section{Introduction}

This chapter offers insights that link the state of Indonesian EFL teachers' proficiency in English (Chapter Three) and issues related to blogging as a form of TPD (Chapter Five). In this chapter, I mainly review language and content features of blogs written by teachers.

Based on the findings of the quantitative data in Section 3.6, Chapter Three, this thesis, we understand that most teachers seek opportunities to read and write in English. They want to share knowledge, participate in professional development programmes and seek opportunities to use different media, in order to develop their English proficiency. However, they are not able to realize these interests because they frequently had to use Indonesian in the classroom and have heavy teaching and administrative tasks. These findings motivate the use of blogging platform as a form of TPD. In other words, Chapter Three provides needs and environment analysis (Nation \& Macalister, 2010) for the present study.

There are number of reasons for using blogging as a form of professional development for foreign language teachers. Blogging provides its users with an opportunity to engage in meaningful, real L2 communication, which may help them maintain or improve their English proficiency, increase their subject matter knowledge and improve computer-assisted language learning (CALL) skills (Brescia \& Miller, 2006; Silvia, 2015; Son et al., 2011; Sun, 2010). Blogging is one of many online platforms that provide teachers with a space to develop their professionalism, keep up with new insights and development relevant to their disciplinary knowledge, and practise their writing skills (Luehmann, 2008). In addition to their own professional development, blogging experience would enable in-service teachers to facilitate their students' use of blogging as a language-learning tool (Vurdien, 2013). Please refer to Subsection 2.4.3 for a detail explanation on the benefits of blogging for teaching and learning. 


\subsection{Purposes of the study}

This study was originally designed to compare Indonesian EFL teachers' writing proficiency before and after a blogging intervention, using inferential statistics. However, as a result of poor participation (only three teachers completed the blogging procedure), a case study research approach was adopted.

The blogging case studies investigate whether or not EFL teacher professionalism can be supported through blogging as a form of TPD. Two research questions were posed:

1. What language and blogging features did teachers use when writing in a blog?

2. How did the teachers engage in critical thinking and reflection in their blog entries informed by the readings?

The blogging outputs of the three bloggers were analysed to answer these questions.

A detailed explanation of the research design, participants, blogging platform, reading materials, writing prompts, training procedure, data collection and data analysis will be provided in the next section.

\subsection{Methodology}

The present study uses quantitative data (the frequency of language and blogging features used in the blog posts) and qualitative data (the teachers' engagement in critical and reflective writing informed by the reading). The quantitative data set was gathered to answer the research question on language and blogging features used by the teacher bloggers. The qualitative data set was used to answer research question on how critical and reflective the teachers were in their blog posts. A case study approach (Duff, 2012:95) was used because it helps to understand and study each blogger's blogging behaviour, performance and knowledge closely and intensively over period of time (Duff, 2012:95).

To gather the data from the EFL teachers, a blogging platform (see Subsection 4.2.2, this chapter) was set up, some reading materials (see Subsection 4.2.3) were prepared and some writing prompts were used to help teachers during their 
reading and writing (see subsection 4.2.4, this chapter). The teachers were asked to write an essay of 250 to 500 words, addressing the questions based on the reading material. The writing prompts consisted of a welcome note, instructions for the teachers on what to do during a particular week or month, and to announce prize draws for those who participated actively in the blogging.

The blogging case studies required the EFL teachers to carry out two key activities: (1) to read some passages and (2) to write a blog entry based on the topics of the reading passages. The EFL teachers were required to read some texts relevant to their subject-matter knowledge as teachers. The aim of the reading is to keep up with "new insights and developments influencing their professional field such as new subject matter, new teaching methods and manuals, new approaches, new pedagogical approaches and new societal developments that have an impact on education and teaching in general" (Kwakman, 2003: 153). This reading activity is more commonly known as professional reading (Kitchen, Jeurissen, \& Gray, 2015; Kwakman, 2003). The EFL teachers were also required to write blog entry items based on the information from external source texts. The texts may come in the form of written texts (reading passages) or audio texts (listening passages) or both. This reading-writing activity, listening-writing activity, or reading-listening-writing is commonly known as integrated writing (Plakans, 2009; Plakans \& Gebril, 2012, 2013).

When the study started, each participating teacher was given a copy of the information sheet (Appendix 1) and consent form (Appendix 2) to read and fill out. The information sheet provided the teachers with the necessary details explaining that the data from their blog posts would be used in a $\mathrm{PhD}$ thesis and is likely to be shared in academic forums and publications.

\subsubsection{Participants}

Twenty-five EFL teachers originally agreed to participate in the blog but only three completed the study. The demographic and blogging background information about these three English teachers from Malang, East Java, Indonesia are summarised in Table 4.1. 
Table 4.1 Information about the three teachers who completed the blogging task

\begin{tabular}{llccc}
\hline Pseudonym & \multicolumn{1}{c}{$\begin{array}{c}\text { Blogging } \\
\text { experience }\end{array}$} & Motivation & $\begin{array}{c}\text { Length of } \\
\text { service }\end{array}$ & Gender \\
\hline Tiara & No & $\begin{array}{c}\text { Networking \& professional } \\
\text { experience }\end{array}$ & 29 years & $\mathrm{F}$ \\
& development & & \\
\hline Rahman & No & Commitment to participate & 2 years & $\mathrm{M}$ \\
& experience & & & \\
\hline Mita & Much & Commitment to participate & 9 years & $\mathrm{F}$ \\
& experience & & & \\
\hline
\end{tabular}

Tiara, who has been teaching since 1995, mentioned that she had no experience of blogging prior to the study. Tiara did not have her own blog and she learned to blog in the study. When she was asked about her motivation to participate in the study, she mentioned two benefits of blogging: networking with her fellow English language teachers and developing personal professionalism. Rahman, the youngest teacher, despite his recent graduation, had no experience in blogging prior to the study. Evidently Rahman knew a little about blogging because he read his friends' blogs prior to the study although he did not have a personal blog. Mita, who has taught since 2004, had a great deal of experience in blogging prior to the study. She learned about blogging without taking a formal course. One of her colleagues and she thought about hosting a blog for high school teachers. She implemented a blogging platform for the EFL high school teachers under the School-Cluster Subject Teacher Working Group (Musyawarah Guru Mata Pelajaran or MGMP) Malang district and became the administrator of the blog. Both, Rahman and Mita, explained that the commitment they made to me at the beginning of the study was the reason why they maintained active participation in the blog until the end.

\subsubsection{Blogging platform}

The blogging platform www.blogger.com was chosen because the website allows its users to create not only personal blogs but also group blogs. A personal blog refers to 'a blog that is created and maintained by one user' (Ince, 2013), and one 
in which just one author (blog administrator or owner) can post. Anyone else can post comments and feedback to existing blog entries. A group blog, on the other hand, allows multiple people to create new entries in the blog. In a classroom context, a group blog may be a class blog (Campbell, 2003) where an entire class have a virtual conversation on projects, tasks, assignments or homework.

A group blog in Blogger was set as the platform for the current study because it allowed the teachers to become co-authors in the group blog. Becoming coauthors in the group blog allows not only the administrator and main author but also the co-authors to write and post blog entries (see Figure 4.1).

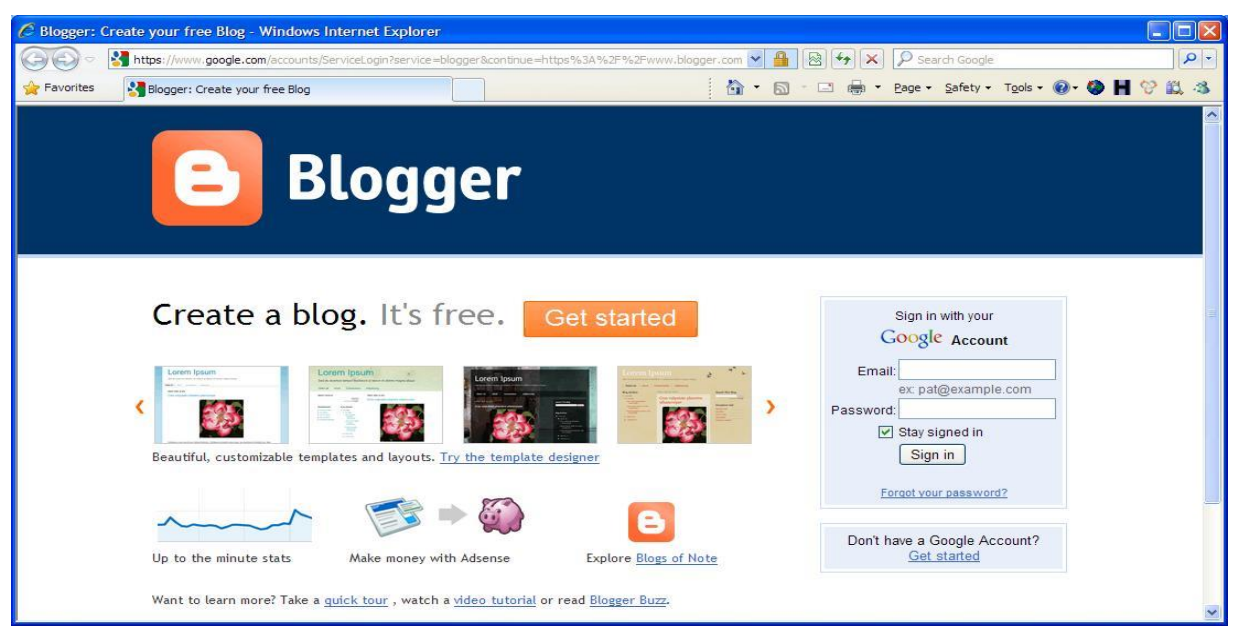

Figure 4.1 Blogging platform

\subsubsection{Reading materials}

The participants were provided with reading materials and writing prompts for blogging once a month. The reading materials were chosen to facilitate the participants' engagement with questions related to EFL teaching, providing them with a starting point for their blog entries. These readings covered theories, research and practice of teaching English as a second/foreign language.

The participating teachers were expected to critically evaluate the readings and reflect on their own teaching practices. The topics of the readings were relevant to issues that EFL teachers encounter in Indonesia, and the timing of the topic introduction matched the high school academic calendar in Indonesia. The topics of the reading materials for each month from October 2013 to April 2014 are listed in Table 4.2. During the first two weeks of each month during the blogging 
procedure, one or two articles were posted for the participating teachers to read, and they were asked to write a blog entry relevant to the issue they chose. These materials were posted in the group blog and also emailed to the participating teachers.

\section{Table 4.2 Topics for blogging}

\begin{tabular}{ll}
\hline \multicolumn{1}{c}{ Time } & \multicolumn{1}{c}{ Topic } \\
\hline First week of October 2013 & $\begin{array}{l}\text { Introducing oneself } \\
\text { Second week of October 2013 }\end{array}$ \\
& $\begin{array}{l}\text { Less teaching more learning and } \\
\text { Project-based learning }\end{array}$ \\
First week of November 2013 & Another failure for exam-based system \\
First week of December 2013 & Language education - Vocabulary \\
First week of January 2014 & Vocabulary acquisition, input and \\
First week of February 2014 & extensive reading \\
First week of March 2014 & Lissessment rubrics \\
First week of April 2014 & Graphic organisers for writing \\
\hline
\end{tabular}

In October 2014, the two topics were: "Less Teaching, More Learning" (http://www.kaganonline.com/free_articles/dr_spencer_kagan/294/Teach-LessLearn-More) and an introduction to "Project-Based Learning" (http://www.gsn.org/web/pbl/ and http://www.bie.org/). The teachers could choose whichever of the two topics that appealed to them. The topics were chosen because the newly introduced Indonesian school curriculum, 2013 Curriculum, recommended the use of the Project-Based Learning (PBL) approach in the teaching and learning process.

In November 2013, the topic was “Another failure for exam-based system”. In Indonesia, mid-term tests for high-schools are typically administered at that time of year, which made this topic timely and relevant. The participating teachers were asked to share their thoughts or give comments on a blog entry (http://www.davedodgson.com/2011/12/another-failure-for-exam-basedsystem.html?). They were given two weeks to post their ideas, read each other's blog entries, discuss other opinions and create another blog entry if necessary. 
In December 2013, I asked Dr Averil Coxhead, in the School of Linguistics and Applied Language Studies (LALS) at Victoria University of Wellington, to write a blog prompt on "Vocabulary in language teaching". I provided an introduction to the blog entry. Dr Coxhead asked the teachers to read and comment on an article written by Professor Paul Nation (“Language education - Vocabulary”), relating Nation's ideas to their classroom, learners and context (http://www.victoria.ac.nz/lals/about/staff/publications/paul-nation/2006Language-education-vocabulary.pdf). Dr Coxhead also invited the participating teachers to try Nation's Vocabulary Size Test, http://my.vocabularysize.com/.

The topic discussed in January 2014 was "Vocabulary acquisition, input and extensive reading”. The participating teachers were asked to read (and listen to) an article about vocabulary (http://jalt-publications.org/tlt/articles/3152-vocabularyacquisition-input-and-extensive-reading-conversation). They were also asked to read an online debate generated by the article (http://jaltpublications.org/tlt/articles/3152-vocabulary-acquisition-input-and-extensivereading-conversation).

In February 2014, the topic was "Assessment rubrics". The participating teachers were given an example of rubrics and they were asked about involving students in creating rubrics (http://www.teachersfirst.com/lessons/rubrics/involvingstudents.cfm).

In March 2014, listening skills were discussed. Nunan (2002) argued that listening was the 'Cinderella skill' in second language learning, suggesting that listening skills were often overlooked compared to other language skills. The teachers were asked to write about how they taught listening skills to their students, what the challenges were, and whether they were teaching listening skills to understand or to answer tests. In the last round, in April 2014, the participating teachers were asked to read an article on the use of graphic organisers in writing (http://www.inspiration.com/visual-learning/graphic-organisers). Altogether, eight reading materials were posted in the form of links or attachment files for the EFL teachers to read from October 2013 to April 2014. 
The percentage of the academic word coverage in each reading material can be found in Table 4.3 and they were not listed in the order of how the topics appeared in the reading but in the order of the highest to the lowest percentage of the academic word coverage in each reading passage. The proportion of academic words (Coxhead, 2000) reflects the nature of the selected passages and helps in estimating their difficulty of comprehension by the EFL teachers. Table 4.3 shows that four out of eight reading passages had high academic word list (AWL) coverage $(10.81 \%-14.14 \%)$, because this coverage is higher than 9.40 for the arts academic sub-corpus in Coxhead (2000). This analysis shows that the input texts were academic in nature. The other four topics had lower AWL coverage (3.73 $7.71 \%$ ), and can be described as less academic in nature. The mean score of AWL coverage across the reading materials was $9.62 \%$, showing that the texts tended to be mostly of an academic nature.

Table 4.3 Academic word coverage in the reading

\begin{tabular}{|c|c|c|c|c|}
\hline No & Topic & $\begin{array}{l}\text { Coverage of AWL in } \\
\text { the blog entries }(\%)\end{array}$ & $\begin{array}{l}\text { Total } \\
\text { tokens }\end{array}$ & $\begin{array}{l}\text { Number } \\
\text { of AWL }\end{array}$ \\
\hline 5. & Assessment rubric & 14.14 & 290 & 41 \\
\hline $1 b$. & $\begin{array}{l}\text { Project-based learning } \\
\text { (PBL) }\end{array}$ & 13.68 & 1630 & 223 \\
\hline 7. & Graphic organisers & 12.50 & 280 & 35 \\
\hline 6. & Listening skills & 10.81 & 1860 & 201 \\
\hline $1 \mathrm{a}$ & $\begin{array}{l}\text { Teaching Less, Learning } \\
\text { More (TLLM) }\end{array}$ & 7.71 & 3487 & 269 \\
\hline 3. & $\begin{array}{l}\text { Language Education - } \\
\text { Vocabulary }\end{array}$ & 7.42 & 4054 & 301 \\
\hline 4. & $\begin{array}{l}\text { Vocab acquisition \& } \\
\text { Extensive Reading (ER) }\end{array}$ & 6.97 & 1965 & 137 \\
\hline 2. & Exam-based system & 3.73 & 563 & 21 \\
\hline & Average & 9.62 & 1766.16 & 153.5 \\
\hline
\end{tabular}




\subsubsection{Writing prompts}

This section describes the details of the writing prompts from September 2013 to April 2014 (Table 4.4). For full text of the prompts, see Appendices 8A-8I

The welcome entry was aimed to help the participating teachers get to know the blogging platform used and the expectations of the blogging activity (see Appendix 8A). On the first week of October 2013, I posted writing prompt for teachers to introduce themselves (see Appendix 8B). I also indicated my willingness to respond to their questions via email. The third writing prompt asks teachers to read one or both articles provided and it provides the teachers with some questions to help them write up their ideas (see Appendix 8C). In the beginning of November 2013, the participating teachers were reminded to post an introductory paragraph as well as their first blog entry, if they had not already done so (see Appendix 8D). I also posted a reminder about the rewards they would receive if they actively participated in the blogging (a certificate of participation and one of four autographed-books by Professor Paul Nation).

\section{Table 4.4 Content of writing prompts}

\begin{tabular}{lll}
\hline Month/year & Content & Appendix \\
\hline September 2014 & Writing prompt 1/A welcome note & Appendix 8A \\
\hline October 2014 & $\begin{array}{l}\text { Writing prompt 2/A request for } \\
\text { participating teachers to introduce } \\
\text { themselves }\end{array}$ & Appendix 8B \\
\hline October 2014 & Writing prompt 3/A call for teachers to & Appendix 8C \\
& $\begin{array}{l}\text { read one or two articles on 'Less } \\
\text { Teaching, More Learning' and 'Project- }\end{array}$ \\
& Based Learning' & \\
\hline November 2014 & Writing prompt 4/A reminder to post an & Appendix 8D \\
& introductory paragraph, first blog entry, & \\
& and a call for a new post on assessment & \\
\hline December 2014 & Writing prompt 5/A call to write a post & Appendix 8E \\
& ideas on vocabulary and language & \\
& education & Appendix 8F \\
\hline January 2015 & Writing prompt 6/A call to post ideas on &
\end{tabular}




\begin{tabular}{lll}
\hline & $\begin{array}{l}\text { vocabulary acquisition, input and } \\
\text { extensive reading }\end{array}$ & \\
\hline February 2015 & Writing prompt 7/Examples of assessment & Appendix 8G \\
& rubrics and a call to discuss involving & \\
& students in creating rubrics & \\
\hline March 2015 & Writing prompt 8/A call to talk about the Appendix 8H \\
& idea that listening is a “Cinderella skill” in & \\
& second language learning & \\
\hline April 2015 & Writing prompt 9/Some examples of & Appendix 8I \\
& graphic organisers and a call to discuss & \\
& benefits of graphic organisers' benefits & \\
\hline
\end{tabular}

The writing prompt for December 2013 was written by my second supervisor. She enthusiastically helped me to write the prompt to encourage teachers to write more and actively participate in the blog (see Appendix 8E). My first supervisor suggested the reading/listening materials and wrote the task used in January 2014. These prompts were designed to encourage the participating teachers to blog more (see Appendix 8F). In February 2014, I provided examples of assessment rubrics for the teachers and a short writing prompt (see Appendix 8G).

The writing prompt for February 2014 was much shorter than the previous prompts, aiming to help the participants to better understand what they had to do (see Appendix 8H). It asks the teachers to give ideas on listening skills. The last writing prompt for April 2015 (see Appendix 8I) is concise with three questions on the use of graphic organisers.

\subsubsection{Training procedure}

All the teachers who agreed to participate in the blogging study $(n=25)$ received training and were invited to join the group blog that I administered. The training session was prepared to provide information about blogs and give the teachers an opportunity to use a blog. Each teacher was asked to bring their personal laptop to the training session to ensure that each participant was able to blog using her/his personal computer. PowerPoint slides created for the training session included images and explanations on creating a blog, based on the materials from 
http://www.wikihow.com/Start-a-Blog-on-Blogger. The training started with an overall introduction to blogs and their use. Then I talked about how to create a personal blog using www.blogger.com. Because a Google account is needed to use blogger.com, teachers who did not have a Google account were given an opportunity to create one during this session. I checked the teachers' ability to follow the instruction while moving around the room. After the participants created their blogs, they were asked to select a blog title and the availability of its URL, enter the word verification and click continue, and choose a starter template. Then, they were able to start blogging by clicking the 'new blog entry' button. Another slide was used to introduce the participants to the text editor features, such as font size, text colour, links, and pictures. Finally, they were guided through the 'publish', 'save', or 'preview' options. The second stage of the training was introducing the participants to the group blog that I created and administered, http://bloggingamongteachersa.blogspot.co.nzl. I then asked the participants to provide their email addresses, so that I could invite them to join the group blog. The following day, an invitation to join the group blog was sent to each teacher who had agreed to participate in the blogging programme.

The training was administered on 16 September 2013 and 21 September 2013. The first session was held for junior and senior high school teachers in one junior high school in Malang district. The other training session was given to the vocational school teachers and some high school teachers who missed the first training. The second session was held in a vocational school in Malang district. I encouraged follow-up questions via email, Facebook, text messages or telephone calls, if necessary. The teachers who already had a personal blog were encouraged to help their colleagues.

\subsubsection{Collection of the blogging data}

The data for the case study were the EFL teachers' blog entries. The data were gathered from the three active participants, and analysed using content analysis. During the blogging study phase from October 2013 to April 2014, each teacher published a different number of blog entries. The introductory blog entries were omitted from the data analysis because they did not reflect the EFL teachers' 
engagement with the reading materials or their reflective thinking. These introductory blog entries were used to familiarise the teachers with the blogging platform, prior to the main activities of the blogging programme.

Mita published 11 blog entries (excluding the introduction blog entry). Only seven of these blog entries were analysed using content analysis. The omitted blog entries $(n=5)$ either did not have enough ideas to be analysed, or the writing did not pass the test of originality, as measured by the TurnItIn software. The second blogger, Rahman, published six blog entries (excluding his introductory blog entry). The third blogger, Tiara, posted seven blog entries, but only five were analysed. The first and fourth blog entries were omitted from the analysis. The first blog entry described her school anniversary and the fourth blog entry was very similar to her third blog entry.

All blog entries that these three teachers wrote were copied and pasted in three separate documents, in their original form. Thus, one file was created for each teacher with all their blog entries. These electronic data were kept in a passwordprotected computer folder. After the introductions had been excluded, originality of the teachers' blog entries was evaluated by submitting their writing to TurnItIn. This was done to ensure that only teachers' own writing was analysed, and not text drawn from directly from the reading materials provided for the blogging topics. I requested help from my main supervisor for uploading anonymised texts into TurnItIn and extracting the originality reports. Figure 4.2 summarises the 
process of the data analysis of the blogging data.

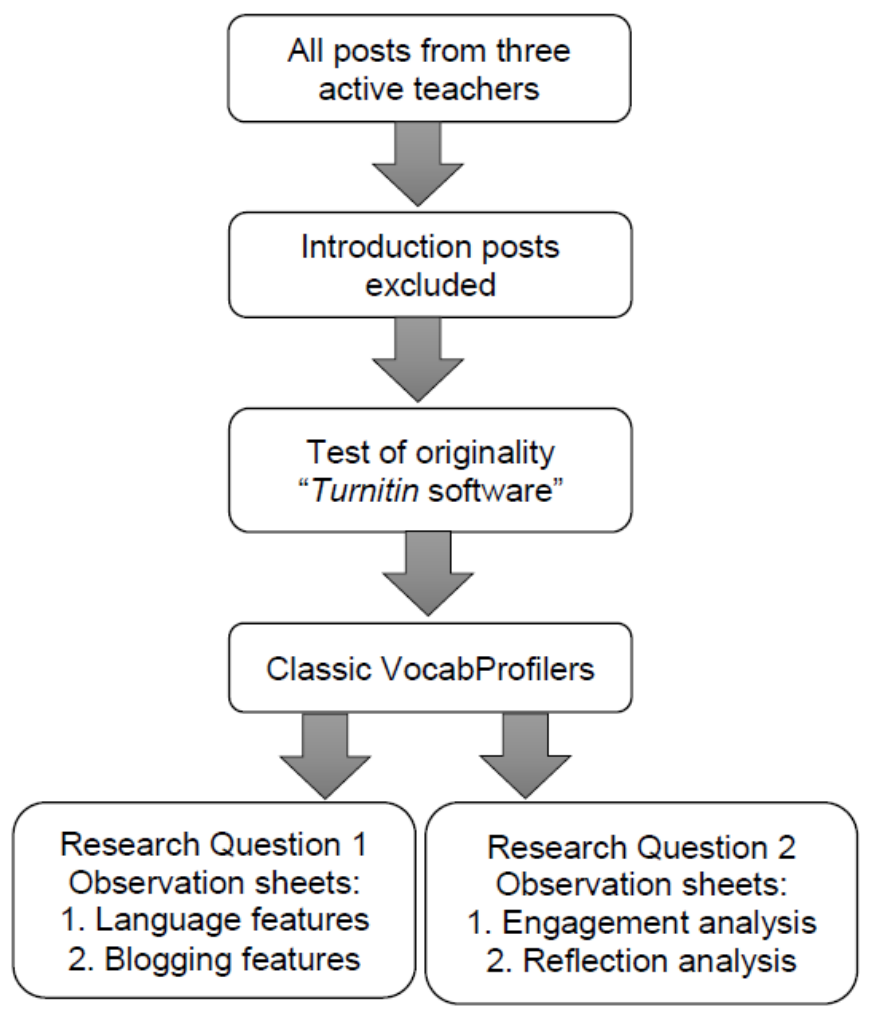

\section{Figure 4.2 Data cleaning and analysis}

The texts from each writer were then analysed using a vocabulary profiler tool, the Classic VocabProfiler (http://www.lextutor.ca/vp/eng/). The VocabProfiler was used to investigate the numbers of words and the use of academic vocabulary (based on Coxhead's Academic Word List, 2000) in the blog entries.

\subsubsection{Approach to the data analysis}

This subsection discusses three distinct approaches to the data analysis: language and blogging feature analysis, critical engagement analysis, and reflection analysis.

To analyse language and content features of the blog entries created by the three participating teachers, the following data were used: number of blog entries, number of words per blog entry, the use of academic vocabulary, and the use of blogging features. Because the teachers were instructed to read and write academic text in the blogging task, the use of academic words was seen as essential. Text analysis was used to establish whether or not the teachers' blog 
entries were related to the reading materials provided, and whether or not they reviewed their own professional practice with regards to the reading materials. An observation sheet (see Table 4.5) was used to carefully record the three teachers' entries and their use of hyperlinks, multimedia, fonts and font sizes.

Table 4.5 Observation sheet for use of language and blogging features

\begin{tabular}{|c|c|c|c|c|c|c|}
\hline & $\begin{array}{c}\text { Number of } \\
\text { blog entries } \\
\text { analysed }\end{array}$ & $\begin{array}{c}\text { Number } \\
\text { of } \\
\text { words } \\
\text { analysed }\end{array}$ & Hyperlink & Multimedia & $\begin{array}{c}\text { Use of } \\
\text { various } \\
\text { font }\end{array}$ & $\begin{array}{l}\text { Use of } \\
\text { various } \\
\text { font size }\end{array}$ \\
\hline Mita & & & & & & \\
\hline Rahman & & & & & & \\
\hline Tiara & & & & & & \\
\hline
\end{tabular}

$\sqrt{ }=$ available, $\mathrm{n} / \mathrm{a}=$ not available, $--=$ no blog entries

Two further observation sheets were created to better understand: (1) the teachers' evaluation of the key ideas from the reading and (2) their reflection on their teaching and learning practices. The observation sheets used two approaches (qualitative and quantitative) to ensure that the necessary information could be identified.

The engagement analysis observation sheet (Table 4.6) recorded to what extent the three teachers' blog entries evaluated the key ideas from reading, quantitatively and qualitatively. The quantitative evaluation looked into how many sentences or paragraphs critically evaluated the key ideas from the reading. More sentences or paragraphs that assess the key ideas critically are seen as an indication that the teachers wrote more critical ideas in their blog entries. With regards to the qualitative evaluation of the teachers' engagement with the reading, I looked into how the sentences or paragraphs in the teachers' blog entries identified and evaluated the key ideas of the reading. If the teachers' blog entries do not evaluate the key ideas from the reading, the teachers' critical engagement of reading is weak. 
Table 4.6 Observation sheet for the critical engagement analysis

\begin{tabular}{llll}
\hline & Weak & Moderate & Strong \\
\hline $\begin{array}{l}\text { Quantitative } \\
\text { evaluation of } \\
\text { key ideas }\end{array}$ & $\begin{array}{l}\text { One or two key } \\
\text { ideas from the }\end{array}$ & $\begin{array}{l}\text { Three to four key } \\
\text { ideas from the }\end{array}$ & $\begin{array}{l}\text { More than four key } \\
\text { ideas from the }\end{array}$ \\
from & picked up in the & up in the blog entry & $\begin{array}{l}\text { picked up in the } \\
\text { reading }\end{array}$ \\
blog entry & & blog entry \\
\hline $\begin{array}{l}\text { Qualitative } \\
\text { evaluation of }\end{array}$ & The sentences/ & The sentences/ & The sentences/ \\
key ideas & teacher's blog entry & teacher's blog entry & teacher's blog entry \\
from & do not evaluate the & agree/disagree with & agree/ disagree \\
reading & key ideas from the & the key ideas from & with the key ideas \\
& reading & the reading but do & from the reading \\
& & $\begin{array}{l}\text { not provide argument } \\
\text { for it }\end{array}$ & $\begin{array}{l}\text { and provide } \\
\text { argument for it }\end{array}$ \\
\hline
\end{tabular}

For example, the topic of the third reading is Language education - Vocabulary (Nation, 2006). The two key ideas that are discussed in the reading are (1) learning and teaching vocabulary using the Four Strands (Nation, 2007) and (2) teachers' opinions about the usefulness of the Vocabulary Size Test (VST) and bilingual VST. One of the bloggers, Mita, wrote:

When I asked them what their opinion would be if I gave them bilingual test, they said that would be a waste of time. So, based on the response of $65 \%$ of total students, time allocation and arrangement at school, and also government limitation, we conclude that a bilingual test won't be useful.

While Mita mentioned bilingual test twice, this particular blog entry did not show that she evaluated one or both key ideas of the reading. Thus, Mita received 'weak' scoring for the 'qualitative evaluation of key ideas from the reading'.

If the teachers' blog entries show agreement or disagreement with the key ideas in the reading, but they do not provide argument for it, the teachers' critical engagement is considered as moderate. To illustrate, I looked into the second topic of reading, "another failure for exam-based system". The key idea of the 
reading is how a test is demotivating and is likely to be seen as hindrance by the students. Looking at Mita's blog entry on the topic, she wrote:

At this phase of life, I agree about the state of the students of being afraid of being tested. That's why there is a difference between having a test and performing a good competency. That's why teachers should tend to have correct classroom design (how to invite the students willingly to do things). A suitable classroom design will help teachers a lot in managing their classrooms.

This blog entry showed that Mita agreed with the author's idea on how testing was demotivating for students. Instead of explaining why she agreed with the idea, she started to discuss classroom design. Thus, she received a 'moderate' score for this blog entry.

Lastly, if the blog entries show agreement or disagreement with the key ideas in the reading, and they provide argument for it, the teachers' critical engagement is strong. Now, let us look at another example. The topic of the seventh reading is graphic organisers. The author of the reading discussed the benefits, types, and functions of graphic organisers and how to use them in writing class. One of the bloggers, Tiara, wrote:

Teaching and learning writing using graphic organisers is the most effective way to students in thinking and exploring ideas through visual display. The graphic organisers help the students to do more concentrate and focus to improve the topic given to be paragraphs or essays. It makes them easier to organise their ideas within the process of their writing. It acts as a pattern to improve the performance of writing guidance so that teacher can easily control their students' illustration in creating their essay based on their concept maps. In addition, I do agree that building writing papers using some kind of the types of graphic organisers through visual learning is a very good way of strategy to enhance the ability of writing.

This blog entry showed that Tiara agreed to the idea of using graphic organisers. She provided extensive explanation as to why graphic organisers were effective to help her students' writing production. Thus, she received a 'strong' scoring for this qualitative evaluation of key ideas from the reading.

Similar to the engagement analysis observation sheet, the reflection analysis observation sheet (Table 4.7) recorded to what extent the teachers reflected on their personal/learning practices in the blog entries, quantitatively and qualitatively. Quantitatively, the reflective writing is described as weak if there 
are only one or two sentences or paragraphs reflecting on their teaching/learning. Three to four sentences or paragraphs that describe their personal teaching or learning practices in the teachers' blog entries are seen as evidence of moderate reflection. The teachers' reflective writing is seen as strong if most of the sentences reflect on their teaching/learning practices.

Table 4.7 Observation sheet for the reflection analysis

\begin{tabular}{|c|c|c|c|}
\hline & Weak & Moderate & Strong \\
\hline $\begin{array}{l}\text { Quantitative } \\
\text { reflection on } \\
\text { personal } \\
\text { teaching/ } \\
\text { learning } \\
\text { practices }\end{array}$ & $\begin{array}{l}\text { One or two of } \\
\text { sentences/paragraphs } \\
\text { of the teacher's blog } \\
\text { entries describe the } \\
\text { teacher's personal } \\
\text { teaching/learning } \\
\text { practices }\end{array}$ & $\begin{array}{l}\text { Three to four } \\
\text { sentences/paragraphs } \\
\text { of the teacher's blog } \\
\text { entries describe the } \\
\text { teacher's personal } \\
\text { teaching/learning } \\
\text { practices }\end{array}$ & $\begin{array}{l}\text { More than four } \\
\text { sentences/paragraphs } \\
\text { of the teacher's blog } \\
\text { entries describe the } \\
\text { teacher's personal } \\
\text { teaching/learning } \\
\text { practices }\end{array}$ \\
\hline $\begin{array}{l}\text { Qualitative } \\
\text { reflection on } \\
\text { personal } \\
\text { teaching/ } \\
\text { learning } \\
\text { practices }\end{array}$ & $\begin{array}{l}\text { The sentences/ } \\
\text { paragraphs the } \\
\text { teacher's blog entry } \\
\text { reflect on their } \\
\text { personal } \\
\text { teaching/learning } \\
\text { practices but they do } \\
\text { not connect to the } \\
\text { issues in the reading }\end{array}$ & $\begin{array}{l}\text { The sentences/ } \\
\text { paragraphs the } \\
\text { teacher's blog entry } \\
\text { reflect on their } \\
\text { personal } \\
\text { teaching/learning } \\
\text { practices and have a } \\
\text { little connection to } \\
\text { the issues in the } \\
\text { reading }\end{array}$ & $\begin{array}{l}\text { The sentences/ } \\
\text { paragraphs the } \\
\text { teacher's blog entry } \\
\text { reflect on their } \\
\text { personal } \\
\text { teaching/learning } \\
\text { practices and they } \\
\text { connect to the issues } \\
\text { in the reading }\end{array}$ \\
\hline
\end{tabular}

The teachers' reflective writing is seen as weak in quality if it discusses their personal teaching or learning practices, but does not connect them to the issues in the reading. For example, the key issues in the third reading are vocabulary acquisition, roles of extensive reading (ER) in the acquisition of various aspects of word knowledge, and the importance of input to the language acquisition process. Tiara, one of the bloggers, wrote:

I do agree that extensive reading is considered to be a part of the way to increase the students' vocabulary. After reading the text materials, the students are asked to make discussion. In this case, the students automatically increase their vocabulary to express their opinion to reply 
their friends' ideas during the discussion. Meaning that, the students will be challenged to read more sources to enhance their knowledge.

While she did mention words such as: extensive reading, increase students' vocabulary, and enhance vocabulary, she did not actually connect her experience to one, two or all three key issues in the third reading. Thus, her qualitative reflection on personal teaching or learning received a 'weak' scoring.

The teachers' blog entries are seen as moderate if their sentences/ paragraphs reflect on their personal teaching/learning practices and have a little connection to the issues in the reading. To illustrate, the topics of the first reading are "teaching less, learning more" (TLLM) and "project-based learning" (PBL). Focusing on one of the two topics, the key points of TLLM are about teaching better, engaging learners and preparing them for life, rather than teaching and preparing them for tests and examinations. In response to this issue, Rahman wrote:

Firstly, I think the concept of "Less Teaching, More Learning" has a close meaning with the words "Learning by Doing". By doing something by the students themselves means there will be three steps of it, those are planning, doing, and evaluating. The students can feel, hear, see, smell, and remember even every step they have taken. If it succeeds, sometimes the students will feel that they once had the best experience in their life and it will become an unforgettable moment.

While Rahman mentioned words such as: Less Teaching, More Learning, learning by doing, and best experience as well as linked the topic with his personal teaching experience, he did not address the issue of preparing students for life. Thus, Rahman's score in this blog entry is moderate.

Lastly, the blog entries are seen as strong if they reflect on their personal teaching/learning experiences and connect to the issues in the reading. As an example, the topic of the sixth reading is listening skills. The reading discusses seven features of an effective listening course, and one of the features is that the materials should be based on a wide range of authentic texts. On this issue,

Rahman wrote:

Sometimes, students feel bored of the materials. So, I usually let them watch a movie that has good moral values and somehow is related to the material. Sometimes, I provide them a few questions of $5 \mathrm{~W} 1 \mathrm{H}$ to be answered while watching the movie. Sometimes, I ask them to find some particular expressions such as offering something, inviting someone, etc. Sometimes, I 
erase some subtitle words and let them fill the blanks with what they have heard. Sometimes, I asked them to count how many particular words will occur during the movie and those who can answer it correctly will get a point or gift from me.

This blog entry shows that Rahman wrote ideas that reflected on his personal teaching practices and linked them to the key point of the reading. Thus, he received 'strong' scoring on this blog entry.

In this section, I have discussed the approaches to the data analysis of the EFL teachers' (1) language and blogging features, (2) critical engagement analysis and, (3) reflection analysis. In the next section, I will present and discuss the principal findings of the present study.

\subsection{Results and discussion}

\subsubsection{What language and blogging features did bloggers use when writing blog entries?}

The language features comprise the number of blog entries, number of words the three teachers wrote, and the use of academic words in their blog entries. The blogging features comprise the number of hyperlinks included by the teachers, use of multimedia, and use of different fonts and font sizes in the teachers' writing.

\subsubsection{Language features}

Table 4.8 details the language features in terms of total number of blog entries each teacher wrote and published (before the TurnItIn analysis) and the number of blog entries analysed, after omissions (as detailed in the previous section).

Table 4.8 Total blog entries and words written and analysed

\begin{tabular}{lcccc}
\hline & $\begin{array}{c}\text { Number of blog } \\
\text { entries posted }\end{array}$ & $\begin{array}{c}\text { Number of blog } \\
\text { entries analysed }\end{array}$ & $\begin{array}{c}\text { Total number of } \\
\text { words analysed }\end{array}$ & $\begin{array}{c}\text { Average words } \\
\text { analysed per entry }\end{array}$ \\
\hline Mita & 11 & 7 & 2280 & 325.71 \\
Rahman & 7 & 6 & 2986 & 497.67 \\
Tiara & 6 & 5 & 3250 & 650 \\
\hline
\end{tabular}

These results show that Mita, Rahman and Tiara fulfilled the requirement of writing between 250 and 500 words per blog entry. Both the total number of 
words written and the average length of blog entries in words varied between the three EFL teachers. Mita's blog entries were mostly short and consisted of many paragraphs. Rahman wrote longer texts but these contained fewer paragraphs than Mita's blog entries. Tiara's blog entries on learning vocabulary and listening were longer than her three other blog entries. Her blog entry on listening topic was the longest at 1530 words (see Table 4.9). While she only wrote five topics and had fewer paragraphs than Mita and Rahman, her total word count was the highest.

The use of academic vocabulary coverage in the three teachers' blog entries can be seen in Table 4.9. The academic word coverage in each of the teachers' blog entry is reported by participant and in the order of the entry with the most academic word coverage to the entry with the least academic word coverage (see Table 4.9). Mita's writing, for example, was often in the form of stories, rather than arguments that supported her claims. She frequently started her blog entries with a story and finished them with key ideas. In Topic 5, creating assessment rubrics with students, Mita used only five academic words: achieve, affected, contrary, finally, and respond. Her original text comprised only a few additional explanations, accompanying a quotation about scoring rubrics that she copied from a website. In Topic 5, for example, she wrote:

Chinese people believe that if you ease someone else's pain, your pain will be eased in return. They prefer to let go of things in many ways. This is highly affected by their religion, Buddhism, which has the largest disciples in China, more than 185 million people, besides Taoists. Buddhism teaches its disciples to be good in any way so that they will get good deed return to them through people around them.

The use of academic words in Mita's writing may have been affected not only by the nature of the reading and the task itself, but also by her preferred rhetorical style.

While the number of the running words/tokens in Mita's Topics 5 and 7 blog entries was similar (330 words and 366 words, respectively), Mita used more academic words in Topic 7 (on the use of graphic organisers). In Topic 7, she used such academic words as: analyse, benefit, chart, concepts, conflicts, contrast, demonstrated, display, identify, inclined, instruction, logical, medium, method, physical, sequence, style, technique, technology, text, topic, and visual. In this 
blog entry, Mita provided an introduction to her ideas and a definition of graphic organisers, described the benefits of using graphic organisers, and attempted to evaluate the idea of using graphic organisers in the classrooms.

Rahman published six blog entries, all of which were analysed further because they showed a high degree of originality (based on the TurnItIn report). High text originality is indicated by a low $(<1 \%$ to $2 \%)$ similarity index that is calculated by comparing a piece of writing with internet sources, publications or students' papers. Rahman's first blog entry on TLLM or PBL has a higher coverage of academic words $(6.84 \%)$ compared to his blog entry about teaching listening $(1.36 \%$ ) in Topic 6 (see Table 4.9). Rahman's first blog entry was written in an argumentative writing style, and includes a thesis statement in the introductory paragraph. It also includes two paragraphs that justify his thesis statement, one paragraph that discusses the weakness of TTLM or PBL, and a concluding paragraph. This blog entry has the highest academic vocabulary coverage compared to his other blog entries. In this blog entry, he used academic words, such as approaches, challenges, communicating, concept, conduct, designed, evaluating, experts, facilitators, facilitates, implement, implementation, and innovations. This suggests that Rahman's treatment of the topic influenced his rhetorical writing style, which necessitated the use of academic vocabulary.

Table 4.9 Academic words coverage in blog entries, by participant

\begin{tabular}{cllll}
\hline & Topic & $\begin{array}{l}\text { Coverage of } \\
\text { AWL in each } \\
\text { blog entry (\%) }\end{array}$ & $\begin{array}{l}\text { Total } \\
\text { tokens }\end{array}$ & $\begin{array}{l}\text { Number of } \\
\text { academic word } \\
\text { token }\end{array}$ \\
\hline Mita & & & 330 & 29 \\
\hline Topic \#7 & Graphic organisers & 8.79 & 280 & 20 \\
\hline Topic \#1 & $\begin{array}{l}\text { Teaching Less, } \\
\text { Learning More } \\
\end{array}$ & 7.14 & & \\
& $\begin{array}{l}\text { (TLLM) or Project- } \\
\text { based learning (PBL) }\end{array}$ & & 126 & 7 \\
\hline Topic \#6 & Listening skills & 5.56 & 262 & 10 \\
\hline Topic \#4 & Vocab acquisition \& & 3.82 & & \\
& Extensive Reading & & & \\
\hline
\end{tabular}




\begin{tabular}{|c|c|c|c|c|}
\hline & (ER) & & & \\
\hline Topic \#2 & Exam-based system & 3.56 & 449 & 16 \\
\hline Topic \#3 & $\begin{array}{l}\text { Language Education - } \\
\text { Vocabulary }\end{array}$ & 3.21 & 467 & 15 \\
\hline Topic \#5 & Assessment rubric & 1.37 & 366 & 5 \\
\hline \multicolumn{5}{|l|}{ Rahman } \\
\hline Topic \#1 & TLLM or PBL & 6.84 & 570 & 39 \\
\hline Topic \#5 & Assessment rubric & 4.82 & 332 & 16 \\
\hline Topic \#4 & $\begin{array}{l}\text { Vocab acquisition \& } \\
\text { ER }\end{array}$ & 4.63 & 735 & 34 \\
\hline Topic \#3 & $\begin{array}{l}\text { Language Education - } \\
\text { Vocabulary }\end{array}$ & 3.27 & 459 & 15 \\
\hline Topic \#7 & Graphic organisers & 2.17 & 230 & 5 \\
\hline Topic \#6 & Listening skills & 1.36 & 660 & 9 \\
\hline Topic \#2 & Exam-based system & $\mathrm{n} / \mathrm{a}$ & $\mathrm{n} / \mathrm{a}$ & $\mathrm{n} / \mathrm{a}$ \\
\hline \multicolumn{5}{|l|}{ Tiara } \\
\hline Topic \#7 & Graphic organisers & 9.04 & 354 & 32 \\
\hline Topic \#4 & $\begin{array}{l}\text { Vocab acquisition \& } \\
\text { ER }\end{array}$ & 7.85 & 242 & 19 \\
\hline Topic \#1 & TLLM or PBL & 7.75 & 331 & 25 \\
\hline Topic \#6 & Listening skills & 6.34 & 1530 & 97 \\
\hline Topic \#3 & $\begin{array}{l}\text { Language Education - } \\
\text { Vocabulary }\end{array}$ & 4.92 & 793 & 39 \\
\hline Topic \#2 & Exam-based system & $\mathrm{n} / \mathrm{a}$ & $\mathrm{n} / \mathrm{a}$ & $\mathrm{n} / \mathrm{a}$ \\
\hline Topic \#5 & Assessment rubric & $\mathrm{n} / \mathrm{a}$ & $\mathrm{n} / \mathrm{a}$ & $\mathrm{n} / \mathrm{a}$ \\
\hline
\end{tabular}

On the topic of listening (Topic 6), Rahman described his past resentment toward L2 listening and his present passion for listening. He explained why he had disliked the listening subject, and a turning point that made him love teaching listening. This relatively long blog entry (660 words) only used nine academic words: available, challenge, conclusion, expert, facilitate, facilities, instructions, occur, and team. Similar to Mita, his use of academic words was mediated by the adopted rhetorical writing style in response to the topic. When he narrated his personal teaching and learning experiences, his writing seemed to have fewer 
academic words, compared to an earlier blog written in a form of an argumentative essay when he used more academic words.

Tiara wrote seven blog entries, two of which were excluded from the analysis because one of them was an introductory blog entry and the other was irrelevant to the required theme, assessment rubric. Five blog entries were analysed using TurnItIn for their originality. All of them were analysed further. Compared to the blog entries written by Mita and Rahman, Tiara's blog entries showed, on average, higher academic words coverage (see Table 4.9) - 7.18\%, compared to that of Mita's (4.78\%) and Rahman's (3.59\%). Tiara's blog entry with the lowest coverage of academic words was on the topic of vocabulary, Topic 3. In this blog entry, Tiara first reiterated what she understood from the reading, and then described a case of vocabulary-focused learning through a writing activity by her students. Although Tiara used quite a few academic words in the discussion of vocabulary-focused learning, this blog entry primarily focused on her students' experiences of the task, which may be the reason for lower proportion of academic words in this blog entry. Still, she used the following tokens from the AWL in this blog entry: academic, analysis, comment, communication, context, data, designed, display, displaying, features, focused, input, and interaction. Tiara's blog entry on graphic organisers (Topic 7) contained the highest proportion of academic vocabulary; she used academic words such as: benefit, concentrate, concept, create, demonstrate, display, enhance, finally, focus, illustrate, impact, and orientation. This is because in this blog entry she elaborated on the benefits of graphic organiser, providing arguments and examples of her teaching practice. Similar to Mita and Rahman, the use of academic vocabulary by Tiara seemed to be affected by the type of the blog entry she wrote and her treatment of the topic.

These findings indicate that Mita, Rahman and Tiara may have been unsure about what style of writing to adopt in the group blog. The writing prompts did not explicitly mention that the teachers had to engage in academic blogging or use argumentative writing style. While Rahman appeared to combine both argumentation and narration in his writing, on average, the proposition of academic words in his blog entries was the lowest, compared to Mita and Tiara. 
Mita focused most on her own teaching experiences, with an exception of Topic 7 , in which her writing included elements of evaluation and analysis. Her average academic word use was only slightly higher than Rahman's writing, but it was much higher on Topic 7. Interestingly, although Tiara's writing also often focused on her personal experiences and presented her points of view, the average academic word coverage in her blog entries was the highest, compared to the other two teachers. Overall, it appears that the teachers' personal writing style preferences and their treatment of individual topics affect their use of academic words.

Comparing the use of academic language in the blogs by the three teachers and their Vocabulary Levels Test results for the L2 AWL, there appears to be a misalignment. For example, Mita used only a few AWL words in her writings, but her receptive AWL knowledge was 30 out of 30, as measured by the VLT test. Rahman attained 24 correct answers out of 30 test items (80\%) on the AWL level of the VLT, and Tiara attained $20(67 \%)$. However, Tiara used more AWL in her writing than both Rahman and Mita. This suggests that the use of academic vocabulary in blogging does not reflect the same dimension of knowledge as the results of the VLT, for the AWL level.

From the three bloggers, Mita wrote more blog entries but used the least words; she also created more paragraphs than the other two participants, but these paragraphs were shorter than those written by Rahman and Tiara. Mita's approach to writing in the group blog may be related to her previous blogging experience and her experience as an administrator of a teacher blog. These experiences may have prompted her to write more blog entries (demonstrating her willingness to be an active blogger), even if this meant writing less per blog entry. Mita's writing style and her use of academic words, to some extent, may also be a result of her understanding of blogs as personal online journals (Blood, 2000; Campbell, 2003), rather than a tool for reflective teaching and learning (Luehmann, 2008). Tiara and Rahman, who were less familiar with blogging (and, therefore, probably less constrained by their construct of blogging), used academic argumentative writing style more freely in their blog entries, whenever they thought it was 
appropriate. They also used a narrative writing style when they wanted to share their teaching and learning experiences.

Taken together, these findings suggest that future studies can use more explicit wording and writing prompts if the academic nature of the writing is the focus of the analysis and assessment. The findings also indicate that if the teachers are expected to show their critical thinking and writing skills in the blogging, the teachers should be given more covert explanation on the expectation as well as the scoring rubrics.

\subsubsection{Blogging features}

Next, I turn to the blogging features used by the three teachers. The blogging features under analysis here include hyperlinks, multimedia and use of fonts and font sizes. These features had been chosen because they showed how motivated the bloggers were as knowledge brokers - people who select and connect their own work and thought to those of others (De Moor \& Efimova, 2004; Lave \& Wenger, 1991; Luehmann, 2008). As mentioned above, the blogging features under investigation were introduced to the teachers in the training session.

The data analysis showed that the three EFL teachers differed dramatically in their use of the blogging features in the group blog (see Table 4.10). Table 4.10 shows Mita used the blogging features extensively, while Rahman did not use any of the features.

Table 4.10 Observation sheet for the use of blogging features, by participant

\begin{tabular}{llcccc}
\hline No & Topic of blog entries & $\begin{array}{c}\text { Hyper- } \\
\text { link }\end{array}$ & $\begin{array}{c}\text { Multi- } \\
\text { media }\end{array}$ & $\begin{array}{c}\text { Use of } \\
\text { various } \\
\text { fonts }\end{array}$ & $\begin{array}{c}\text { Use of } \\
\text { various } \\
\text { font sizes }\end{array}$ \\
\hline Mita & & & & & \\
\hline Topic & TLLM or PBL & n/a & $\sqrt{ }$ & $\sqrt{ }$ \\
$\# 1 \mathrm{a} / 1 \mathrm{~b}$ & & & $\sqrt{ }$ & \\
\hline Topic & Another failure for & $\sqrt{ }$ & & & \\
$\# 2$ & exam-based system & & $\sqrt{ }$ & $\sqrt{ }$ \\
\hline Topic & Language education - & $\mathrm{n} / \mathrm{a}$ & $\sqrt{ }$ & \\
$\# 3$ & Vocabulary & & & & \\
\hline
\end{tabular}




\begin{tabular}{|c|c|c|c|c|c|}
\hline $\begin{array}{l}\text { Topic } \\
\# 4\end{array}$ & $\begin{array}{l}\text { Vocab acquisition \& } \\
\text { ER }\end{array}$ & $\mathrm{n} / \mathrm{a}$ & $\sqrt{ }$ & $\sqrt{ }$ & $\sqrt{ }$ \\
\hline $\begin{array}{l}\text { Topic } \\
\# 5\end{array}$ & Assessment rubrics & $\mathrm{n} / \mathrm{a}$ & $\sqrt{ }$ & $\sqrt{ }$ & $\sqrt{ }$ \\
\hline $\begin{array}{l}\text { Topic } \\
\# 6\end{array}$ & Listening skills & $\sqrt{ }$ & $\sqrt{ }$ & $\sqrt{ }$ & $\sqrt{ }$ \\
\hline $\begin{array}{l}\text { Topic } \\
\# 7\end{array}$ & $\begin{array}{l}\text { Graphic organisers for } \\
\text { writing }\end{array}$ & $\sqrt{ }$ & $\sqrt{ }$ & $\sqrt{ }$ & $\sqrt{ }$ \\
\hline Rahman & & & & & \\
\hline $\begin{array}{l}\text { Topic } \\
\# 1 \mathrm{a} / 1 \mathrm{~b}\end{array}$ & TLLM or PBL & $\mathrm{n} / \mathrm{a}$ & $\mathrm{n} / \mathrm{a}$ & $\mathrm{n} / \mathrm{a}$ & $\mathrm{n} / \mathrm{a}$ \\
\hline $\begin{array}{l}\text { Topic } \\
\# 2\end{array}$ & $\begin{array}{l}\text { Another failure for } \\
\text { exam-based system }\end{array}$ & -- & -- & -- & -- \\
\hline $\begin{array}{l}\text { Topic } \\
\# 3\end{array}$ & $\begin{array}{l}\text { Language education- } \\
\text { Vocabulary }\end{array}$ & $\mathrm{n} / \mathrm{a}$ & $\mathrm{n} / \mathrm{a}$ & $\mathrm{n} / \mathrm{a}$ & $\mathrm{n} / \mathrm{a}$ \\
\hline $\begin{array}{l}\text { Topic } \\
\# 4\end{array}$ & $\begin{array}{l}\text { Vocab acquisition \& } \\
\text { ER }\end{array}$ & $\mathrm{n} / \mathrm{a}$ & $\mathrm{n} / \mathrm{a}$ & & \\
\hline $\begin{array}{l}\text { Topic } \\
\# 5\end{array}$ & Assessment rubrics & $\mathrm{n} / \mathrm{a}$ & $\mathrm{n} / \mathrm{a}$ & $\mathrm{n} / \mathrm{a}$ & $\mathrm{n} / \mathrm{a}$ \\
\hline $\begin{array}{l}\text { Topic } \\
\# 6\end{array}$ & Listening skills & $\mathrm{n} / \mathrm{a}$ & $\mathrm{n} / \mathrm{a}$ & $\mathrm{n} / \mathrm{a}$ & $\mathrm{n} / \mathrm{a}$ \\
\hline $\begin{array}{l}\text { Topic } \\
\# 7\end{array}$ & $\begin{array}{l}\text { Graphic organisers for } \\
\text { writing }\end{array}$ & $\mathrm{n} / \mathrm{a}$ & $\mathrm{n} / \mathrm{a}$ & $\mathrm{n} / \mathrm{a}$ & $\mathrm{n} / \mathrm{a}$ \\
\hline Tiara* & & & & & \\
\hline $\begin{array}{l}\text { Topic } \\
\# 1 \mathrm{a} / 1 \mathrm{~b}\end{array}$ & TLLM or PBL & $\mathrm{n} / \mathrm{a}$ & $\mathrm{n} / \mathrm{a}$ & $\mathrm{n} / \mathrm{a}$ & $\mathrm{n} / \mathrm{a}$ \\
\hline $\begin{array}{l}\text { Topic } \\
\# 2\end{array}$ & $\begin{array}{l}\text { Another failure for } \\
\text { exam-based system }\end{array}$ & -- & -- & -- & - \\
\hline $\begin{array}{l}\text { Topic } \\
\# 3\end{array}$ & $\begin{array}{l}\text { Language education } \\
\text { vocabulary }\end{array}$ & $\mathrm{n} / \mathrm{a}$ & $\sqrt{ }$ & $\mathrm{n} / \mathrm{a}$ & $\mathrm{n} / \mathrm{a}$ \\
\hline $\begin{array}{l}\text { Topic } \\
\# 4\end{array}$ & $\begin{array}{l}\text { Vocab acquisition \& } \\
\text { ER }\end{array}$ & $\mathrm{n} / \mathrm{a}$ & $\mathrm{n} / \mathrm{a}$ & $\mathrm{n} / \mathrm{a}$ & $\mathrm{n} / \mathrm{a}$ \\
\hline $\begin{array}{l}\text { Topic } \\
\# 5\end{array}$ & Assessment rubrics & -- & -- & -- & -- \\
\hline
\end{tabular}




\begin{tabular}{llllll}
\hline $\begin{array}{l}\text { Topic } \\
\# 6\end{array}$ & Listening skills & n/a & n/a & n/a & n/a \\
& & & & & \\
\hline Topic & Graphic organisers for & n/a & n/a & n/a & n/a \\
$\# 7$ & writing & & & & \\
\end{tabular}

Legend: $\mathrm{n} / \mathrm{a}=$ not available, $--=$ no blog entries

Notes: *Tiara encountered technical problems and could no longer publish her own blog entries starting from topic 4 .

Mita used hyperlinks, multimedia and different fonts and font sizes. She embedded hyperlinks to other resources that were relevant to the topics being discussed in three out of her seven-blog entries. Mita used pictures in all her seven-blog entries to visually support the points she was making in her writing. For example, she talked about how students were like puddings and teachers were like knives. She then placed an image of a pudding in the blog entry (see Figure 4.3). Other blog features used by Mita were a variety of fonts, font sizes, and a range of highlighted and coloured letters, words and paragraphs (see Figure 4.3).

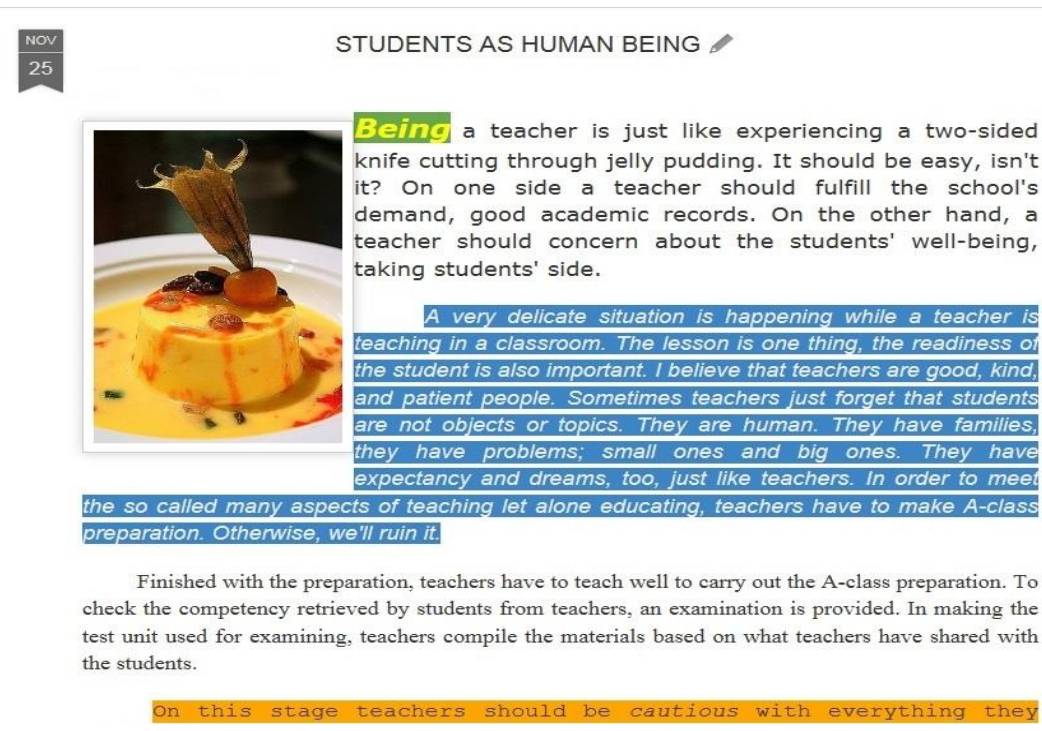

Figure 4.3 Mita's blog entry

These observations show that Mita was a proficient blogger, who displayed extensive knowledge of creating feature-rich blog entries utilising affordances of the blogging medium. 
Dear everybody,

In my opinion, writing is a great activity because it can keep the productivity and creativity of thinking. That is why writers are usually smart and intelligent because their thinking is very deep and sharp. Actually I do not really like writing because there are a lot of rules such as organization, coherence, punctuation, capitalization, grammar, and so on that must be followed. However, writing can be fun if we write something that we like. One of the ways is by using graphic organizers.

At school where I have been working, the principal encourages the teachers to use mind map. The students feel happy and enthusiastic in using it in the beginning but then they feel bored and unhappy when all the teachers ask them to make mind map.

In writing, I think the use of mind map can help learners to make brief points in a different way. We may say that mind map (graphic organizers) is the first step to do when they want to write about something. It can help me to teach writing.

Based on my own experience, the problem that I faced was I did not know where to start. I always let my mind flow and wrote ideas that came up. This condition may also be felt by learners. Therefore, asking them to use graphic organizers is a suitable way to solve their problem.

Cheers.

\section{Figure 4.4 Rahman's blog entry}

Rahman did not add pictures or photographs to his writing. The format of

Rahman's blog entries was simple and straightforward (see Figure 4.4). He did not use any of the available blogging features.

Tiara embedded some pictures in one of her early blog entries (see Figure 4.5).

However, Tiara did not submit her second blog entry and her use of the blogging features could not be evaluated beyond her third blog entry because she encountered technical problems and could no longer publish her own blog entries.

She had to send me her texts, and I posted them in the blog and added my own pictures, as I saw fit. 


\section{WRITING DESCRIPTIVE PARAGRAPH WHILE LEARNING NEW VOCABULARIES}

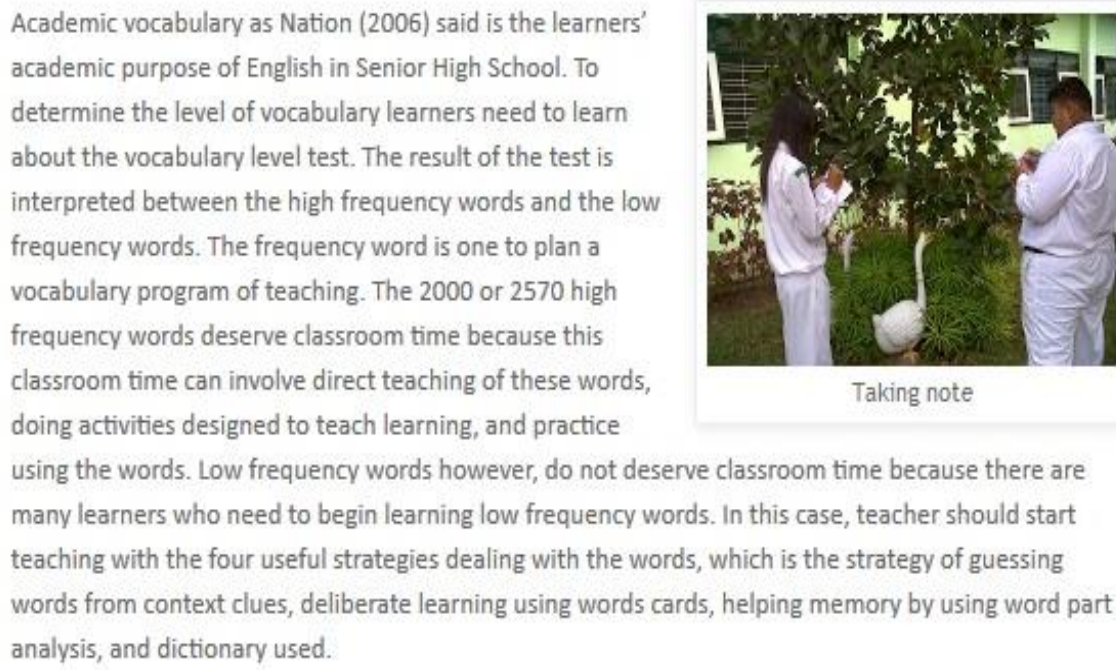

Taking note

using the words. Low frequency words however, do not deserve classroom time because there are many learners who need to begin learning low frequency words. In this case, teacher should start teaching with the four useful strategies dealing with the words, which is the strategy of guessing words from context clues, deliberate learning using words cards, helping memory by using word part analysis, and dictionary used.

\section{Figure 4.5 Tiara's blog entry}

Further analysis suggests that Mita did not use all blogging features effectively, and in some cases, her use of these features was distracting and took the reader's focus away from the messages communicated in her writing. Effective use of blogging features is important because it shows that teachers are able to connect their own work and with the work of other teachers (Luehmann, 2008: 290). Only some of Mita's blog entries used hyperlinks (see Table 4.10). In addition, Mita's use of various fonts and font sizes was rather distracting, rather than helping her readers to understand her message (see Figure 4.3). In addition, the pictures and the quotes she embedded did not always help her readers to connect her ideas with the issues discussed in the readings (see Figure 4.6). 
So, whether we have deliberate vocabulary

learning and learning from reading, it doesn't

matter. What does matter the most then? It is how we

present them and know how much to be taken, not

too little not too much. But, how much is too much?

How interesting a presentation could be? Those are

for other posts.

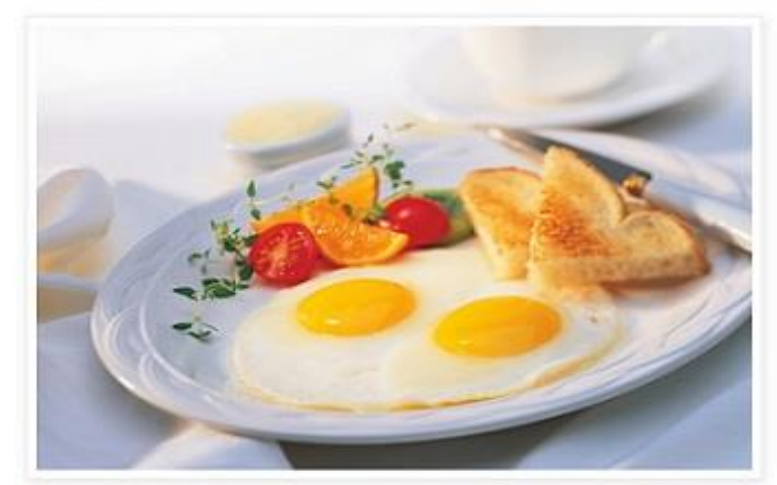

\section{Figure 4.6 Mita's use of picture}

Unlike Mita, Rahman and Tiara did not have prior experience of blogging. They

did not use or rarely used the hyperlinks, pictures, different fonts and different

font sizes. Interestingly, the absence of the blogging features, such as: hyperlinks, multimedia, different fonts and font sizes, did not lessen the quality of Rahman (see Figure 4.7) and Tiara's writings.

In my opinion, listening to a favorite song is also good for students to help them learn English. Sometimes, I provide the lyric with some blanks on LCD and I let them fill the blanks while listening to the song. Sometimes, I provide the lyric with some false words and I let students to find and correct them. Sometimes, I provide the lyric with some ungrammatical words and $\mathrm{I}$ let students to find and correct them.

Games are also necessary in learning English to avoid boredom. I think "Simon Says" is a good choice because students are supposed to not only catch what the speaker says but also think fast to execute the speaker's instructions. Or we can try another game, I do not know the name but I sometimes do it. Let us call it "Whispering Our Neighbors". I usually divide the class into four groups and determine the first speaker of each group, who will receive the first information from me and continue it to the second speaker and so on, and the last speaker of each group, who will write down and report the information to me. At last but not the least, we should not forget the mainstream way. 1 think it is still important to help students learn English. Moreover, we need it to prepare students in facing the National Examination. There are many good books which provide listening practice for students. We should facilitate it as well for students' success.

In conclusion, I think we should combine both teaching all kinds of listening materials and the National Examination materials because each of them has its own importance.

\section{Figure 4.7 Rahman's simple blog entry}


This finding suggests two key points: the overuse of blogging features has made the messages in the blog entries difficult to understand and the blog entries that did not use blogging features were easier to understand. These findings seem to be consistent with previous studies which found that effective use of blogging features, such as hyperlinks and pictures, was seen as an evidence of how bloggers could capitalise on their potential as knowledge brokers (De Moor \& Efimova, 2004; Lave \& Wenger, 1991; Luehmann, 2008). In other words, if bloggers cannot use blogging features effectively, they will spoil the potential to share ideas and knowledge to bloggers and other readers. In the present study, I found that one of the bloggers used pictures, different fonts, and font sizes ineffectively in most of her blog entries. This ineffective use of blogging features had lessened their potential to assist her to communicate her ideas well to the other EFL teachers and other readers of her blog entries.

These findings indicate that although blogging training had been administered at the start of the study, and my online support was available upon their request throughout the blogging programme, these attempts were not sufficient for the teachers to be able to use the blogging features effectively in their blog entries. In the present study, the three teachers started with different background knowledge of blogging and motivation to blog (see Table 4.1). Two of them were originally compelled to complete the study because of the commitment they had made. However, I also observed that, as the study progressed, the teachers' motivation to connect with other teachers, to develop professionally and to practise blogging had encouraged them to continue reading and writing. Nevertheless, even with this new found motivation, they were not able to develop effective blogging skills in the course of the study (as measured by their use of the blogging features).

In the following section, I investigate how these three teachers engaged with the reading materials, applied critical thinking to the readings, and made links with their own teaching and learning experience, in their blog entries. 


\subsubsection{How did the teachers engage in critical thinking and reflective writing informed by the reading?}

This section reports the teachers' engagement with the reading materials and reflections on their teaching and learning practices. In this subsection, I discuss (1) how many and which propositions from the reading were being picked up by the teachers, (2) which key ideas were evaluated and how the teachers evaluated them, and (3) how the teachers linked the propositions in the reading with their current practices, i.e., how reflective their blog entries were.

\subsubsection{Mita}

The context analysis of Mita's blog entries using the observation sheet for reading engagement (see Tables 4.6) showed that her reading engagement was weak to moderate. She picked up one to four propositions from each reading to discuss, but the propositions were not evaluated critically. For example, one of the propositions of the first reading was that "Teach Less, Learn More (TLLM) is about a richer interaction between teacher and student - about touching hearts and engaging minds". Mita demonstrated her agreement with TLLM proposition. She wrote that she had been inspired by TLLM and had attempted to implement this approach by making self-access activity materials from newspaper clippings, cartoon clippings, short stories and personal stories available to her students. However, she did not engage in an in-depth discussion of the TLLM idea. She did not explain how she understood the expressions, "a richer interaction between teacher and student", and "touching hearts, and engaging minds".

Another example of Mita's level of engagement with the readings can be seen in her writing about the fourth topic, extensive reading (ER) and vocabulary acquisition. She wrote:

Reading extensively can eventually generate our memory and help us to be up-to-date in every angle in life. Language is an angle and language is part of culture of a country. If you want to learn a language you also should learn the culture. In terms of English, we can learn about a Royal tea party along with the language, or playing BINGO and find out what is the origin of the bingo the dog. Everything is connected. So, whether we have deliberate vocabulary learning and learning from reading, it doesn't matter. What does 
matter the most then? It is how we present them and know how much to be taken, not too little not too much.

Some of the propositions being picked up from the reading are: (1) whether ER or deliberate vocabulary learning was the more effective method in learning a second language, and (2) whether ER and deliberate vocabulary learning were compatible. However, rather than critically evaluating the two approaches to vocabulary learning, she only provides reasons why she believes ER is important.

In the analysis of the quality of reflection, i.e., the connections between the propositions in the readings and Mita's current teaching practices, I found that Mita provided weak to moderate evaluation of her teaching practice. Four of seven of Mita's blog entries are weak in quality because they reflected on her personal teaching/ learning practices but did not connect to the issues in the reading. One example is her blog entry on the fifth reading, scoring rubrics. The key ideas of the reading are the significance of involving students to create scoring rubrics to assess their study. She wrote:

I believe that if someone is trusted enough, he will get a feeling that he is accepted; if he feels accepted, he will also open himself to others.

Based on that thought, I propose that we, teachers should give a chance to our students in taking parts to compose their rubric. What I have proudly done has been marvellous.

This quote shows that Mita mentioned the idea about giving students chances to compose their own scoring rubrics. However, she did not provide further explanation of why her students need to compose their scoring rubrics. Thus, the relevant blog entry received weak scoring.

An example of her moderate reflection of her personal teaching or learning practices can be seen in her response to the reading on graphic organisers, i.e., she chose to focus on the advantages of using them as a reading tool. Her use of pronouns shifted from "I" to "they" (graphic organisers or students) and to "we" (teachers). These pronoun shifts mark the shift in the focus from personal experiences to 'objective' evaluation, and then back to application (thinking about characteristics of her students). She wrote: 
When this topic came up on the blog, it struck my mind right on its peak. I used to use this method in reading comprehension. But not anymore. Frankly speaking, I can't remember the reason why I stopped using this method. Never mind, then, as I still remember the good times doing it.

Graphic organisers may look like simple fill-in-the-blank worksheets, but they are actually so much more. These pieces of paper full of circles, squares and connecting lines help improve students' comprehension and encourage them to think critically. Whether they are used to compare and contrast, analyse relationships, brainstorm, explore concepts or just take notes, graphic organisers help students see their reading and writing instruction in a new way.

As the technology always develops, we are dealing with students who are accustomed to visual material......

Mita only had three or four sentences that described her personal learning experience. She put some efforts to review the reading critically although she repeated the benefits of graphic organisers as stated in the reading material. Thus, she received moderate scoring on reflection analysis for this particular blog entry.

Overall, I conclude that Mita's blog entries evaluated the ideas and propositions from the reading 'weakly' or 'moderately'. Most of the time she expressed agreement with the ideas in the reading; she rarely questioned them or examined the validity or teaching philosophy behind what was suggested in the texts. She attempted to link the key ideas in the readings with her teaching but she was not always successful in doing so. Mita's blog entries created an image of an enthusiastic teacher, who was usually eager to adopt new ideas without engaging in critical evaluation prior to their adoption.

\subsubsection{Rahman}

Turning now to Rahman's blog entries, the content analysis showed that he had moderate to strong engagement with the readings, which is evident from the number of the key ideas from the readings that he had picked up and discussed in his writing. In three of his six-blog entries, he mentioned three to four key ideas from the readings and, in the other three-blog entries, he referred to more than four key ideas. In his first blog entry, on TLLM, he referred to the following propositions: educators should teach better, they should engage with the students, and students should learn from each other. He wrote: 
Firstly, I think the concept of "Less Teaching, More Learning" has a close meaning with the words "Learning by Doing". By doing something by the students themselves means there will be three steps of it, those are planning, doing, and evaluating. The students can feel, hear, see, smell, and remember even every step they have taken. If it succeeds, sometimes the students will feel that they once had the best experience in their life and it will become an unforgettable moment.

He explains that TLLM provides opportunities for teachers to give more autonomy to their students, so that they can become independent learners.

In another blog entry, Rahman discussed vocabulary in language education (based on Nation, 2006). He picked up several ideas from the reading, such as how to deal with high/low frequency words, learning vocabulary through reading, learning vocabulary through speaking, learning vocabulary through writing and monitoring, and encouraging progress. However, he did not evaluate these key ideas clearly, based on the information available in the readings. On learning vocabulary through reading, he wrote:

Based on my experience, the students still feel difficult in guessing the meaning of English words when they do not know what the real meaning is. Therefore, it can be a barrier for them to comprehend the next ideas. I think that learning vocabulary through reading is the most suitable solution to solve the problem because by reading a lot, the students will meet a lot of new words that they have to know the meaning to get the point of the ideas.

While some of Rahman's arguments are valid (i.e., extensive reading exposes language learners to a great deal of vocabulary), and he attempts to discuss some issues that may arise in extensive reading (i.e., not having enough vocabulary may create a barrier in reading comprehension), he fails to make clear conclusions about the importance of measuring vocabulary load and matching it with learners' current vocabulary knowledge. Nation (2006) suggests that for a language learner to be an independent reader of an academic text, s/he needs to understand about $98 \%$ of the running words. Thus, too many new and unfamiliar words would hinder the learner's understanding of the text.

Most of Rahman's writing described his personal teaching or learning practices, and related them to the issues brought up in the readings to some degree. Four of his blog entries (on vocabulary in language education, vocabulary acquisition input and extensive reading (ER), listening skills and graphic organisers) 
extensively recounted his teaching experiences as a new teacher and his learning experiences when he was taking his Bachelor Degree in ELT. On his experiences with ER as a student, he wrote:

I remember when I was still a college student, my lecturer always gave me and my friends reading assignment that we usually called it extensive reading. Every week we should read English books as many as possible and make the written report at home. During the class, we made a small group and should retell what we had read. Time passed and we knew that it was very beneficial for our improvement

Although Rahman picked up many propositions from the reading, there was little connection between his reflection and these propositions. One of the main issues in the fourth topic was the comparison between ER and deliberate vocabulary learning, i.e., using flash cards (Elgort, 2011). Rahman's blog entry, however, was essentially about ER in his experience as a student, and not about connecting his experiences as a language teacher (or learner) with the main issue raised in the readings, i.e., affordances of different approaches to vocabulary acquisition.

To sum up, Rahman's blog entries attempted to critically evaluate the issues introduced in the readings. However, he mainly expressed agreement with some specific points from the readings, but did not provide robust reasons for his views. His reflections showed that his prior learning experiences contributed to his current teaching practices. However, his critical reading and reflection skills (in English) require further development.

\subsubsection{Tiara}

Three out of five Tiara's blog entries picked up more than four propositions from the readings. The three topics that showed Tiara's strong engagement with the readings are vocabulary in language education, listening skills and using graphic organisers for writing. For example, in her blog entry on listening skills, she discussed the importance of listening in the language classroom, many different types of listening, roles of listeners, allowing students to have some control over the class, and the learner-centred dimension of listening classes. She argued "being able to listen well is an important part of communication for everyone". 
She evaluated many key ideas from the readings and provided some clear reasoning for her views. For example, on the listening skill topic, Tiara's argued that listening was crucial because it provided input to students, and without comprehensible input, no learning would take place. She wrote:

Material should be focus on particular purpose of a listening activity. Worksheet should be completed with the clearly example otherwise, it creates the students feeling confused and frustrated. The consequence of this case, the indication of the students' level in listening comprehension skill is not accurate because they don't understand the worksheet and not because of the listening activities themselves. For instance, the beginners' level of SMA or X and XI class have activities like as follows: pair work activities that is student A and student B have the same worksheet -about lyrics of the songs, where some information is missing. Thus, students must ask to each other for the missing words of the song. In this case, the students have practiced the effective communication with their partner. Finally, to confirm whether the answers are correct, it confirms by listening the accurate song.

Even though her writing is characterised by many lexical and grammar errors (in the use of passive voice and past tense), Tiara offered a good explanation for her evaluation of the listening task materials, and supported it with an example.

Tiara's writing varied in terms of the amount of reflection on her teaching or learning experiences, and the degree of correlation between her reflections and the key ideas in the readings. Tiara's blogging was not very reflective on the topics of TLLM, vocabulary acquisition and extensive reading, and listening skills. She reflected a little on the graphic organisers' topic, and reflected a lot on vocabulary in language education. Her personal reflection on the teaching of vocabulary in class was strong because she described her activities with her students in detail. In her introduction, she wrote:

In applying of teaching to the learners at SMAN7 Malang, I have done some teaching activities. One of them is writing activities. Through the writing activities, I ask the students of X IS3 class the year of 2013-2014 to write descriptive paragraph to describe the Indonesian local fruit trees, which are growing around the schoolyard. The class is divided into 7 groups of 5 . The groups are asked to spread out around the schoolyard to find one local fruit tree. They are not allowed to describe the same object.

Tiara provided a step-by-step description of her teaching. This paragraph also showed that she picked up two propositions from the reading: teaching vocabulary through writing and encouraging autonomy among learners. However, in another 
blog entry she did not relate the key ideas from the reading to her personal experience. On extensive reading (ER) and acquiring vocabulary knowledge she wrote:

I do agree that extensive reading is considered to be a part of the way to increase the students' vocabulary. After reading the text materials, the students are asked to make discussion. In this case, the students automatically increase their vocabulary to express their opinion to reply their friends' ideas during the discussion. Meaning that, the students will be challenged to read more sources to enhance their knowledge. Otherwise they will have limited information to get involve in discussion.

This blog entry did not discuss any personal practice of using ER in her classroom, or did she attempt to compare ER and other approaches to improving one's vocabulary. To conclude, Tiara's blog entries mostly picked up the propositions from the readings. However, she demonstrated only a moderate ability to evaluate these propositions. Although she described her personal teaching or learning practice, only some of these descriptions could be related to the propositions from the readings, and few had explicit connections with the key ideas in the readings.

The EFL teachers rarely expressed a critical stance when discussing core ideas posed in the readings; instead, they were usually eager to embrace these ideas. Mita, for example, never discussed strengths, weaknesses or possibilities for improvement of the key ideas from the readings in her blog entries. The analysis of Tiara's blog entries showed that she would easily agree with the key ideas presented in the reading, and that she would seldom evaluate these ideas. She did not consider whether or not the points conveyed in the readings were feasible in the Indonesian teaching and learning context. However, she enjoyed sharing her own teaching and learning experiences with her readers. On the other hand, some of Rahman's argumentation was more elaborate and critical; for example, when discussing new teaching approaches, and he was more likely to question ideas presented in the readings. He also analysed the context of his teaching before thinking about implementing the teaching techniques. Nevertheless, Rahman did not always connect personal experiences with the core ideas from the readings. Rahman's writing tended to be presented in the form of argumentative essays, although he was not always successful in doing so. 
The findings of the study indicate that a more comprehensive environment and needs analysis is essential. Nation \& Macalister (2010) maintain that environment and needs analysis prior to training, i.e. language training, enables teachers and stakeholders to estimate what their students really need and what resources and supports are needed to ensure the effectiveness of the programme. This idea is aligned with Timperley et al.'s (2007) framework of effective TPD, in which socio-cultural contexts (teachers' needs and context where they teach) are crucial for professional learning to happen.

To conclude, the use of the case study approach (Duff, 2012) allowed a principled analysis of the blogging experiences and outputs of the three active bloggers. The approach enabled me to observe the blogging activities closely and intensively, in order to understand individual teachers' behaviours. While the findings of the present study may not be universal and cannot be generalised due to its descriptive in nature, they yielded insights that are relevant to a number of research fields, including blogging for professional development, adult learning, adult language learning and integrating ICT in professional development.

\section{Summary}

Four key findings emerge from the data analysis. First, the study found that quantity and quality of the teachers' writing in the blog varied considerably, and that there was no clear relationship between the teachers' AWL vocabulary levels scores and their use of academic vocabulary in writing blog entries. Second, the three bloggers' writing style and use of academic words appear to be affected by their previous knowledge of blogging. Mita who had prior knowledge of blogging tended to use the blog as a personal online journal and used fewer academic words than the other two bloggers. Rahman and Tiara who did not have prior knowledge of blogging, tended to use argumentative writing style and more academic words in their blog entries. Third, the present study found that the three blogger-teachers mentioned and discussed some key points from the reading in their blogs entries, but the blog entries were mostly descriptive, lacking in a thorough critical evaluation of the points raised in the reading. Fourth, the teachers willingly narrated their own teaching and learning experiences, but they rarely provided 
critical reflection of these experiences or connected them with the core ideas from the readings. 


\section{Chapter 5 Blogging as a Form of Professional Development}

\section{Introduction}

This chapter offers insights that link the EFL teachers' blogging case studies (Chapter Four) and issues related to teacher training and professional development (Chapter Six).

The study was originally envisaged as an exploratory blogging treatment, in order to investigate whether blogging is a worthwhile form of professional development in English, for in-service and pre-service EFL teachers in Indonesia. However, the research changed as a result of poor teacher participation in the blogging programme. Only three out of 25 volunteers completed the programme.

Therefore, the study was redesigned as an investigation into institutional and individual aspects of professional development for EFL teachers in Indonesia. A key part of this investigation is developing an understanding about what prevented EFL school teachers from taking part in this programme.

\subsection{Purposes of the study}

This chapter focuses on the EFL teachers' blogging experiences and behaviors and affordances and barriers of blogging from the perspectives of teachers, teacher coordinators, District Ministry of Education officers, teacher educators, and teacher trainers. Questionnaires and interview with these stakeholders were conducted to better understand why the blogging uptake was so poor in this study, and what factors might influence teachers' uptake of similar professional development opportunities within the Indonesian context in the future.

In this section, I look into four research questions. I attempt to investigate the EFL teachers' blogging and experiences and behaviours, and to identify the barriers and opportunities that blogging offers EFL teachers in Indonesia from the perspectives of teachers themselves, and those of other educational stakeholders. 
The first two questions concern the EFL high school teachers' blogging experiences and behaviors:

1. To what degree are EFL teachers familiar with blogging?

2. How frequently do teachers engage in blogging?

The other two questions concern the teachers' and educational stakeholders' perceptions of blogging as a form of professional development, in Malang District of Indonesia:

1. What are the perceived benefits of blogging?

2. What are the perceived barriers to blogging?

\subsection{Methodology}

As indicated in Chapter Four, this chapter uses quantitative (questionnaire) and qualitative (interview) data to answer the four research questions in Section 5.1. In the present study, the data from the questionnaire was analysed using the Statistical Package for the Social Sciences (SPSS) 20. The data from the interview were analysed using the thematic analysis (TA). To understand both data, a mixed-methods data analysis approach was used. The mixed-methods approach is appropriate because the interview data compliment the questionnaire data (Creswell, 2014). The questionnaire data provides a more general view of the EFL teachers' blogging experiences and behaviours. The interview data provides deeper and more extensive views on the benefits and limitations of blogging intervention among EFL teachers and stakeholders.

\subsubsection{Participants}

The data were collected from three sets of participants. Firstly, this study drew on the questionnaire data from the group of 68 Indonesian EFL pre-service and inservice teachers, who took part in the L2 proficiency study reported in Chapter Three (see Table 3.1, Chapter Three). The in-service teachers were from three groups of high schools: junior high schools, senior high schools and vocational senior high schools.

Further data gathering was undertaken with nine EFL teachers (see Table 5.1) including the three teachers who participated fully in the blogging study (see 
Section 4.2.1, Chapter Four), three teachers who started blogging but dropped out after the first or second blog entry (hereafter, drop-out bloggers), and three teachers who chose not to participate in the blogging study (hereafter, nonbloggers). Data from these participants included questionnaires and interviews. The questionnaire and interview guides used in this study were the same questionnaire and interview guides used in the teacher L2 proficiency study (Chapter Three) and professional development study (Chapter Six). Please refer to Section 5.2.2 for the details of the data collection instruments.

Table 5.1 provides background information about each of these participants, including their pseudonym, blogging experience, blogging status in the present research, when they started teaching, length of teaching service, and gender. Four of these teachers self-reported that they had no (or almost no) experience in blogging: Rahman, Tiara, Waskito, and Bintang. Four teachers stated that they had learned about blogging but rarely blogged: Arum, Agni, Adya, and Wulan. Only one teacher self-identified as a highly experienced blogger: Mita. The longest serving teacher was Tiara who started in 1995 and had been teaching for 29 years. The teachers with the shortest length of service were Rahman and Waskito, who started teaching in 2011. Wulan had no experience of teaching high school at the time the study was conducted. The average teachers' length of service was 9.56 years $(\mathrm{SD}=9.70)$. The participants were predominantly women $(n=7)$ and only two male teachers participated.

Table 5.1 Characteristics of the EFL teachers interviewed about blogging

\begin{tabular}{|c|c|c|c|c|c|}
\hline Pseudonym & $\begin{array}{l}\text { Previous } \\
\text { blogging } \\
\text { experience }\end{array}$ & $\begin{array}{l}\text { Blogging } \\
\text { status (in } \\
\text { this } \\
\text { research) }\end{array}$ & $\begin{array}{l}\text { Started } \\
\text { teaching }\end{array}$ & $\begin{array}{l}\text { Length } \\
\text { of } \\
\text { service } \\
\text { (to 2013) } \\
\end{array}$ & Gender \\
\hline Mita & $\begin{array}{l}\text { A great deal of } \\
\text { experience }\end{array}$ & Blogger & 2004 & 9 years & $\mathrm{F}$ \\
\hline Agni & $\begin{array}{l}\text { Some } \\
\text { experience }\end{array}$ & $\begin{array}{l}\text { Non- } \\
\text { blogger }\end{array}$ & 1994 & 19 years & $\mathrm{F}$ \\
\hline Arum & $\begin{array}{l}\text { Some } \\
\text { experience }\end{array}$ & $\begin{array}{l}\text { Drop-out } \\
\text { blogger }\end{array}$ & 1998 & 15 years & $\mathrm{F}$ \\
\hline Adya & $\begin{array}{l}\text { Some } \\
\text { experience }\end{array}$ & $\begin{array}{l}\text { Non- } \\
\text { blogger }\end{array}$ & 2010 & 3 years & $\mathrm{F}$ \\
\hline Wulan & $\begin{array}{l}\text { Some } \\
\text { experience }\end{array}$ & $\begin{array}{l}\text { Non- } \\
\text { blogger }\end{array}$ & $\mathrm{n} / \mathrm{a}$ & 0 year & $\mathrm{F}$ \\
\hline Tiara & No experience & Blogger & 1995 & 29 years & $\mathrm{F}$ \\
\hline
\end{tabular}




\begin{tabular}{|c|c|c|c|c|c|}
\hline Bintang & No experience & $\begin{array}{l}\text { Drop-out } \\
\text { blogger }\end{array}$ & 2006 & 7 years & $\mathrm{F}$ \\
\hline Rahman & No experience & Blogger & 2011 & 2 years & M \\
\hline Waskito & No experience & $\begin{array}{l}\text { Drop-out } \\
\text { blogger }\end{array}$ & 2011 & 2 years & M \\
\hline
\end{tabular}

The final set of participants was a group of 11 educational stakeholders (see Table 5.2) who were interviewed for this study. These participants were selected because they represented a wide range of perspectives and interest in teacher education in Malang district. These participants included two heads of schools, two teacher-coordinators, two District Ministry of Education officers, two teacher educators, and three teacher trainers. Table 5.2 below outlines their ICT literacy, current jobs, when started service in their current jobs, previous or other jobs, and gender. The average service years of the stakeholders was 9.82 years $(\mathrm{SD}=8.35)$. The number of female and male stakeholders was well balanced, with six females and five males.

Table 5.2 Characteristics of the educational stakeholders

\begin{tabular}{|c|c|c|c|c|c|}
\hline Pseudonym & $\begin{array}{l}\text { Estimated ICT } \\
\text { literacy }\end{array}$ & Current jobs & $\begin{array}{c}\text { Started } \\
\text { current } \\
\text { jobs }\end{array}$ & $\begin{array}{c}\text { Previous/other } \\
\text { jobs }\end{array}$ & Gender \\
\hline Faizal & $\begin{array}{l}\text { Extensive } \\
\text { knowledge }\end{array}$ & Head of school & 2011 & $\begin{array}{l}\text { Mandarin \& } \\
\text { English } \\
\text { teacher }\end{array}$ & $\mathrm{M}$ \\
\hline Archie & $\begin{array}{l}\text { A great deal of } \\
\text { knowledge }\end{array}$ & $\begin{array}{l}\text { District Ministry } \\
\text { of Education's } \\
\text { officer }\end{array}$ & 2005 & $\begin{array}{c}\text { No work } \\
\text { experience }\end{array}$ & $\mathrm{M}$ \\
\hline Cahaya & $\begin{array}{l}\text { A great deal of } \\
\text { knowledge }\end{array}$ & $\begin{array}{l}\text { Teacher } \\
\text { educator }\end{array}$ & 2006 & EFL Lecturer & $\mathrm{F}$ \\
\hline Prasetyo & $\begin{array}{l}\text { A great deal of } \\
\text { knowledge }\end{array}$ & Teacher trainer & 1986 & EFL Lecturer & M \\
\hline Ninih & $\begin{array}{l}\text { A great deal of } \\
\text { knowledge }\end{array}$ & Teacher trainer & 1999 & EFL Lecturer & M \\
\hline Dada & $\begin{array}{l}\text { A great deal of } \\
\text { knowledge }\end{array}$ & $\begin{array}{l}\text { Teacher } \\
\text { coordinator }\end{array}$ & 2009 & EFL teacher & $\mathrm{F}$ \\
\hline Wiwid & $\begin{array}{l}\text { Some } \\
\text { knowledge }\end{array}$ & $\begin{array}{l}\text { Teacher } \\
\text { educator }\end{array}$ & 2003 & EFL Lecturer & $\mathrm{F}$ \\
\hline Salsa & $\begin{array}{l}\text { Some } \\
\text { knowledge }\end{array}$ & Teacher trainer & 1990 & EFL Lecturer & $\mathrm{F}$ \\
\hline Laksmi & $\begin{array}{l}\text { Some } \\
\text { knowledge }\end{array}$ & $\begin{array}{l}\text { District Ministry } \\
\text { of Education's } \\
\text { officer }\end{array}$ & 2012 & EFL teacher & $\mathrm{F}$ \\
\hline Nana & $\begin{array}{l}\text { Some } \\
\text { knowledge }\end{array}$ & $\begin{array}{l}\text { Teacher } \\
\text { coordinator }\end{array}$ & 2009 & EFL teacher & $\mathrm{F}$ \\
\hline Budi & Not available & Head of school & 2006 & Psychology & $\mathrm{M}$ \\
\hline
\end{tabular}


In the interview, the stakeholders were asked whether or not they integrated ICT in their work and the extent to which they participated in ICT-mediated activities and projects. Based on their responses, I estimated their ICT literacy (Table 4.12). Faizal, Archie, Cahaya, Prasetyo, Ninih, and Dada had extensive ICT knowledge as each was involved in ICT-based projects with their colleagues and/or students. Faizal, for example, was working on engaging students in his English class by designing a programme that allowed his students to complete English language tests through mobile or smart phones. Cahaya and her students had a writing forum using Edmodo, "a unique social network designed especially for learning communities. Edmodo is different from Facebook because it provides students a safe, protected educational experience, a place to safely practice the digital-age social networking and learning skills they will need in increasingly connected personal, academic, and later professional lives" (Carlson, 2015: 5-6). Please visit the following website for more information about Edmodo, https://www.edmodo.com/.

Wiwid, Salsa, Laksmi and Nana also indicated that they had some knowledge of ICT; they were familiar with ICT but were not currently working on any ICTbased projects. Wiwid, for example, reported that she learned about blogging and had a blog. However, she could not remember how to post a blog because she rarely used it and she could not remember her blog address (URL). I could not estimate Budi's ICT knowledge and skills well. In an attempt to estimate them, I talked to him and proposed sending some electronic invitations for seminars, workshops or trainings through email for the EFL teachers under his supervision. He said that he would give me the school's email address. However, he did not provide it. It was not clear whether or not he had his own email address and why he wanted to give his school email address rather than his personal address. It was also not clear if he used internet-based activities at all. Thus, I did not have enough evidence to make a conclusion about Budi's ICT knowledge and skills. The stakeholders' previous or other job experiences were also sought, because they provided a proxy for their familiarity with EFL teaching and learning. For 
nine out of the 11 stakeholders, previous or other jobs had immediate relation to the teaching of English in high schools but, for Budi and Archie, this was not the case. Archie had received a Bachelor Degree in Archaeology, and Budi was an Educational Psychology graduate and worked as a psychology teacher.

Prasetyo, a professor of English language teaching, had the longest time in his present employment (Table 5.2). He had a special interest in English language assessment. The stakeholder with the shortest current job experience was Laksmi, a District Ministry of Education officer. However, she had been an EFL teacher in a state junior high school in Malang before being promoted to her current position. The stakeholders with some background knowledge about and experience with EFL teaching and learning are likely to have a better understanding of the ICT use in the field than those with less or no experience. In total, 20 people were interviewed in the present study (see Table 5.3).

Table 5.3 Summary of interview participants

\begin{tabular}{lclc}
\hline Teachers & Number & Stakeholders & Number \\
\hline Bloggers & 3 & Head of schools & 2 \\
Drop-out bloggers & 3 & Teacher co-ordinators & 2 \\
Non-bloggers & 3 & Teacher educators & 2 \\
& & Teacher trainers & 3 \\
& & Officers from the Ministry & 2 \\
& & of Education & 11 \\
Total & 9 & Total & $\mathbf{2 0}$ \\
\hline
\end{tabular}

While it is very important to be able to have random samples approach to recruit the stakeholders, it was not possible for this study. The samples of the stakeholders in the present study were selected because they were accessible. Thus, the respondents were all samples of convenience (Friedman, 2012; McMillan \& Schumacher, 1993).

The teachers and stakeholders interviewed in the present study were selected because they gave multiple emic (insider) and etic (outsider) perspectives (Friedman, 2012: 182) on the issues of TPD policies and practice in Malang, 
Indonesia. The emic perspectives came from the teachers and teacher coordinators. The etic perspectives came from the school principals, teacher educators, teacher trainers, and Ministry of Education officers. They were also interviewed on the basis of geographical proximity (Malang district) and their willingness and availability at the time of the interview when it was scheduled (from August to October 2014).

\subsubsection{Data collection instruments}

The instruments to gather data from the EFL teachers and stakeholders were questionnaire and interview guides.

\subsubsection{Questionnaire}

Responses to a subset of questions from the "Survey of Indonesian EFL Teachers" (Appendix 3) were used to investigate the ICT literacy of EFL teachers in Indonesia. Self-report data were sought on the teacher behavior (Question 4.1) and their evaluation of competency (Questions 3.3) in relation to specific ICT tools and technologies.

The questionnaire used in this study was the same as the one used for the L2 proficiency study (Chapter Three) and TPD study (Chapter Six). Only answers to the questions about the teachers' blogging knowledge and activities were used in this analysis.

\subsubsection{Interview guides}

Different interview guides were used to interview the teachers and stakeholders. The aim of the interview was to investigate the teachers' and stakeholders' attitudes to affordances of and barriers to using ICT and blogging in EFL TPD in Indonesia. The interview was conducted through long-distance phone calls, using Skype calls or Facebook video chats. The semi-structured interview format used in this study allowed me to investigate the same core themes across all interviews, while adjusting the specific questions to make them more relevant to the participants being interviewed.

Table 5.4 presents questions from the interview guide used with nine EFL teachers. Within this group, the three groups of teachers (bloggers, drop-out 
bloggers, and non-bloggers) were asked different sets of questions (Table 5.4).

For example, only the three active bloggers were asked about their overall impression of the blogging study. Instead, the drop-out bloggers were asked about the reason why they had initially agreed to participate in the study but later decided to withdraw.

Table 5.4 Questions from the interview guide used with the teachers

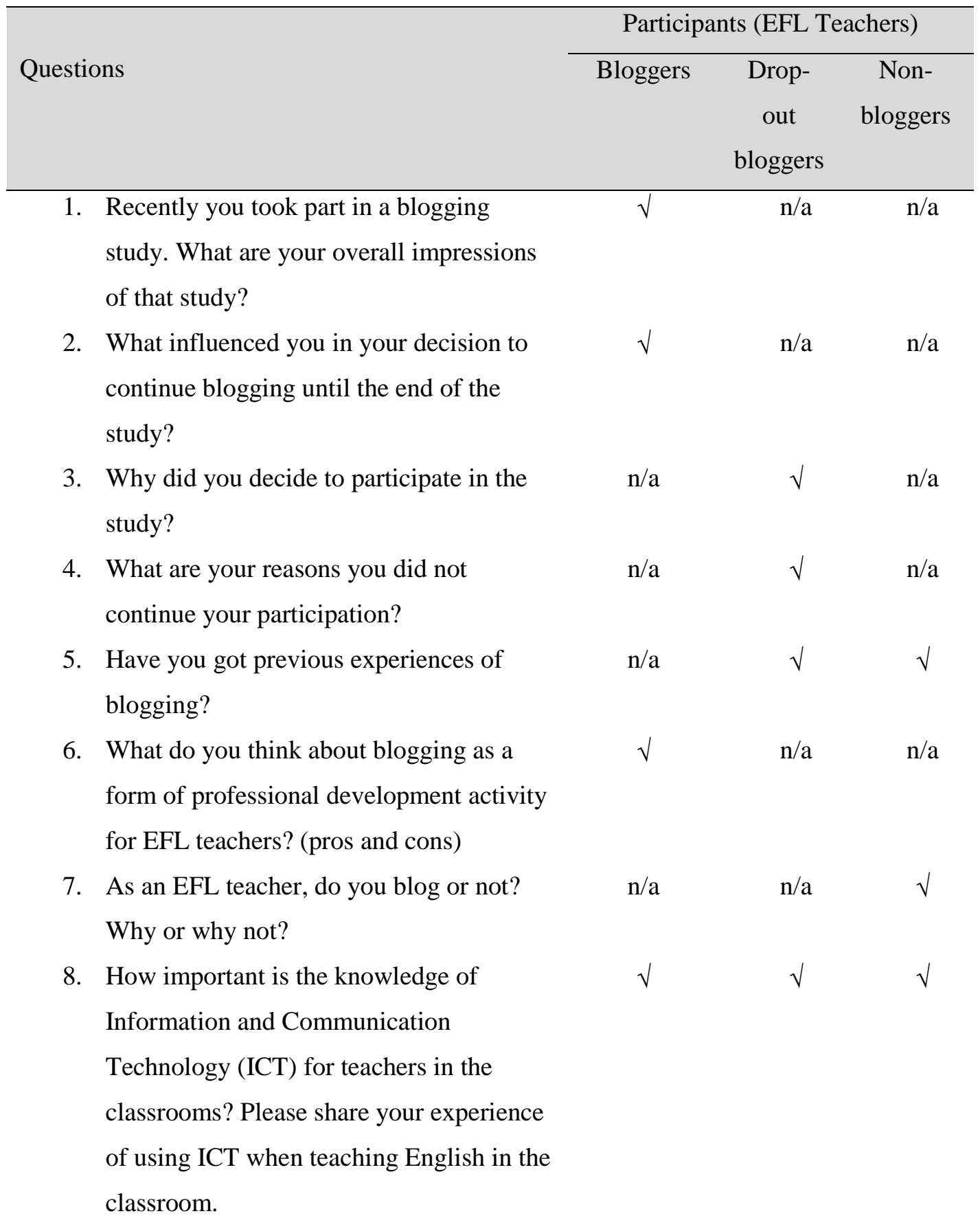


9. What could you do with blogging to improve your teaching and professional development?

A different guide was used when interviewing the stakeholders (see Table 5.5). The interview guide for stakeholders mostly asked about ICT in general and the stakeholders' views on the use of technology in the classrooms. Using two different interview guides (and targeting questions with each guide to specific participant groups) enabled me to obtain views that illuminated the issue of ICT use from both etic (the EFL teachers) and emic (the stakeholders) perspectives. By referring to the data collected from the EFL teacher practitioners, PD policy makers, and those who were implementing the policies locally, I was able to construct a more accurate picture in response to my research questions.

Table 5.5 Questions from the interview guide used with the stakeholders

\begin{tabular}{|c|c|c|c|c|c|}
\hline \multirow[b]{2}{*}{ Questions } & \multicolumn{5}{|c|}{ Participants (Educational Stakeholders) } \\
\hline & $\begin{array}{l}\text { Teacher } \\
\text { co- } \\
\text { ordinators }\end{array}$ & $\begin{array}{l}\text { Heads } \\
\text { of } \\
\text { schools }\end{array}$ & $\begin{array}{l}\text { Staff of } \\
\text { District } \\
\text { MoEC }\end{array}$ & $\begin{array}{l}\text { Teacher } \\
\text { educators }\end{array}$ & $\begin{array}{l}\text { Teacher } \\
\text { trainers }\end{array}$ \\
\hline $\begin{array}{l}\text { 1. How long have you been a } \\
\text { teacher coordinator/ head of } \\
\text { school/ district education } \\
\text { officer/teacher } \\
\text { educator/teacher trainer? }\end{array}$ & $\sqrt{ }$ & $\sqrt{ }$ & $\sqrt{ }$ & $\mathrm{n} / \mathrm{a}$ & $\mathrm{n} / \mathrm{a}$ \\
\hline $\begin{array}{l}\text { 2. What do you do as a teacher } \\
\text { coordinator? What are the job } \\
\text { descriptions of a teacher } \\
\text { coordinator? }\end{array}$ & $\sqrt{ }$ & $\mathrm{n} / \mathrm{a}$ & $\mathrm{n} / \mathrm{a}$ & $\mathrm{n} / \mathrm{a}$ & $\mathrm{n} / \mathrm{a}$ \\
\hline $\begin{array}{l}\text { 3. What did you do before } \\
\text { serving as a head of } \\
\text { school/district education } \\
\text { officer? }\end{array}$ & $\mathrm{n} / \mathrm{a}$ & $\sqrt{ }$ & $\sqrt{ }$ & $\mathrm{n} / \mathrm{a}$ & $\mathrm{n} / \mathrm{a}$ \\
\hline $\begin{array}{l}\text { 4. What are your suggestions to } \\
\text { in-service teachers on the }\end{array}$ & $\sqrt{ }$ & $\mathrm{n} / \mathrm{a}$ & $\sqrt{ }$ & $\mathrm{n} / \mathrm{a}$ & $\mathrm{n} / \mathrm{a}$ \\
\hline
\end{tabular}


issues of EFL teachers'

English proficiency and on

ICT knowledge?

5. How important is the

$\mathrm{n} / \mathrm{a}$

knowledge on ICT for EFL

teachers?

6. What are the contribution of

$\mathrm{n} / \mathrm{a}$

$\mathrm{n} / \mathrm{a}$

$\mathrm{n} / \mathrm{a}$

$\mathrm{n} / \mathrm{a}$ teacher education on EFL

teachers' English proficiency

and ICT knowledge? Does

your institution offer $\mathrm{CMC}$ or

CALL subject to your

students?

\subsubsection{Data collection}

The administration of the research questionnaire is described in Section 3.2.3.3, while the administration of the interviews with the teachers is described in Section 3.2.3.5 of Chapter Three. Similar to the interviews with the EFL teachers, the interviews with the stakeholders were done in Bahasa Indonesia and the participants could choose to answer in Bahasa Indonesia or English. Unlike the nine EFL teachers who all responded in Bahasa Indonesia, three out of 11 stakeholders chose to answer the interview questions in English (one of the District Ministry of Education and Culture staff and two teacher co-ordinators).

The stakeholders were interviewed during the period of September - October 2014, after the interviews with the teachers had been completed. This sequencing enabled me to adjust and fine-tune the interview guides that the stakeholders used, in order to better address and further clarify points raised by the teachers. The full interview period was between August and October 2014

\subsubsection{Approach to data analysis}

SPSS 20 (IBM Corp, 2011) was used to analyse the teachers' responses to questions 3.3 and 4.1 of the questionnaire (Appendix 3) that addressed teachers' experiences with using ICT, and blogging in particular, in their own teaching 
practice. The questionnaire data was used to inform the semi-structured interviews. I aimed to establish a more balanced view of teacher attitudes towards the role of ICT in EFL teaching and TPD by interviewing not only the three teachers who completed the blogging study but also the teachers who dropped out and those who declined an invitation to participate in the blogging activity. A further insight was gained by interviewing relevant educational stakeholders. The interview data is treated as the main dataset in this investigation.

As indicated earlier (see Section 3.3.2, Chapter Three), theoretical thematic analysis (TA) was used in data coding. The codes were generated, driven by the research goal to investigate the perceived affordances of and barriers to blogging among teachers. Thematic analysis provides systematic ways to identify and organise themes across data sets and offers insights into the meaning of those themes (Braun \& Clarke, 2006; Braun \& Clarke, 2012). TA typically includes semantic (explicit) and latent (interpretative) level analysis and usually focuses on one level of investigation: sematic level or latent level. An ideal analytic process involves a progression from description to interpretation (Braun \& Clarke, 2006: 84).

Edge and Richards (1998) and Duff (2012) emphasise that qualitative researchers have to be ready with questions on internal validity, external validity, reliability and objectivity that are known as credibility, transferability, dependability and confirmability in qualitative research design. To achieve credibility, I triangulated the data from the teachers' blog entries, and their responses to the questionnaire and the interviews. To gain a broader range of views, in addition to the bloggers, I also interviewed three teachers who dropped out from the blogging study, three teachers who decided not to participate in the blogging study, and 11 educational stakeholders. To ensure the transferability, I used a thick description (Cohen \& Crabtree, 2006), as by "describing a phenomenon in sufficient detail one can begin to evaluate the extent to which the conclusions drawn are transferable to other times, settings, situations, and people". The dependability and conformability were achieved by making sure that the research documentation could be reconstructed. These study findings are not broadly generalisable 
because of the nature of participant recruitment that relied on convenience sampling. Instead, I seek to particularise the results of the study (Duff, 2012).

During the data analysis, similar themes were grouped together and emerging patterns were checked for their consistency and variability. To interpret the themes or codes, I read and re-read them in reference to relevant literature (Braun \& Clarke, 2006). After reviewing the themes, I continued refining them, narrating the results of the analysis, and finally reported the analysis

\subsection{Results and discussion}

\subsubsection{EFL high school teachers' blogging experiences and behaviors}

The EFL teachers' familiarity with blogging in particular, and their ICT knowledge in general, was estimated based on the questionnaire data. While 68 teachers participated in the study, not every teacher answered all questions in the questionnaire. The questionnaires that had missing data for one or more questions were not excluded from the data analysis. Therefore, the total number of responses may vary between questions and different response sets.

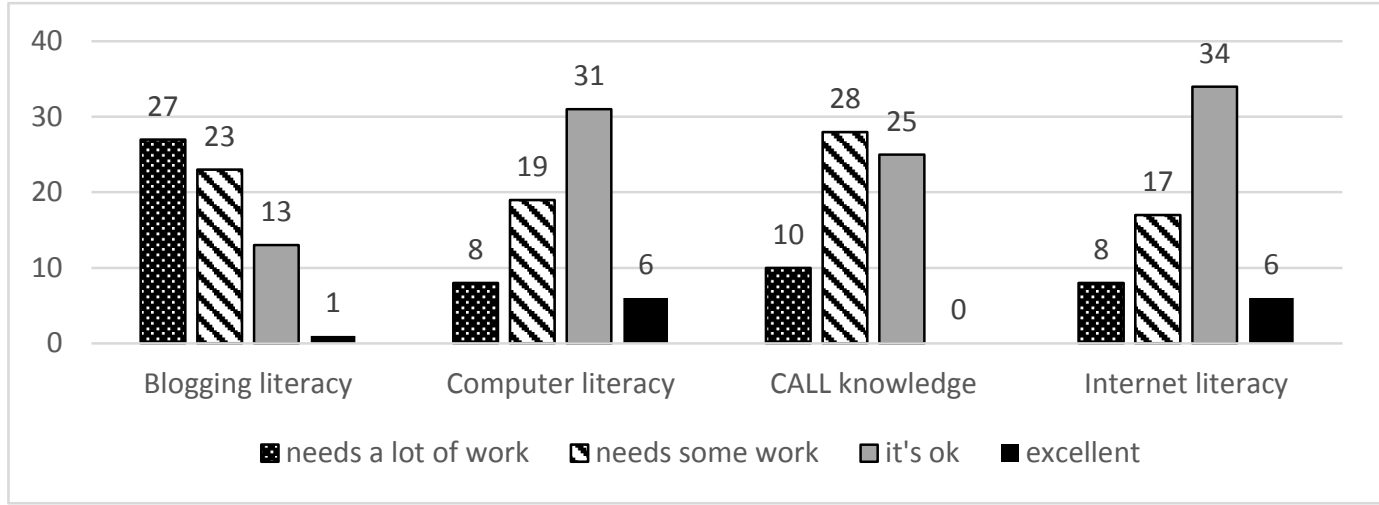

Figure 5.1 Teacher ICT literacy $(n=68$, with a varying number of missing values in each category)

Most of the EFL teachers had little confidence in their blogging literacy.

Compared to other categories of ICT knowledge, such as computer literacy, internet literacy and CALL, the teachers were less familiar with blogging (Figure 5.1). The majority of the teachers believed that they had sufficient computer and internet literacy (58\% and 63\% respectively) but they were less confident in their CALL skills, with 59\% admitting that it needed more work, and no participants self-identifying as experts in this area. Nevertheless, 25 teachers (39\% of 63) 
thought their CALL skills were satisfactory. Conversely, only one teacher (from the 64 respondents) believed that her blogging literacy was excellent and 13 teachers $(20 \%)$ reported that their blogging literacy was 'ok', while 50 teachers $(78 \%)$ responded that their blogging literacy needed work. Overall, this suggests that blogging was the weakest of the four types of ICT literacy examined in the survey. These findings indicate that computer and the internet have become parts of the EFL teachers' day to day activities. However, blogging appears to be less familiar and thus, the affordances of blogging were not well explored. Such findings confirm the theory of affordance (Gibson, 2015; van Lier, 2000: 252). Van Lier states "what becomes an affordance depends on what the organism does, what it wants, and what is useful for it". In other words, the findings indicate that blogging has fewer affordances for the EFL teacher than computer or the internet.

The pattern of teacher responses to the question about patterns of their engagement in ICT-based activities outside their school settings, including blogging, was aligned with that of the previous question about the four types of ICT literacy (Figure 5.2).

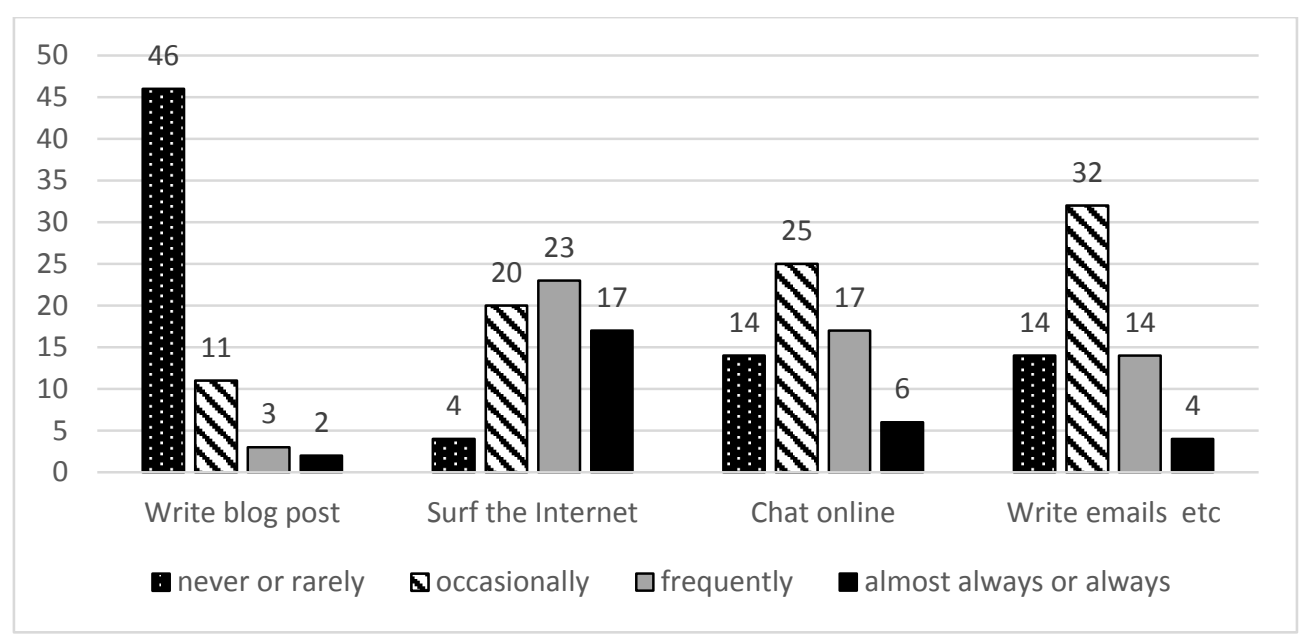

Figure 5.2 Teacher engagement with ICT and blogging-related activities ( $n=68$, with a varying number of missing values in each category)

The results show that only five teachers ( $8 \%$ of the respondents) frequently wrote blog entries, and the majority (74\%) had never used blogs. Compared to the frequency of surfing the Internet, chatting online, writing emails/electronic letters or text messages, writing blog entries was the least frequent activity. These 
findings further confirm the idea of affordance (van Lier, 2000). The affordance of blogging relies on what the EFL teachers do with it, what they want from it, and what part of blogging is useful for them. On one hand, the EFL teachers saw more affordances of the internet than blogging. They could surf the internet for information, chat with others, and write emails using the internet. On the other hand, they were not familiar with blogging and were not aware of its affordances. Together, these findings are in agreement with Sari's (2012) findings which showed that ICT literacy posed challenges to the integration of ICT in the classroom unless they are addressed.

The interviews with the nine teachers revealed that their knowledge about blogging varied considerably. Four teachers, Rahman (blogger), Tiara (blogger), Waskito (drop-out blogger) and Bintang (drop-out blogger), had limited knowledge about blogs, usually from friends, colleagues or teacher trainers. Rahman had not created his own blog entries, but had read his friend's blog. Tiara chose to participate in the present blogging study because she wanted to know more about blogging. Four teachers, Arum (drop-out blogger), Agni (nonblogger), Adya (non-blogger), and Wulan (non-blogger), had once had personal blog, in which they wrote blog entries in Bahasa Indonesia. At the time of the interview they no longer blogged regularly, but continued writing blog entries from time to time. One of the interviewed teachers, Mita, perceived herself as a confident user of blogs; she used to manage a group blog for EFL high school teachers in Malang district prior to the study. These findings indicate that familiarity and experience of blogging promote teachers' confidence in using blogging and the affordances of blogging for the teachers.

Looking at the three categories of teachers (see Table 5.1), it appears that prior blogging experience does not explain EFL teachers' willingness to participate in blogging as a form of professional development. Most of the stakeholders (see Table 5.2) interviewed seemed to have no significant hands-on experience of blogging, although they reported using other types of ICT, such as the Internet and email, extensively. Thus, they did not see the affordances of blogging. Overall, the questioners and the interviews with the teachers suggest that the affordances of blogging come with familiarity and experience. However, little 
could be gleaned from the interviews with the stakeholders about their personal knowledge about their blogging experiences and behaviours.

\subsubsection{Perceived benefits of blogging}

The teachers and stakeholders identified three benefits of blogging. It is a medium for L2 writing practice, a place to share knowledge and ideas about teaching, and a place to connect EFL teachers with other teachers or with their students. Firstly, three teachers, Rahman (blogger), Adya (non-blogger) and Wulan (non-blogger), indicated the possibility for teachers to express their ideas through blogging. These three teachers believed that blogging was a medium for those who wanted to practice their writing skills. Adya, mentioned that expressing ideas in a blog, with peer readers in mind, would help teachers to improve their language and writing skills. She said:

I believe blogging is good because we have to, for example, write when blogging. If we have expressed our ideas in the blogs, some people would read them. Knowing others would read them, we had to write them well. This knowledge would trigger people to improve their linguistic skills. The problem is the fact that Indonesian teachers are still lagging behind those ideas.

This quote indicates that blogging does not only help EFL teachers to practise writing but also improve their L2 writing skills. This finding shows that blogging as a form of personal professional development created a need for teacherbloggers to use their L2 to communicate with their readers. Thus, blogging supports their need to maintain and improve their English proficiency. These results are in accord with the theory of affordance (Gibson, 2015; van Lier, 2000) and more recent studies. The finding about the affordance of blogging to express oneself is consistent with that of Deng and Yuen (2011) and De Almeida Soares (2008). For the teacher-bloggers, this consistency might be due to the fact that the targeted blogging activities in the present study allowed EFL teachers to express ideas about what they understood from the reading and about what they experienced during their teaching. For the drop-out bloggers and non-bloggers, the consistency of blogging as a place to express their ideas may be due to its affordance as a personal online journal (Campbell, 2003). 
Another benefit of blogging is that it acts as a place to share knowledge and ideas about teaching. Bintang (drop-out blogger) and Wulan (non-blogger) explained that through blogs they could share professional knowledge and teaching ideas with fellow teachers. Wulan said:

...from teachers' point of view, the benefit of blogging is being able to share different teaching ideas with other teachers. They can also read, comment, and write in English. The teachers can also introduce blogging to their students.

This quote conveys an opinion that blogging provides a means for EFL teachers to communicate on professional topics in English and to become knowledge brokers (De Moor \& Efimova, 2004; Lave \& Wenger, 1991; Luehmann, 2008) by sharing knowledge or ideas to people who have common interest in English language teaching and learning.

The other benefit of blogging is that it is a place to connect with colleagues or students. On networking with colleagues, Tiara (blogger) said that participating in blogging had allowed her to meet friends virtually. On the affordance of blogging to connect teachers and students, one stakeholder, Prasetyo, said:

I believe teachers have to master ICT, especially for teaching. In the future, I believe that blogging is essential for learning. The students don't have to come to the classroom. The teachers can send assignments and tasks via blog. If the teachers or students can't come to class, alternative ways can always be suggested, such as using other learning sources.

This quote indicates that blogging helps EFL teachers to connect with other teachers and to connect with their students regardless of distance and time differences. This finding corroborates the idea of Silvia (2015: 241). She found that blogging supported "collaborative professional learning among English teachers without any geographic and temporal barriers". In the present study, Prasetyo saw the potential that blogging has to offer to EFL teachers and students if one of them could not attend their class. The teaching and learning processes could continue by utilising blogging as a hub for teachers and students to communicate. Thus, blogging diminishes the barriers of space and time that may hinder teachers-to-teacher or teacher-to-student communication. 
The three benefits of blogging also demonstrate that blogging provides a means for EFL teachers to communicate on professional topics in English and to become knowledge brokers (De Moor \& Efimova, 2004; Lave \& Wenger, 1991; Luehmann, 2008) by sharing knowledge or ideas to people who have common interest in English language teaching and learning. In relation to the affordance of blogging for knowledge brokering, De Moor and Efimova (2004), Lave and Wenger (1991) and Luehmann (2008) claim that the use of blogging special features (i.e. hyperlinks, pictures) showed the extent to which someone becomes a knowledge broker. Luehmann (2008: 334) find that Ms. Frizzle (pseudonym), her case study participant, was a truly knowledge broker because she made full use of the blogging special features effectively. Ms. Frizzle used hyperlinks extensively to connect her audience with other blogs and online resources. Ms. Frizzle did not just make the links available but also offered her review on the strengths and weaknesses of the links by reflections on her own practice. The results of the present study on the extensive use and disuse of blogging special features appear to be consistent with those of Luehmann (2008). The present results show that an extensive use of blogging features without considering the effectiveness of those features tends to obscure the messages that the author wanted to deliver (see Subsection 4.2.2.1, Chapter Four). On the other hand, the blogging entries that did not use blogging special features did not always mean that the messages could not be delivered through the readers. The disuse and the ineffective use of blogging special features in the present study indicate that the three teacher bloggers had not realised the opportunities of becoming knowledge brokers offered to them by blogging. The present results also indicate that blogging has potential to allow its users to express themselves and share ideas to their readers. Van Lier (2000: 252) states:

In the forest a leaf can offer very different affordances to different organism. It can offer crawling on for a tree frog, cutting for an ant, food for caterpillar, shade for a spider, medicine for shama, and so on. In all cases, the leaf is the same; its properties do not change; it is just that different properties are perceived and acted upon by different organism.

Parallels to blogging can be similarly drawn. On the whole, blogging can offer EFL teachers a medium for L2 writing practice, a place to share knowledge and 
ideas, a place to connect with others, an online journal and so on. However, if the EFL teachers do not involve and engage actively, those affordances will dissipate easily.

This section has focused on the benefits of blogging, as perceived by EFL teachers and other educational stakeholders. The next section discusses barriers in using blogs: heavy workloads, demanding writing tasks and EFL teachers' poor L2 writing proficiency, and limited internet access.

\subsubsection{Perceived barriers to blogging}

The first and most frequently mentioned factor that hindered teachers' active participation in blogging was their heavy teaching loads and excessive additional administrative tasks they were responsible for at their schools. Three teachers and two stakeholders mentioned this issue. Waskito, one of the drop-out teachers, wrote:

It was a work-related issue in the beginning of the study. I am more than just a teacher. I am a staff member and a public relation officer too at school. I had a lot of tasks lately and I could not focus myself into the blog. I lost my concentration. I had not only some working problems but also a personal problem. The tasks from schools accumulate because I am a teacher, an administrative staff member, and a public relation officer in the same time. I finished my duty at school in the afternoon and later I still had to give private English courses until late at night.

This quote indicates that EFL teachers do not only teach at school, but also have various tasks as members of school organisation. However, the present study shows that the EFL teachers' time investment in blogging was often challenged by their teaching and administrative duties. Thus, these duties had been perceived as barriers for teachers to set aside time for blogging. This conclusion was supported by another drop-out blogger, Arum who said:

Every time you posted, sent links, I always downloaded. I saved. I copied. I read. They are relevant to the issues I face. I wanted to respond in any ways possible. At that time, I always printed them out and brought them wherever I went. I attempted to respond. I had so many duties. It was also the time for school examination. Well, I run out of my time. When I did have time to do the tasks, I was already exhausted. When I did have time, I was too shy because I had been late. I did want to continue writing. 
Waskito and Arum agreed that having sufficient time was significant for EFL teachers to be able to actively participate in blogging. Previous study shows that time investment in blogging is vital for a teacher-blogger to allow self-reflection and analysis of practice to happen, and is likely instrumental in maintaining her interest of blogging (Luehmann, 2008: 302). In the present study, the EFL teachers had a lot of duties and tasks both at school and outside school. Thus, they did not put sufficient effort into blogging, even though they knew the activity could help them acquire, maintain or improve their individual or professional competencies and their English proficiency through critical reading and reflective writing in the blog.

The present study shows that the EFL teachers' workloads, teaching and administrative duties, had kept them busy and could not find time to blog. The EFL teachers' inability to blog actively for not having sufficient time because of their workloads seems to be consistent with other research which found that time was one of substantial factors to integrate ICT in professional development. Widodo and Riandi (2013: 387) describe the teachers in their study were challenged by time arrangement and time utilisation. While the teachers in their study "were formally given one day off for TPD, many of them could not make use it because they were busy doing administrative tasks". In addition, Silvia (2015: 234) finds that time is one of three crucial elements of online TPD besides relevancy to professional needs and contextual content. In a similar vein, Luehmann (2008) argues that investments in terms of time and efforts and thoughtful choices of topics to write are substantial elements for teachers to achieve the most out of blogging.

Another barrier to blogging is the EFL teachers' perceived poor L2 proficiency. The teachers were reluctant to participate in blogging actively because they perceived that the writing tasks were demanding and they had insufficient L2 proficiency to do the tasks. Nana (one of the teacher co-ordinators) voiced her fellow teachers' and her own concern about blog writing in English. She apologised on behalf of her fellow teachers, who participated in the study, and provided a reason why they were reluctant to write in English. She admitted that many of her fellow teachers complained that writing blog entries in the present 
study was a highly challenging task. The reading and writing activities of the study were seen as a problem rather than an opportunity to develop professionally. She explained:

In writing English? I don't know. We are lazy. They, they complained about your programme. Goodness! What is it? Writing? So sorry about that.

I invited Mr Kaka (pseudonym) about a year ago. However, my colleagues said that it was not interesting topic. Well, the topic was about writing for journals. Well, you know, EFL teachers are expected to be able to write in English Maybe this is, I think this is a challenge for.... who is responsible for that? Well, I start to write but it was not easy. I have a lot of work to do. So many things to do.

This quote suggests that the EFL teachers resisted the ideas of blogging as a form of professional development. The reason behind their resistance is they had to write their blog entries in English. Nana admitted that blogging in English was not the only activity they resisted. Another professional development programme, in which English became the medium of writing for academic journals, was also perceived as challenging by the EFL teachers. Another professional development programme, in which English became the media of writing, writing for academic journals, was also perceived as challenging by the EFL teachers.

While it was expected that the EFL teachers would be able to read materials relevant to their field, critically review the reading, and write reflective blog entries on the issues raised in the reading, the idea to write in English, coupled with critical reading and writing engagement, had appear to make most of the EFL teachers who agreed to blog discontinued blogging. Only 3 out of 25 EFL teachers continued blogging until the end of the blogging intervention phase. This finding is contrary to that of Sun (2010) who found that blogging afforded bloggers to use language authentically and purposely and enhanced their writing proficiency. It appears that the demand to read and write critically in English when blogging demotivated most EFL teachers. It also appears that the EFL teachers' perceived English proficiency had discouraged them from writing in English rather than encouraged them to write in English.

The other barrier to blogging is limited access to internet connection. One of the drop-out teachers, Wulan, explained: 
The first reason why I quit blogging is ... you know when I blog actively, I need to be online all the time. I have to teach. I have a heavy teaching load. I can't focus in blogging. Secondly, I have no internet connection at home.

Wulan's quote suggests that access to internet is not always available at home. This situation impeded the teachers' possibility to participate in blogging. The issue of limited access to internet connection was also mentioned by one of the MoEC staff, Laksmi who said:

When in the border, very far away schools, for example, close to the, high to mountain or close to the beach. Internet is not easy to access. So they find difficulties to search everything dealing with this kind of media.

Wulan and Laksmi agreed that limited access to Internet connection had exposed EFL teachers to issue of becoming less enthusiastic to blog or to use ICT for their personal professional development. This finding matches that observed in earlier studies (Sari, 2012; Widodo \& Riandi, 2013) where limited access to internet was one of the barriers of online TPD in some parts of Indonesia. This finding also indicates that there have been a few significant changes took place to improve the limited internet connection in Indonesia since then. The barriers to blogging significantly obstructed the EFL teachers' participation and retention in blogging.

The finding on the inadequacy of supporting infrastructure appears to be consistent with data observed in earlier studies that investigated the integration of ICT in teachers and EFL teachers' professional development. Research on the use of ICT in professional development has been extensively done in Indonesia including the investigation of an online learning community or OLC (Sari, 2012), a Massive Open Online Courses (MOOC), Coursera, a virtual online platform (Silvia, 2015), and a dual-mode TPD that combines face-to-face sessions and online sessions (Widodo \& Riandi, 2013). The challenges for each study were diverse but one issue persists, the access to ICT, i.e. access to a stable Internet connection. (Sari, 2012; Silvia, 2015; Widodo \& Riandi, 2013) claim that supporting infrastructure was available but was not sufficient for teachers to carry out blogging integrated professional development. The results of the present study show that the integration of blogging to maintain and improve the EFL teachers' L2 proficiency and ICT skills was challenged by the access to Internet (see Subsection 4.2.2.3, Chapter Four) too. This result indicates that not much change 
has happened to improve the existing computer or internet-related facilities and infrastructure. While programmes to integrate ICT in TPD were encouraged, facilities and supports for the integration had not matched the programmes. This result has led us to ask a question on whether or not environment and needs analysis have been carried out prior to the administration of TPD to ensure the successfulness and effectiveness of the programme.

In this section, I have investigated the teachers' blogging experiences and behaviours, and the perceived benefits of and barriers to blogging. The findings show that the affordances of blogging may explain the EFL teachers' willingness or unwillingness to participate in it. Blogging was perceived as beneficial because it allowed EFL teachers to write in the target language (English), to share knowledge and ideas about teaching, and to connect with other EFL teachers or with their students. The factors that were perceived as inhibiting were heavy teaching and administrative loads, teachers' low English proficiency, and limited or no internet access.

The findings of the quantitative data analysis on the EFL teachers' blogging experiences and behaviours have prompted the present study to investigate closely the teachers' and stakeholders' personal views of blogging as a form of professional development. The mixed-methods approach helped me to uncover the reasons why the blogging study was challenged by high attrition rates.

An important lesson learnt from this experience is that an in-depth environment and needs analysis must be undertaken prior to conducting similar research in the future. This should be done in order to verify that the offered PD programmes represent the perceived (as well as objective) needs of the participants and are viable in the socio-cultural context, in which they are implemented. Furthermore, attrition rates could be reduced if clear goals and objectives are discussed and agreed on with the participants.

\section{Summary}

To conclude, the findings of the study of blogging as a form of professional development make an important contribution to our understanding of blogging as 
a personal professional development tool for EFL teachers. One of the key lessons learnt is that, if blogging as a form of professional development is to be used successfully in the Indonesian context, its benefits have to be assessed carefully and its barriers have to be mitigated systematically. Chapter Six will detail findings of the investigation into policies and practice of Indonesian EFL teacher development initiatives at the personal and institutional levels. 
This page is intentionally left blank 


\section{Chapter 6 Policies and Perceptions of Teacher Development}

\section{Introduction}

This chapter starts with an introduction that describes the aim of the study. Then, the methodology and results of the study are described. The chapter ends with a summary of the study.

\subsection{Purposes of the study}

The aims of the present study are to explore the existing TPD policy and implementation document and to investigate the EFL teachers' and stakeholders' views of TPD policies and practices. I frame my discussion using Farrell (2015) and Richards and Farrell's (2005) framework, institutional and individual professional development framework.

The research question in this chapter is "What institutional and individual teacher development initiatives are established to maintain and improve EFL teachers' L2 proficiency and ICT skills in Indonesia?" This question is subdivided into three subquestions:

1. To what extent do Indonesian TPD policy and implementation documents discuss institutional and individual teacher development for EFL teachers to maintain or improve their subject matter knowledge and ICT skills?

2. To what extent do the TPD policy and implementation documents are effective?

3. What do Indonesian teachers and stakeholders know and think about TPD policies and practice?

\subsection{Methodology}

Two sets of data were gathered to answer the research questions: the document data and the interview data. Both data are qualitative and are analysed using qualitative analysis data approach. The document data is analysed using the 
qualitative document analysis (QDA) (Altheide, Coyle, DeVriese, \& Schneider, 2010; Altheide, 1996; Altheide, Gray, Janisch, Korbin, Maratea, Neill, Reaves, \& Deman, 2001; Spalding, Zimmerman, Fruhauf, Banning, \& Pepin, 2010) and the interview data is analysed using the thematic analysis (TA) (Braun \& Clarke, 2006: 79; 2012). A major benefit of QDA is its ability to compare a number of different documents. The approach is expected to be able to investigate similar or different themes in the TPD documents. These themes, in turn, help to understand TPD policies and their implementation among teachers and stakeholders.

Similarly, TA is used to explore the results of interviews with teachers and stakeholders on views of TPD policies and practices. A detailed explanation of QDA is available in Subsection 6.2.1.3, this chapter. TA is explained further in Subsection 6.2.2.2.

The following subsections detail the data sets. The subsections also specify the participants of the interviews and data analysis of the document and interview data.

\subsubsection{Document data}

The document data comes from two resources: policy documents and implementation documents. In this study, policy documents refer to formal documents issued by the Indonesian government represented by the President of Indonesia, Ministry of National Education or MoNE that is now called Ministry of Education and Culture (MoEC), Ministry of Administrative and Bureaucratic Reform, or other relevant ministries. There are four policy documents explored in this study. They are:

1. Undang-undang Republik Indonesia No. 20 tahun 2003 tentang Sistem Pendidikan Nasional (UU Sisdiknas 2003) or the No.20 Year 2003 Law on National Education System,

2. Undang-undang Republik Indonesia No. 14 tahun 2005 tentang Guru dan Dosen (UUGD 2005) or the No.14 Year 2005 Law on Teachers and Lecturers,

3. Peraturan Pemerintah No. 74 tahun 2008 tentang Guru (PPG 2008) or the No. 74 Year 2008 Government Regulation on Teachers, 
4. Keputusan Menteri Pendayaan Aparatur Negara dan Reformasi Birokrasi No. 16 tahun 2009 tentang Jabatan Fungsional Guru dan Angka Kreditnya (KEMENPAN 2009) or the No.16 Year 2009 Ministerial Decree of the Ministry of Administrative and Bureaucratic Reform on Teachers' Position and their Credit Points/Teacher Decree.

The implementation documents are a Handbook of CPD and two annual work plans of School-Cluster Subject Teacher Working Groups. The details are as follows.

1. Buku Pedoman Pengembangan Profesi Guru Berkelanjutan tahun 2010 or the Handbook of Continuous Professional Development/CPD handbook.

2. Rencana Kerja Tahunan Musyawarah Guru Mata Pelajaran Sekolah Menengah Pertama (MGMP SMP) or the annual work plan of SchoolCluster Subject Teacher Working Groups at junior secondary school.

3. Rencana Kerja Tahunan Musyawarah Guru Mata Pelajaran Sekolah Menengah Kejuruan (MGMP SMK) or the annual work plan of SchoolCluster Subject Teacher Working Groups at vocational secondary school. All these seven documents are in Bahasa Indonesia and only relevant chapters, articles or sections of the documents were translated in to English. Having sufficient skills to translate the documents from Indonesian to English, I translated all the relevant documents myself.

\subsubsection{Teacher professional development policy documents}

The four policy documents were purposely chosen because they represent the different layers of laws and regulation of TPD policies in Indonesia. The description of the four policies and who they represent is described as follows.

The first law, the 2003 Law on National Education System represents the government or central government policy about education in Indonesia in general. The second law, the 2005 Law on Teachers and Lecturers represents the government or central government policy about teachers and lecturers. The third law, the 2008 Government Regulation on Teachers was issued by the central government and was addressed to teachers only. The fourth law, the 2009 Ministerial Decree on Teachers' Position and their Credit Points was issued by the 
Ministry of Administrative and Bureaucratic Reform and details four competencies Indonesian teachers must have. The first three laws were authorized by the President of Indonesia. The fourth document was authorized by the Minister of Administrative and Bureaucratic Reform. In a hierarchical way, the levels of the documents can be summarised as follows (see Figure 6.1).

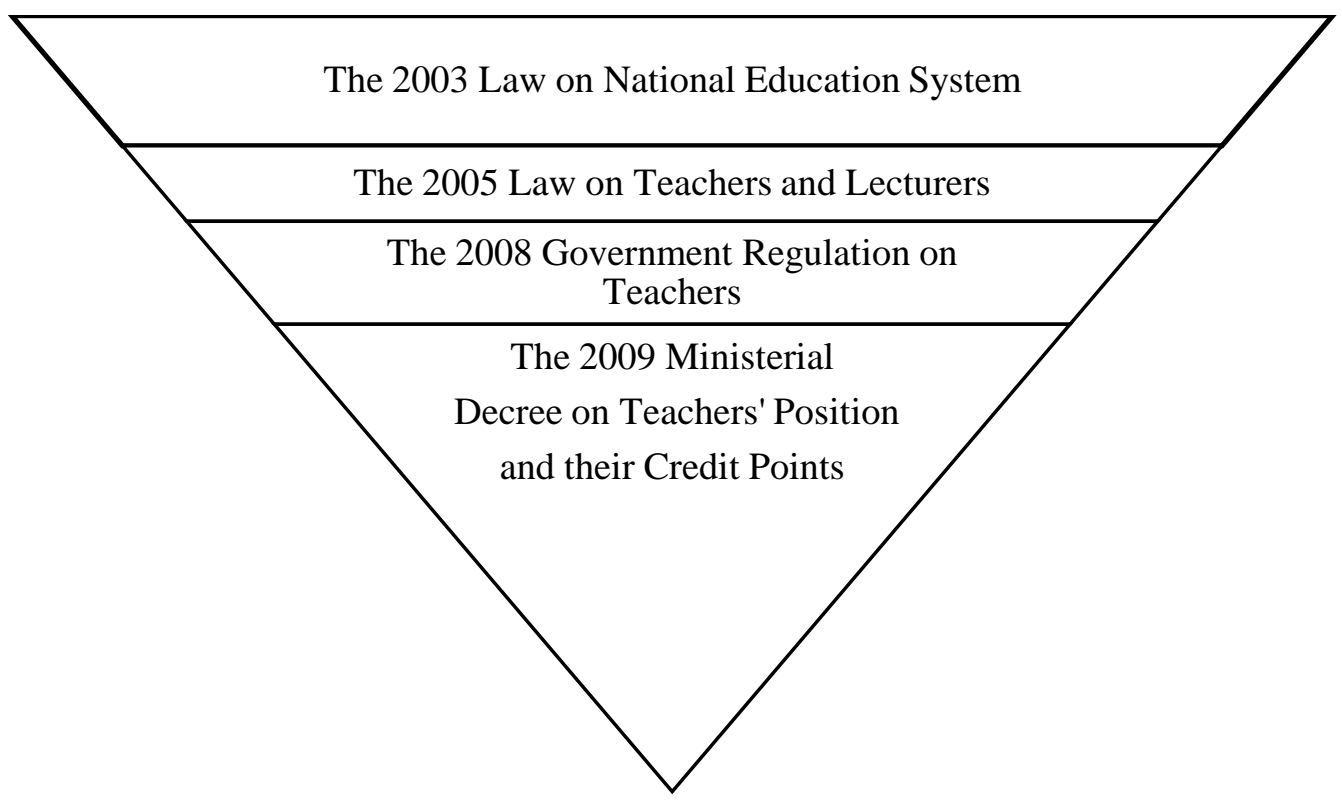

\section{Figure 6.1 Hierarchy of four policy documents}

Figure 6.1 shows that the 2003 Law on National Education System is the umbrella for the other policies. For example, the 2003 Law on National Education System discusses teachers and lecturers in general manners. A more detailed information of the teachers and lecturers' rights and obligations is given in the 2005 Law on Teachers and Lecturers. A more detailed information of teachers' qualification, competencies, certification, rights and obligation is provided in the 2008 Government Regulation on Teachers. The fourth policy document provides more detailed information of teachers' position and credit points. The lower the level of the policies, the more specific and targeted they are.

\subsubsection{Implementation documents of TPD}

The implementation documents are essential to understand how the policy documents are interpreted and implemented by the teachers and stakeholders. The first implementation document is the Handbook of CPD. It was published by the Directorate General of Educators and Educational Staff Quality Improvement that 
works under the MoEC. The format of the handbook is different from the policy documents because it is a guide book for teachers and stakeholders who want to understand what continuous professional development CPD is. It was written by a team of eight authors from four different institutions. They are four specialists from the Directorate of Educator Profession, two specialists from two universities, one specialist from the Centre for Development and Empowerment of Teachers and Educational Personnel, and one foreign consultant from Better Education through Reformed Management and Universal Teacher Upgrading (BERMUTU) programme, a World Bank project. The handbook also states that TPD is developed based on many laws including the 2003 Law on National Education System, the 2005 Law on Teachers and Lecturers, the 2008 Government Regulation on Teachers, and the 2009 Ministerial Decree on Position and Teacher Credit Point.

The annual work plans of Musyawarah Guru Mata Pelajaran (MGMP) or the School-Cluster Subject Teacher Working Group were created by the EFL teachers and were authorized by the head of MGMP. These documents provide secondary school EFL teachers with the planning activities in one academic year. They were obtained from the vocational school-cluster teacher working group and from the junior high school-cluster teacher working group. The annual work plan of the senior high school-cluster teacher working group was not represented because I could not obtain the document from the senior high school MGMP coordinator. Because letters of consents were not given by the MGMP coordinators, the annual work plans are not available in the appendix of this study. However, the details of the documents described below are expected to be clear to understand them.

Both annual work plans are in the form of a piece of paper with a title, a table and some information of who created and who acknowledged the documents. The table in each document informs what, when and how or where the TPD programme was administered. Some of the activities the teachers planned include a workshop of designing Listening skills teaching materials, a debate competition for teachers and students of vocational schools, a seminar about designing English for Specific Purposes (ESP) syllabus for vocational high schools, a workshop of 
creating lesson plans for junior high schools, a workshop on assessment, an outing, and other pedagogical related workshops, seminars or talks.

\subsubsection{Document data analysis}

This subsection highlights four important features that I used to analyse the document data: the description of the qualitative document analysis (QDA), the language curriculum (LCD) framework, the data coding, and an example of the data analysis.

A qualitative data analysis that is called as qualitative data analysis or QDA (Altheide et al., 2010; Altheide, 1987, 1996, 2000; Altheide, Gray, Janisch, Korbin, Maratea, Neill, Reaves, \& Deman, 2001; Spalding et al., 2010) was used to examine the existing TPD policies and the extent the policies reflect the demands for teachers to sustain or improve their English proficiency and ICT skills. The QDA approach is sometimes also referred to ethnographic content analysis or ECA. The QDA approach was used because it is dynamic and flexible. It is dynamic because it can track discourse by following certain issues, words, themes, and frames over a period of time, across different issues and across different news media (Altheide et al., 2010). The QDA is flexible because it uses a protocol — a way to ask questions of a document — that can be drafted, edited and revised to gain the most cogent reflections of social activities the protocol wants to capture (Altheide et al., 2010; Altheide, 1996).

However, because of its dynamic and flexible nature, QDA also has some weaknesses. Altheide et al. (2010: 149) stated that 'the emergent features of the research act make detailed replication very difficult.' QDA also sees that generalization is not its chief aim in investigating documents. In addition to that, Altheide et al. (2010: 138) also said that QDA investigated documents that usually projected a particular expression of culture and language, whose creators belong to specific communities, and whose audience was specific and changes continuously.

I also used the language curriculum design/LCD framework (Nation \& Macalister, 2010) to design the research protocols. While the LCD framework consists of three important features: environment analysis, needs analysis, and 
language teaching principles, this study investigated only the environment and need analyses of the documents. Both environment and needs analyses are essential because they help me to understand if the policy and implementation documents are appropriate and realistic. The third feature, the language teaching principles are not investigated because they are not discussed in the policy and implementation documents.

In the LCD framework, Nation and Macalister (2010) describe that the environment analysis consist of three aspects: teachers, student and situation. In the present study, the three aspects of environment analysis are instructors or teacher trainers, EFL teachers and context of TPD programmes. This environment analysis is essential because it helps to ensure that the EFL teachers will get the most out of the programmes they participate in. Nation and Macalister (2010) describe that needs analysis explores the second language learners or students. In this study, however, needs analysis refers to the analysis of the EFL teachers' necessities, lacks and wants. This needs analysis is important because it helps to recognise whether the TPD programmes administered are relevant to the needs of the EFL teachers.

To analyse the data, the documents were coded based on the categories they belonged to, main or implementation documents. For example, ' $\mathrm{P}$ ' code refers to policy documents and 'I' code refers to the implementation documents. ' 1 ' code refers to document number 1, the 2003 Law about National Education System and '2' code refers to the 2005 Law on Teachers and Lecturers, and so forth. Figure 6.2 showed that all the four documents were investigated by looking at how the documents reflected the environment analysis protocols. There are three elements involved in the analysis: the EFL teachers (EFLTs), the instructors (Is), and the situation of teacher professional development (S). Thus, 'P1.1' code refers to the analysis of the first aspect of the environment analysis (EFL teachers) in the No. 20 Year 2003 Law. Later, the data that came from different documents but under the same protocols were compared and summarised. Figure 6.2 provides an example of how the documents were being compared, summarised, and analysed. 


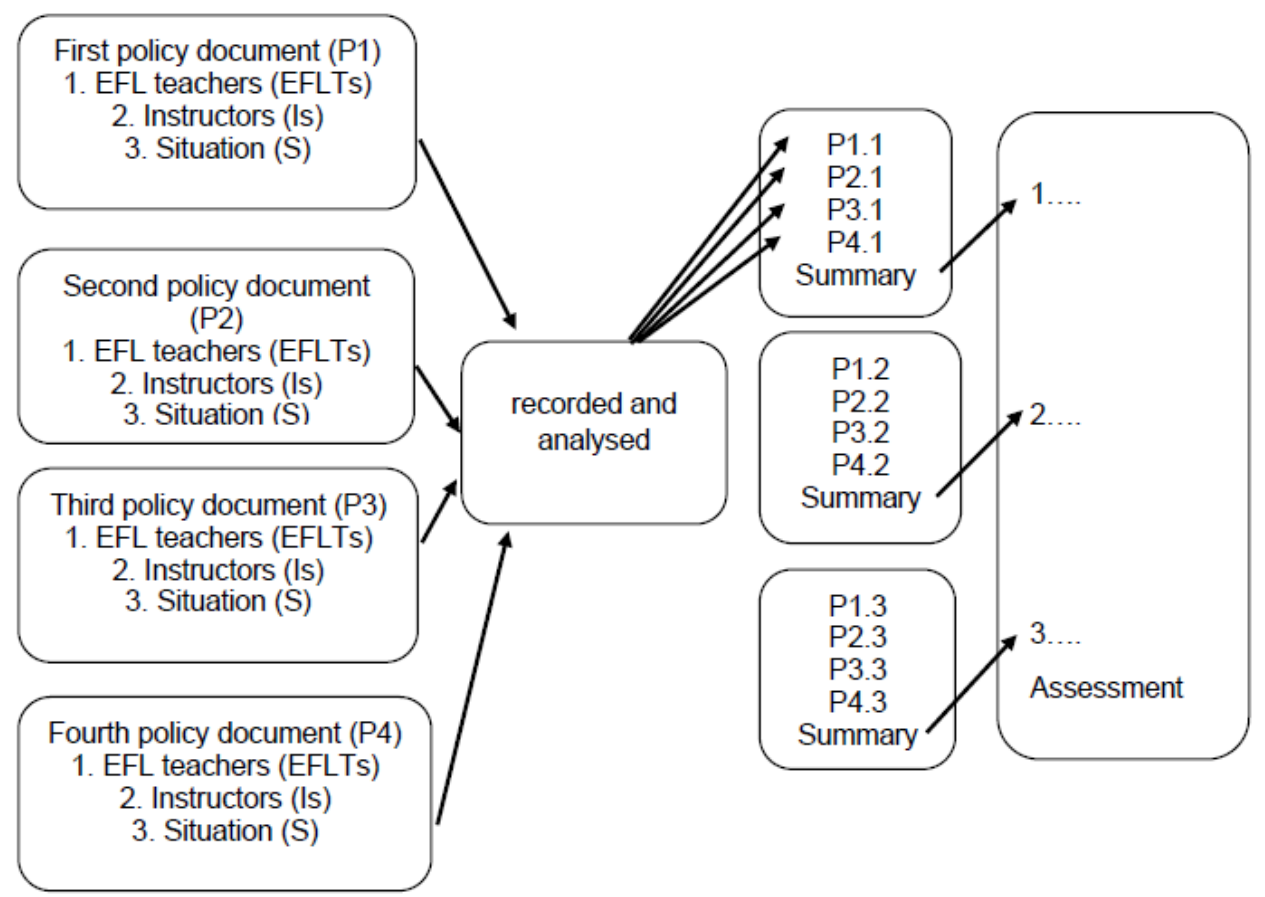

Figure 6.2 Comparing and summarizing document data

The fourth step led into the fifth step, the final overview of the study. This step aimed to understand how the policies of TPD and the stakeholders' and teachers' perceptions of policies and practices of TPD explain the EFL teachers' unsatisfactory L2 proficiency and low participation in the blogging study.

The following explanation provides an example of how the TPD-related policies were analysed. First step, to investigate whether environment analysis was present or not in the four policy documents, I gathered and analysed the documents. Second step, in the data comparison stage, I compared each element of the environment analysis of the first, second, third, and fourth policy documents by using some protocol questions. Some of the protocol questions I asked during the stage were: (1) "Is there any discussion of who the participants of the TPD programmes are?" (2) "Is there any discussion of who the instructors of the TPD programmes are?" (3) "Is there any discussion of how to administer the TPD programmes?" Third step is summarizing. Whether I obtained some answers of the questions or not, I summarised the results of the analysis. In the fourth step, the preliminary overview stage, I analysed the summaries of each element from 
the data comparison stage. For example, I summarised the analysis of the first element of environment analysis, students or EFL teachers, in the first, second, third and fourth policy documents.

To complete the investigation of teacher development practice among EFL teachers, the interview data about the EFL teachers and stakeholders' perceptions of TPD policies and practice is discussed.

\subsubsection{Interview data}

The interview data that I analysed in this chapter are the same interview data being analysed in Chapters Three and Five. This chapter highlights the interview data that is relevant to teacher development. The questions being asked of the teachers were also asked of the stakeholders. However, three questions (questions 14, 15 and 16) were only asked of the stakeholders (see Appendix 11). The question on the roles of teacher development have on teacher career progress (Question 4) was asked of the stakeholders. The question aims to examine how stakeholders see the relevance of TPD to teacher career advancement. Question 15 on format of teacher development and question 16 on rules during teacher development were asked of the stakeholders who usually administer the programme for teachers. Questions 1 to 17 were all used to interview the stakeholders and question 1 to 13 and 17 were used to interview the teachers.

\subsubsection{Participants}

To investigate the teachers and stakeholders' perception of the existing policies and the real practices of TPD in Indonesia, the data is drawn from interviews with the same participants as in Chapter Five (see Tables 5.1, 5.2 and 5.3).

\subsubsection{Interview data analysis}

The present study was driven by a research question on the teachers and stakeholders' perceptions of TPD policies and practices. The interview data that was analysed using a thematic analysis (TA) approach. TA is a process of analysing data by identifying, analysing, and reporting themes within the data (Braun \& Clarke, 2006: 79, 2012). TA was used because it provides systematic ways to identify and organise themes and offers insights into the meaning of the themes. 
The analysis was done by making myself familiar with the data, generating initial codes, searching for themes, reviewing potential themes, defining and naming the themes, and producing the reports (see Section 3.3.2, Chapter Three for detail explanation of the steps). After making myself familiar with the data by listening to the interviews, I transcribed all the interviews with the 20 participants.

A sample data from the interviews with a group of stakeholders, teacher trainers, were read and some initial general themes and codes were generated. Table 6.1 provides an example of how I generated preliminary codes from the interview with a stakeholder.

\section{Table 6.1 Data extract with codes}

\begin{tabular}{ll}
\hline \multicolumn{1}{c}{ Data extract } & \multicolumn{1}{c}{ Codes } \\
\hline $\begin{array}{ll}\text { Basically, when we see in the field, most of the time } \\
\text { teachers do not want to participate in the professional }\end{array}$ & $\begin{array}{l}\text { 1. Don't want to participate } \\
\text { in TPD }\end{array}$ \\
$\begin{array}{ll}\text { development programme. They rarely enrol for their } \\
\text { own sakes or on behalf of their profession to such }\end{array}$ & $\begin{array}{l}\text { 2. Lacked internal } \\
\text { motivation }\end{array}$ \\
$\begin{array}{l}\text { trainings. They usually wait for some invitations from } \\
\text { the provincial government or other governmental }\end{array}$ & $\begin{array}{l}\text { 3. Relied on government } \\
\text { funding. You know, it's free of charge. The central }\end{array}$ \\
$\begin{array}{l}\text { government pays for their trainings. For the } \\
\text { independent trainings, it is very unfortunate that they }\end{array}$ & to participate in TPD \\
rarely participate. That's not good. (Archie) & \\
\hline
\end{tabular}

These codes were later categorised and initial themes emerged from the patterns of these categorised data. The themes were later reviewed, defined and named the before the results were reported.

In the following section, the results of the document and interview data are described and discussed.

\subsection{Results and Discussion}

This section details the answers to the research questions on (1) the extent to which Indonesian TPD policy and implementation documents discuss institutional and individual EFL teacher development to maintain or improve their subject 
matter knowledge and ICT skills, (2) the extent to which the TPD policy and implementation documents reflect the environmental analyses and needs analyses frameworks, and (3) the perception of Indonesian teachers and stakeholders about TPD policies and practice.

\subsubsection{Maintaining L2 proficiency and improving ICT skills in the TPD documents}

The first research question (RQ1) is "To what extent do Indonesian TPD policy and implementation documents discuss institutional and individual teacher development for EFL teachers to maintain or improve their subject matter knowledge and ICT skills?" The answer to the question was not easy to find but the study shows that subject matter knowledge and ICT skills are addressed in the TPD policy documents in general manner.

In the following subsections, I will discuss two key findings from the data analysis of the policy and implementation documents on EFL teachers' L2 proficiency and ICT skills.

\subsubsection{Unspecific discussion of EFL teachers' $L 2$ proficiency}

All the policy documents and one implementation document explicitly discuss the needs for teachers to maintain or improve their subject matter knowledge (see Table 6.2). The table summarises the content and purpose of the policy and implementation documents. The content of the documents shows that while the four policy documents and the three implementation documents address the need for all teachers to maintain or improve their subject matter knowledge, they do not explicitly mention the need for EFL teachers to maintain or improve their English language proficiency. The purposes of the policies and of the implementation documents are similar to each other, providing regulations and guidelines for teachers in general to maintain and improve their professionalism.

The investigation of the TPD documents show that all policy documents discuss institutional and/or individual goals of teacher development in Indonesia, to maintain or improve teachers' subject matter knowledge. The 2003 Law on National Education states that one of the rights of educators and educational staff 
is to receive career development programmes that are administered based on the demand for quality improvement (Chapter 11, Article 40, Verse 1c). This law provides a general institutional goal of TPD where teachers are expected to improve their teaching quality.

In a more specific way than the 2003 Law on Indonesian National Education system, the 2005 Law on Teachers and Lecturers states that two out of eleven teachers' rights are (1) having opportunities to develop and improve their academic qualification and competencies and/or (2) participating in trainings and professional development relevant to their subject knowledge (Chapter 4, Section 2 , Article 14, Verses $1 \mathrm{j} \& 1 \mathrm{k}$ ). This law reveals that teachers have the rights to improve the individual aspects of their professionalism, i.e. academic qualifications, teaching competencies, and subject matter knowledge.

In the 2008 Government Regulation on teachers, the discussion about the needs for teachers to improve their subject matter knowledge becomes clearer. This document describes four competencies teachers are expected to have: pedagogical, social, personal and professional competencies. Professional teachers are expected to master concepts, teaching and learning methods, and technology or arts that conceptually embrace and are relevant to the subject matters, lessons, and/or the subject clusters they are going to teach. Similar to the previous two laws, this government regulation reveals that the Indonesian government requires teachers to address one out of six areas of individual professional development, subject matter knowledge.

My analysis shows that the Handbook of TPD as a guide for teachers and stakeholders to administer continuous TPD indicates that improving individual aspect of TPD is critical. This can be found in the Chapter One (introduction section) of the handbook where rationales of on-going TPD were justified and Chapter Two (concepts and implementation of on-going TPD) where theories of why on-going TPD is important and how to implement it were described (Direktorat Jenderal Peningkatan Mutu Pendidik dan Tenaga Kependidikan, 2010). The handbook also describes the needs for all teachers to improve their teaching competencies. The aims and the benefits of the TPD programme are 
described in the introduction section that also discusses and describes the goals and advantages of TPD for learners, teachers, schools, parents/society, and Indonesian government.

Table 6.2 Summary of documents analysis

\begin{tabular}{|c|c|c|c|}
\hline Policy documents & Purpose of document & $\begin{array}{c}\text { Subject } \\
\text { matter } \\
\text { knowledge }\end{array}$ & $\begin{array}{l}\text { ICT } \\
\text { skills }\end{array}$ \\
\hline $\begin{array}{l}\text { The } 2003 \text { Law on } \\
\text { National Education } \\
\text { System }\end{array}$ & $\begin{array}{l}\text { Provide basic laws of how to } \\
\text { administer education in Indonesia }\end{array}$ & $\sqrt{ }$ & $\sqrt{ }$ \\
\hline $\begin{array}{l}\text { The } 2005 \text { Law on } \\
\text { Teachers and } \\
\text { Lecturers }\end{array}$ & $\begin{array}{l}\text { Provide detailed laws of what } \\
\text { competencies teachers and lecturers } \\
\text { must have and how to administer } \\
\text { education in Indonesia }\end{array}$ & $\sqrt{ }$ & $\sqrt{ }$ \\
\hline $\begin{array}{l}\text { The } 2008 \text { Government } \\
\text { Regulation on } \\
\text { Teachers }\end{array}$ & $\begin{array}{l}\text { Provide detailed explanation of } \\
\text { what four competencies teachers } \\
\text { must have and their rights and } \\
\text { obligations }\end{array}$ & $\sqrt{ }$ & $\sqrt{ }$ \\
\hline $\begin{array}{l}\text { The } 2009 \text { Ministerial } \\
\text { Decree on Teachers' } \\
\text { Functional Position } \\
\text { and its Credit Points }\end{array}$ & $\begin{array}{l}\text { Provide detailed activities of } \\
\text { teachers and their credit points for } \\
\text { their functional position }\end{array}$ & $\sqrt{ }$ & $\sqrt{ }$ \\
\hline
\end{tabular}

\begin{tabular}{lll}
\hline $\begin{array}{l}\text { Implementation } \\
\text { documents }\end{array}$ & \\
\hline Handbook of & $\begin{array}{l}\text { Guide teachers and stakeholders to } \\
\text { administer continuous teacher }\end{array}$ & $\sqrt{ }$ \\
Continuous & professional development & \\
Professional & & \\
Development & & \\
\hline
\end{tabular}

\begin{tabular}{lll}
\hline Annual Work Plan of & Provide one year work plan for & - \\
Vocational High & ELT teachers of vocational schools & \\
School & & \\
\hline Annual Work Plan of & Provide one year work plan for & - \\
Junior High School & ELT teachers of junior high schools & - \\
\hline
\end{tabular}


The investigation of the other two implementation documents, the Annual Work Plans for vocational and junior secondary schools, focuses on only one aspect of individual teacher development, pedagogical competency. The discussion of the pedagogical competency in the two work plans is described as follows.

There are five similarities between the annual work plan for vocational high school and the annual work plan for lower secondary school. First, both documents described how many times the Musyawarah Guru Mata Pelajaran (MGMP) or School-Cluster Subject Teacher Working Group were going to meet, in which month, what they were going to discuss and some note on the venue of the meetings or whether the programmes had been done or not. Second, there was some information about the people in charge of the work plans. Third, neither document provided information on the rationales, goals, administration and evaluation for each of their programme. Fourth, neither document showed how the EFL teachers address the four competencies: pedagogical, personal, social, and professional competencies or which programmes that could address the four competencies. Lastly, no activities were designed and prepared for the members of the MGMP to improve their L2 competence and ICT skills in both annual work plans.

Besides having the similarities, the annual work plan for vocational high school and the annual work plan for lower secondary school have three differences. First, the vocational school's work plan has eight activities for one academic year. In contrast, the lower secondary school's work plan has fourteen activities in one academic year. The meetings for EFL teachers in lower secondary schools were more frequent than the meetings for EFL teachers in vocational schools. Second, the activities of vocational school's work plan were administered only in five months out of the 12 available months while the meetings in lower secondary schools were administered ten times in one academic year. Third, the activities covered in the vocational schools' TPD are improving teachers' competence, such as a workshop to create teaching materials for Listening skills, training to become debate competition adjudicators, seminar to design English for Specific Purpose (ESP) syllabus for vocational schools, and meeting to write and gather test items for students to practice prior to the commencement of National Examination. The 
activities in the secondary schools' TPD are various workshops on different themes such as analysing curriculum, assess learners' learning outcomes, and creating teaching media.

The similarities and differences of the two work plans show that they mostly aim to improve the EFL teachers' individual teaching skills and to achieve the institutional goal of their schools, better students' learning outcomes

Overall, these findings show that the needs for EFL teachers to improve their L2 proficiency are discussed in a very general manner in the TPD policy documents and in one of the implementation document. Terms in the documents, such as quality improvement, improve the quality of education, develop and improve academic qualification, participate in trainings and professional development in the teachers' fields, master concepts and teaching and learning methods suggest that EFL teachers and other teachers are obliged to sustain and/or improve their subject knowledge. For EFL teachers, improving their subject knowledge means that they have to improve their linguistics and metalinguistic knowledge. English language proficiency although the phrase English proficiency were not mentioned explicitly in those documents. The other implementation documents, the Annual Work Plans, do not discuss the idea of developing their English competence. In other words, while the four policy documents and the three implementation documents explicitly or covertly mention the need for all teachers to maintain or improve their subject matter knowledge, neither of the documents explicitly mention the need for EFL teachers to maintain or improve their English language proficiency.

Taken together, the findings from the document analysis indicate that improving English seemed to be overlooked by the TPD policies and implementation documents. In addition, unlike Vietnam which has agreed on the use of the CEFR to benchmark their EFL teachers' language proficiency with international framework (Dudzik \& Nguyen, 2015), Indonesia has not agreed on and established standardised benchmark of the EFL teachers' L2 proficiency. Thus, the existing TPD documents mainly describe and discuss general definition and the EFL teachers' L2 proficiency are not addressed. 


\subsubsection{Specific discussion of ICT skills in the documentation}

All the four policy documents and one implication document require all teachers to keep up with the development of knowledge in science, technology, and arts in the $21^{\text {st }}$ century (see Table 6.2).

The findings show that all four policy documents overtly mention the need for teachers to keep up with development of ICT. The first policy document, the 2003 Law on National Education System, states that the national curriculum of Indonesian educational system is created by considering 10 significant aspects of education in Indonesia, one of which is the development of science, technology and arts (State Secretariat of the Republic of Indonesia, 2003: Chapter 10, Article 36, Verse 3g). The second policy document, the 2005 Law on Teachers and Lecturers, Chapter 4, Article 20 says that teachers have an obligation to improve and develop their academic qualification, and competencies continuously. The efforts are done in the lights of keeping up with the development of knowledge. The third and fourth policy documents mention more specific points than the previous two documents on the needs for teachers to have ICT skills. The third document mentions the need for teachers to master information and communication technology (ICT) for teaching and learning (Chapter 2, Articles 4. 6 and 7). The fourth document states that one of the teacher obligations is to:

Continuously improve and develop their academic qualification and competencies to keep up with the development of science, technology, and arts.

Because they are all policy documents, they do not provide detailed explanation on what ICT knowledge or skills that teachers in general must possess and specifically EFL teachers must have.

The significance of ICT skills was also mentioned several times in the Handbook of CPD and were not mentioned at all in the Annual Work Plans. First, it is stated in the rationale of continuous TPD that a robust and comprehensive mastery of science and technology, teachers' strong characters, and quality teaching and learning experience would enable teachers to encourage their students to love science and technology (Direktorat Jenderal Peningkatan Mutu Pendidik dan Tenaga Kependidikan, 2010: 2). Second, it is mentioned in the benefit section of 
the handbook that teacher professional development (TPD) provides some assurance for teachers to master science and technology to face the $21^{\text {st }}$ Century during their career as teachers (Direktorat Jenderal Peningkatan Mutu Pendidik dan Tenaga Kependidikan, 2010: 7). Third, in the same handbook, mastering ICT skills is mentioned as one of the skills that teachers must master to reach particular standard and/or to improve their teaching profession (Direktorat Jenderal Peningkatan Mutu Pendidik dan Tenaga Kependidikan, 2010: 14). The other implementation documents, the Annual Work Plans for vocational and lower secondary schools, do not focus on improving the EFL teachers' ICT skills. Most of the activities in the work plans were mostly to improve the EFL teachers' pedagogical competence and improving the teachers' technology-related knowledge was not in the MGMP annual plan.

In brief, five out of seven documents that I investigated reflect the need for teachers to sustain or to improve their ICT knowledge so that they can keep up with the development of technology, especially teaching-related technology. It is urgent for those who are not familiar with the ICT skills to start learning them because the National Curriculum of Indonesia requires teachers to master them. The handbook shows that improving ICT skills are mentioned several times in the chapters. However, no further explanation is provided on the types of activities or rationales for EFL teachers to improve their ICT skills. In addition, while the annual work plans were designed by EFL teachers, the documents overlooked the need for EFL teachers to improve their ICT skills. The documents show that there are no workshops or trainings on improving ICT skills were available for teachers. Together these findings indicate that the affordances of ICT in TPD practices among EFL teachers is somewhat low. While the institutional policy perceives ICT skills are important for the teachers in general and EFL teachers in particular, the individual and local (school) practices reveal different patterns. Affordance (Gibson, 2015; van Lier, 2000: 252) refers to "a property of neither the actor nor of an object: it is the relationship between the two". It appears that the EFL teachers did not see significant affordances offered by having ICT skill courses or including ICT skill course in TPD practices. Although the policy documents mention that ICT skills are necessary for teachers, the EFL teachers did not see it 
the same way. Thus, the implementation documents of EFL teachers' TPD in Malang district Indonesia did not prioritise improving ICT skills in their activities.

Together, the findings discussed in this section show that L2 proficiency maintenance and ICT skills improvement receive insufficient attention in the policy documents and implementation documents.

The next section looks into the effectiveness of the TPD policy documents and the implementation documents using the environment and needs analysis framework (Nation \& Macalister, 2010). It also investigates the monitoring and evaluation aspects of these documents.

\subsubsection{Ineffectiveness of the TPD policies and implementation}

\section{documents}

The investigation of TPD policy and implementation documents that was conducted using the environment and needs analysis framework (Nation \& Macalister, 2010) shows that only one out of the seven documents investigated discussed the need for environment and needs analyses (see Table 6.3).

In the following subsections, I discuss three important findings of the document data analysis using Nation and Macalister's (2010) Language Curriculum Design framework, especially by investigating the environment analysis, needs analysis and evaluation aspect of the existing policy and implementation documents.

\subsubsection{Unacknowledged environment analyses}

Four policy documents and three implementation documents were analysed but only the Handbook of CPD that discusses environment and needs analyses. The environment analysis has three aspects: context, participant and instructor aspects of TPD (see 2.1.3, Chapter Two for more explanation on environment analysis). The handbook has an explicit explanation of the context aspect of the TPD programme and implicit explanation of the participants (student aspect) and instructor (teacher aspect) of the programme. 
Table 6.3 Summary of document analysis: Environment and needs analyses

\begin{tabular}{|c|c|c|c|c|}
\hline \multirow[b]{2}{*}{ Policy documents } & \multicolumn{2}{|c|}{$\begin{array}{l}\text { Environment } \\
\text { analysis }\end{array}$} & \multicolumn{2}{|c|}{$\begin{array}{l}\text { Needs } \\
\text { analysis }\end{array}$} \\
\hline & Yes & no & Yes & no \\
\hline 1. The 2003 Law on National Education System & - & $\sqrt{ }$ & - & $\sqrt{ }$ \\
\hline 2. The 2005 Law on Teachers and Lecturers & - & $\sqrt{ }$ & - & $\sqrt{ }$ \\
\hline 3. The 2008 Government Regulation on Teachers & - & $\sqrt{ }$ & - & $\sqrt{ }$ \\
\hline \multicolumn{4}{|l|}{ Functional Position and its Credit Points } & $\sqrt{ }$ \\
\hline \multicolumn{5}{|l|}{ Implementation documents } \\
\hline $\begin{array}{l}\text { 1. Handbook of Continuous Professional } \\
\text { Development }\end{array}$ & $\sqrt{ }$ & - & $\sqrt{ }$ & - \\
\hline 2a. Annual Work Plan of Vocational High School & - & $\sqrt{ }$ & - & $\sqrt{ }$ \\
\hline 2b. Annual Work Plan of Junior High School & - & $\sqrt{ }$ & - & $\sqrt{ }$ \\
\hline
\end{tabular}

The handbook explains two key points: the context in which TPD is situated and the reasons why the programme is urgent in the Indonesian teaching and learning context. Teachers are integral parts of the educational organisation at school. Thus, to be able to meet and keep up with the changes and uncertainty of the modern life, all organisations - including educational organisations like schoolmust use the learning organisation approach where everyone "recognises their common stake in the future of the school system and the things they can learn from one another" (Senge et al., 2000: 5). To realise the goal, the Indonesian government through the MoEC support teachers to develop their on-going professionalism. Thus, personally and/or collectively, teachers have to be supported to become parts of the learning organisation with full conscience, without forces from outside, and to develop their professionalism continuously. This finding support that of Richards and Farrell (2005) that point out institutional and individual teacher development would be successful if there was sufficient support from their institutions. The finding of the present study also further support the idea put forward by Harvey et al. (2010) on the need of schools support for a TPD programme to run successfully and continuously. This finding is also relevant to Adey, Hewitt, Hewitt, and Landau (2004) and Harwell (2003) 
ideas who argue that one of the requirements for a TPD programme to be effective is it is offered for an extended period of time and should not be a one-shot activity.

Two documents mention the participants of TPD programmes, the 2009 Ministerial Decree and the Handbook of CPD. The ministerial decree states that the learners in the CPD programmes are all teachers who are teaching at the nursery, kindergarten, primary schools, and secondary schools who work under the Ministry of Education and Culture (MoEC), Ministry of Religious Affairs (MoRA), and community based institutions (Direktorat Jenderal Peningkatan Mutu Pendidik dan Tenaga Kependidikan, 2010: 8). No information is available about the instructors of TPD in the ministerial decree.

The handbook generally mentions that the participants are all teachers in Indonesia but it does not explicitly discuss the instructor aspect of TPD programme. However, in the Concepts and Implementation section of the handbook, some resources for CPD activities are discussed. The resources of CPD are essential in the administration of TPD because they provide information about different people or institutions who can work together with the teachers in the continuous TPD. Three levels of resources are described in the handbook. The levels include the intra-school, inter-school, and beyond school resources (see Figure 6.3). The core circle is the intra-school resources that include individual teachers in the same school. The mid-circle is the inter-school resources that include same-subject teachers in the same district, province, or country or from different countries. The outer circle is the beyond school resources that include Pusat Pengembangan dan Pemberdayaan Pendidik dan Tenaga Kependidikan (PPPP-TK) or Centre for Development and Empowerment of Teachers and Educational Personnel, Lembaga Penjaminan Mutu Pendidikan (LPMP) or Educational Quality Assurance Institution, Lembaga Pendidikan Tenaga Keguruan (LPTK) or Tertiary Institution of Teacher Education, Asosiasi Profesi (Professional Association), and other TPD providers such as the Southeast Asian Minister of Education Organisation (SEAMOLEC) Regional Language Centre or (RELC), the Regional English Language Office (RELO) of the United States, the 
World Bank, and the Indonesian-based or foreign-based online training and education centres.

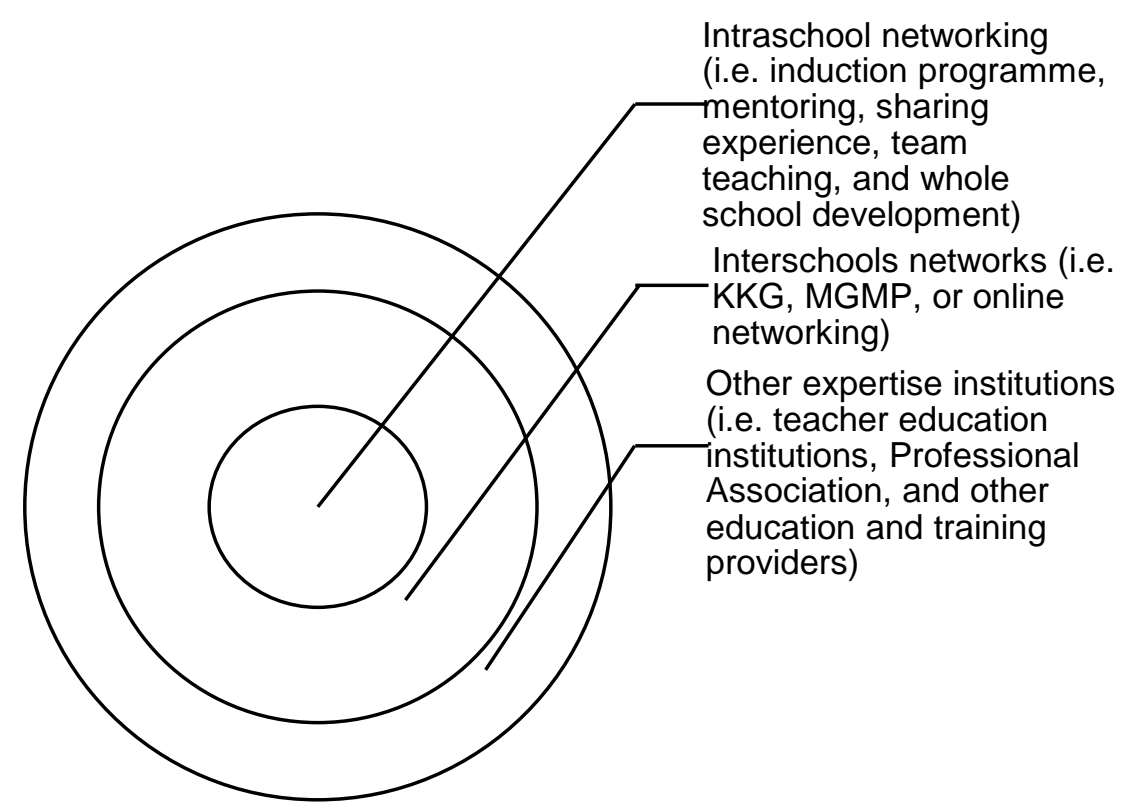

Figure 6.3 Resources of Continuous TPD

These three layers of resources show that teachers in general and EFL teachers specifically can work with their fellow teachers in the same school. They can expand the collaboration by working with teachers from other schools in the same school cluster or even with other teachers from faraway places through online networking. Ultimately, they can also work with expertise institutions that can help them to maintain and improve their professionalism as teachers by providing instructors that can share knowledge with the teachers. These institutions can provide financial support to fund the TPD programmes or non-financial support, i.e. instructors.

To summarise, most TPD policies and implementation documents do not explain the three significant aspects of environment analysis, situation, participants and instructors of TPD. Only one implementation document, the Handbook of CPD, provides explanation of the situation and participants of the professional development programme but it does not provide sufficient explanation of who should be the instructors of the programmes and what characteristics and qualities the instructors should have to train the EFL teachers. 


\subsubsection{Undervalued needs analyses}

Needs analysis is undervalued in most TPD policies and implementation documents. Only the Handbook of TPD details the importance of needs analysis, and the details were described in the mechanism of continuous TPD or stages of TPD (see Figure 6.4). The figure shows that there are nine stages of CPD. This section would discuss stages 1 to 6 because they are relevant to the issue of needs analysis. The first stage of the system allows teachers to administer selfevaluation of what they had done in the beginning and end of their school academic year. The second stage is the formative appraisal for the teachers. There is a form that the teachers have to fill to self-evaluate themselves. The form consists of some key points on (1) what the teachers have been doing to improve their competencies in the last twelve months, (2) what outcomes or effects they achieve from the activities, (3) what success they achieve during the previous academic year, (4) what challenge them in their duties, (5) what personal drawback/s, if any, they have, including some new skills they want to master, (6) what outcomes they know out of their induction and recent performance assessment, (7) what activities they plan for self-development in the coming academic year, (8) what activities they plan to refine their profile and credit points, (9) what independent activities they plan, (10) what activities they plan to do collaboratively with other teachers, and (11) what competence development they need and other assistance they need to achieve their goals.

The third stage is where the CPD coordinators and teachers discuss and plan the TPD programmes. In the fourth stage, the feedback and CPD plan are later brought by the TPD coordinators to the head of schools and MGMP coordinators. Then, they decide what TPD programmes to be finalized and realised. In the fifth and sixth stages, the teachers accept and participate in the programmes.

Stages 1 to 6 shows that needs analysis (Nation \& Macalister, 2010) is acknowledged by the Handbook of TPD. However, the other policies and implementation documents do not acknowledge the critical role that the needs analysis play in the EFL teachers' professional development. 


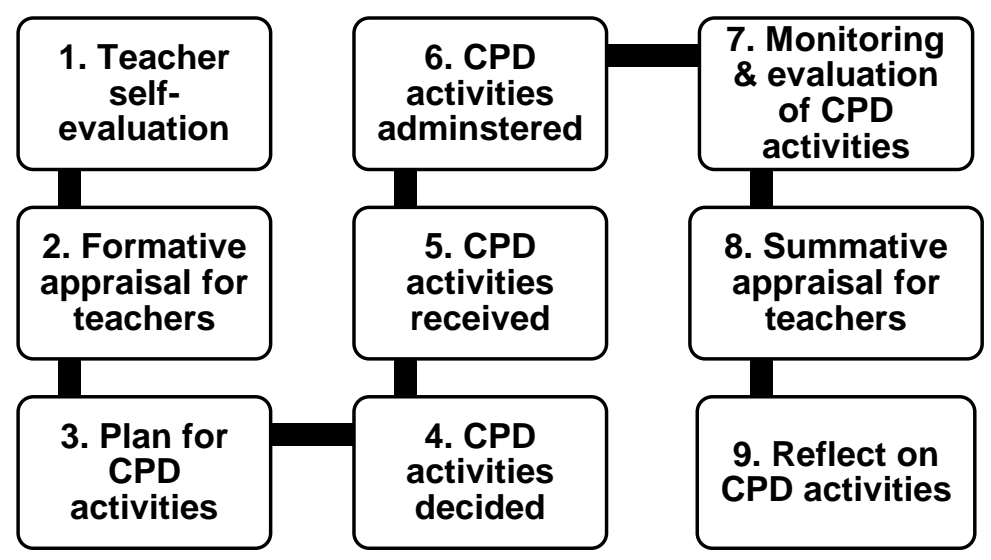

Figure 6.4 Stages of Continuous TPD

Stages 7 to 9 are explored in the next subsection that discusses monitoring and evaluation of TPD.

\subsubsection{Unrecognised TPD monitoring and evaluation}

The monitoring and evaluation of TPD was unrecognised in most of the TPD policies and implementation documents. Only one implementation document, the Handbook of Continuous TPD Information, discussed how to monitor and evaluate TPD (see Figure 6.4). Stages 7 to 9 show the monitoring and evaluation of continuous TPD. The handbook explains that the monitor and evaluation are aimed to assess both the programmes (Stage 7) and the participants (Stage 8) of TPD.

The monitoring and evaluation stage seeks to find answers of five questions on: (1) whether or not the TPD programmes are in line with the teachers' formative assessment administered by their school coordinators and teachers' selfevaluation, (2) whether or not the programmes effective and what problems challenge them, (3) the benefits of TPD are, (4) the implementation of TPD in the classroom practices, and (5) the accountability and the continuity of the programmes.

The summative appraisal for teachers is done by the municipal and MGMP coordinators (Stage 8). The evaluation for the teachers is given in the form of credit points which will be accounted for the teachers' future positions, tasks, rewards, or penalties. Finally, Stage 9 requires teachers and TPD coordinators to reflect on what they have done during the TPD programme, whether or not the 
programmes beneficial to sustain or improve their pedagogical, professional, social, and personal competencies.

While previous studies show that the three aspects of TPD discussed in this section are crucial (Nation \& Macalister, 2010; Sari, 2012; Widodo \& Riandi, 2013), this study shows that only one out of seven documents address the exigency of environment analysis, needs analysis, monitoring and evaluation for the existing TPD programmes. Hence, the TPD documents and implementation documents are ineffective to address the institutional aspect of TPD (institutional development) and the personal aspects of TPD (language upgrading and improve subject matter knowledge).

In the next section, I would look into the EFL teachers and stakeholders' views of TPD concepts, practice and policies.

\subsubsection{Uneven knowledge about concepts, policies and practice of $T P D$}

The third research question (RQ3) is "What do Indonesian teachers and stakeholders know and think about TPD policies and practice?" Four threads of important findings emerge from the interviews with the EFL teachers and stakeholders on their knowledge of the TPD-related policies and their practice.

The four threads are the EFL teachers and stakeholders' mixed concepts of goals and definition of TPD, various ideas of administering TPD, unclear concept of TPD evaluation and imbalance benefits and challenges of TPD. The findings are reported in the order of the most agreed to the least agreed by the teachers and stakeholders.

\subsubsection{Mixed concepts of teacher development's goals and definition}

Investigating the teachers and stakeholders' understanding of goals and definition of TPD are significant for two reasons. First, the teachers and stakeholders' understanding of TPD goals and definition may reflect their knowledge of the TPD policies and implementation documents available in Indonesia. This is so because two documents (the No.19 Year 2009 Ministerial Decree and the Handbook of Continuous TPD) have a working definition of teacher professional 
development (see Table 5.4). Second, the teachers and stakeholders' understanding of goals and definition of TPD and TPD documentation can determine the level of knowledge of administration, evaluation, benefits, and challenges of TPD.

In response to the interview question on what the goals and definition of TPD, the EFL teachers and stakeholders appeared to be confused of the two concepts. Thus, this subsection discusses issues on goals and definition of TPD and concludes with implications of the findings to the institutional and individual aspects of teachers' professional development.

There are three categories of the EFL teacher and stakeholders' answers of TPD goals: improving competency and language proficiency, aligning teachers' individual professional development to the 2015 ASEAN Community Scheme, and preparing teacher to carry out teacher online appraisal system that started in 2015.

Most of EFL teacher and stakeholders reported that the goal of TPD programmes was to improve the teacher quality by improving their four teaching competencies but there were variations in their answers. The four teaching competencies mentioned in the 2008 Government Regulation on Teachers are pedagogical, personal, social and professional competency (State Secretariat of the Republic of Indonesia, 2008). Improving two out of four teaching competencies is the most common answers the teachers gave when they were asked about their purpose of participating in the TPD programmes.

Improving the teachers' pedagogical competency was the most mentioned goal of TPD. An example is provided by Dada, a teacher coordinator, who said:

To me, PD is a programme, it is a kind of programme where we can upgrade our professionalism in English proficiency and in turns it must give effects in the improvement of our quality in teaching English. Improvement can be in many formats; the formats can be proficiency, improving pedagogical skills, and use of information and communication technology (ICT) or in teaching process. 
The second most mentioned competency mentioned by the EFL teachers and stakeholders was language proficiency or professional competency. One teacher educator, Cahaya, said:

The goals of TPD are to improve the competencies of teachers. It will also indirectly help teachers to improve their English proficiency. I believe that English proficiency should receive the same proportion of priority in TPD besides the pedagogical skills. I saw that teachers' proficiency is in a serious problem.

This quote suggest that the teachers' English proficiency should receive the same attention as their pedagogical competency. This idea is consistent with Richards and Farrell's ideas (2005) on the urgency for second language teachers to have sufficient subject matter knowledge and pedagogical expertise. Another support is provided by Wulan, a teacher, who described:

Professional development for teacher is a programme where teachers are able to develop their teaching ability, academic ability or language proficiency. They participate in seminars or trainings and write articles. These activities are authentic tests of professionalism. I believe that teachers' duties are not only teaching but also developing knowledge. As language teachers, ones just could not stay in one place. They must have additional values. There are many ways to develop themselves.

Overall, out of the four competencies that teachers must have: pedagogical, personal, social and professional competency (State Secretariat of the Republic of Indonesia, 2003), this study finds only two competencies: pedagogical and professional competencies that were addressed in the TPD programmes. These findings also indicates that three out of the six areas of individual professional development (Richards \& Farrell, 2005), subject matter knowledge, pedagogical expertise and understanding curriculum and materials were acknowledged by EFL teachers and stakeholders.

While all the teachers and stakeholders believed that TPD helped teachers improving the teachers' pedagogical competencies, only two stakeholders, Cahaya and Prasetyo, mentioned that the goal of TPD was to face the enactment of the 2015 ASEAN Community scheme that demands Indonesian national education quality to conform to the ASEAN educational standard (ASEAN Secretariat, 2009; Widiati \& Hayati, 2015). They mentioned that it was imperative for teachers to have good command of English and robust ICT skills to face the 
challenge of 2015 ASEAN Community Scheme, i.e. aligning Indonesian educational standards to the ASEAN standards. Prasetyo, a teacher trainer, said that the ASEAN community has become a recent issue within Southeast Asian countries. He believed that the Indonesian government had to focus on improving the Indonesian teachers' ability to compete with other teachers from other Southeast Asian countries. He said:

With the introduction of the ASEAN Community, Indonesian teachers can teach in other ASEAN nations. Likewise, the teachers from other ASEAN nations can also teach in Indonesia. The keyword in this scheme is competition and the keyword to be able to compete is competence. Well, if Indonesian teachers do not have the necessary competencies and they have to compete with other teachers from ASEAN. In other words, these teachers (from other ASEAN countries) will be in Indonesian classrooms because our teachers are incapable of teaching. The Indonesian government has to see this situation.

On the teachers' skills to master information and communication technology for teaching, Prasetyo further explained that Indonesian EFL teachers should not only master English language but also master ICT-based skills. He again emphasized the urgency for teachers to be proficient in English, ICT-skills, and other subjects, across curriculum to be able to compete in the Southeast Asian level. These findings match those observed in earlier study on institutional teacher development in Indonesia (Widiati \& Hayati, 2015). Widiati \& Hayati (2015) find that one of the institutional goals of TPD in Indonesia is for EFL teachers to be able to collaborate and communicate in English with their students and other teachers in Southeast Asia. Thus, they suggest that teacher education in Indonesia be more explicit in the integration of ASEAN curriculum in its curriculum.

The third reason why ICT skills are necessary for EFL teachers' professional development is the introduction of online teacher assessment in Indonesian teacher appraisal system in 2015. The goal of this online assessment is to support the Indonesian educators and educational staff to master information technology, internet (Padamu Negeri Indonesiaku, nd). Thus, knowing and understanding how to work on and with Padamu Negeri Indonesiaku system is urgent for all teachers. Only one stakeholder mentioned that TPD was aimed to help teachers to engage actively in the recent online teacher appraisal system in Indonesia. The stakeholder, Archie, a staff at the District Ministry of Education, described that 
teachers had to master ICT-based skills because the necessity for teachers to report online in the near future. He said:

At the moment, an online application is being introduced. It is still in its pilot stage. It takes some time to introduce the application to teachers because there are some ICT problems surface. It is hoped that everything relates to the improvement of teachers' quality is reported online to the Ministry of Education in Jakarta. I am one of staff who is responsible to administer the programme. It is called PADAMU NEGERI application. PADAMU NEGERI stands for Pangkalan Data Penjaminan Mutu Pendidikan Negara Kesatuan Republik Indonesia (the Indonesian Education Quality Assurance Database).

He further explained that this online report was administered because the Indonesian government through its Ministry of National Education (MoNE) wanted to crosscheck that the reports submitted by the principals and teachers completed each other. He also said that there had been some indications that what was reported by the teachers and principals did not reach the Ministry of National Education. Thus, a more direct means of communication becomes essential. This is where ICT skills becomes very significance because teachers will not be able to report online to the central government unless they are well-equipped and welltrained in technology. This is rather sad because the previous study on blogging, Chapter Five, showed that the ICT-based activity, blogging, was lacking participants and the interviews and questionnaire showed that the teachers' ICT skills were rather poor.

The EFL teachers and stakeholders defined TPD as improving teachers' four teaching competencies and activities to improve professionalism. The first definition overlaps with the goals of TPD and has been discussed in the beginning of this subsection. The other definitions of TPD are discussed as follows.

Several teachers and stakeholders defined TPD as the teachers' participation in MGMP, seminars, workshops, trainings and courses. They mentioned various materials that teachers learn from the activities. They include understanding new curriculum, improving teaching techniques, designing lesson plans, learning ICT skills, sustaining language proficiency, designing classroom action research (CAR), and other issues relevant to teaching and learning. An example of a teacher's definition of TPD was given by Bintang. She said: 
...the examples of activities during the MGMP meeting are learning about the 2013 curriculum, designing test items for the National Examination. You know, it's like what you did. So we have a speaker, an expert, and we learn some new information from the speaker.

Another teacher, Agni, give a similar definition by saying:

Professional development can be done through MGMP meeting. In the meeting we can talk and share knowledge about new curriculum, design lesson plans or practice to write classroom action research.

These findings indicate that the EFL teachers and stakeholders understood and defined TPD as various activities to enhance their teaching skills such as learning about new curriculum, designing lesson plans or sharing knowledge. These quotes also indicates that two out of the six areas of individual professional development (Richards \& Farrell, 2005), pedagogical expertise and understanding curriculum and materials were acknowledged by EFL teachers and stakeholders.

One teacher and one stakeholder defined TPD as an opportunity for teachers to further their study in the postgraduate programmes through Indonesian government-based scholarship and one stakeholder defined TPD as the efforts that the teachers did to gather evidence of their teaching and learning activities. Mita (a teacher) and Wiwid (a teacher trainer) perceived TPD as taking post-graduate study. Mita said:

Sending teachers to higher education. However, I do not agree with the idea of sending teachers to post graduate studies. Twice I rejected the offer to study in postgraduate studies because the university does not offer applied linguistics programme. I find that the programme is the most applicable one. I don't want to chase for position and status only. I did some classroom action research and I was supported by my institution.

The quote shows that taking post-graduate degree through scholarship was seen as a professional development effort too. While Leung (2009) and Richards and Farrell (2005) do not discuss taking post-graduate degrees as one of the areas of individual professional development, upgrading teachers' academic qualification through post-graduate studies addresses all the six areas of individual professional development. By taking post-graduate studies, EFL teachers are expected to improve their subject matter knowledge, pedagogical expertise, self-awareness, understanding of learners, understanding of curriculum and materials and to advance their career. 
Still another stakeholder defined TPD as the efforts that the teachers made to gather evidence of their teaching and learning activities. For example, Faizal, a vice principal, was somewhat bewildered when being asked about professional development before providing details of what the teachers could do in the programme. He said:

We obey the rules just like the civil servant teachers. We have to gather a kind of portfolio that includes some proof of our academic writing, product of innovative teaching media, and certificates of development including certificates during participating or presenting in seminars and in trainings. I understand that teacher supervisors also require us to submit all of them. It is compulsory for us to submit lesson plans, teaching media, scoring rubrics and other relevant rubrics and many more.

The illustrations showed that the concept of TPD was sometimes perceived in academic (furthering studies) and practical (following the rules and obligations) ways by some teachers and stakeholders.

The definitions provided by the participating teachers and stakeholders showed that some of them were not familiar with the given definition as written in the TPD-related documents, such as the 2009 Ministerial Decree and the Handbook of Continuous TPD (see Table 6.4). They also appeared to be confused of the definition and the goals of TPD.

Together, the findings show three key points. First, the institutional goals of TPD in Indonesia are to enhance teacher professionalism through on-going professional development and to improve the students' learning outcomes. This finding is consistent with the three areas of institutional professional development suggested by Richards and Farrell (2005): institutional development, career development and enhanced levels of students learning.

Second, the goals of TPD as perceived by the teachers and stakeholders are relevant to the objectives of professional development written in the 2009 Ministerial Decree and the Handbook of CPD. In general, the EFL teachers and stakeholders understood the aims of TPD programmes. The Handbook of CPD describes that TPD has two goals, general and specific goals (Direktorat Jenderal Peningkatan Mutu Pendidik dan Tenaga Kependidikan, 2010: 6). The general objective of TPD is to improve the quality of education by improving the quality 
of educational service at schools. The end goal of this objective is to better the students' learning outcome. This general objective is operationalized into four specific objectives (see Table 6.4). The table shows that the three goals of TPD perceived by the teachers and the stakeholders are relevant to the objectives of TPD in the Handbook of CPD and the ministerial decree. Only one objective of CPD that was not acknowledged by the teachers and the stakeholders. These findings indicate that EFL teachers in Indonesia are aware of the institutional goals of TPD.

Table 6.4 Goals and definitions of TPD

\begin{tabular}{|c|c|}
\hline \multicolumn{2}{|l|}{ Goals of TPD } \\
\hline $\begin{array}{l}\text { Interviews with the } \\
\text { EFL teachers \& } \\
\text { stakeholders }\end{array}$ & $\begin{array}{l}\text { - } \quad \text { Competency and language proficiency } \\
\text { - } 2015 \text { ASEAN Community scheme } \\
\text { - } \text { Online teacher appraisal system in } 2015\end{array}$ \\
\hline $\begin{array}{l}\text { The } 2009 \\
\text { Ministerial Decree }\end{array}$ & - Develop teachers' professionalism \\
\hline $\begin{array}{l}\text { The Handbook of } \\
\text { Continuous TPD }\end{array}$ & 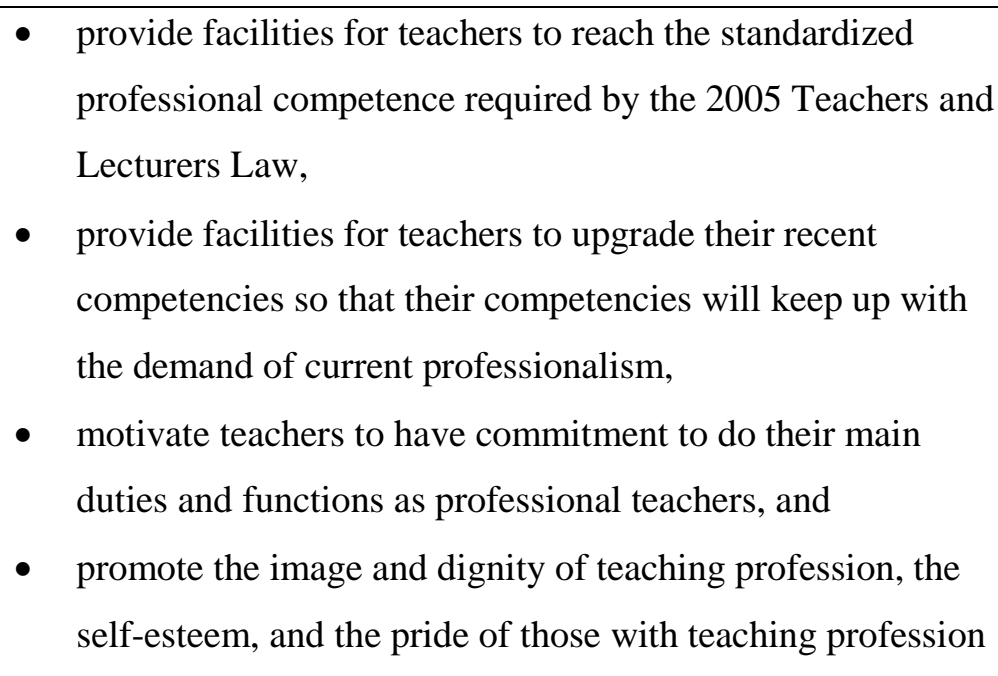 \\
\hline \multicolumn{2}{|l|}{ Definition of TPD } \\
\hline $\begin{array}{l}\text { Interviews with the } \\
\text { EFL teachers \& } \\
\text { stakeholders }\end{array}$ & $\begin{array}{l}\text { - Improving teachers' four teaching competencies } \\
\text { - } \\
\text { - } \\
\text { Oarticipation in professional development activities } \\
\text { gathering teaching portfolio) }\end{array}$ \\
\hline $\begin{array}{l}\text { The } 2009 \\
\text { Ministerial Decree }\end{array}$ & $\begin{array}{l}\text { - teacher competence development that is administered } \\
\text { continuously when needed and is carried out in different } \\
\text { stages of teachers' teaching service }\end{array}$ \\
\hline
\end{tabular}




\begin{tabular}{lll}
\hline The Handbook of & $\bullet$ & a continuous learning process for teachers \\
Continuous TPD & $\bullet$ & a primary medium for teachers to help their students to \\
& attain success \\
\hline
\end{tabular}

Third, the definitions of TPD as perceived by the teachers and stakeholders are mixed up with the goals of TPD and the definitions they gave are not relevant to the definition of TPD in the 2009 Ministerial Decree and the Handbook of CPD. These findings suggest that the EFL teachers and stakeholders might not be aware of the difference between goals and definition of TPD. These three key points demonstrate that a mismatch between written TPD policies and EFL teachers and stakeholders' understanding is likely to happen because of various reasons including their unfamiliarity with the policies. Thus, there is also a possibility for EFL teachers and stakeholders to have different ideas on the other aspects of TPD, such as administering TPD.

\subsubsection{Various ideas of administering TPD}

Data analysis shows that there are six key aspects of administering professional development programmes for teachers. They are (1) the teacher participation, (2) the funding, (3) the learning materials, (4) the instructors, (5) the formats, and (6) the venues of the TPD programmes.

Those six aspects are essential because they are the reasons why environment and needs analyses have to be done prior to TPD programmes (Nation \& Macalister, 2010; Sari, 2012; Widodo \& Riandi, 2013). Without some vigorous environment and needs analyses, it is not easy to determine the constraints of the programmes and the necessities, lacks and wants of the teachers. Lacking knowledge of the constraints and needs of the EFL teachers, instructors and situation may mean that assessing the success of the programme and evaluation is hard to achieve. Thus, the interviews were used to investigate the EFL teachers and stakeholders' perceptions of how to carry out professional development. The first aspects I am going to discuss are participation and funding aspects.

This subsection discusses the participation of EFL teachers and the funding issue in the same frame because teachers' participation is usually closely linked to the 
availability of funding (Widodo \& Riandi, 2013). This subsection describes findings about EFL teachers' participation of TPD and financing TPD from the interview data and compares these findings to the policies and implementation documents.

Generally, the EFL teachers' participation in government-initiated TPD depends on the permission they received from the heads of schools or top-down. The teachers participated in the TPD programme if they received invitation from the District Ministry of Education or the MGMP coordinator or were appointed by the head of school. In the provincial and national levels, the government through the Head of District Ministry of Education, principals, or head of MGMG decided who should go and participate in the trainings or workshops. The administrators of TPD would send invitation to schools and the heads of schools would appoint one of the available teachers to participate. One of the teacher co-ordinators, Dada, said:

For some schools, the policy of their principals in these events is different. Some principals always appoint a particular person to attend the event. There was no chance for other teachers to attend to our event. That would be beyond my control.

In addition, Dada also mentioned that the TPD funding came from the government and to be able to acquire the fund, the EFL teachers had to write a proposal. This top-down policy poses problems, such as, the teachers' dependency towards the government-based funding TPD, unmatched need and funding, and a privilege for only a few teachers received to participate in the TPD programmes.

Some teachers did not want to participate in the teacher development programme unless some available funding was available for them. Tiara, one of the teachers, said:

TPD has something to do with the funding. There were some expenses for meal and transportation and only the expenditure of one teacher was tackled by the association. The other teachers from the same school have to pay for themselves.

This quote shows that the top-down policy has made EFL teachers relied on the government-based funding to participate in the TPD programme. The funding also appears to make EFL teachers relied on the government heavily and prevented them from being more independent and self-reliant. This finding resonates the one 
claimed by Widodo and Riandi (2013: 389), where "teachers are unlikely to participate in TPD unless it is formally required and financial support is provided".

Without necessary needs analysis, even if funding were available for EFL teachers to use, the results of the TPD programmes would not be as efficient if the analysis was done. Prasetyo, one of the teacher trainers, said:

The policy is a top-down one. It is just a project. The programme is usually not in line with the teachers' needs. So, there was some funding but there was no need assessment. I believe if both (funding and need assessment) are combined, the results will be great. Well, we have the funding. Then, we have to do the needs analysis. They will be good. What happened now is that we have the funding but the programme does not address the teacher's needs. Or the teachers need to learn something but the funding is not available.

This quote reveals that both funding and needs analyses are essentials part of effective professional development (Adey et al., 2004; Widodo \& Riandi, 2013). The heads of schools sometimes only appointed their favourite teachers to be sent in the programme. Dada, one of the MGMP coordinator, said:

... For some schools, the policy of their principals in this event [TPD] is different from one to another. Some principals always appoint a particular person to attend the event. There was no chance for other teachers to attend the TPD programme.

It is very unfortunate that the seminars and workshops held by the district, provincial or central government allowed only some selected teachers to participate. Thus, only a few teachers received the privilege to always participate in the TPD programme held by the government. However, in a few exceptional cases, some teachers self-nominated themselves to participate in the TPD programmes although they had to finance themselves. It is expected that there would be more self-motivated and self- reliant teachers in the near future so that they can sustain and improve their professionalism with or without support from the government (Widodo \& Riandi, 2013).

The funding used in the programme might come from different sources. The funding for TPD may come from the government, school, or personal fund. The interview data suggests that the institutions invited or sent the teachers to the 
programme were responsible for the funding. For example, if a school, through its head of school, sent a teacher to a TPD programme outside their school, the school was responsible for the accommodation and transportation fees for the teacher. If it was the teacher' initiative to participate, she/he had to wait for a permission from the head of school and might have to use her/his own fund to attend the programme. Dada, one of the teacher coordinators, stated that schools provided financial support for teacher development although the principals' decision on whom being sent was the uncontrollable part. He said:

In general the support is fine, good. Whenever we want to attend seminars and workshop, many schools want to supports the event. They provide the venue, they provide the meals. What we can't control is the policy of each school to appoint one person only and not just that one.

While some schools seemed to be very supportive, the District Ministry of Education was seen as rather unsupportive by one of the stakeholders, Nana. She reported that the institution had slow response to disperse fund for the teacher development. She emphasized that the teachers had to use their own fund and that there was no support was available for junior high school teachers from the government either.

All the four policy documents and one implementation document discuss the sources of funding for TPD. However, only the Handbook of TPD that discuss the issue in details. A general statement about the obligation of the government and local government to fund education in general and teachers more specifically can be found in Verse 3, Article 41, Chapter 9 on Educators and Educational Staff, of the 2003 Law on National Education System. It states that the government and local government are responsible for providing facilities for Indonesian education, educators, and educational staff to ensure the quality of education in Indonesia. A more detail explanation than the previous law is available in the 2005 Law on Teachers and Lecturers. Verse 3, Article 34, Section 5 on Trainings and Improvements, Chapter 4 of the 2005 Law states:

Government and local government must provide funding to improve the professionalism and dedication of teachers in every subject that is administered by government, local government, and/or community. 
The 2008 Government Regulation on teachers offers more detailed explanation on funding for teacher professional development than the previous two laws. The explanation can be seen in Verse 5, Article 47, Section 13 on Development and Academic Qualification Improvement, Competencies, and Teaching Profession. The verse states:

Government and/or local government provide funding for the development and improvement of academic qualification and competency as stated in Verse 1, Verse 3, and Verse 4 of this Article.

The fourth policy document, the No.16 Year 2009 Ministerial Decree of the Ministry of Administrative and Bureaucratic Reform on Teachers' Position and their Credit Points/Teacher Decree does not provide explanation on the funding for TPD. The handbook mentions that the funding for the implementation of TPD programmes in Indonesia may come from several sources: government, local government, and personal funding. Government refers to the Indonesian central government and local government refers to the provincial and district (municipal or regency) government.

Taken together the findings show that the teacher participation and funding have a dynamic relationship where both seemed to affect each other. The teacher participation of TPD programme in a more formal way (organised seminars, workshops, conferences) seemed to rely on the availability of the funding. Without funding provided by the government (local, provincial or central government), the teachers seemed to be reluctant to participate. Central government funding is available for schools or teachers to access but schools and teachers' initiatives are also welcome. These findings help us to understand why there seems to be some disagreement between what were written and what were perceived. Although teachers or EFL teachers are the cores of the TPD programme, they are the last people to understand how much funding is available for their programmes. Figure 6.5 helps to explain the layers of authorities and sequence of government-based funding for improving the quality of education in Indonesia. 


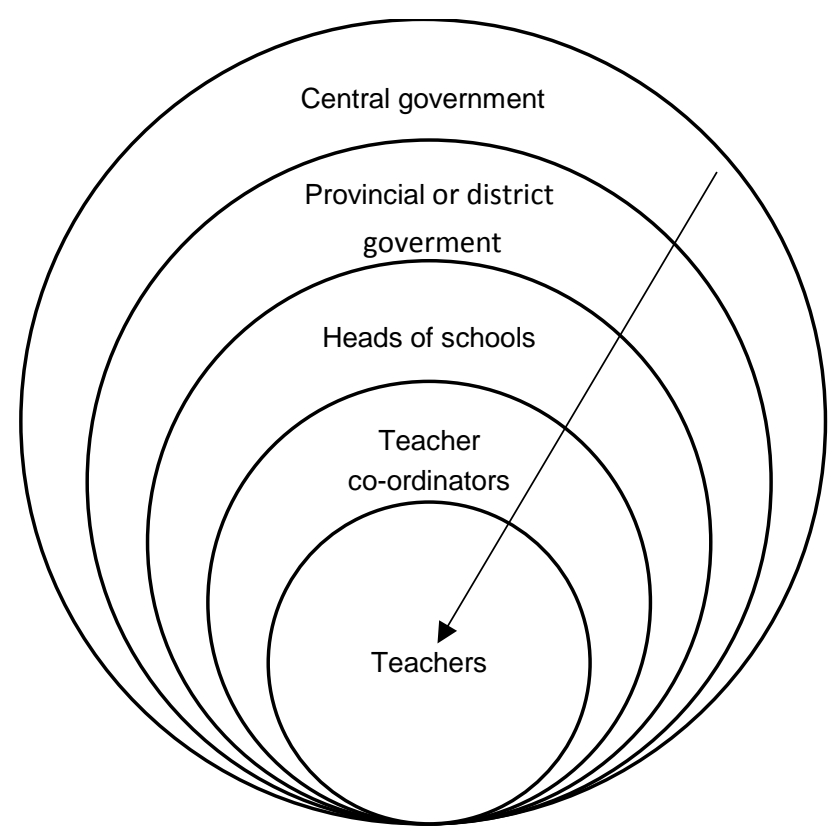

\section{Figure 6.5 Layers of authorities}

The next subsection describes the materials or contents of EFL teacher development programmes as perceived by the EFL teachers and stakeholders. At the school or district level, the content of TPD programmes addressed three areas: teachers' pedagogical knowledge, ICT skills, and L2 proficiency. The discussion of this subsection starts with the three areas of TPD content and ends with the implications of the findings.

All teachers and stakeholders stated that most of the time, TPD programme delivered practical materials that could be used by teachers in the classrooms. The materials may include designing lesson plans for particular themes or topic, introduction of new curriculum, innovative teaching methods, planning for classroom action research, designing scoring rubrics or writing articles for presentation or journal. Budi, a high school principal, stated:

Besides MGMP, there are some trainings. However, trainings are not usually administered by the MGMP. They are commonly administered at the provincial or national level. Recently we had trainings about understanding 2013 curriculum, a transition from 2006 to 2013 curriculum. The teachers were sent to the programme based on their subject knowledge.

Quite a few teachers learned about the 2013 Curriculum during the TPD programmes. Trainings were administered and teachers were sent by schools to attend the socialization programme. 
The ICT-related materials may include the introduction of ICT and the use social media, i.e. Facebook, Twitter or other interned-based media, i.e. Edmodo and blog for teaching and learning. Waskito, one of teachers, said:

The programmes that I participated include improving teaching and learning methods. We invited some lecturers from some universities in Malang District. We also learned to use Edmodo and blog.

Various ICT-related skills were introduced to teachers. The administrators of the trainings or workshops were the Musyawarah Guru Mata Pelajaran (MGMPs) or the School-Cluster Subject Teacher Working Groups. These MGPMs were working with some higher education institutions in Malang Districts to realise that.

Five teachers and two stakeholders mentioned that L2 proficiency was not addressed in professional development programme. In his response to the interview question about whether sustaining L2 proficiency, English language, was included in the professional development programme for teachers, one of the stakeholders, Dada said:

Well, so far no because we believe that the English teachers must have the specific skills. The professional development programme is usually only for the pedagogical skills. We never touch things such as how to improve or develop proficiency in English like speaking, reading, writing or listening. When I asked my fellow teachers, they said, "As English teachers, we must know how to speak in English." English teachers must know how to communicate in English. If they can't then they are not English teachers, right? That's why we don't have such programmes.

Three teachers and two stakeholders said that L2 proficiency used to be available for teachers. A few L2 proficiency-related materials disseminated in the programme include classroom English, and basic communication skills. In different schools, not only English teachers but also all teachers had to participate in the English course provided by the schools. They invited some language trainers to train the teachers and staff to be able to communicate in English inside and outside their schools. Mita and Arum, both teachers, said that there used to be some language trainings for all teachers in their schools. In Mita's school, there used to be an English Day school programme where everyone had to use English on a particular day. Faizal, a vice principal, said that at the moment English was 
not a priority. All the teachers in his school had to learn Mandarin because they had some teachers from China come to his school. In brief, the interview data showed that L2 proficiency was less prioritized than pedagogical and ICT-related materials in TPD programmes.

Now, looking at the analysis of the TPD policy and TPD implementation documents (see Section 6.2.2) and the interview data (see Section 6.2.3), we can see a discord between the documentation and the teachers and stakeholders' perception of the content of TPD. While EFL teachers and stakeholders viewed that there were three areas of content they usually shared or learned through TPD, the documentation did not discuss the teacher professional development learning materials in details. The investigation of the TPD policies shows that the teacher subject matter knowledge and ICT skills were mentioned in general manners. In addition, the two samples of the MGMPs' annual work plans show that most of the materials of the EFL teachers were about improving their pedagogical knowledge. The maintenance and improvement of the EFL teachers' L2 proficiency were not tackled. I will now discuss another aspect in the administration of TPD, the instructors.

Turning now the discussion to the definition of instructors and the perceptions of the participants on TPD instructors. In this study, an instructor refers to an individual, a trainer, and a team of trainers who shares knowledge with teachers during the TPD programme. The administrator of the programmes relies on who initiates the activities. MGMP and its coordinator are potential administrators in the school and districts levels.

The interview data reported that some instructors were invited to share knowledge or to lead workshops for teachers. The instructors were experts in their fields. These specialist speakers might comprise of pedagogic specialists (i.e. teacher trainers, teacher educators, lecturers), ICT specialists (i.e. IT consultants, media consultants), and/or other specialists from institutions that concern about the quality of teachers in Indonesia (i.e. trainers from teacher training institutions, universities, or non-government institutions). Besides the specialists, teachers 
themselves might become speakers in a TPD programme. On the collaboration of teachers with other institutions, Cahaya, a teacher educator said:

The initiative has to come from the teachers themselves and they have to work with authorities. By authorities, they refer to the local government and District Ministry of Education. The authorities have to map the teachers' proficiency before they could design professional development programme for teachers. The programme has to be relevant to the teachers' wants and lacks. It has to address the teachers' needs. If they are not capable, they can work with some universities to do some preliminary research or to administer the needs analysis. We need to collaborate with many institutions. We also attempt to initiate and administer some teacher development programmes. I believe they came from the demands in the fields.

In general, as a subject teacher association in the district level, MGMP spearheads the programme by assisting teachers to connect with the instructors and to prepare for the venues in the school or district levels.

Only a little explanation is given in the documentation on who should become instructors in the TPD programmes. The Handbook of CPD describes that the administrators of the programmes determine the instructors and venues of the TPD programmes. A more teacher-initiated programme might invite experts or colleagues from around their areas and their schools. However, no explanation is given on what the instructors should accomplish or what qualifications they should have to be eligible as TPD instructors. The four policy documents and two implementation documents (the annual work plans of junior and vocational secondary schools) do not mentioned or discussed the issue of TPD instructors. In this study, the formats of the TPD programmes refer to a form or a way to present the learning materials so that the EFL teachers are able to learn the materials (Nation \& Macalister, 2010). This subsection discusses the analysis of the interview data on the EFL teachers and stakeholders' perception of the format of TPD.

The interview data revealed that EFL teachers and stakeholders categorised the formats of TPD programme into two, formal and informal activities. The formal TPD activities encompass more organised and structured activities compare to the informal ones. The formal activities include teachers further their study (post 
graduate studies) and other relevant activities such as seminars, courses, trainings, workshops, and language competition among teachers. The informal programme may include sharing ideas with colleagues and instructors in less formal and less organised situation. Ninih, a teacher trainer, explained:

I believe the formal and informal teacher professional developments are two separate things. Teachers can choose. They know their weaknesses. They can learn independently. Whether they wanted to have some trainings or do internships or apprenticeships, it is up to the teachers.

The paragraph showed that the delivery modes of TPD could be formal or informal based on the levels of casualness or formality of the forums. The casualness and formality of the forums are defined by how they are organised and administered. It is interesting to note that what the teachers and stakeholders reported as formal and informal modes of delivery were not found in the official documents of TPD policies. However, what the teachers and stakeholders perceived as formal TPD activities are functional trainings and informal TPD activities refer to the collective activities as mentioned by the written documents. In this example, informal TPD refers to the endeavours teachers took by learning independently and formal TPD refers to the trainings, internships or apprenticeships.

The format of the TPD programme is not explicitly discussed in the documents of TPD policy and implementation documents but they can be inferred from one of the section in the Handbook of TPD, the components of continuous professional development (Figure 6.6). There are three components in the Indonesian' TPD programmes: (1) teacher personal development, (2) teacher academic publication, and (3) teacher innovative outcomes. These three components are described in the 2009 Ministerial Decree on Teacher Position and their Credit Points and the 2010 Handbook of CPD (page 12-17). 


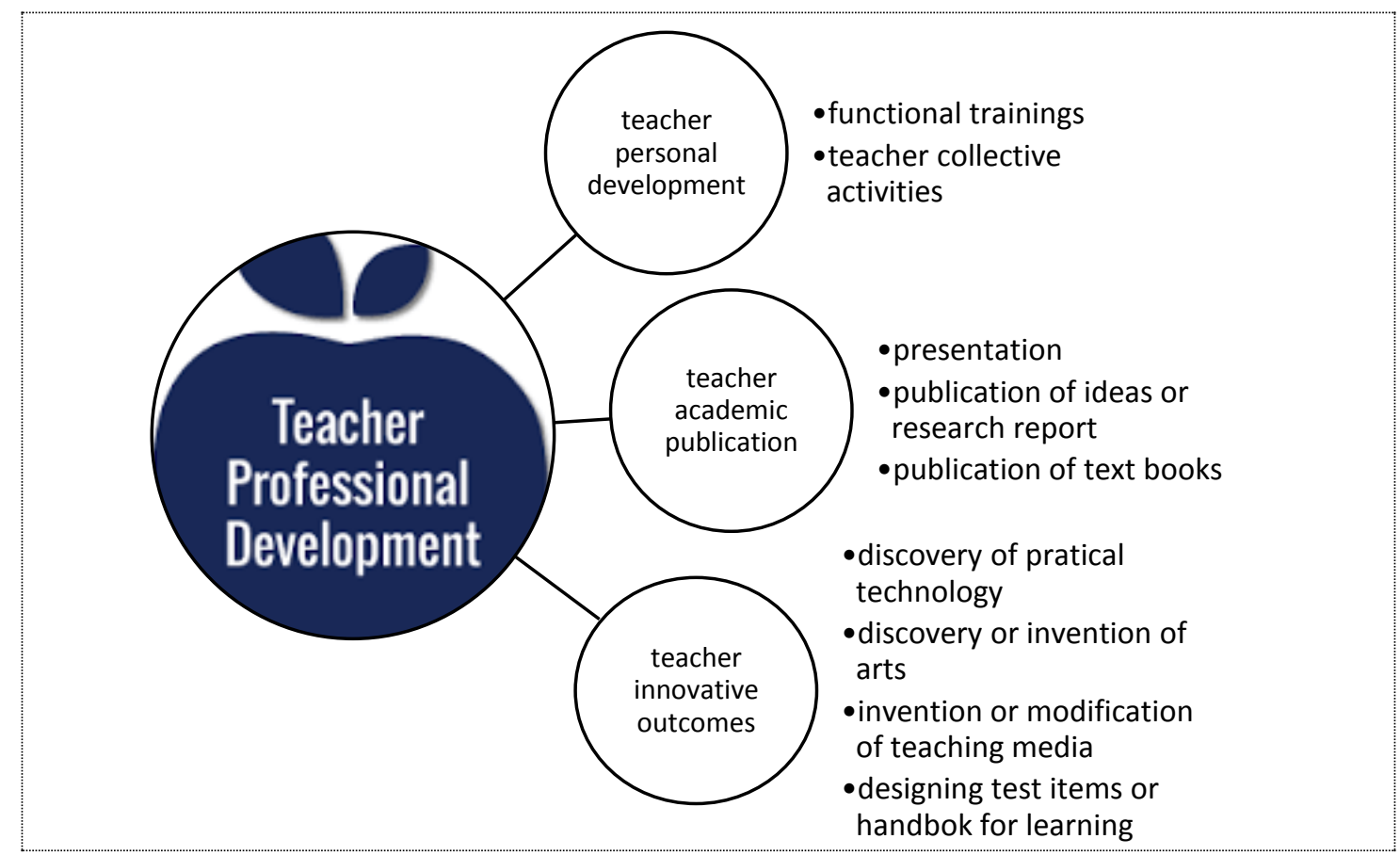

\section{Figure 6.6 Components of continuous TPD}

The formats of teacher personal development include functional trainings and teacher collective activities. The functional trainings are trainings that are administered by government and they may take from 30 to 960 credit hours. The teacher collective activities include trainings and workshops that are administered by the Musyawarah Guru Mata Pelajaran (MGMPs) or the School-Cluster Subject Teacher Working Groups, the teacher participation in seminar colloquiums or panel discussions, and other teaching and learning activities. In the teacher personal development component, teachers are to participate in some trainings, workshops, conferences, panel discussion, or MGMP regular meetings. In the teacher academic publication and teacher innovative products components, teachers are to present ideas, publish articles, or innovate in their teaching methods.

Overall, there is another mismatch between the EFL teachers and stakeholders' perception and the TPD documentation. The teachers and stakeholders described the format of TPD as formal and informal activities. These two formats appear to come up from their TPD practice. In addition, the TPD policy documents also do not explain the various formats that the teachers could use to administer TPD. One implementation document, the Handbook of continuous TPD, describes the 
components of TPD that include teacher personal development, teacher academic publication, and teacher innovative outcomes. However, it was not clear whether these three TPD components were designed by considering the environment in which the professional development programmes are going to be used (i.e. in the urban or rural areas of Indonesia), the needs of the teachers (i.e. pedagogical, personal, social or professional competency), and the principles of effective teacher development (i.e. needs and environment analyses).

In the present study, venue refers to the place where TPD activities take place. In this subsection, I discuss the venue of TPD as described by the results of the interviews and the Handbook of CPD.

The interviews data revealed that not much was discussed by the EFL teachers and stakeholders on the venues of TPD. The participants' lack of discussion on the venues of TPD might have been resulted from the interview questions that did not openly ask about the issue to the participants. On the venues of TPD, one of the teachers, Tiara said:

In the past, we used to visit other schools for MGMP meetings. However, many teachers decided not to come if the place was too far away. In the beginning, many teachers attended the meetings. Then, there were only ten of them. Next, the participants were getting fewer and fewer than before. Well, they just did not want to be bothered by teacher development activities.

The quote shows that schools that are reachable and most strategic ones are the most common place to hold TPD. The schools that are located in remote areas might be used as the venues of TPD but it was not without challenges. Not too many participants would come to the venues if the TPD programmes were held in the remote areas. This finding indicates that the EFL teachers in remote areas might also be challenged by distance if they wanted to attend TPD in other schools or in the capital of their district, province, or country. This finding also correlates with the participation and funding aspects. Without enough funding, these teachers would not be able to participate in the TPD programmes that were held far from their schools. 
The Handbook of TPD discusses where TPD can take place and who can participate in the programmes. TPD programmes can involve teachers and educational staff in the same school (intra-school networking) or in different schools (interschool networking) or between teachers and experts from higher education institutions, professional associations and other training providers. The venues in this school or district level programmes would be schools under the same MGMP in the same district. A wider-scope programme initiated by the local, provincial or central government might include national or international experts and might take place in capital cities around Indonesia. This is where this subsection intertwines with the previous subsection and creates complicated issues for EFL teachers in particular and teachers in general. The EFL teachers seemed to have minor authority on the decision of instructors and venues of TPD programmes. They acted and were treated as if they were the objects rather than the subjects of TPD programmes. Thus, these teachers also appeared to have no sense of belonging of the programmes and would depend on government-based funding to participate in them.

Together, these findings show that the EFL teachers and stakeholders had various ideas about the administration of TPD. The findings also show that there are some discords between what the EFL teachers and stakeholders understood about the administration of TPD and the written explanation of how to organise TPD as explained in the Handbook of TPD or the other TPD documentation.

\subsubsection{Unclear concept of TPD evaluation}

The third thread of the finding on the EFL teachers and stakeholders' uneven knowledge about TPD is that they did not have a clear concept of TPD evaluation. This section is essential because the EFL teachers and stakeholders' knowledge and practice of evaluating TPD reflect each other. The knowledge of EFL teachers and stakeholders on what define successful TPD programmes is critical because they would be able to set their individual professional development goals and criteria of success. Later, they can also measure the achievement by reflecting to the goals and outcomes. Based on their ideas about evaluating TPD, the participants are categorised into three groups: those who thought that ways to 
measure the success of TPD were through assessment and evaluation, those who thought that the success of TPD relied upon its goals, and those who did not have any ideas about how to evaluate the success of TPD. This section describes those three groups of participants and ends with the implications of the findings.

The interviews showed that the success of TPD could be measured using particular assessment or evaluation. The EFL teachers and stakeholders mentioned about some direct and indirect ways to measure the success of TPD programmes. The direct ways to test the teachers' understanding of the materials of the programme were observing their regular attendance, and/or submitting written report of the teachers' participation in the programme. When the EFL teachers participated in a workshop of designing a lesson plan, it is expected that they submit an example of the lesson plan for their own class when the programme ends to the administrators of the TPD programmes as well as to their principals. The indirect ways to measure the success of the TPD programmes were done by observing the teachers' practices in the classroom, their teaching quality, and the students' learning outcomes. Some of the interviewees mentioned modes of how to measure the effectiveness of the programme.

The success of TPD appears to be depended upon the availability of TPD goals. One stakeholder stated that the indicators of success of a particular TPD programme relied on the goals of the programme. Another stakeholder viewed that the administrators of TPD at the district or local level had no thorough understanding of the indicators of success of TPD. Cahaya, one of the teacher trainers, explained that the She said:

The indicators of success are decided after looking at what professional development the teachers participate in. You know, there are a lot of TPD programmes like MGMP meetings, the regular ones. I think it is a good idea for MGMP to have mentors or supervisors who will guide the teachers in MGMP to set goals since the very beginning. Some goals or objectives for a year to come. What are the indicators? Are they achieved or not, and so forth. If the teachers want to develop in one competency, then the indicators are this and that. The success can be observed in the field or can be gathered through questionnaires. At least, we can gather the teachers' perception of their competencies. We can ask them whether their competencies improve or not. Well, it is a bit complicated but that's what the teachers need to do. 
Two teachers and two stakeholders mentioned about the unavailability of the indicators or their uncertainty about whether they existed or not. To illustrate their uncertainty, let us look at what one of the teachers, Agni, said:

The indicators of success eh? I don't know what indicate the success of TPD programmes. The most important thing we should do when we participate in the trainings offered by the District Ministry of Education is to submit a report. For examples, in a classroom action research (CAR) training, teachers must submit a proposal of CAR. Regarding the indicators or success or not, I don't have any ideas.

The Handbook of Teacher CPD shows that one chapter of the book is dedicated to discuss the monitoring and evaluation of TPD (see also Subsections 6.2.2.3 and 6.2.2.4, this chapter). The book chapter also provides some template sheets for teacher self-evaluation (prior to TPD activities) and self-reflection (after TPD activities). The self-evaluation sheet is used before the TPD and aimed to provide feedback for the teacher annual work plan. The teacher self-reflection sheet is filled after TPD and aimed to see how relevant the TPD activities that have recently done and how it can be used for coming annual work plan. The Handbook of TPD has some explanation on the evaluation of TPD. In this book, the teachers are asked to self-evaluate their performance as teachers in the beginning of every teaching year (see Figure 6.4). This is done to ensure that teachers and teacher coordinators could gain feedback of what the teachers need, want, and lack. In the end of the academic year, the teachers are also asked to reflect on what they have done during the past academic year. Together, the results of this study show that the EFL teachers and stakeholders appear to have vague ideas of how to evaluate the success of TPD.

Overall, the interview data shows that the EFL teachers and stakeholders' perceptions of TPD evaluation do not match with explanation provides in the Handbook of TPD. This discord might be explained by the fact that teachers and stakeholders might not read or understand the documents well. Another possible reason for the discord is not enough socialization programmes are available for teachers or stakeholders to help them understand the handbook, or more importantly to understand the concepts of monitoring and evaluating TPD. 
The next subsection discusses the benefits and challenges of TPD as reflected in the interviews with the EFL teachers and stakeholders.

\subsubsection{Imbalance benefits and challenges of TPD}

The last thread that discussed the findings of the EFL teachers and stakeholders' perception of concepts, policies and practice of TPD is the benefits and challenges of TPD. Understanding them is important for three reasons. Having sufficient knowledge of the advantages of TPD helps to recognise the significance of professional development for teachers. Then, knowing what aspects challenge the practices of TPD helps to identify the threats and possibilities so that they can be addressed in the future. Finally, recognizing both benefits and challenges of TPD also help to see if teachers and stakeholders perceived teachers as the subject or the object of the programmes. This is critical to understand what motivate EFL teachers in the programmes.

The interview data shows that there were more obstacles that the EFL teachers faced to administer TPD than its benefits. In their responses to the interview questions about what TPD means for teachers, both EFL teachers and stakeholders discussed the benefits of TPD and giving accounts on what motivate teachers to participate in the programme. Some of teachers and stakeholders also discussed the challenges the teachers faced when participating in TPD programmes.

Out of 20 interviewees, only two of them mentioned the advantages of TPD. The benefits are meeting colleagues and sharing knowledge. Two teachers (Agni and Tiara) thought that TPD helped them to meet their colleagues who teach in different schools. Agni, one of the nine teachers, said:

TPD is beneficial. In general, it allows me to network with my fellow teachers. I can meet other teachers.

Reviewing the information from the questionnaire on the EFL teachers' personal information, the claim was justified because during MGMP meetings the EFL teachers met their fellow EFL teachers from other schools.

One teacher (Agni) and one stakeholder (Prasetyo) mentioned that sharing knowledge with colleagues was the other advantage of TPD. Agni, a teacher, said: 
A more specific benefit from TPD is it allows me to share knowledge, from having no knowledge to being knowledgeable. From 'do not know' to 'have knowledge'.

These findings are thought provoking because out of 20 interviewees, only two of them mentioned the advantages of TPD explicitly. These findings also indicate that the EFL teachers and stakeholders' knowledge of the available policies and concepts of TPD was insufficient for them to recognise the importance of TPD for the personal and institutional development. It also appears that the EFL teachers and stakeholders perceived more challenges than the benefits of TPD.

From the interviews with the EFL teachers and stakeholders, I identified that EFL teachers in Malang were exposed to several issues when administering or participating in TPD programme. I grouped the issues into two categories, external and internal challenges.

The external challenges refer to the issues that come from outside the teachers. They comprise of the teachers' lack of follow-up activities, teachers' teaching and additional administrative loads, and inadequate infrastructure. Many TPD programmes for EFL teachers were carried out as one-shot activities. This is especially true if the TPD programmes were aimed to improve the institutional goals of schools, districts, provinces or nation. For example, during the implementation of bilingual school policy in Indonesia, many schools provided English language trainings or ICT skills for the teachers who would teach in English and Indonesian. However, once the curriculum or policy shifted, the efforts to maintain those English language skills and ICT skills discontinued. Tiara, one of the teachers, said that the trainings for teachers to maintain their L2 proficiency were available. However, no follow-up trainings were available. This idea was also discussed by one of the stakeholders, Cahaya who said:

Well, I guess there many forums to maintain or improve the teachers' professionalism. The constraints are the unideal teachers' teaching load and minimal follow-up activities. Although the teachers may learn one or two lesson from the programmes, they have to complete some paperwork reporting the results of the programmes.

The finding about the teachers' lack of follow-up activities show that efforts to improve EFL teachers' professionalism have been done. However, most of the 
activities did not take place over extended period of times and thus the results might not as substantial as expected. These findings support Adey et al. (2004) and Harwell's ideas (2003) on the significance of on-going TPD if it is carried out over longer period of time.

The next external challenges of TPD are teachers' teaching and additional administrative tasks and time arrangement. These two constraints may also hinder teachers' participation in the TPD programme because teachers might choose teaching their students rather than leaving their classes to improve their teaching competency. The MGMPs of junior, senior and vocational high schools in Malang District agreed that they had one day for MGMP meeting or TPD programme each week. However, their pedagogic and administrative duties sometimes did not allow them to participate actively in the teacher development programme.

There are many additional tasks that the teachers must do. They are in charge of many things including taking care of the students' affairs, becoming treasurers or others. There was so much work to do and we still have to do the administrative tasks.

The quote reveals that heavy teaching loads and administrative tasks do not only restrict the EFL teachers to maintain or improve their English proficiency (see 3.6.4, Chapter Three) but also limit the EFL teachers to participate actively in the professional development programmes.

The other problem was the inadequacy of the facilities at some schools. For example, internet connection was not available at schools and the EFL teachers had to travel to faraway places to participate in TPD or to the cities where they can access internet. This can be seen from what was explained by Laksmi, one of the MoEC staff. She stated:

When EFL teachers live in the border, very far away school, for example, they live close to the, high in the mountain or close to the beach. Internet is not easy to access. So they find difficulties to search everything dealing with this kind of media.

This insufficiency of the infrastructure may result from the imbalance facilities that urban and rural areas in Indonesia received. This finding is in accord with a recent study indicating that the most common factors affecting the use of English teachers' use of computer in their classroom include limited facilities, students' 
lack of computer skills, limited time, limited access to internet and teachers' lack of computer skills (Son et al., 2011). From these results, we can infer that limited facilities and limited access to internet are still perceived as continuing challenges in Indonesia. Not much has changed from the previous study and this situation is worsened by the existence of internal challenges.

The internal challenges in this study refer to the issues that come from within the teachers. They include lack of motivation and lack self-confidence. A few teachers perceived that their retirement age and obligation to attend TPD are demotivating. These teachers were close to their retirement and felt that they were too old to learn anything from the TPD. Thus, they decided not participate or contribute to the TPD programme. Tiara, one of the teachers, said:

After teachers are certified as professional teachers, they received financial rewards. They are supposed to use some of the fund for TPD. However, a lot of teachers are disobedient and did not want to use the fund for TPD to participate in TPD because they were almost retired. What for is a professional development?

Two EFL teachers spoke on behalf of other teachers too when they were asked about why participating in TPD. They thought that in general EFL teachers participated in TPD programmes because it was their obligation as teachers to come and attend. These findings show that lack of motivation becomes a threat for teachers' individual professional development. These findings resonate the one discussed by Widodo and Riandi (2013: 388). They believed that "unless teachers themselves develop the motivation they will not seriously participate in the programme". The present study also shows that the EFL teachers' motivation has some effect to their participation in the TPD programmes.

Still others found that lacking of self-confidence had prohibited them from going or participating in the TPD programmes. In Malang and other places around Indonesia, TPD programmes and MGMP meetings facilitate teachers from different schools in the same school cluster. They may come from state schools or private schools. While the TPD programmes or the MGMP meetings enable teachers to meet their fellow teachers from other schools, this gathering has also posed a threat to some teachers who were afraid of being underestimated by other 
teachers. This condition was observed by one of the teacher co-ordinators, Dada, who stated:

From my experience, the EFL teachers' willingness to participate in TPD is still low. They think it is a kind of routine activity, if they do not get the benefits of that kind of activity. Their participation is still low. They just come to the events, the MGMP meetings. For some parts it their lack of participation is because most of them do not have the self-confident in joining that kind of event. They feel that they will be underestimated by the other teachers, especially those senior teachers who come from public vocational schools.

There was not much we can say about the EFL teachers' lack of confidence and further investigation has to be done to understand why some teachers would be afraid of participating in TPD and be afraid of being underestimated by other teachers. These internal challenges coupled with the external challenges show just how formidable the issues are that the EFL teachers have to contend with. While most teachers and stakeholders agreed that teacher development was beneficial for teachers, both of them also agreed that active participation was not as easy as it seemed. These findings suggest that having one of the two aspects of TPD, individual or institutional aspect, may still result in achieving not many benefits of TPD. However, effective TPD requires both institutional and individual efforts (Richards \& Farrell's, 2005).

These findings also highlight the need to have a framework for analysing the effectiveness of professional learning experiences (Timperley et al., 2007). The framework used by Timperley et. al. provides TPD practice in Indonesia with a benchmark to investigate its effectiveness. Referring to the framework (see Figure 2.1, Chapter Two), TPD practice among EFL teachers in Indonesia has its wider social context that include TPD policy documents, discourse to improve professionalism, and teacher associations, such as MGMP, as their social organization. An important end goal of TPD is to improve the teachers' (as learners) learning outcomes, while accommodating the diversity of the teachers' learning styles. However, this study suggests that the content of professional development and learning activities under investigation were not constructed to promote the learning processes or respond to the diverse teachers' needs. 
The third research question of this study set out to determine the Indonesian teachers' and stakeholders' perceptions of TPD policies and their practices. This investigation shows that both EFL teachers and stakeholder had (1) mixed ideas about the concepts, policies and practice of TPD, (2) various ideas about the administration of TPD, (3) unclear concept of TPD evaluation and (4) imbalance ideas about supporting factors and constraints of TPD.

\section{Summary}

Overall, the answers to all three-research questions suggest that the EFL teachers at high schools in Malang, Indonesia and stakeholders had partial knowledge of the concepts of TPD and had partial understanding of the TPD policy documents. Their partial knowledge and understanding of TPD were reflected in their institutional and individual efforts to improve their professionalism. While institutional and individual teacher professional development play significant role to improve teachers' personal teaching and learning quality and school, district, provincial or national educational quality, the efforts might prove less effective than they are supposed to be if the administrators of TPD consider teachers as the objects rather than the subjects of the programmes.

The next chapter, Chapter Seven, is dedicated to the discussion of the key point findings from Chapters Three, Four, Five, and Six. I will focus on two issues: institutional and individual aspects of teacher professional development among EFL teachers in Malang, Indonesia. 


\section{Chapter 7 Discussion}

\section{Introduction}

In Chapter One, I highlight the importance of maintaining and improving EFL teachers' professional and pedagogical competency, in order to keep up with changes and innovations in second language education and meet the increasing demand for proficient English teachers. Administering an on-going TPD is one of many ways that EFL teachers can reach these two goals.

This chapter discusses three main issues from the four studies described in Chapters Three, Four, Five, and Six. First, I start the chapter with a discussion on the issue of EFL teachers' L2 proficiency. Then, I discuss the issue of EFL teachers' ICT and blogging skills. I end this chapter with a discussion on the issue of institutional and individual teacher development among EFL teachers.

\subsection{Issue One: EFL Teachers' L2 Proficiency}

From the analysis of the EFL teachers' L2 proficiency tests, two themes emerge: the dissonance between the EFL teachers' perceived and actual L2 proficiency and negative correlation between EFL teachers' years of service and their L2 proficiency.

\subsubsection{Dissonance between the EFL teachers' perceived and actual}

\section{L2 proficiency}

The teachers' proficiency study, reported in Chapter Three, showed three key findings. The L2 proficiency tests showed that the EFL teachers had solid lowfrequency vocabulary mastery and that their writing skills were minimally adequate. However their knowledge of mid-frequency vocabulary, academic words and low frequency words, and their reading ability were lower than expected (see Section 3.4, Chapter Three). From the questionnaire and interview data, we learned that the EFL teachers tend to overestimate their vocabulary mastery, reading and writing skills, and their English maintenance practices (see Section 3.6, Chapter Three). 
A possible explanation for the EFL teachers' solid high-frequency vocabulary but low mid, high and academic word levels and low reading proficiency is the possible correlation between vocabulary knowledge and reading proficiency (Laufer, 1997, 2012; Laufer \& Ravenhorst-Kalovski, 2010; Lee \& Schallert, 1997). The finding that the EFL teachers did not do well on the reading comprehension test suggests that they may not have been able to access their knowledge of mid-frequency and academic vocabulary. This because a high proportion of unknown words in a text makes it higher probable that the reader misses or misinterprets contextual clues needed to answer comprehension questions (Laufer \& Ravenhorst-Kalovski, 2010: 31).

On the other hand, the EFL teachers showed that they had basic English writing skills, even though their average scores on the writing test were slightly lower than the set baseline of 5.5 IELTS. A possible explanation why teachers' writing results were closer to the standard than their reading results is topic familiarity, as the EFL teachers are likely to be mostly familiar with the topic given to them as a writing prompt (i.e. retirement age). Furthermore, the knowledge of basic English vocabulary (the mastery of the first 2000 words and moderate knowledge at the 3000 word and academic word level) was sufficient to write an essay on a familiar topic.

A possible explanation for the difference between the EFL teachers' actual and perceived proficiency may be that the EFL teachers were experiencing language attrition. Schmid (2011: i) defines language attrition as "a loss of, or changes to, grammatical and other features of a language as a result of declining use by speakers who have changed their linguistic environment and language habits". It appears that the EFL teachers in the present study perceived that their English proficiency was satisfactory compared to the existing baseline, i.e. an average of 5.5 IELTS band-scale for reading and writing proficiency. However, the results of their L2 proficiency tests showed that their actual L2 proficiency was lower than the baseline. This difference may be due to the fact that the frequency of using the target language outside of the classroom was insufficient to maintain their baseline target language proficiency. The results suggest that, while the EFL teachers taught English as a foreign language in Indonesian high schools, they 
experienced a period of declining use. The EFL teachers had used English to communicate with their teacher trainers and classmates during their initial teacher education. However, once they graduated and started teaching in an EFL teaching context, most of their students and colleagues did not speak English. Thus, they could not use English frequently to communicate with others. These results support Schmid's (2011) conclusion that the decline of use due to changes in one's linguistic environment and language habits may negatively affect language proficiency. The results further confirm the association between second/foreign language attrition and external factors, such as contact with and/or use of the language (Bardovi-Harlig \& Stringer, 2010; Schmid \& Mehotcheva, 2012). Bardovi-Harlig and Stringer, (2010) argue that decreased opportunities to communicate using the target language are associated with second language attrition. They claim that the time second language learners spend away from using the target language is the period of fewer chances in language use. In addition, Schmid and Mehotcheva (2012) maintain that once a foreign language user is removed from their supportive environment, there is a greater possibility for her not to be able to retain the language.

\subsubsection{Negative correlation between EFL teachers' years of service and L2 proficiency}

The EFL teachers' years of service were found to be negatively correlated with their L2 proficiency, for the academic word knowledge, and reading and writing ability (see Section 3.5, Chapter Three). This finding may be accounted for by considering the status and role of English in the Indonesia (see Section 2.2.1, Chapter Two). According to Dardjowidjojo (2000), Jazadi (2000), and Lauder (2008), English is a foreign language in Indonesia and is one of compulsory subject in secondary high schools and tertiary education in Indonesia. This means that English is mostly confined inside the classrooms' walls and is rarely used outside the classrooms. Lengkanawati's (2005), Lie's (2007), and Marcellino's (2005) studies show that English was challenging for EFL teachers both inside and outside the classrooms. 
This result of the present study extend Bardovi-Harlig and Stringer's (2010) claim about the effect of the duration and nature of reduced input and use (see Section 2.2.3, Chapter Two) beyond high school students, missionary returnees, and federal employees whose jobs include the use of second language to in-service teachers of English as a foreign language in Indonesia. The present study shows that in-service teachers with longer years of service tended to have lower academic vocabulary, reading proficiency and writing proficiency than those who have shorter years of service. The present study also shows that the pre-service teachers tended to have higher academic word knowledge, reading proficiency and writing proficiency than the in-service teachers. On the basis of this evidence, it seems fair to conclude that reduced target language input and use result in L2 attrition in EFL teachers.

The negative correlation between EFL teachers' years of service and their academic word knowledge and reading and writing proficiency also appear to validate the view that, for second/foreign language users, the issues of acquisition and attrition of the target language are multifaceted (Bardovi-Harlig \& Stringer, 2010; Schmid \& Mehotcheva, 2012). Schmid and Mehotcheva (2012) argue that second/foreign language users are challenged by factors that come from within the linguistic system and from the surrounding environment, as well as by internal factors within the second/foreign language users themselves. The analysis of the interview data shows that the teachers were challenged by a number of extra linguistic factors, such as the lack of time, excessive use of the L1, Bahasa Indonesia, and lack of exposure to the target language (see Section 3.6.4, chapter Three). Thus, the EFL teachers in the present study were challenged by some of the extra linguistic variables identified by Bardovi-Harlig and Stringer (2010) and Schmid and Mehotcheva's (2012). Further studies are needed to fully consider the effect of external and internal factors on the foreign language attrition among EFL teachers in Indonesia.

\subsection{Issue Two: EFL Teachers' ICT and Blogging Skills}

ICT literacy is important for Indonesian EFL teachers to keep abreast with the changes and innovations in their field. This is embodied in the educational 
policies in Indonesia (see Subsection 6.2.1.2, Chapter Six). On the other hand, review of literature shows that blogging offers EFL teachers a number of benefits for teaching and learning (see Section 2.3.3, Chapter Two). These two key findings are discussed as follows.

\subsubsection{ICT literacy}

My analysis of the TPD policy and implementation documents and questionnaire data provides useful information about the EFL teachers' ICT literacy.

Most of the TPD policy documents and their implementation documents explicitly mention the needs for teachers in general to maintain and improve their ICT skills (see Subsection 6.2.1.2, Chapter Six). However, maintaining or improving ICT skills was not recognised and operationalised in the local level (see Subsection 6.2.1.2, Chapter Six). The Handbook of TPD also states that keeping up with technology helps teachers to be ready to face the challenges of the 21 st Century. However, no further explanation is given in these documents about what ICT skills the EFL teachers must master, why and how they are expected to masters these skills, when and where ICT training should be administered, and how often the trainings should be administered. Neither implementation documents nor the annual work plans present evidence of activities that aim to train teachers in the ICT skill to satisfy the requirements of the policy documents and the handbook.

The present study also reveals that five out of seven TPD documents reflected the need for EFL teachers to maintain or improve their ICT knowledge and skills, to keep up with the development of teaching and learning-related technology. This finding indicates maintaining or improving EFL teachers' ICT skills received sufficient recognition from the government. However, ICT skills have been given little attention in the practice of TPD at the local level. No tools were available to assess or benchmark the EFL teachers' past, present or future ICT skills. No activities were explicitly designed to maintain or improve ICT skills in the EFL teachers' annual work plans. Son et al. (2011); UNESCO (2006); Widodo and Riandi (2013); and Yusri and Goodwin (2013) indicate that EFL teachers should be given chances and tools to assess and benchmark their recent ICT skills, in order to maintain or improve their computer-based and web-based skills. The 
study results show that is not yet the case in the case of EFL teachers' in Indonesia.

The questionnaire data shows that most EFL teachers were confident in their basic computer skills and Internet literacy (see Section 5.2.1 and Figures 5.1 and 5.2, Chapter Five). These findings are consistent with those of Son et al. (2011: 2829), who found that the EFL teachers' self-rated computer and the internet competency was lower than their actual levels of computer and the internet knowledge and skills. The dissonance may be the result of the top-down administration of ICT aspects of the TPD programmes, similar to other aspects of professional development programmes offered in Indonesia (Bjork, 2006; Widiati \& Hayati, 2015; Widodo \& Riandi, 2013). This means that even though teachers are compelled to participate in the training, they are not empowered by it. The results show that the EFL teachers' sense of ownership of their professional development was low and, thus, the trainings tended to be ineffective.

\subsubsection{Blogging literacy}

To investigate the EFL teachers' blogging literacy, I explored the TPD policy and implementation documents, questionnaire, and interviews. The TPD policy and implementation documents do not discuss the need for blogging literacy among teachers in general or EFL teachers in particular (see Subsection 6.2.1.2, Chapter Six). A possible explanation to this finding is the fact that the policy documents are general in their nature, aimed to regulate Indonesian national education (see Subsection 6.1.1.1, Chapter Six). However, the EFL teachers' annual TPD work plans did not spell out the needs for EFL teachers to gain or maintain their blogging skills either.

The EFL teachers' self-assessment points to their poor blogging literacy (see Figure $5.1 \& 5.2$, in Section 5.2.1, Chapter Five), with the majority reporting never or rarely writing blog entries. Finally, the interview data showed both perceived benefits of blogging and perceived barriers to blogging, but it appears that the benefits did not outweigh the barriers. These findings support the theory of affordances (Gibson, 2015; van Lier, 2000). In the present study, the EFL teachers perceived more challenges than the affordances of blogging (see Sections 
5.3.2 and 5.3.3, Chapter Five). While blogging allowed the EFL teachers to practice writing in English, share pedagogical knowledge with other teachers, and connect with their colleagues or students, it did not help them to reduce their heavy teaching loads and administrative tasks. The challenge became heavier because they were asked to read and write critically in the blog. This has apparently demotivated most of the participating teachers to continue writing as the expectation escalated from a narrative introductory post to argumentative or exploratory posts.

In the end, little useful information on the topic of blogging could be obtained from the analysis of the Indonesian TPD policy and implementation documents, the questionnaire, or the interviews with the EFL teachers and stakeholders. Future investigations should explore why the potential of blogging as a form of TPD are not profiled in the policy and implementation documents and not built upon in the EFL teachers' professional development programmes in Indonesia.

\subsection{Issue Three: Institutional and Individual Teacher Development among EFL Teachers}

A seminal study on teacher professional education suggests that Indonesia aims to improve the quality of education and teacher education to conform to the spirit of ASEAN Community 2015 scheme (Widiati \& Hayati, 2015). In my analysis of the teacher professional development documentation in Indonesia, I found two key points. First, the 2003 Law on National Education and the 2005 Law on Teachers and Lecturers require teachers to maintain and improve their disciplinary knowledge and ICT skills. Second, there are gaps between the TPD policies and their implementation at the individual and institutional levels. National education in Indonesia has two institutional goals for EFL teacher development to achieve; that is, to keep up with change and innovation in second language education and to answer the increasing demand for competent English teachers worldwide. In the end, these two institutional goals are aimed to improve the students' learning outcomes. This has raised a question of whether the teacher professional development (TPD) policies for EFL teachers in Indonesia and their 
implementation have reflected these institutional goals and addressed teacher personal goals.

\subsubsection{Institutional teacher development}

In my analysis of the TPD policy documents in Indonesia and their implementation documents, I found that (1) EFL teachers should keep up with change and innovation in second language education and be ready to answer the increasing demand for competent English teachers worldwide, but (2) the implementation of TPD for EFL teachers at the local level appeared to be mismatched with the existing TPD policy documents.

\subsubsection{Keeping up with changes and innovations in subject matter knowledge}

The present study reveals that the TPD implementation documents on subject matter knowledge at the local level did not match the existing TPD policy documents that were created by the central government. While policy documents are general in nature and address all Indonesian citizens, the local level implementation documents (in this case, the junior high school and vocational school Annual Work Plans) are specifically designed by and for EFL teachers.

The analysis of the TPD policy documents and their implementation documents in Indonesia reveals that most of them explicitly mention the needs for teachers in general to maintain and improve their subject matter knowledge (see Table 6.2, Subsection 6.2.1.1, Chapter Six). However, subject matter knowledge was not properly operationalised by the EFL teachers in Malang district in the local TPD practices. It is necessary for TPD policy and implementation documents to facilitate EFL teachers' needs to maintain or improve their subject matter knowledge in English. Grundy and Robison (2004) and Richards and Farrell, (2005) point out that keeping abreast with changes and innovations in second language education is important for EFL teachers because subject matter knowledge constantly changes and innovations in teaching strategies are introduced from time to time. It is inevitable that new teaching methods are introduced, novel assessment techniques are developed, or innovative curriculum is proposed. This is where determining needs, setting goals, selecting participants, 
considering principles of adult learning, supporting the programmes, evaluating what have been learned and sharing the results of TPD are important (Nation \& Macalister, 2010; Richards \& Farrell, 2005: 17-21).

The present study also reveals that environmental and needs analysis, and evaluation were explicitly discussed only in one out of the seven documents (in the Handbook of TPD), but were not addressed in the TPD policy documents and the other two implementation documents (see Subsections 6.3.2.1 to 6.3.2.3, Chapter Six). While the annual work plans outlined teacher development activities and their timing, this information was not sufficient to understand why the specified activities were chosen, who the intended participants of the activities were, where they were going to be held, how much funding was needed, who were the organizers or administrators of the activities, and who would be responsible for the monitoring and evaluation of the activities. Because the policy documents act as general guidelines for the education system in Indonesia that encompass the primary, secondary, tertiary education and pre-school education, more detailed explanations of the TPD components may not be appropriate at this level. It is important for those who administer TPD programmes to invest time into the analysis of the constraints, necessities, lacks and wants of the teachers prior to the implementation of specific in-service teacher training courses and workshops, in order to ensure that the set goals are achievable and that any potential problems they may arise during the TPD implementation are addressed in a timely manner (Nation \& Macalister, 2010; Richards \& Farrell, 2005). Overall, the findings indicate that the EFL teachers and their coordinators need to work together to provide additional guidelines to translate and implement the TPD policy documents at the local level. For example, on the issue of environmental analysis, the administrators of TPD have to understand the specific context in which programmes are implemented (e.g., whether technology is involved, whether participants have reliable access to the Internet, sufficient for the planned activities) recognise who the participants are (e.g., whether they are novice or senior teachers, or both) and who the trainers are (e.g., whether they are well trained). On the issue of needs analysis, for instance, the administrators of TPD have to know and be aware of the EFL teachers' necessities (what knowledge they 
are supposed to have), lacks (what knowledge they are lacking), and wants (what knowledge they wish to learn).

\subsubsection{Answering the increasing demand for competent English teachers}

The analysis of the TPD policy documents and one implementation document, the Handbook of TPD, shows that teachers (in general) can maintain their professionalism in various ways including by improving their academic qualifications (i.e. doing postgraduate study), participating in training (e.g., in a new curriculum) and in professional development, publishing ideas or research and inventing or designing teaching media (see Subsections 6.2.1.1 and 6.2.1.2, Chapter Six). The 'subject matter knowledge' in the policy documents refers to any subjects that the teachers are taught in high schools, i.e., English language, Indonesian language, mathematics, science or arts. The document analysis shows that maintaining or improving the EFL teachers' target language proficiency per se was not the priority of the existing TPD policy and implementation documents. Indeed, 'subject matter knowledge' may strongly refer to the subject the EFL teachers taught at school. However, it appears that this understanding might not be equally the same from teacher to teacher. Thus, similar to the maintenance or improvement of ICT skills, an additional guideline might help EFL teachers to understand that the meaning of subject matter knowledge in the documents is equal to the target language they teach.

Furthermore, the EFL teachers who create annual work plans may overlook the needs to maintain and develop their second language proficiency as a result of inaccurate perceptions of their own English proficiency (see Sections 3.6.1 and 3.7.3, Chapter Three). The results of the L2 proficiency study in the present thesis show that the teachers tended to overestimate their L2 proficiency. If this perception were shared by most of EFL teachers, this would explain the absence of L2 proficiency development from the activities in the annual work plans. The blogging study also showed that the three EFL teachers who completed the blogging task were not able to engage with the reading materials or to write reflectively, using the blogging platform (see Section 4.2.2, Chapter Four). 
Finally, the analysis of the TPD policies, the Handbook of TPD and the annual work plans did not show that the environment and needs analysis and evaluation were three important steps in the development of the TPD policies for EFL teachers and their implementation by local education bodies (see Subsection 6.2.2, Chapter Six). This means that the specific need of the EFL teachers to maintain and improve their L2 proficiency may not be fully understood by the TPD policy and implementation decision makers.

In addition, the findings of the interviews with the teachers and stakeholders suggest that the EFL teachers do not contribute sufficiently towards the planning, administration and evaluation of institutional teacher development programmes, especially those carried out by the government. This represents a lost opportunity for the EFL teachers to have a voice in the matter and to take a more self-directed approach to the development of their professionalism.

The present findings on the unavailability of specific definition of 'subject matter knowledge' term in the TPD policy and implementation documents, unacknowledged significance of target language proficiency for EFL teachers, and the EFL teachers' lack of contribution to their TPD activities demand some actions to be carried out. The actions may include chances to evaluate and benchmark the EFL teachers' L2 proficiency and give the more voice in the decision making of policies or tools to improve their professionalism. The view that I express on the issue of improving EFL teachers' subject matter knowledge and L2 proficiency is in line with that of (Dudzik \& Nguyen, 2015; Farrell, 2015; Harvey et al., 2010; Korompot, 2012; Richards, 2017; Richards \& Farrell, 2005). These authors indicate that opportunities and tools to evaluate and benchmark the EFL teachers' current L2 proficiency should be given to maintain or improve their language proficiency. Korompot (2012) and Widodo and Riandi (2013) also suggest that giving EFL teachers more autonomy in developing their PD activities based on their needs is critical, while receiving guidance and support from administrators of the TPD programmes. Giving EFL teachers a voice in defining their own professional development will bring about a sense of ownership of the TPD programmes (Widodo \& Riandi, 2013: 389). Giving teachers a bargaining power in making decision about materials, instructors, venues, and formats and, 
would improve their motivation to participate actively in the programmes. Having specific EFL teacher groups in mind as participants of the trainings workshops would potentially increase the effectiveness and efficiency of the programmes. Arguably, to be able to answer the increasing demand of competent EFL teachers, EFL teachers and stakeholders in Indonesia have a great deal of undertakings to do and accomplish.

Together, this study indicates that the institutional aspects of TPD have been formulated by the central government. Inasmuch as the aspects were decided topdown from the central government to the provincial government, district government, and local users (head of schools, teacher coordinators and EFL teachers), the translation and implementation of the TPD policy documents may not always be similar to the expectation set up by the policy makers. Let us now consider the individual aspects of TPD among EFL teachers in Indonesia.

\subsubsection{Individual teacher development}

Farrell (2015) and Richards and Farrell (2005) introduced seven areas of individual professional development (see 2.1.2, Chapter Two). Four out of the seven areas of individual professional development are relevant to the findings of Chapters Three, Four and Five. They are upgrading language, maintaining subject matter knowledge, improving pedagogical knowledge, and getting prepare for career advancement.

\subsubsection{Language upgrading}

The findings of the blogging case studies (Chapter Four) show that the three EFL teachers had uneven critical reading and writing skills, as indicated by the quality of their writing in the blog. During the blogging programme, the three teachers who carried out the integrated writing (blogging) task could rarely demonstrate critical L2 reading or writing skills.

Kitchen et al. (2015: 63) highlight the importance of "sustaining teacher learning through professional reading". Kwakman (2003: 153) defines "professional reading as teacher reading activity to keep up to date with new insights and developments influencing the professional field such as new subject matter, new 
teaching methods and manuals, new pedagogical approaches, and with the new societal developments that have an impact on education and teaching in general". However, the three bloggers in the blogging case studies appeared not to use the reading materials to help them to write in a more reflective and critical fashion. Their blog entries were not as reflective or critical as I expected. Most of the blog entries narrated the teachers' own experiences related to the topic of their readings, but did not critically evaluate the ideas.

Furthermore, Cobb (2007: 38) points out that "there is a lexical paradox at the heart of reading in a second language". He argues that, in terms of vocabulary knowledge and learning, "prospective readers of English must bring to reading the same knowledge they are intended to get from reading". The finding from the blogging case studies appear to extend Cobb's lexical paradox to writing in a second language, i.e. prospective writers of English (as a second language) must bring to writing the same knowledge they are intended to get from writing. This means, if blogging is to be used as a way of maintaining target language proficiency by EFL teachers, they need to start engaging in this activity when they are still in training, so that they have the required language competency to sustain an on-going online interaction with colleagues even after their formal training is over. This is because once language attrition has set in, the blogging activity may be too much of a stretch for an in-service teacher, and less demanding forms of TPD may need to be used to boost teachers' L2 proficiency.

Together, the evaluation of the EFL teachers' L2 proficiency and writing quality in their blog entries highlights the need for EFL teachers to engage in professional development activities in order to improve and maintain their proficiency in reading and writing and their vocabulary knowledge, especially of the midfrequency and academic vocabulary.

\subsubsection{Maintaining subject matter knowledge}

The TPD policy documents analysed in Chapter Six recognise the needs for teachers to improve their subject matter expertise, but they do not explicitly direct EFL teachers to maintain or improve their English language competence. Evans et al. (2009) found that hiatuses between teacher education and professional 
development opportunities existed in Indonesia. Besides, Jalal et al. (2009) found that teachers had low professional competency. In addition, Korompot (2012) found that teacher development policy documents were commonly developed by a team of standard developers with little or no input from teachers. In the current EFL teachers' TPD opportunities, it seems that those three issues are persistent and have not been addressed well. The findings of the policy document and interview analysis reported in Chapter Six show that the EFL teachers appeared not to understand the term 'subject matter expertise' (see Section 6.2.3, Chapter Six). For example, as a manifestation of poor understanding of TPD goals, the work plans that the EFL teachers planned and designed overlooked the needs for EFL teachers to maintain their L2 proficiency. In other words, what was articulated in general terms in the policy documentation might not always be operationalized correctly in the implementation.

Another possible explanation of the use of term subject matter knowledge in the Indonesian TPD policy documents may be the basic assumption that all EFL teachers have received their professional qualification in English and, therefore, have the required knowledge to teach it. In the light of this assumption, the Indonesian government provides TPD guidelines that aim primarily to activate creativity, stimulate changes and encourage innovation among teachers, rather than to direct teachers specifically to maintain their baseline proficiency in the subject matter. It is conceivable that the government may expect that EFL teachers to be able to accurately evaluate their own L2 proficiency (i.e., their subject matter expertise) and translate the TPD policies into personal teacher development programmes that benefit both teachers and their institutions. However, this study shows that while EFL teachers had knowledge about teaching and learning second language, they were less able to accurately self-evaluate their L2 proficiency and, consequently, operationalise their PD to address their needs. In other words, the Indonesian government may overestimate the EFL teachers' ability to translate their policies and regulations into TPD programmes and activities that are needed to achieve the desired level of L2 education quality in Indonesia. 


\subsubsection{Maintaining pedagogical expertise}

The analysis of the TPD policy documents shows that teachers in Indonesia must improve their pedagogical, personal, professional and social competency. However, the analysis of the TPD implementation documents and interviews with the EFL teachers and stakeholders show that the focus of individual professional development for EFL teachers in Malang, Indonesia is improving the teachers' pedagogical competency.

Silvia (2015) and Widodo and Riandi (2013) point out that the target of professional development in other areas in Indonesia was also improving pedagogical competency. According to Widodo and Riandi's ( 2013) paper, other teaching competency: personal, professional and social competency were not mentioned or discussed by the respondents when they were asked about what they needed in the professional development programmes. Likewise, Silvia (2015) found that the EFL teachers in her study believed that TPD programmes helped them to make better teaching plan and select teaching materials better. The findings of the present study appear to resonate the findings of Silvia (2015) and Widodo and Riandi (2013) where pedagogical expertise has been the main focus of TPD. These findings indicate that the recent TPD programmes among EFL teachers in Malang, Indonesia have been greatly focused in improving the teachers' pedagogical expertise, and improving the other teaching competency (professional, personal and social competency) appears to be overlooked. These findings suggest that professional, personal and social competency should also be addressed to ensure more solid professional development.

\subsubsection{Career advancement}

The sixth area of second language teacher personal development is getting prepared for career advancement (Richards \& Farrell, 2005: 10).. This area of professional development demands second language teachers to acquire 'knowledge and expertise necessary for personal advancement and promotion, including supervisory and mentoring skills'. 
The data from the interviews with the EFL teachers and stakeholders suggests two themes that are relevant to the discussion of career advancement among EFL teachers: understanding TPD and taking part in national and international events.

The interview data showed that all teachers and stakeholders agreed that improving the teachers' competency and teaching quality was the main goal of TPD (see Section 6.2.2.1, Chapter Six). It is important that the EFL teachers and stakeholders recognize the significance of professional development programmes for teachers. Farrell (2015) and Richards and Farrell (2005) note that professional development is not a sign of inadequate training. They indicate that teaching profession is dynamic, and that teachers need to keep abreast with changes and innovations. Thus, understanding the goals of TPD is important because it may reflect the teachers' knowledge of improving their professionalism and advancing their career.

However, the teachers and stakeholders' understanding of definition, administration, evaluation, benefits, and challenges of TPD varied considerably (see Section 6.2.3, Chapter Six). This finding is somewhat alarming because their various understanding of the five aspects of TPD appears to be mirrored in their TPD practice. While accurate understanding of TPD may not be directly linked to the EFL teachers' personal advancement and promotion, the EFL teachers' limited understanding of TPD identified in this study may render TPD activities 'challenging' and 'daunting'.

Jalal et al. (2009: 26) noted that there are three key components to accelerate teacher professionalism are government support, teacher on-going individual professional development and stakeholder supervisory role. They further noted that career development and financial rewards provided further incentives for teachers to improve their professional knowledge and skills. Thus, the inconsistent understanding and practice of TPD among EFL teachers in the present study may negatively affect the EFL teachers' career advancement.

However, the EFL teachers should not be fully held responsible for their inconsistent understanding and practice of TPD. The interviews with the teachers showed that they had heavy teaching loads and additional administrative duties 
(see Section 3.6.4, Chapter Three). This finding was also endorsed by the stakeholders. One of the teacher coordinators, Nana said:

Yes, that's right. The teachers are not only teaching. They have many additional tasks. They are also in charge of everything. They become the student advisers or school treasurers too. There is so much work to do and you know we are also responsible for some administrative tasks.

The policy documents, such as the 2005 Teachers and Lecturers Law, show that in general teachers have to teach for 24 credit hours to 40 credit hours in a week (State Secretariat of the Republic of Indonesia, 2005: 16). At the same time, they have to be responsible for their main duties: planning, teaching, and assessing learning processes, guiding students and doing additional duties, such as administrative tasks and supervising students in and outside their teaching hours (State Secretariat of the Republic of Indonesia, 2005: 16).

Together, the findings about EFL teachers' understanding of TPD show that there is a dissonance between what the Indonesian government asked from the teachers and what they offered to develop teachers' professionalism and career. These findings indicate that it is essential to align the institutional goals to the teachers' individual professional development goals. This alignment is in line with the suggestion put forwards by Farrell $(2007,2015)$ and Richards and Farrell (2005) in the implementation of professional development.

The interview data showed that professional development and teacher advancement could be achieved through an active participation in national or national events. In response to the ASEAN Community 2015 scheme (ASEAN Secretariat, 2009: 1), English language teachers in high schools should be aware of the scheme, be well-informed of the scheme, be ready to help their students to learn the interconnectedness among cultures, peoples, economies, governments and ecosystems (Widiati \& Hayati, 2015). The present study shows that the EFL teachers were unaware of these national, regional and international challenges. However, two stakeholders, one teacher trainer and one teacher educator saw the needs for Indonesian EFL teachers to master both English language and ICT skills, in order to compete regionally, in the Southeast Asia level (see Subsection 6.2.3.1, Chapter Six). ICT skills are also critical in the implementation of the 
online teacher assessment (see Subsection 6.2.3.1, Chapter Six). Although it is encouraging that some stakeholders acknowledged that teachers should be able to compete in a wider international arena, and to engage in the online assessment, none of the nine teachers or remaining stakeholders mentioned these issues. This finding substantiates one of the challenges of teacher professional education in Indonesia (Widiati \& Hayati, 2015), the need to reframe teacher professional education to the ASEAN standard of teacher education programs. Without having sufficient English proficiency and ICT skills, the EFL teachers will face problems in keeping up with the ASEAN EFL teacher standard. Further research is required to explore the issue.

Together, the three studies (L2 proficiency study, blogging case studies and TPD study) extend our knowledge of teacher language proficiency and the design and provision of TPD among EFL teachers in the Indonesia. I found that TPD activities in Indonesia have been evolving around improving students' learning outcomes and teaching methodology. What is missing is the chance for EFL teachers to develop their professionalism to teach English as a foreign language. The mixed-methods research design (Creswell, 2006, 2014; Creswell \& Clark, 2007) has allowed me to explore all three issues which might have been difficult to realise if only one type of data (i.e. quantitative or qualitative data) was explored and analysed. The case study approach (Duff, 2012) was also effective in exploring the three active bloggers' writing by paying attention to their use of linguistic and special blogging features and the critical and reflective aspects of their writing. The qualitative document analysis (Altheide, 1996; Altheide, Gray, Janisch, Korbin, Maratea, Neill, Reaves, \& Van Deman, 2001; Altheide, Coyle, DeVriese, \& Schneider, 2008) and thematic analysis (Braun \& Clarke, 2006, 2012) were also pertinent to explore and analyse the TPD documents and interview data. The sequential exploratory strategy (Creswell, 2014; Creswell \& Clark, 2007) used in this thesis was effective in understanding the quantitative and qualitative data that were gathered and explored in the three studies: (1) L2 proficiency study (Chapter Three), (2) blogging studies (Chapter Four and Five), and (3) professional development study (Chapter Six). The most important limitation lies in the fact that the research has been very dynamic and the amount 
of data was vast. Notwithstanding the limitation, the present study was carefully recorded and analysed to ensure that the results of the study offers significant insights into the fields of EFL teachers' L2 proficiency, the affordances of blogging and the provision of TPD among EFL teachers in Indonesia and beyond.

\section{Summary}

Taken together, the study findings (Chapters Three, Four, and Five) suggest that the TPD policy and implementation documents appear to play more of a controlling rather than a guiding role in the administration of TPD. The documents provide EFL teachers and stakeholders with general guidelines on how to administer TPD programmes. The documents control TPD practices by providing rules and regulations to ensure that the administration runs smoothly. The TPD programmes in Indonesia aim to assist the teachers in improving the learning outcomes of their students, enhancing their status and profile of the teaching profession, and aligning their practices with educational policies (Day \& Sachs, 2004). However, the study also shows that the other goals of TPD, such as keeping up with the new challenges, educational innovations, and current issues of teaching and learning (Grundy \& Robison, 2004) are overlooked. The EFL teachers' demanding administrative and teaching loads, lack of support to access the computer and Internet, and insufficient English language skills create barriers for their engagement in innovative forms of professional development. Practical solutions to these problems need to be identified and implemented.

The next chapter, Chapter Eight will address implications of the findings, and outline research limitations and suggestions for future research. 
This page is intentionally left blank 


\section{Chapter 8 Conclusion}

\section{Introduction}

This thesis has addressed the issues of institutional and individual professional development among EFL teachers in Indonesia. The research has contributed to studies of two areas of expertise among EFL teachers, target language proficiency (that is conceptualised as a key component of subject matter knowledge) and ICT skills (with a particular focus on blogging).

This chapter describes the implications of the findings for the institutional and individual teacher development. The limitations of this study and suggestions for future studies are also discussed. I end the chapter with the conclusion of the thesis.

\subsection{Implications and Recommendations}

My overarching research questions address the issues of L2 proficiency among EFL teachers in Indonesia and efforts to assist them to maintain or improve their L2 proficiency using technology-integrated professional development.

Blogging was used as a vehicle to facilitate this professional development because the Indonesian national education system expects teachers to master ICT in their teaching practice. I explored three major topics: EFL teachers' English language proficiency (as a core component of their professional knowledge), blogging activity as a form of individual professional development that targeted their English language and ICT skills, and Indonesian national TPD policy documents and their implementation. I followed Richards and Farrell's (2005) model of institutional and individual teacher development to understand the nature of existing TPD policy and implementation documents and the practices of TPD among EFL teachers. The findings of this study have a number of important implications to the issues related to EFL teachers' L2 proficiency, ICT skills, and TPD policy and implementation documents. 


\subsubsection{Implications for TPD targeting EFL teachers' L2 proficiency}

The present study finds that at the individual level, efforts to improve ICT skills have been acknowledged and partially administered by EFL teachers. However, the other three concerns: maintaining L2 proficiency, maintaining subject matter knowledge, and improving critical thinking have not been fully acknowledged and addressed. The findings of the present study indicate that L2 proficiency was not top priority for EFL teachers' professional development. Thus, it is important to fully acknowledge and support the need for EFL teachers to maintain and upgrade their L2 proficiency as part of their individual teacher development.

The government can support the maintenance of EFL teachers' L2 proficiency by proposing ideas on what characterise excellent foreign language proficiency or what level of proficiency to benchmark the Indonesian EFL teachers' language proficiency internationally. This idea is inspired by the availability of benchmark in one of Southeast Asian nations, Vietnam (Dudzik \& Nguyen, 2015).

Alternatively, through their teacher association (i.e. TEFLIN association or district MGMP), EFL teachers can actively propose or participate in their local TPD programmes and acknowledge their needs to improve as well as to continuously maintain their target language proficiency. Harvey et al. (2010: 1213) maintain:

Becoming proficient in another language takes time. Learning language is long process, and it can be a challenge to sustain learning, so motivation may fluctuate over the time. ... and teachers at the lower levels of target language proficiency need to be encouraged to continue learning the target language until they do have considerable knowledge so they can be fully effective.

Indeed, the EFL teachers' motivation to develop their professionalism and the government support to the betterment of national education need to go hand in hand to achieve these goals.

The study findings suggest that Indonesian government through its Ministry of Education and Culture (MoEC) need to review the administration of TPD among EFL teachers in particular and/or among teachers in general. The central MoEC, through its district and provincial branches, should consider better integrating both bottom-up and top-down approaches to TPD. This is because the top-down 
approach is needed to ensure that the government (central, provincial, and/or district government) provides financial support and other relevant resources; but the top-down approach alone is insufficient to address the necessities, lacks, and wants of the EFL teachers. The idea of teacher-driven professional development should be cherished and supported because this bottom-up approach builds the teachers' sense of ownership of the TPD programmes (Adey et al., 2004; Avalos, 2004; Widodo \& Riandi, 2013) and better serves the teachers' perceived needs (Noom-ura, 2013).

However, there are no easy ways to encourage in-service EFL teachers to have a better sense of ownership and be more motivated to participate in TPD activities. Two possible approaches might help. The first one is giving the EFL teachers more voice during the design of the TPD activities, i.e. by considering the results of the EFL teachers' self-assessment at the beginning and end of the academic year. The results of the assessment should not serve as regulatory and control function, but used as professional developmental guides, in order to help EFL teachers to plan, administer and evaluate their TPD activities. Second, the EFL teachers should consider designing and creating their own Handbook of Continuous Professional Development for English language teachers. The existing handbook was published as an explanation of the general TPD policy documents, was designed and created by educational experts and did not specifically target EFL teachers or for teachers of other subjects in Indonesian secondary schools. The direct involvement of EFL teachers' in the development of handbooks of TPD that translate general policy documents into more discipline specific, practical and understandable texts will empower them and bring about a sense of ownership among them. Although this may add to teachers' workload, the step is worth trying because, in the long run, more EFL teachers would benefit from it. Finally, for individual professional development of the teachers, an environment analysis and needs analysis should be carried out prior to making decisions about individual goals. For example, during one of the MGMP meetings at the beginning of each school year, each EFL teacher needs to decide on their shortterm and long-term goals and explore strategies on how these goals can be achieved. They should also critically evaluate what they planned in the previous 
school year, what have been done to achieve last year's goals, whether or not the goals have been achieved (and, if not, why not), and what should or will be done for the upcoming school year.

In conclusion, efforts to maintain EFL teachers' L2 proficiency and subject matter knowledge, ICT skills, and critical thinking skills should be aligned to the institutional goals. Likewise, efforts to keep up with changes and innovations in ELT should consider EFL teachers' individual professional development. In addition, environment and needs analysis should be administered prior to the commencement of individual or institutional professional development to ensure that aims and results are in line. If there are discords between the objectives and outcomes, ways to solve the issues should also be available.

What can we learn from the discussion on the implications of the study to the institutional and individual aspects of professional development among EFL teachers, in Malang, Indonesia? Does the discussion help us to understand the issue of blogging for EFL teachers' TPD? Let us now discuss the issue.

\subsubsection{Implications for TPD targeting ICT-related issues}

Mastering ICT skills is acknowledged in the TPD policy and implementation documents in Indonesia. However, support from schools, heads of school, teacher training institutions, and government have been quite low. Thus, if blogging were to be used as a means of EFL teacher professional development, a certain level of English language proficiency and ICT skills are needed. Blogging as a form of professional development may not be suitable for TPD programme, but would be better used to maintain a curtain proficiency level (e.g. for new teacher graduates), overcoming the dangers of target language attrition overtime. Or, for more confident teachers (bloggers/ICT leaders), it can be used to demonstrate leadership by engage their colleagues in professional dialogue through creating and leading regional EFL teacher blogs. This way those who may not be at the right proficiency or ICT level could simple observe initially, and join the conversation when they are ready. In conclusion, the idea of using blogging as a form of professional development among EFL teachers has to be assessed and considered carefully to ensure the effectiveness of the programme. Without giving 
a thorough consideration and evaluation, not much can be expected from the programme.

\subsubsection{Implications for the TPD policy and implementation}

The study findings inform our understanding of how EFL teachers and stakeholders perceive teacher development policies and practice. The study finds that policy documents and implementation documents only partially addressed the needs for teachers to keep up with changes and innovations in ELT. The institutional TPD held by EFL teachers at the district level did not focus on supporting the teachers to maintain and improve their two areas of expertise, English proficiency and ICT skills. These findings, while preliminary, indicate that clarifying and calibrating teachers' perceptions of the goals, administration, and evaluation of TPD could help to build a more positive image of TPD and, as a consequence, assist teachers in their preparation for individual advancement and promotion. To realise the idea of building a positive image of TPD, teachers need to work with a range of stakeholder: teacher supervisors (teacher coordinators, heads of school, and school supervisors), educational institutions (schools, district MoEC, and the government), and other organizations (higher education and donor organisations, i.e. the World Bank, AusAID, USAID, JICA). Another way for EFL teachers and their coordinators to calibrate and clarify their perceptions of TPD is by working together to provide additional guidelines to translate and implement the TPD policy documents at the local level.

At the school level, professional development refers to both school and teachers' needs. Making decisions about the institutional goals may rely on the agreement between the heads of schools, teachers, school supervisors and parent associations. Thus, for the administrators of teacher development at the institutional level (school, district, provincial or national level), the recommendation is to include information on the rationale, goals, context, content, sequencing, format, presentation, monitoring and assessing in their annual work plans (Nation and Macalister, 2010). It is recommended that EFL teachers and stakeholders invest time to analyse the constraints, necessities, lacks and wants prior to TPD implementation, in order to ensure that goals set are achievable and 
that any potential problems that may arise during the TPD implementation can be addressed in a timely manner (Nation \& Macalister, 2010; Richards \& Farrell, 2005). For example, on the issue of environmental analysis, the administrators of TPD have to understand the specific context in which programmes are implemented (e.g., whether technology is involved, whether participants have reliable access to the Internet, sufficient for the planned activities), recognise who the participants are (e.g., whether they are novice or senior teachers, or both) and who the trainers are (e.g., whether they are well trained). The environmental analyses should be done to ensure that the institutional TPD programmes target the right participants, have appropriate instructors, and address the context of TPD effectively and efficiently. On the issue of needs analysis, for instance, the administrators of TPD at the local level have to know and be aware of the EFL teachers' necessities (what knowledge they are supposed to have), lacks (what knowledge they are lacking), and wants (what knowledge they wish to learn). The needs analyses should be administered to ensure that the activities proposed in the work plans are relevant to the EFL teachers' and their schools' immediate and long-term needs, lacks and wants.

It also appears that career advancement was acknowledged but support was not always obtainable easily. Career advancement would be more achievable if EFL teachers participate in appropriate professional development, especially if it facilitates opportunities for them to contribute beyond their local level. The present study shows that all EFL teachers were aware of the need to improve their teaching quality and maintain a certain level of English language proficiency, although they did not necessarily express it in the same way as the official policy documents. This finding indicates the urgency for EFL teachers to plan for shortterm and long-term individual goals, select strategies for their achievement, and find support from others (i.e. fellow teachers, teacher coordinators, school principals, teacher trainers, and donors). If, for example, an English teacher's long-term goal is to raise her chances to be promoted through her contribution in the ELT innovation, she can start her efforts by presenting the results of her action research in an international seminar. Her short-term goals may include finding the most appropriate seminar she could attend, writing up an abstract to be submitted, 
and looking for some fund to support the presentation. The strategies to reach the goals may include a small scale online investigation of what international seminars will be held in the coming months and whether or not she needs a copresenter to write the abstract and present in the seminar.

\subsection{Limitations and Suggestions for Future Research}

There are several limitations of the study that need to be acknowledged. Firstly, the teacher L2 proficiency study has examined the relationship between EFL teachers' years of service and their target language proficiency. However, not all participants were able to complete the testing in a group setting. A small number of participants took these tests individually, which may have affected their test scores. Unfortunately, this testing condition (individual vs. group) could not be accounted for statistically, because the teachers who were tested individually were mostly pre-service teachers. Thus, the two variables (the testing condition and the teacher group) are conflated, and cannot be teased out.

One of the challenges of the present study was gathering data from EFL teachers from three types of secondary schools in Malang District, Indonesia: Sekolah Menegah Pertama (SMP or lower secondary schools), Sekolah Menegah Atas (SMA or public higher secondary schools), and Sekolah Menegah Kejuruan (SMK or vocational higher secondary schools). Each type of school has its own MGMP and schedule for regular meetings. There was also a policy of taking a turn in attending the MGMP meetings or TPD programmes. Thus, although efforts were made to ensure all teachers attended the MGMP meetings or teacher development programmes and could collaborate with other groups of teachers, it was difficult to realise it. For this reason, teacher participation in the two data gathering sessions was uneven, which makes it difficult to fully match the data sets. The data sets encompass questionnaire data, the results of the three L2 proficiency tests, and interview data. The first issue surfaced because the questionnaire data was gathered anonymously from 68 EFL teachers while the proficiency tests $(n=62)$ and interviews $(n=20)$ were gathered with the teachers or stakeholders' name. The second issue surfaced when the heads of schools enacted the policy of taking a turn in attending TPD. Thus, some EFL teachers 
who participated in the questionnaire session could not participate in the proficiency test session. It was difficult to trace back who participated and did not participate in the questionnaire session and match with the participants of the proficiency test session. In the future, it may be more applicable to focus on each type of school separately, in order to achieve higher data integrity. The findings from each type of school can be then considered together to build a more comprehensive picture across the three types of secondary schools.

Another limitation is that only reading and writing proficiency and vocabulary knowledge were investigated in the Teacher L2 proficiency study. Listening and speaking skills were not tested. Future studies should evaluate all four language skills (i.e. reading, writing, speaking, and listening) and two aspects of L2 knowledge (i.e. vocabulary and grammar). Furthermore, using standardised tests developed specifically for measuring teacher target language proficiency would ensure comparability across studies and better means of conducting regular needs analysis (Elder \& Kim, 2013; Smadi \& Al-Ghazo, 2013; Zhang \& Elder, 2009)). This idea is somewhat similar to the idea suggested by Richards (2017: 28) in which the EFL teachers have to master both L2 proficiency and teaching ability to ensure that the ability teach effectively in English.

The present study used EFL teachers' self-report instruments, the questionnaire and interviews, to gather information about their perceived English proficiency. The issue of the credibility of self-reports is persistent because "the respondents are subject to various sources of inaccuracy, self-deception, loss of memory, selfconsciousness, rapport, transference, and modelling" (Paulhus \& Vazire, 2009: 228). However, by using language proficiency tests alongside the self-report data from the questionnaire and individual interviews created the triangulation needed to construct a more balanced narrative.

Still another limitation can also be found in the L2 proficiency study. The use of target language, English, in the information sheet, consent form, questionnaire and writing prompts of blogging activity appeared to stymie the EFL teachers' understanding and responses to forms, questionnaire and blog writing. The teachers' L1, Indonesian, could have been used to elicit their responses so that 
they could express themselves well and were not stymied by their English proficiency. Future studies might consider the use of the participants' L1 and/or L2 to ensure that the requested responses are understood and expressed well.

Other limitations are the difficulty to decouple years of service and age and the existence of other potentially confounding factors, such as: the status of English in Indonesia over time, the quality of English education received by successive cohorts of student teachers in Indonesia, easier access to English and the increase of international conferences attended by teachers in the recent years. The age of the EFL teachers was not one of the factors considered in the study although it is highly positively correlated with the teachers' years of service. While all preservice teachers ( 0 year of teaching service, $n=8$ teachers) have higher proficiency level, I argue that the teachers' high proficiency was not caused by the change of status of English in Indonesia. The status of English remains the same as it was announced 4 years after the Independence of Indonesia in 1945. English is a foreign language now and then (Dardjowidjojo, 2000; Jazadi, 2000; Lauder, 2008). Future studies should consider the possibility (1) of dissociating years of service and age and (2) factoring the other confounding factors, i.e. the quality of EFL teachers' English education, access to English in and outside schools and participation to relevant conferences (although this is likely to be very difficult to accomplish in practice).

Several limitations should also be acknowledged in relation to the second study and third study. In the blogging case studies and teacher development study, I analysed the blogging entry data and the TPD documents without the assistance of other analysts. The choice not to use other analysts was based on Duff' idea (2012: 10) that analysing data independently without the assistance of other analysts is done "to demonstrate the consistency, accuracy, or validity" of the analysis. However, Duff (2012: 107) highlights that "having someone else to examine at least a subset of the data would ensure the consistency, transparency, logic, or clarity of themes in relation to larger study". In relation to Duff's idea on having another rater, it is highly recommended that future studies use other analysts or raters to examine blogging data to see how consistent and understandable rubrics for scoring writing and to ensure consistency, 
transparency, logic or clarity, especially if the study is bigger and covers wider areas.

Similar to Duff (2012), it is essential to have another rater to analyse the policy and implementation documents of TPD for reliability and careful sampling for validity (Friedman, 2012: 194). She states that:

...to enhance reliability when coding qualitative data one can use multiple raters, each of whom codes the data separately. The coding schemes are then compared, and differences are negotiated until a consensus is achieved."

Thus, future studies are recommended to use multiple raters to increase the reliability of the findings of the study.

In the present study, convenience sampling method has challenged the generalisability of the findings on the correlation between years of service and EFL teachers' L2 proficiency. The participants of the proficiency study were 54 in-service teachers and 8 pre-service teachers who were not randomly chosen and may not be representative of the population of EFL teachers in Malang, Indonesia. In addition, there are three types of secondary schools in Malang District, as I described earlier: lower secondary schools, public higher secondary schools, and vocational higher secondary schools. The EFL teachers who work under these types of schools have different supporting factors and barriers to TPD, i.e. heads of school' support, availability of internet connection at school, and number of EFL teachers in one school. By gathering the EFL teachers in a school that had reliable internet connection, for example, I may have missed the chance to understand the actual difficulties that they faced to administer or to participate in an online TPD. It would be worth further exploring the types of professional development of EFL teachers in each group of schools or in one group of schools but with a wider scope, i.e. in one province rather than just in one district, and using a random sampling to achieve accurate representation of the population. These steps should be done to achieve more robust findings and better generalisability of the findings than the present study. 


\subsection{Conclusion}

This study contributes to the discussion of institutional and individual perspectives of teacher development and the importance of environment and needs analysis in the TPD curriculum design process. This study also contributes to the investigation of the EFL teachers' perceived understanding of the TPD policy documents and their actual practices. Finally, this study also sheds light on the EFL teachers' disciplinary knowledge (EFL teachers' target language proficiency as a core component of their professional knowledge) and ICT skills (especially the EFL teachers' blogging skills). 
This page is tentionally left blank 


\section{References}

Abdullah, U. (2015). Learning through Teacher Professional Training: English Teacher Certification Program in Indonesia (Unpublished PhD thesis). The Ohio State University, United States -- Ohio. Retrieved from http://search.proquest.com/docview/1699717948/abstract

Adey, P., Hewitt, G., Hewitt, J., \& Landau, N. (2004). The Professional Development of Teachers: Practice and Theory | Philip Adey | Springer. Dordrecht, The Netherlands: Kluwer Academic Publishers. Retrieved from http://www.springer.com/us/book/9781402020056

Aiello, J., Di Martino, E., \& Di Sabato, B. (2015). Assessing will-be CLIL teachers' language competence: Issues if testing and languange competence of education professionals. Rivista Di Psicolinguistica Applicata, 15(1), 61-76.

Altheide, D., Coyle, M., DeVriese, K., \& Schneider, C. (2010). Emergent qualitative document analysis. In S. N. Hesse-Biber \& P. Leavy (Eds.), Handbook of Emergent Methods (pp. 127-154). New York and London: Guilford Press.

Altheide, D. L. (1987). Reflections: Ethnographic content analysis. Qualitative Sociology, 10(1), 65-77. https://doi.org/10.1007/BF00988269

Altheide, D. L. (1996). Qualitative Media Analysis. 2455 Teller Road, Thousand Oaks California 91320 United States of America: SAGE Publications, Inc. Retrieved from http://srmo.sagepub.com/view/qualitative-mediaanalysis/SAGE.xml

Altheide, D. L. (2000). Tracking discourse and qualitative document analysis. Poetics, 27(4), 287-299. https://doi.org/10.1016/S0304-422X(00)00005-X 
Altheide, D. L., Coyle, M., DeVriese, K., \& Schneider, C. (2008). Emergent Qualitative Document Analysis. In S. Hesse-Biber \& P. Leavy (Eds.), Handbook of Emergent Methods. Guilford Press.

Altheide, D. L., Gray, B., Janisch, R., Korbin, L., Maratea, R., Neill, D., ... Deman, F. V. (2001). News constructions of fear and victim: An exploration through triangulated qualitative document analysis. Qualitative Inquiry, 7(3), 304-322. https://doi.org/10.1177/107780040100700304

Altheide, D. L., Gray, B., Janisch, R., Korbin, L., Maratea, R., Neill, D., ... Van Deman, F. (2001). An exploration through triangulated Qualitative Document Analysis. Qualitative Inquiry, 7(3), 304-322.

Aritonang, M. (2016). Investigating Indonesian teachers' experience, motivation, and confidence in English-medium content teaching through a professional development blended learning environment (Unpublished $\mathrm{PhD}$ thesis). University of Waikato, Waikato, New Zealand. Retrieved from http://researchcommons.waikato.ac.nz/handle/10289/10250

ASEAN Secretariat. (2009). Roadmap for an ASEAN community (2009-2015). ASEAN Secretariat.

Avalos, B. (2004). CPD policies and practices in the Latin American region. In C. Day \& J. Sachs (Eds.), International Handbook on the Continuing Professional Development of Teachers (pp. 119-145). Berkshire, England: Open University Press. 
Bardovi-Harlig, K., \& Stringer, D. (2010). Variables in second language attrition: Advancing the state of the art. Studies in Second Language Acquisition, $32(1), 1-45$.

Beglar, D., \& Hunt, A. (1999). Revising and validating the 2000 Word Level and University Word Level Vocabulary Tests. Language Testing, 16(2), 131162. https://doi.org/10.1177/026553229901600202

Best, B. (2014). A study of elementary school Thai English teachers' perceived English proficiency and self-reported English teaching efficacy. Language in India, 14(7), 77-195.

Blood, R. (2000, September 7). Weblogs: A history and perspective. Retrieved 13 January 2014, from http://www.rebeccablood.net/essays/weblog_history.html

Braun, V., \& Clarke, V. (2006). Using thematic analysis in psychology. Qualitative Research in Psychology, 3(2), 77-101. https://doi.org/10.1191/1478088706qp063oa

Braun, V., \& Clarke, V. (2012). Thematic analysis. In APA handbook of research methods in psychology (Vol. 2, pp. 57-71). American Psychological Association. Retrieved from http://search.proquest.com.helicon.vuw.ac.nz/docview/1547568159/abstra ct/EFE1FE2DEEED49CEPQ/1?accountid=14782

Brescia, W., \& Miller, M. T. (2006). What's it worth? The perceived benefits of instructional blogging. Electronic Journal for the Integration of Technology in Education, 5(1), 44-52. 
Butler, Y. G. (2005). Comparative perspectives towards communicative activities among elementary school teachers in South Korea, Japan and Taiwan. Language Teaching Research, 9(4), 423-446. https://doi.org/10.1191/13621688051r176oa

Cambridge IELTS 6. (2007). In Examination papers from University of Cambridge ESOL examinations: English for speakers of other languages (p. 176). Cambridge, UK: Cambridge University Press.

Campbell, A. P. (2003). Weblogs for use with ESL classes. The Internet TESL Journal, IX(2). Retrieved from http://iteslj.org/Techniques/CampbellWeblogs.html

Carlson, G. (2015). Let's get social: The educator's guide to Edmodo (First edition..). Eugene, Oregon: International Society for Technology in Education. Retrieved from http://site.ebrary.com/lib/vuw/Doc?id=11155266

Cobb, T. (1999). Breadth and depth of lexical acquisition with hands-on concordancing. Computer Assisted Language Learning, 12(4), 345-360.

Cobb, T. (2007). Computing the vocabulary demands of L2 reading. Language Learning \& Technology, 11(3), 38-63.

Cohen, D., \& Crabtree, B. (2006, July). Thick Description. Retrieved 23 February 2016, from http://www.qualres.org/HomeThic-3697.html

Coxhead, A. (2000). A new Academic Word List. TESOL Quarterly, 34(2), 213238. https://doi.org/10.2307/3587951

Creswell, J. W. (2006). Qualitative inquiry and research design: Choosing among five approaches (2nd edition). Thousand Oaks: SAGE Publications, Inc. 
Creswell, J. W. (2014). Research design: Qualitative, quantitative, and mixed methods approaches (Fourth Edition). Los Angeles, USA: SAGE Publications, Inc.

Creswell, J. W., \& Clark, D. V. L. P. (2007). Designing and Conducting Mixed Methods Research (1 edition). Thousand Oaks, Calif: Sage Publications, Inc.

Creswell, J. W., Plano Clark, V. L., Gutmann, M. L., \& Hanson, W. E. (2003). An expanded typology for classifying mixed methods research into designs. In A. Tashakkori \& C. Teddlie (Eds.), Handbook omixed mehtods in social and behavioral research (pp. 209-240). Thousand Oaks, CA: SAGE.

Dardjowidjojo, S. (2000). English Teaching in Indonesia. EA Journal, 18(1), 2230.

Day, C., \& Sachs, J. (2004). Professionalism, performativity and empowerment: Discourse development. In C. Day \& J. Sachs (Eds.), International Handbook on the Continuing Professional Development of Teachers (pp. 3-32). Berkshire, England: Open University Press.

de Almeida Soares, D. (2008). Understanding class blogs as a tool for language development. Language Teaching Research, 12(4), 517-533.

De Moor, A., \& Efimova, L. (2004). An argumentation analysis of weblog conversations. In The 9th International Working Conference on the Language-Action Perspective on Communication Modelling (LAP 2004). Retrieved from https://pure.uvt.nl/portal/files/605522/Moor_Efimova.pdf

Deng, L., \& Yuen, A. H. (2011). Towards a framework for educational affordances of blogs. Computers \& Education, 56(2), 441-451. 
Direktorat Jenderal Peningkatan Mutu Pendidik dan Tenaga Kependidikan.

(2010). Buku 1: Pedoman pengelolaan pengembangan keprofesian (PKB).

Dörnyei, Z., \& Csizér, K. (2011). How to Design and Analyze Surveys in Second Language Acquisition Research. In A. Mackey \& S. M. Gass (Eds.), Research Methods in Second Language Acquisition (pp. 74-94). John Wiley \& Sons, Ltd.

Dudzik, D. L., \& Nguyen, Q. T. N. (2015). Vietnam: Building English Competency in Preparation for ASEAN 2015. In S. Richmond \& K. Kimura (Eds.), ASEAN Integration and the Role of English Language Teaching (pp. 41-71). Phnom Penh, Cambodia: IDP Education (Cambodia).

Duff, P. A. (2012). How to Carry out Case Study Research. In A. Mackey \& S. M. Gass (Eds.), Research Methods in Second Language Acquisition (pp. 95116). John Wiley \& Sons, Ltd.

Edge, J., \& Richards, K. (1998). May I see your warrant, please? : Justifying outcomes in qualitative research. Applied Linguistics, 19(3), 334-356.

Elder, C., \& Kim, S. H. O. (2013). Assessing teachers' language proficiency. In The Companion to Language Assessment. John Wiley \& Sons, Inc.

Elgort, I. (2011). Deliberate learning and vocabulary acquisition in a second language. Language Learning, 61(2), 367-413. https://doi.org/10.1111/j.1467-9922.2010.00613.x

Eslami, Z. R., \& Fatahi, A. (2008). Teachers' Sense of Self-Efficacy, English Proficiency, and Instructional Strategies: A Study of Nonnative EFL 
Teachers in Iran. Teaching English as a Second or Foreign Language, 11(4), 1-19.

Evans, D., Tate, S., Navarro, R., \& Nicolls, M. (2009). Teacher education and professional development in Indonesia: A gap analysis. USAID, Aguirre Division of JBS International, Inc.

Farrell, T. S. C. (2007). Reflective language teaching: from research to practice. New York: Continuum.

Farrell, T. S. C. (2015). Language Teacher Professional Development. (T. Press, Ed.). TESOL Publications.

Farrell, T. S. C., \& Richards, J. C. (2007). Teachers' language proficiency. In Reflective Language Teaching: From Research to Practice (1 edition). London; New York: Bloomsbury Academic.

Field, A. P. (2013). Discovering statistics using IBM SPSS statistics: and sex and drugs and rock ' $n$ ' roll (4th ed). Los Angeles: Sage.

Fraga-Cañadas, C. P. (2010). Beyond the classroom: Maintaining and improving teachers' language proficiency. Foreign Language Annals, 43(3), 395421. https://doi.org/10.1111/j.1944-9720.2010.01090.x

Friedman, D. A. (2012). How to collect and analyze qualitative data. In A. Mackey \& S. M. Gass (Eds.), Research Methods in Second Language Acquisition (pp. 180-200). John Wiley \& Sons, Ltd. Retrieved from http://onlinelibrary.wiley.com.helicon.vuw.ac.nz/doi/10.1002/9781444347 340.ch10/summary

Ghasemboland, F., \& Hashim, F. B. (2013). Teachers' Self-efficacy Beliefs and their English Language Proficiency: A Study of Nonnative EFL Teachers 
in Selected Language Centers. Procedia - Social and Behavioral Sciences, 103, 890-899. https://doi.org/10.1016/j.sbspro.2013.10.411

Gibson, J. J. (2015). The theory of affordances. In The Ecological Approach to Visual Perception (Classic Edition, pp. 119-135). New York: Taylor \& Francis Group.

Grundy, S., \& Robison, J. (2004). Teacher professional development: Themes and trends in the recent Australian experience. In C. Day \& J. Sachs (Eds.), International Handbook on the Continuing Professional Development of Teachers (pp. 146-166). Berkshire, England: Open University Press.

Harvey, S., Conway, C., Richards, H., \& Roskvist, A. (2010). A report to the Ministry of Education: Evaluation of Teacher Professional Development Languages(TPDL)in years 7-10 and the impact on language learning opportunities and outcomes for students (p. 123). Wellington, New Zealand: Ministry of Education.

Harwell, S. H. (2003). Teacher Professional Development: It's Not an Event, It's a Process. The Center for Occupational Research and Development (CORD).

IBM Corp. (2011). IBM SPSS Statistics for Windows (Version 20.0) [IBM SPSS Statistics for Windows, Version 20.0]. Armonk, NY.

Ince, D. (2013). Personal blog - Oxford Reference. Retrieved 20 August 2015, from http://www.oxfordreference.com/view/10.1093/acref/9780191744150.001. 0001/acref-9780191744150-e-4304 
Jalal, F., Samani, M., Chang, M. C., Stevenson, R., Ragatz, A. B., \& Negara, S. D. (2009). Teacher certification in Indonesia : A strategy for teacher quality improvement (No. 48578) (pp. 1-219). The World Bank.

Jazadi, I. (2000). Constraints and resources for applying communicative approaches in Indonesia. EA Journal, 18(1), 31-40.

Kitchen, M. C., Jeurissen, M., \& Gray, S. (2015). Primary school teachers' uptake of professional readings: Understanding the factors affecting teachers' learning. New Zealand Journal of Teachers' Work, 12(1), 63-77.

Kitchen, M., Jeurissen, M. J., \& Gray, S. M. (2015). Primary school teachers' uptake of professonal readings: Understanding factors affecting teachers' learning. New Zealand Journal of Teachers' Work, 12(1), 63-77.

Korompot, C. A. (2012). Giving teachers their voices: Indonesian EFL teachers' perspectives on professional teaching standards in the context of teacher certification programs in Indonesia (Unpublished $\mathrm{PhD}$ thesis). The University of New England, UK.

Kučera, H., \& Francis, W. N. (1967). Computational analysis of present-day American English. Michigan: Brown University Press.

Kwakman, K. (2003). Factors affecting teachers' participation in professional learning activities. Teaching and Teacher Education, 19(2), 149-170. https://doi.org/10.1016/S0742-051X(02)00101-4

Lauder, A. (2008). The status and function of English in Indonesia: A review of key factors. Makara, 12(1), 9-20. 
Laufer, B. (1997). The lexical plight in second language reading. In Second Language Vocabulary Acquisition: A Rationale for Pedagogy. Cambridge University Press.

Laufer, B. (2012). Vocabulary and writing. In The Encyclopedia of Applied Linguistics. John Wiley \& Sons, Inc. Retrieved from http://onlinelibrary.wiley.com.helicon.vuw.ac.nz/doi/10.1002/9781405198 431.wbeal1432/abstract

Laufer, B., \& Ravenhorst-Kalovski, G. C. (2010). Lexical threshold revisited: Lexical text coverage, learners' vocabulary size and reading comprehension. Reading in a Foreign Language, 22(1).

Lave, J., \& Wenger, E. (1991). Situated learning: Legitimate peripheral participation. Cambridge university press. Retrieved from https://books.google.co.nz/books?hl=en\&lr=\&id=CAVIOrW3vYAC\&oi=f nd\&pg=PA11\&dq=situated+learning:+legitimate+peripheral+participation \&ots=OBoytr0FHh\&sig=Kg_h4yZtP8A3X1bV51emShp3YcE

Lee, J.-W., \& Schallert, D. L. (1997). The relative contribution of L2 language proficiency and L1 reading ability to L2 reading performance: A test of the threshold hypothesis in an EFL context. Tesol Quarterly, 31(4), 713-739.

Lengkanawati, N. S. (2005). EFL teachers' competence in the context of English curriculum 2004: Implications for EFL teacher education. TEFLIN Journal: A Publication on the Teaching and Learning of English, 16(1), 79-92. 
Leung, C. (2009). Second language teacher professionalism-Whose agenda? In A. Burns \& J. C. Richards (Eds.), The Cambridge Guide to Second Language Teacher Education. Cambridge ; New York: Cambridge University Press. Lie, A. (2007). Education policy and EFL curriculum in Indonesia: Between the commitment to competence and the quest for higher test scores. TEFLIN Journal: A Publication on the Teaching and Learning of English, 18(1), $1-13$.

Luehmann, A. L. (2008). Using blogging in support of teacher professional identity development: A case study. Journal of the Learning Sciences, 17(3), 287-337. https://doi.org/10.1080/10508400802192706

Mackey, A., \& Gass, S. M. (2005). Second language research: Methodology and design. Mahwah, NJ: Lawrence Erlbaum.

Mai. (2014). Towards a holistic approach to developing the language proficiency of Vietnamese primary teachers of English. Electronic Journal for the Integration of Technology in Education, 11(2), 342-357.

Marcellino, M. (2005). Competency-based language instruction in speaking classes: Its theory and implementation in Indonesian contexts. Indonesian Journal of English Language Teaching, 1(1), 33-44.

McMillan, J. H., \& Schumacher, S. (1993). Research in education: A conceptual introduction (THIRD EDITION edition). New York, USA: HarperCollins College Publishers.

Mori, S., Ming, T. S., Nor, N. F. M., Suppiah, V. L., \& Imm, O. S. (2011). Attribution tendency and its relationship with actual and perceived poficiency. GEMA Online® Journal of Language Studies, 11(3), 199-218. 
Multon, K. D. (2010). Interrater reliability. In Encyclopedia of Research Design (pp. 627-629). 2455 Teller Road, Thousand

Oaks California 91320 United States: SAGE Publications, Inc. Retrieved from http://srmo.sagepub.com/view/encyc-of-research-design/n194.xml

Musthafa, B. (2001). Communicative language teaching in Indonesia: Issues of theoretical assumptions and challenges in the classroom practice. TEFLIN Journal: A Publication on the Teaching and Learning of English, 12(2), 184-193.

Nation, I. S. P. (1983). Testing and teaching vocabulary. Guidelines, 5(1), 12-25.

Nation, I. S. P. (1990). Teaching and learning vocabulary. New York, NY, US: Newbury House Publishers.

Nation, I. S. P. (2006). How large a vocabulary is needed for reading and listening? Canadian Modern Language Review/La Revue Canadienne Des Langues Vivantes, 63(1), 59-82.

Nation, I. S. P., \& Macalister, J. (2010). Language curriculum design. New York and London: Routledge.

Nation, P. (2006). Language Education - Vocabulary. In K. Brown (Ed.), Encyclopedia of Language \& Linguistics (Second Edition) (pp. 494-499). Oxford: Elsevier. Retrieved from http://www.sciencedirect.com/science/article/pii/B0080448542006787

Nation, P. (2007). The four strands. International Journal of Innovation in Language Learning and Teaching, 1(1), 2-13. 
Noom-ura, S. (2013). English-teaching problems in Thailand and Thai teachers' professional development needs. English Language Teaching, 6(11). https://doi.org/10.5539/elt.v6n11p139

Nunan, D. (2002). Listening in language learning. In Methodology in language teaching: An anthology of current practice (pp. 238-241). Retrieved from http://books.google.co.nz/books?hl=en\&lr=\&id=VxnGXusQ1I8C\&oi=fnd $\& p g=P A 238 \& d q=$ discriminating + between+second+language+learning+te $\mathrm{xt}+$ types\&ots=qfwpnjgygN\&sig=88KfzRUkRtO5S1h1XNPF-dl6HgE

Nurhemida, N. (2007). The relationship between morphological awareness and English vocabulary knowledge of Indonesian senior high school students (Unpublished Master Thesis). The University of Queensland, Queensland, Australia.

Padamu Negeri Indonesiaku. (no date). Retrieved 27 January 2016, from http://padamu.siap.web.id/

Pallant, J. (2011). SPSS survival manual: A step by step guide to data analysis using SPSS (4th ed.). McGraw-Hill Education.

Park, C. N., \& Son, J.-B. (2009). Implementing computer-assisted language learning in the EFL classroom: Teachers' perceptions and perspectives. International Journal of Pedagogies and Learning, 5(2), 80-101.

Paulhus, D. L., \& Vazire, S. (2009). The self-report method. In R. W. Robins, R. C. Fraley, \& R. F. Krueger (Eds.), Handbook of Research Methods in Personality Psychology (pp. 224-239). New York: Guilford Press. 
Plakans, L. (2009). The role of reading strategies in integrated L2 writing tasks. Journal of English for Academic Purposes, 8(4), 252-266. https://doi.org/10.1016/j.jeap.2009.05.001

Plakans, L., \& Gebril, A. (2012). A close investigation into source use in integrated second language writing tasks. Assessing Writing, 17(1), 18-34. https://doi.org/10.1016/j.asw.2011.09.002

Plakans, L., \& Gebril, A. (2013). Using multiple texts in an integrated writing assessment: Source text use as a predictor of score. Journal of Second Language Writing, 22(3), 217-230. https://doi.org/10.1016/j.jslw.2013.02.003

Riazi, A. M., \& Candlin, C. N. (2014). Mixed-methods research in language teaching and learning: Opportunities, issues and challenges. Language Teaching, 47(2), 135-173. https://doi.org/10.1017/S0261444813000505

Richards, J. C. (2017). Teaching English through English: Proficiency, pedagogy and performance. RELC Journal, 48(1), 7-30.

Richards, J. C., \& Farrell, T. S. C. (2005). Professional development for language teachers: Strategies for teacher learning. Cambridge, UK: Cambridge University Press.

Sari, E. R. (2012). Online learning community: A case study of teacher professional development in Indonesia. Intercultural Education, 23(1), 63-72. https://doi.org/10.1080/14675986.2012.664755

Schmid, M. S. (2011). Language Attrition. Cambridge: Cambridge University Press. Retrieved from http://ebooks.cambridge.org/ebook.jsf?bid=CBO9780511852046 
Schmid, M. S., \& Mehotcheva, T. (2012). Foreign language attrition. Dutch Journal of Applied Linguistics, 1(1), 102-124. https://doi.org/10.1075/dujal.1.1.08sch

Schmid, M. S., \& Mehotcheva, T. H. (2012). Foreing language attrition. Dutch Journal of Applied Linguistics, 1(1), 102-104.

Schmitt, N., Schmitt, D., \& Clapham, C. (2001). Developing and exploring the behaviour of two new versions of the Vocabulary Levels Test. Language Testing, 18(1), 55-88. https://doi.org/10.1177/026553220101800103

Senge, P. M., Cambron-McCabe, N., Lucas, T., Smith, B., Dutton, J., \& Kleiner, A. (2000). Schools that learn: A fifth discipline fieldbook for educators, parents, and everyone who cares about education. Broadway, New York: Doubleday.

Silvia, A. (2015). COURSERA online: A platform for English teachers' meaningful and vibrant professional development. TEFLIN Journal, 26(2), $228-246$.

Smadi, O. M., \& Al-Ghazo, A. (2013). Jordanian teachers' language proficiency, and experiential knowledge and their relationship to teachers' classroom practices. International Journal of Business and Social Science, 4(11), $230-257$.

Son, J.-B., Robb, T., \& Charismiadji, I. (2011). Computer literacy and competency: A survey of Indonesia teachers of English as a foreign language. $C A L L-E J, 12(1), 26-42$.

Spalding, R., Zimmerman, T. S., Fruhauf, C. A., Banning, J. H., \& Pepin, J. (2010). Relationship advice in top-selling men's magazines: A qualitative 
document analysis. Journal of Feminist Family Therapy, 22(3), 203-224. https://doi.org/10.1080/08952833.2010.503795

State Secretariat of the Republic of Indonesia. (2008). Peraturan Pemerintah Nomor 74 tahun 2008 tentang Guru. State Secretariat of the Republic of Indonesia.

State Secretariat of the Republic of Indonesia (SSRI). (2003). Undang-undang Republik Indonesia nomor 20 tahun 2003 tentang Sistem Pendidikan Nasional.

Sun, Y. (2010). Extensive writing in foreign- language classrooms: a blogging approach. Innovations in Education and Teaching International, 47(3), 327-339. https://doi.org/10.1080/14703297.2010.498184

Tantri, N. R. (2014). A program evaluation of MGMP (teacher professional development forum) program for English senior high school teachers in Sidoarjo (Unpublished Master Thesis). State University of Malang, Indonesia.

Thamrin, M. (2011). Enhancing Professional Development through Classroom Action Research Projects: A Case Study of Secondary English Teachers in Palu City, Central Sulawesi, Indonesia (Unpublished Master Thesis). Victoria University of Wellington, Wellington, New Zealand. Retrieved from http://researcharchive.vuw.ac.nz/handle/10063/2086

Timperley, H., Wilson, A., Barrar, H., \& Fung, I. (2007). Teacher Professional Learning and Development: Best Evidence Synthesis Iteration (BES). New Zealand Ministry of Education. Retrieved from http://www.educationcounts.govt.nz/publications/series/2515/15341 
UNESCO. (2006). Teachers and educational quality: Monitoring Global Needs for 2015. UNESCO Institute for Statistics.

van Lier, L. (2000). From input to affordance:Social-interactive learning from an ecological perspective. In Sociocultural Theory and Second Language Learning (pp. 245-259). Oxford: Oxford University Press.

Vurdien, R. (2013). Enhancing writing skills through blogging in an advanced English as a Foreign Language class in Spain. Computer Assisted Language Learning, 26(2), 126-143.

Webb, S. A., \& Chang, A. C.-S. (2012). Second Language Vocabulary Growth. RELC Journal, 43(1), 113-126. https://doi.org/10.1177/0033688212439367

West, M. P. (1953). A general service list of English words. California, USA: Longmans, Green.

Widiati, U., \& Hayati, N. (2015). Teacher professional education in Indonesia and ASEAN 2015: Lessons learned from English language teacher education programs. In ASEAN integration and the role of English language teaching (pp. 121-148). Phnom Penh, Cambodia: IDP Education (Cambodia).

Widodo, A., \& Riandi. (2013). Dual-mode teacher professional development: Challenges and re-visioning future TPD in Indonesia. Teacher Development, 17(3), 380-392. https://doi.org/10.1080/13664530.2013.813757

Yusri, I. K., \& Goodwin, R. (2013). Mobile Learning for ICT Training: Enhancing ICT Skill of Teachers in Indonesia. International Journal of E- 
Education, E-Business, E-Management and E-Learning, 3(4), 293.

https://doi.org/http://dx.doi.org/10.7763/IJEEEE.2013.V3.243

Zhang, Y., \& Elder, C. (2009). Measuring the Speaking Proficiency of Advanced EFL Learners in China: The CET-SET Solution. Language Assessment Quarterly, 6(4), 298-314. https://doi.org/10.1080/15434300902990967 
Appendices 
VICTORIA UNIVERSITY OF WELLINGTON

Te Whare Wānanga o te Ūpoko o te Ika a Māui

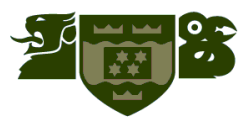

\section{Appendix 1 Information Sheet for Participants}

\section{Project title:}

\section{Blogging among in-service teachers}

\section{Researcher}

Anik Nunuk Wulyani, School of Linguistics and Applied Language Studies

Victoria University of Wellington (VUW), New Zealand

I am a doctoral student at Victoria University of Wellington (VUW). As part of my $\mathrm{PhD}$, I am conducting research on in-service teachers' blogging activity.

This research provides language teachers with insights about the potential of blogging. It is hoped that these insights can contribute directly to teacher's professional development. This research is supervised by Dr Irina Elgort and Dr Averil Coxhead.

I would like to invite you to participate in this research study. Your participation is voluntary. Your name will not be revealed and it will not be possible for you to be identified personally. You will be identified under a pseudonym. This research has been approved by the Human Ethics Committee of VUW. Below is a description of what I would like you to do if you agree to take part in this study:

\section{Participants' involvement}

If you agree to take part in this study, you will be required to fill in a survey at the beginning and end of the study. In the beginning of the study, I would like you to fill in a survey on Blogging in English. The survey should take no longer than 30 minutes. You will be asked to include your contact details in the survey so that I can contact and invite you to participate in the next part of the study.

The next part of my study involves several steps:

- a pre-study reading and writing task (100 minutes)

- two meetings of blogging training session ( 2 x 60 minutes $)$ 
- a six-month blogging activity programme on the topic of project-based learning (2-3 hours in a month)

- a post-study reading and writing task (100 minutes)

- post-study survey ( $\leq 30$ minutes)

- a final interview (30 minutes)

I estimate that the total time commitment required for the project is about 600 minutes or about 10 hours. First, the pre -study task is an IELTS-like test: a 60-minute Reading task and a 40-minute Writing task. The data from the tasks will not be used for anything other than the study. The second stage involves joining blogging training sessions. Each meeting will take about 60 minutes. The training sessions will be followed by posting a monthly report on the research blog, on the topic of Project-Based Learning for six months. This report is a 250-to-500-word essay on the assigned topic. You will receive some feedback on the content of your essays. The next step is a post-reading and writing task, which is an IELTS-like test similar to the pre-study task. Lastly, I will interview you for approximately 30 minutes. You will be interviewed after the post-study reading and writing task. I will audio-record the interview and then transcribe the interview verbatim. Any information from the interview will be checked with you for accuracy. This will approximately take less than 30 minutes.

\section{Sharing of information}

The data collated and examined will be part of my $\mathrm{PhD}$ thesis that will be available through Victoria University of Wellington library, Education Department of Malang Municipality and State University of Malang. The only persons who will have access to the data will be my supervisors and me. All collected data (recordings, transcripts and notes) will be kept on password-protected system and destroyed five years after the end of the research. All collected data (recordings, transcripts and notes) will be kept on a password protected system and it will all be destroyed five years after the end of the research. If you would like, I could provide you with a summary of the research findings and results of your tests. The results of this research may be published in academic journals or presented at academic conferences. 


\section{Confidentiality}

You have the right to withdraw from the research at any time before data analysis commences without providing any explanation. The information gathered from you will be destroyed after your withdrawal.

If you have any questions about this project please contact me at Anik.Wulyani@vuw.ac.nz, or my supervisors at Irina.Elgort@vuw.ac.nz or Averil.Coxhead@vuw.ac.nz. If you have any ethical concerns please contact Dr. Allison Kirkman (Allison.Kirkman@ @uw.ac.nz), Chair of Victoria University of Wellington, human ethics committee.

Thank you for your cooperation.

Researcher:

Anik Nunuk Wulyani

New Zealand Address:

School of Linguistics and Applied

Language Studies

Victoria University of Wellington

PO Box 600

Wellington 6140, New Zealand

Phone: +64221902573

E-mail: Anik.Wulyani@vuw.ac.nz

$\underline{\text { Dr Irina Elgort }}$

Central Academic Development (CAD) 10 Waiteata Road

Victoria University of Wellington

PO Box 600

Wellington 6140

Phone: +644 4635970

E-mail: Irina.Elgort@vuw.ac.nz
Indonesian Address:

Jurusan Sastra Inggris

Fakultas Sastra

Universitas Negeri Malang (UM)

Jl Semarang 5 Malang, 65145

Jawa Timur, Indonesia

Phone: +6281 1368681

E-mail: Anik.Wulyani@vuw.ac.nz

\section{$\underline{\text { Dr Averil Coxhead }}$}

School of Linguistics and Applied

Language Studies

Victoria University of Wellington

PO Box 600

Wellington 6140

Phone: +644 4635625

E-mail: Averil.Coxhead@vuw.ac.nz 


\section{Appendix 2 Consent form}

\section{Project title:}

Blogging among in-service teachers

\section{Researcher}

Anik Nunuk Wulyani, School of Linguistics and Applied Language Studies

Victoria University of Wellington (VUW), New Zealand

Please read each of the following statements carefully before acknowledging your participation in the research.

- I agree to participate in this research project.

- I have been provided with enough information about the nature and objectives of this research and I have been given the opportunity to seek further clarification.

- I understand that my identity will remain confidential.

- I understand that any information I provide will be kept at a secure location, and will only be available to the researcher and her supervisors

- I understand that I can withdraw from the project before the data analysis is commenced, which is 1 May 2014.

- I understand that all research notes and data will be destroyed five years after the conclusion of the research

- I understand that the information I have provided will be used only by Anik Nunuk Wulyani for this research project, publications and presentation arising from this research

- I understand that the final thesis will be kept at the Victoria University library, Education Department of Malang Municipality and State University of Malang library and may be used in publications and conferences

- I understand that I may contact the researcher or her supervisors if I require further information or to make a complaint relating to my involvement in the research. 
Signed:

I would like to receive a summary of the results of this research when it is completed YES/NO

I would like to receive the results of my tests (pre- and post-reading and writing tasks) when they are completed

YES/NO

My mailing or email address for the summary and test's results:

Mailing/email address 


\section{Appendix 3 Survey for Indonesian EFL Teachers}

This survey is administered to know the participants' individual information, professional development, professional characteristics and skills, use of English and miscellaneous issues related to the topic of the study. Please take your time answering these questions (20-30 minutes max). Answer them as accurately and truthfully as possible and remember that your name will be kept confidential. Your participation in this survey is voluntary and you can choose not to continue at any time. Your insights are very valuable and very much needed in the professional of language teaching and teacher education programs. I encourage you to contact me should you have any concerns: Anik.Wulyani@vuw.ac.nz.

\section{Section 1 Individual Information}

1.1 How long have you been teaching English (ENG) (in years and months)?

1.2 What is you first (native) language?

1.3 What other language(s) do you speak or know?

1.4 What is your gender? $\square$ Female $\square$ Male

1.5 What is your date of birth?

1.6 Please check $(\sqrt{ })$ all the degree (s) you received, write your major (s), and the year you graduated

\begin{tabular}{|l|l|l|c|}
\hline & \multicolumn{1}{|c|}{ Degree (s) } & Major (s) & Year \\
\hline$\square$ & Diploma degree & & \\
\hline$\square$ & Bachelor degree & & \\
\hline$\square$ & Master's degree & & \\
\hline$\square$ & Doctoral degree & & \\
\hline$\square$ & Other ( & & \\
\hline
\end{tabular}

\section{Section 2 Professional Development}

2.1 Since you have received your teaching qualification, do you think your overall ENG proficiency has ?
$\square$ improved
$\square$ stayed the same
declined
$\square$ not sure 
2.2 To what extent do you think your teacher preparation program has prepared you in the following areas? Mark your response by a check $(\sqrt{ })$.

\begin{tabular}{|l|l|l|l|l|}
\hline & $\begin{array}{c}\text { To a great } \\
\text { extent }\end{array}$ & To some extent & Not all & Not sure \\
\hline Listening & & & & \\
\hline Reading & & & & \\
\hline Writing & & & & \\
\hline Speaking & & & & \\
\hline Grammar & & & & \\
\hline $\begin{array}{l}\text { Computer assisted } \\
\text { language learning (CALL) }\end{array}$ & & & & \\
\hline
\end{tabular}

2.3 In the last three school years (since July 2010) have you participated in any professional development exclusively for ENG teachers provided by your district or country?

$\square$ Yes No $\rightarrow$ skip to 2.5

2.4 Please describe these professional development opportunities exclusively for ENG teachers? $\rightarrow$ continue to 2.6

2.5 English teachers have different reasons for not participating in professional development opportunities. Can you share some of your reasons for not participating in these opportunities?

2.6 To what extent does your school district or county provide you with opportunities to....

\begin{tabular}{|l|l|l|l|l|}
\hline & $\begin{array}{l}\text { To a great } \\
\text { extent }\end{array}$ & $\begin{array}{l}\text { To some } \\
\text { extent }\end{array}$ & Not at all & Not sure \\
\hline Maintain or improve ENG proficiency & & & & \\
\hline Maintain or improve your CALL skills & & & & \\
\hline
\end{tabular}


2.7 What year are you teaching this academic year? (Please check all that apply)

$\square$ Year $7 \quad \square$ Year 8 $\square$ Year 9 $\square$ Year 10 $\square$ Year 11 Year $\square$

2.8 What year do you normally teach? (Please check all that apply)
Year 7
$\square$ Year 8
$\square$ Year 9
Year 10
Year 11 Year $\square$

2.8 Are you currently a member of any English teacher associations or organisations?

(Please check all that apply)

$\square$ MGMP $\quad \square$ TEFLIN $\square$ Other(s)

2.9 Since July 2010, how many (if any) English-speaking conferences have you attended? (include international, national, and state conferences)
$\square 0$ (skip to 3.1)
$\square 1 \square 2$
$\square 4$
$\square 5 \quad \square 6$ or more

2.10 How many times, if at all, have you presented at English-speaking conference(s) since July $2010 ?$

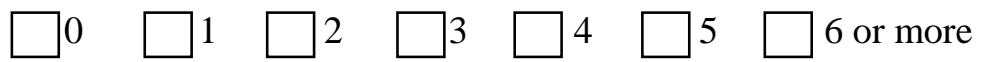

\section{Section 3 Professional Characteristics and Skills}

3.1 Please indicate to what extent you disagree or agree with the following statements, mark your response by a check $(\sqrt{ })$ :

\begin{tabular}{|l|l|l|l|l|}
\hline & $\begin{array}{l}\text { Strongly } \\
\text { agree }\end{array}$ & agree & Disagree & $\begin{array}{l}\text { Strongly } \\
\text { disagree }\end{array}$ \\
\hline I frequently seek opportunities to write in ENG & & & & \\
\hline I frequently seek opportunities to read ENG & & & & \\
\hline $\begin{array}{l}\text { I believe my reading proficiency in ENG has } \\
\text { improved since I started teaching }\end{array}$ & & & & \\
\hline $\begin{array}{l}\text { I believe my writing proficiency in ENG has } \\
\text { improved since I started teaching }\end{array}$ & & & & \\
\hline $\begin{array}{l}\text { I believe my CALL skills have improved since } \\
\text { I started teaching }\end{array}$ & & & & \\
\hline $\begin{array}{l}\text { I frequently incorporate authentic English } \\
\text { language materials to use in my classrooms. }\end{array}$ & & & & \\
\hline
\end{tabular}

3.2 Thinking about the English teaching profession, how important are these characteristics to you? Mark your response by a check $(\sqrt{ })$

\begin{tabular}{|l|l|l|l|l|}
\hline & $\begin{array}{l}\text { Very } \\
\text { important }\end{array}$ & Important & $\begin{array}{l}\text { Somewhat } \\
\text { important }\end{array}$ & $\begin{array}{l}\text { Not } \\
\text { important }\end{array}$ \\
\hline $\begin{array}{l}\text { Having native-like communication skills } \\
\text { (both written and spoken) in English }\end{array}$ & & & & \\
\hline $\begin{array}{l}\text { Knowledge of language teaching } \\
\text { methodology }\end{array}$ & & & & \\
\hline CALL skills & & & & \\
\hline Being able to interact successfully with & & & & \\
\hline
\end{tabular}


native speakers in English

Being able to communicate successfully

with non-native speakers in English

Being able to comprehend oral and written

media in ENG

3.3 At present, how would you describe your.....

\begin{tabular}{|l|l|l|l|l|}
\hline & Excellent & It's OK & $\begin{array}{c}\text { Needs some } \\
\text { work }\end{array}$ & $\begin{array}{c}\text { Needs a lot } \\
\text { of work }\end{array}$ \\
\hline ENG Reading proficiency & & & & \\
\hline ENG Writing proficiency & & & & \\
\hline CALL knowledge & & & & \\
\hline $\begin{array}{l}\text { Lexical proficiency (word knowledge and } \\
\text { use) }\end{array}$ & & & & \\
\hline Computer literacy & & & & \\
\hline Internet literacy & & & & \\
\hline Blogging literacy & & & & \\
\hline
\end{tabular}

\section{Section 4 Use of English}

4.1 Thinking only outside the school settings, how often have you had time to engage in the following activities during the last three school years (since July 2010)?

\begin{tabular}{|l|l|l|l|l|}
\hline & $\begin{array}{l}\text { Almost } \\
\text { always or } \\
\text { always }\end{array}$ & Frequently & Occasionally & $\begin{array}{l}\text { Never } \\
\text { or } \\
\text { rarely }\end{array}$ \\
\hline Read a book in ENG & & & \\
\hline $\begin{array}{l}\text { Read magazines, newspapers, reports in } \\
\text { ENG }\end{array}$ & & & & \\
\hline Watched TV in ENG & & & & \\
\hline Watched a movie in ENG & & & & \\
\hline Listened to music in ENG & & & & \\
\hline Had entire conversations in ENG & & & & \\
\hline Surfed internet in ENG & & & & \\
\hline Chatted online in ENG & & & & \\
\hline $\begin{array}{l}\text { Wrote letters/e-mail / text messages to } \\
\text { friends or colleagues in ENG }\end{array}$ & & & & \\
\hline Wrote blog posts in ENG & & & & \\
\hline \begin{tabular}{l} 
Other English language activities: \\
\hline
\end{tabular} & & & & \\
\hline
\end{tabular}

\section{Section 5 Miscellaneous}

5.1 What other things come to mind in relation to the topics covered in this survey.

Anything else you would like to share? 
Thank you for your co-operation! 


\section{Appendix 4 Interview guides}

Appendix 4A Interview guide for teachers

Appendix 4B Interview guide for stakeholders 


\section{VICTORIA UNIVERSITY OF WELLINGTON \\ Te Whare Wānanga o te Ūpoko o te Ika a Māui

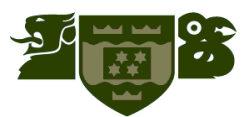

\section{Appendix 4A Interview guide for teachers}

\section{General questions:}

1. How are you?

2. Tell me about yourself. (You can tell me about your name, job, how long you have been on the job, and what you like about your job.)

3. Tell me more about your educational background. (You can explain about where and when you studied and what you learned during your study.)

\section{Questions on the study and other relevant issues:}

1. Recently you took part in a blogging study. What are your overall impressions of that study?

2. What influenced you in your decision to continue blogging until the end of the study?

3. What do you think about blogging as a form of professional development activity for EFL teachers? (pros and cons)

4. You mentioned in the questionnaire that your language proficiency was (improved, stay the same or declined). Why did you think that your language proficiency was (improved, stay the same or declined)?

5. What do you do outside school to maintain your English proficiency?

6. (looking at the results of their proficiency tests) Now look at the results of your tests. The one that I have sent you. Please tell me what you understand about the scores you have here.

7. How important is the knowledge of Information and Communication Technology (ICT) for teachers in the classrooms? Please share your experience of using ICT when teaching English in the classroom. 


\section{Questions on Professional Development:}

1. What do you know about a professional development (PD) programme? What is it?

2. Tell me, what PD programmes are available for EFL teachers in your district?

3. What views do you have on PD programmes?

4. What do you think are their goals/objectives?

5. How are those objectives implemented, in your experience?

6. What indicators are used to measure their success?

7. Have you taken part in a PD programme? What was/were these programme/s?

8. Is L2 proficiency maintenance is included in PD programmes or not?

9. (If not) Why not? What do you usually do on PD programmes? Please describe the activities. How effective and efficient are the programmes?

10. (If yes) How would you describe the program? What is like? How effective and efficient are the programmes?

11. Do you know what I mean by Computer Mediated Communication (CMC)? Is CMC training offered to EFL teachers in the PD programmes you've participated in?

12. What are the strengths and weaknesses of the training related to EFL teaching?

13. In your opinion, what are the challenges of teacher education in the future?

14. Before we finish, what questions or comments do you have for me?

\section{Closing: thanking the interviewee(s)}

I really appreciate the time you have spent to participate in the study. I believe that your answers will provide insights and will contribute to the betterment of teacher education and teacher professionalism. Thank you. 


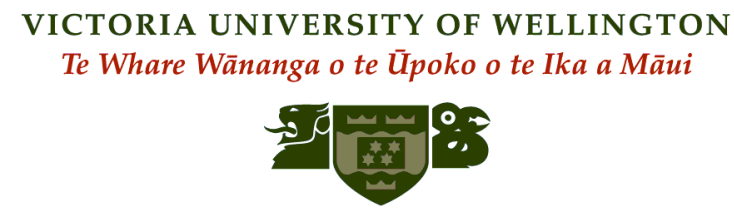

\section{Appendix 4B Interview guide for stakeholders}

I am interviewing you to have a full picture of EFL English Proficiency and Professional Development in Indonesia in general and for more specific, in Malang district. Please be advised that the interview will be recorded.

\section{General questions:}

1. How are you?

2. Tell me about yourself. You can tell me about your name, job, how long you have been on the job, and how you like your job.

\section{Specific questions}

1. How would you describe the EFL teachers' English proficiency in Indonesia and in Malang in general?

2. To the best of your knowledge, do you think their English proficiency is sufficient for them to teach in English?

3. Do you think their English proficiency can assist them to communicate in spoken and written forms with colleagues and native speakers of English well? Why or why not?

4. What are your suggestions to in-service teachers and pre-service teachers on the issue (of the Indonesian EFL teachers' English proficiency)?

5. How important is the knowledge on ICT for EFL teachers?

\section{Questions on Professional Development:}

1. What do you know about a professional development (PD) programme? What is it?

2. What do you think are their goals/objectives?

1. How are those objectives implemented, in your experience?

2. Tell me, what PD programmes are available for EFL teachers in your district?

3. What views do you have on PD programmes? 
4. What indicators are used to measure their success?

5. Have you taken part in a PD programme? What was/were the programme/s?

6. Is L2 proficiency maintenance is included in PD programmes or not?

7. (If not) Why not? What do you usually do on PD programmes? Please describe the activities. How effective and efficient are the programmes?

8. (If yes) How would you describe the program? What is like? How effective and efficient are the programmes?

9. Do you know what I mean by Computer Mediated Communication (CMC)? Is CMC training offered to EFL teachers in the PD programmes you've participated in?

10. What are the strengths and weaknesses of the training related to EFL teaching?

11. In your opinion, what are the challenges of teacher education in the future?

12. What are the roles of PD in the teachers' career progress?

13. Is there any format for PD? What is it like? Or why there is no format?

14. What should/shouldn't the teacher do in a PD programmes? Are there any rules?

15. Before we finish, what questions or comments do you have for me?

\section{Closing: thanking the interviewee(s)}

I really appreciate the time you have spent to participate in the study. I believe that your answers will provide insights and will contribute to the betterment of teacher education and teacher professionalism. Thank you. 


\section{Appendix 5 The Vocabulary Levels Test}

\section{A vocabulary levels test: Version 2}

Name:

This is a vocabulary test. You must choose the right word to go with each meaning. Write the number of that word next to its meaning. Here is an example.

1 business

2 clock part of a house

3 horse animal with four legs

4 pencil something used for writing

5 shoe

6 wall

You answer it in the following way.

1 business

2 clock

- 6 part of a house

3 horse

3 _ animal with four legs

4 pencil

4 _ something used for writing

5 shoe

6 wall

Some words are in the test to make it more difficult. You do not have to find a meaning for these words. In the example above, these words are business, $\underline{\text { clock}}$, and shoe.

If you have no idea about the meaning of a word, do not guess. But if you think you might know the meaning, then you should try to find the answer. 
Version 2 The 2,000 word level

$\begin{array}{ll}1 \text { copy } & \\ 2 \text { event } & \text { end or highest point } \\ 3 \text { motor } & \text { this moves a car } \\ 4 \text { pity } & \text { thing made to be like } \\ 5 \text { profit } & \text { another } \\ 6 \text { tip } & \end{array}$

1 admire

2 complain

3 fix

make wider or longer

(1)

bring in for the first

4 hire

time

5 introduce

have a high opinion of

6 stretch

1 accident

2 debt

loud deep sound

1 arrange

3 fortune

something you must

pay

2 develop

3 lean

4 pride

having a high opinion 5

4 owe

of yourself

5 prefer

someone

roar

6 thread

6 seize

$\begin{array}{ll}1 \text { coffee } & \\ 2 \text { disease } & \text { money for work } \\ 3 \text { justice } & \text { a piece of clothing } \\ 4 \text { skirt } & \text { using the law in the } \\ 5 \text { stage } & \text { right way }\end{array}$

1 blame

2 elect

3 jump

4 manufacture

5 melt

6 threaten

1 clerk

1 ancient

2 frame

a drink

2 curious

not easy

3 noise

office worker

4 respect

unwanted sound

3 difficult

very old

4 entire

related to God

5 theatre

6 wine

5 holy

6 social

$\begin{array}{ll}1 \text { dozen } & \\ 2 \text { empire } & \text { chance } \\ 3 \text { gift } & \text { twelve } \\ 4 \text { opportunity } & \text { money paid to the } \\ 5 \text { relief } & \text { government }\end{array}$

1 bitter

2 independent beautiful

3 lovely small

4 merry

liked by many people

5 popular

6 slight 


\section{Version 2 The 3,000 word level}

1 bull
2 champion
3 dignity
4 hell
5 museum
6 solution

1 blanket

2 contest

3 generation

4 merit

5 plot

6 vacation

1 comment

2 gown

3 import

4 nerve

5 pasture

6 tradition

1 administration

2 angel

3 frost

4 herd

5 fort

6 pond

___ holiday
good quality
__ wool covering used on
beds

$\ldots \_$formal and serious manner
winner of a sporting event
building where valuable
objects are shown

2 dwell

3 oblige

4 pursue

5 quote

6 resolve

1 assemble

2 attach

3 peer

4 quit

5 scream

6 toss

$1 \mathrm{drift}$

2 endure

3 grasp

goods from a foreign

country

__ part of the body which

carries feeling

4 knit

5 register

6 tumble

1 atmosphere

2 counsel

3 factor

4 hen

5 lawn

6 muscle
1 brilliant

2 distinct

3 magic

4 naked

5 slender

6 stable

\begin{tabular}{ll} 
group of animals & \\
spirit who serves God & \\
\hline & \\
managing business and & distinct \\
affairs & 3 magic \\
& 4 naked \\
& 5 slender \\
& 6 stable
\end{tabular}

advice

a place covered with

grass

female chicken

1 aware

2 blank

3 desperate

4 normal

5 striking

6 supreme live in a place

follow in order to catch

leave something

permanently look closely

stop doing something

cry out loudly in fear suffer patiently

join wool threads

together

hold firmly with your

hands

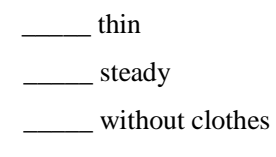

best or most important

knowing what is

happening 


\section{Version 2 The 5,000 word level}

$\begin{array}{ll}1 \text { analysis } & \\ 2 \text { curb } & \text { eagerness } \\ 3 \text { gravel } & \text { loan to buy a house } \\ 4 \text { mortgage } & \text { small stones mixed with } \\ 5 \text { scar } & \text { sand }\end{array}$

6 zeal

$\begin{array}{ll}1 \text { cavalry } & \\ 2 \text { eve } & \text { small hill } \\ 3 \text { ham } & \text { day or night before a } \\ 4 \text { mound } & \text { holiday } \\ 5 \text { steak } & \text { soldiers who fight from } \\ 6 \text { switch } & \text { horses }\end{array}$

1 circus

2 jungle

3 nomination

4 sermon

5 stool

6 trumpet

1 artillery

2 creed

3 hydrogen

4 maple

5 pork

6 streak

1 chart

2 forge

3 mansion

4 outfit

5 sample

6 volunteer

place where metals are

made and shaped
1 contemplate

2 extract

3 gamble

4 launch

5 provoke

6 revive

1 demonstrate

2 embarrass

3 heave

obscure

5 relax

6 shatter

1 correspond

2 embroider

3 lurk

4 penetrate

5 prescribe

6 resent

1 decent

2 frail

3 harsh

4 incredible

5 municipal

6 specific

1 adequate

2 internal

enough

3 mature

4 profound

fully grown

5 solitary

6 tragic

things exchange letters

hide and wait for someone

feel angry about something weak

concerning a city

difficult to believe

alone away from other 


\section{Version 2 Academic vocabulary}

\begin{tabular}{|c|c|c|c|}
\hline 1 area & & 1 alter & \\
\hline 2 contract & __ written agreement & 2 coincide & __ change \\
\hline 3 definition & ___ way of doing something & 3 deny & ___ say something is not \\
\hline 4 evidence & ___ reason for believing & 4 devote & true \\
\hline 5 method & something is or is not & 5 release & ___escribe clearly and \\
\hline 6 role & true & 6 specify & exactly \\
\hline 1 debate & & 1 correspond & \\
\hline 2 exposure & $\ldots$ plan & 2 diminish & ___ keep \\
\hline 3 integration & ___ choice & 3 emerge & __ match or be in \\
\hline 4 option & $\ldots$ joining something into a & 4 highlight & agreement with \\
\hline 5 scheme & whole & 5 invoke & $\ldots$ ___ give special attention \\
\hline 6 stability & & 6 retain & to something \\
\hline
\end{tabular}

1 access

1 bond

2 gender

male or female

2 channel

make smaller

3 implementation

study of the mind

3 estimate

guess the number or

4 license

entrance or way in

5 orientation

4 identify

5 mediate

6 psychology

6 minimize

size of something

recognizing and naming

a person or thing

1 accumulation

2 edition

3 guarantee

4 media

5 motivation

6 phenomenon

collecting things over
time
promise to repair a
broken product
feeling a strong reason
or need to do something

1 explicit

2 final

last

3 negative

stiff

4 professional

meaning 'no' or 'not'

5 rigid

6 sole

or need to do something

1 adult

2 exploitation

3 infrastructure

4 schedule

5 termination

6 vehicle end

machine used to move

people or goods

list of things to do at

certain times
1 abstract

2 adjacent

3 controversial

4 global

5 neutral

___ next to

added to

concerning the whole

world

6 supplementary 


\section{Version 2 The 10,000 word level}

1 alabaster
2 chandelier
3 dogma
4 keg
5 rasp

6 tentacle

$\begin{array}{ll}1 \text { benevolence } & \\ 2 \text { convoy } & \text { kindness } \\ 3 \text { lien } & \text { set of musical notes } \\ 4 \text { octave } & \text { speed control for an } \\ 5 \text { stint } & \text { engine }\end{array}$

6 throttle

engine

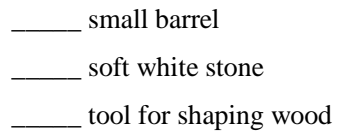

1 bourgeois

2 brocade

3 consonant

4 prelude

5 stupor

6 tier

1 alcove

2 impetus

3 maggot

4 parole

5 salve

6 vicar

1 alkali

2 banter

3 coop

4 mosaic

stealth

6 viscount

pieces of glass or stone
1 dissipate

2 flaunt

3 impede

4 loot

5 squirm

6 vie

1 contaminate

2 cringe

3 immerse

4 peek

5 relay

6 scrawl

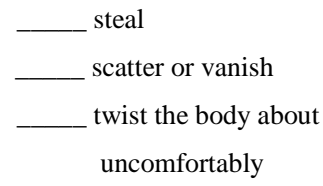

1 blurt

2 dabble

3 dent

4 pacify

5 strangle

6 swagger

1 illicit

2 lewd

3 mammoth

4 slick

5 temporal

6 vindictive

1 indolent

2 nocturnal

3 obsolete

4 torrid

picture made of small 5

5 translucent

6 wily walk in a proud way

kill by squeezing

someone's throat

say suddenly without thinking

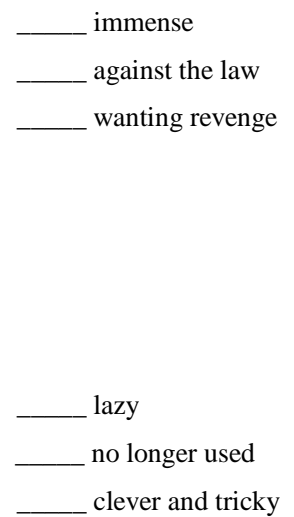


Appendix 6 Writing scoring rubrics 


\section{IELTS TASK 2 Writing band descriptors (public version)}

\begin{tabular}{|c|c|c|c|c|}
\hline Band & Task Achievement & Coherence and Cohesion & Lexical Resource & Grammatical Range and Accuracy \\
\hline 9 & $\begin{array}{l}\text { - fully addresses all parts of the } \\
\text { task } \\
\text { - presents a fully developed } \\
\text { position in answer to the } \\
\text { question with relevant, fully } \\
\text { extended and well supported } \\
\text { ideas }\end{array}$ & $\begin{array}{l}\text { - uses cohesion in such a way that it } \\
\text { attracts no attention } \\
\text { - skilfully manages paragraphing }\end{array}$ & $\begin{array}{l}\text { - uses a wide range of vocabulary } \\
\text { with very natural and } \\
\text { sophisticated control of lexical } \\
\text { features; rare minor errors occur } \\
\text { only as 'slips' }\end{array}$ & $\begin{array}{l}\text { - uses a wide range of structures with full } \\
\text { flexibility and accuracy, rare minor errors } \\
\text { occur only as 'slips' }\end{array}$ \\
\hline 8 & $\begin{array}{l}\text { - sufficiently addresses all parts } \\
\text { of the task } \\
\text { - presents a well-developed } \\
\text { response to the question with } \\
\text { relevant, extended and } \\
\text { supported ideas }\end{array}$ & $\begin{array}{l}\text { - sequences information and ideas } \\
\text { - logically } \\
\text { - manages all aspects of cohesion well } \\
\text { appropriately }\end{array}$ & $\begin{array}{l}\text { - uses a wide range of vocabulary } \\
\text { - fluently and flexibly to convey } \\
\text { precise meanings } \\
\text { - skilfully uses uncommon lexical } \\
\text { items but there may be } \\
\text { occasional inaccuracies in word } \\
\text { choice and collocation } \\
\text { - produces rare errors in spelling } \\
\text { and/or word formation }\end{array}$ & $\begin{array}{l}\text { - uses a wide range of structures } \\
\text { - the majority of sentences are error-free } \\
\text { - makes only very occasional errors or } \\
\text { inappropriacies }\end{array}$ \\
\hline 7 & $\begin{array}{l}\text { - addresses all parts of the task } \\
\text { - presents a clear position } \\
\text { throughout the response } \\
\text { - presents, extends and } \\
\text { supports main ideas, but there } \\
\text { may be a tendency to } \\
\text { overgeneralise and/or } \\
\text { supporting ideas may lack } \\
\text { focus }\end{array}$ & $\begin{array}{l}\text { - logically organises information and } \\
\text { ideas; there is clear progression } \\
\text { throughout } \\
\text { - uses a range of cohesive devices } \\
\text { appropriately although there may be } \\
\text { some under-/over-use } \\
\text { - presents a clear central topic within } \\
\text { each paragraph }\end{array}$ & $\begin{array}{l}\text { - uses a sufficient range of } \\
\text { vocabulary to allow some } \\
\text { flexibility and precision } \\
\text { - uses less common lexical items } \\
\text { with some awareness of style } \\
\text { and collocation } \\
\text { - may produce occasional errors } \\
\text { in word choice, spelling and/or } \\
\text { word formation }\end{array}$ & $\begin{array}{l}\text { - uses a variety of complex structures } \\
\text { - produces frequent error-free sentences } \\
\text { - has good control of grammar and } \\
\text { punctuation but may make a few errors }\end{array}$ \\
\hline 6 & $\begin{array}{l}\text { - addresses all parts of the task } \\
\text { although some parts may be } \\
\text { more fully covered than others } \\
\text { - presents a relevant position } \\
\text { although the conclusions may } \\
\text { become unclear or repetitive } \\
\text { - presents relevant main ideas } \\
\text { but some may be } \\
\text { inadequately } \\
\text { developed/unclear }\end{array}$ & $\begin{array}{l}\text { - arranges information and ideas } \\
\text { coherently and there is a clear overall } \\
\text { progression } \\
\text { - uses cohesive devices effectively, but } \\
\text { cohesion within and/or between } \\
\text { sentences may be faulty or mechanical } \\
\text { - may not always use referencing clearly } \\
\text { or appropriately } \\
\text { - uses paragraphing, but not always } \\
\text { logically }\end{array}$ & $\begin{array}{l}\text { - uses an adequate range of } \\
\text { vocabulary for the task } \\
\text { - attempts to use less common } \\
\text { vocabulary but with some } \\
\text { inaccuracy } \\
\text { - makes some errors in spelling } \\
\text { and/or word formation, but they } \\
\text { do not impede communication }\end{array}$ & $\begin{array}{l}\text { - uses a mix of simple and complex } \\
\text { sentence forms } \\
\text { - makes some errors in grammar and } \\
\text { punctuation but they rarely reduce } \\
\text { communication }\end{array}$ \\
\hline
\end{tabular}




\begin{tabular}{|c|c|c|c|c|}
\hline 5 & $\begin{array}{l}\text { - addresses the task only } \\
\text { partially; the format may be } \\
\text { inappropriate in places } \\
\text { - expresses a position but the } \\
\text { development is not always } \\
\text { clear and there may be no } \\
\text { conclusions drawn } \\
\text { - presents some main ideas but } \\
\text { these are limited and not } \\
\text { sufficiently developed; there } \\
\text { may be irrelevant detail }\end{array}$ & $\begin{array}{l}\text { - presents information with some } \\
\text { organisation but there may be a lack of } \\
\text { overall progression } \\
\text { - makes inadequate, inaccurate or over } \\
\text { use of cohesive devices } \\
\text { - may be repetitive because of lack of } \\
\text { referencing and substitution } \\
\text { - may not write in paragraphs, or } \\
\text { paragraphing may be inadequate }\end{array}$ & $\begin{array}{l}\text { - uses a limited range of } \\
\text { vocabulary, but this is minimally } \\
\text { adequate for the task } \\
\text { - may make noticeable errors in } \\
\text { spelling and/or word formation } \\
\text { that may cause some difficulty } \\
\text { for the reader }\end{array}$ & $\begin{array}{l}\text { - uses only a limited range of structures } \\
\text { attempts complex sentences but these } \\
\text { tend to be less accurate than simple } \\
\text { sentences } \\
\text { - may make frequent grammatical errors } \\
\text { and punctuation may be faulty; errors can } \\
\text { cause some difficulty for the reader }\end{array}$ \\
\hline 4 & $\begin{array}{l}\text { - responds to the task only in a } \\
\text { minimal way or the answer is } \\
\text { tangential; the format may be } \\
\text { inappropriate } \\
\text { - presents a position but this is } \\
\text { unclear } \\
\text { - presents some main ideas but } \\
\text { these are difficult to identify } \\
\text { and may be repetitive, } \\
\text { irrelevant or not well } \\
\text { supported }\end{array}$ & $\begin{array}{l}\text { - presents information and ideas but } \\
\text { these are not arranged coherently and } \\
\text { there is no clear progression in the } \\
\text { response } \\
\text { - uses some basic cohesive devices but } \\
\text { these may be inaccurate or repetitive } \\
\text { - may not write in paragraphs or their } \\
\text { use may be confusing }\end{array}$ & $\begin{array}{l}\text { - uses only basic vocabulary } \\
\text { which may be used repetitively } \\
\text { or which may be inappropriate } \\
\text { for the task } \\
\text { - has limited control of word } \\
\text { formation and/or spelling; errors } \\
\text { may cause strain for the reader }\end{array}$ & $\begin{array}{l}\text { - uses only a very limited range of structures } \\
\text { with only rare use of subordinate clauses } \\
\text { - some structures are accurate but errors } \\
\text { predominate, and punctuation is often } \\
\text { faulty }\end{array}$ \\
\hline 3 & $\begin{array}{l}\text { - does not adequately address } \\
\text { any part of the task } \\
\text { - does not express a clear } \\
\text { position } \\
\text { - presents few ideas, which are } \\
\text { largely undeveloped or } \\
\text { irrelevant }\end{array}$ & $\begin{array}{l}\text { - does not organise ideas logically } \\
\text { may use a very limited range of } \\
\text { cohesive devices, and those used may } \\
\text { not indicate a logical relationship } \\
\text { between ideas }\end{array}$ & $\begin{array}{l}\text { - uses only a very limited range of } \\
\text { words and expressions with } \\
\text { very limited control of word } \\
\text { formation and/or spelling } \\
\text { - errors may severely distort the } \\
\text { message }\end{array}$ & $\begin{array}{l}\text { - attempts sentence forms but errors in } \\
\text { grammar and punctuation predominate } \\
\text { and distort the meaning }\end{array}$ \\
\hline 2 & $\begin{array}{l}\text { - barely responds to the task } \\
\text { - does not express a position } \\
\text { - may attempt to present one or } \\
\text { two ideas but there is no } \\
\text { development }\end{array}$ & $\begin{array}{l}\text { - has very little control of organisational } \\
\text { features }\end{array}$ & $\begin{array}{l}\text { - uses an extremely limited range } \\
\text { of vocabulary; essentially no } \\
\text { control of word formation and/or } \\
\text { spelling }\end{array}$ & $\begin{array}{l}\text { - cannot use sentence forms except in } \\
\text { memorised phrases }\end{array}$ \\
\hline 1 & $\begin{array}{l}\text { - answer is completely } \\
\text { unrelated to the task }\end{array}$ & - fails to communicate any message & $\begin{array}{l}\text { - can only use a few isolated } \\
\text { words }\end{array}$ & - cannot use sentence forms at all \\
\hline 0 & \multicolumn{4}{|c|}{$\begin{array}{l}\text { - does not attend } \\
\text { - does not attempt the task in any way } \\
\text { - writes a totally memorised response }\end{array}$} \\
\hline
\end{tabular}




\section{Appendix 7 EFL teachers' scores}

EFL teachers' scores of the vocabulary, reading and writing tests $(n=62)$

\begin{tabular}{|c|c|c|c|c|c|c|c|}
\hline Teacher & $\begin{array}{c}2000 \\
\text { Word } \\
\text { List }\end{array}$ & $\begin{array}{c}3000 \\
\text { Word } \\
\text { List }\end{array}$ & $\begin{array}{l}5000 \\
\text { Word } \\
\text { List }\end{array}$ & $\begin{array}{c}10000 \\
\text { Word } \\
\text { List }\end{array}$ & $\begin{array}{c}\text { Academic } \\
\text { Word }\end{array}$ & $\begin{array}{c}\text { Reading } \\
\text { IELTS } \\
\text { band-scale }\end{array}$ & $\begin{array}{c}\text { Writing } \\
\text { IELTS } \\
\text { band-scale }\end{array}$ \\
\hline 1 & 14 & 12 & 7 & 0 & 3 & 3 & 5.5 \\
\hline 2 & 26 & 16 & 6 & 1 & 23 & 3.5 & 5.5 \\
\hline 3 & 29 & 29 & 24 & 14 & 28 & 5.5 & 6 \\
\hline 4 & 30 & 30 & 28 & 27 & 30 & 7 & 7 \\
\hline 5 & 27 & 25 & 17 & 6 & 29 & 6 & 5.5 \\
\hline 6 & 30 & 30 & 28 & 21 & 30 & 6 & 6 \\
\hline 7 & 29 & 28 & 22 & 0 & 30 & 3.5 & 6 \\
\hline 8 & 13 & 8 & 14 & 0 & 11 & 4 & 4 \\
\hline 9 & 29 & 20 & 9 & 6 & 23 & 5 & 5.5 \\
\hline 10 & 27 & 24 & 15 & 5 & 27 & 3 & 4 \\
\hline 11 & 23 & 25 & 22 & 13 & 20 & 5 & 4 \\
\hline 12 & 25 & 14 & 11 & 0 & 0 & 3 & 5 \\
\hline 13 & 21 & 13 & 14 & 8 & 15 & 5 & 4 \\
\hline 14 & 29 & 21 & 19 & 0 & 4 & 3.5 & 3 \\
\hline 15 & 27 & 24 & 3 & 2 & 17 & 5 & 4.5 \\
\hline 16 & 30 & 27 & 25 & 11 & 30 & 5 & 5.5 \\
\hline 17 & 23 & 25 & 12 & 0 & 20 & 5 & 5.5 \\
\hline 18 & 24 & 20 & 12 & 4 & 24 & 3 & 5 \\
\hline 19 & 29 & 24 & 18 & 1 & 26 & 5.5 & 6 \\
\hline 20 & 25 & 25 & 20 & 3 & 20 & 5 & 5 \\
\hline 21 & 30 & 30 & 28 & 17 & 30 & 5.5 & 5 \\
\hline 22 & 29 & 30 & 24 & 1 & 30 & 6.5 & 6.5 \\
\hline 23 & 24 & 20 & 20 & 5 & 21 & 4 & 5.5 \\
\hline 24 & 29 & 26 & 21 & 6 & 25 & 4.5 & 6 \\
\hline 25 & 29 & 26 & 21 & 6 & 24 & 5 & 6.5 \\
\hline 26 & 28 & 27 & 14 & 2 & 24 & 5 & 5.5 \\
\hline 27 & 30 & 29 & 28 & 12 & 27 & 6 & 6.5 \\
\hline 28 & 29 & 26 & 8 & 1 & 20 & 5 & 5 \\
\hline
\end{tabular}




\begin{tabular}{|c|c|c|c|c|c|c|c|}
\hline 29 & 29 & 28 & 21 & 11 & 27 & 4.5 & 6.5 \\
\hline 30 & 28 & 22 & 18 & 1 & 23 & 5 & 5.5 \\
\hline 31 & 28 & 20 & 21 & 5 & 26 & 5 & 6 \\
\hline 32 & 22 & 17 & 11 & 0 & 10 & 2.5 & 4.5 \\
\hline 33 & 28 & 18 & 22 & 2 & 25 & 2.5 & 3 \\
\hline 34 & 27 & 21 & 15 & 0 & 8 & 2 & 2.5 \\
\hline 35 & 26 & 25 & 15 & 1 & 18 & 2 & 4 \\
\hline 36 & 22 & 22 & 22 & 0 & 0 & 1 & 4 \\
\hline 37 & 29 & 24 & 22 & 8 & 24 & 3.5 & 5.5 \\
\hline 38 & 23 & 21 & 15 & 6 & 22 & 4.5 & 5 \\
\hline 39 & 30 & 29 & 28 & 16 & 30 & 6.5 & 5.5 \\
\hline 40 & 30 & 29 & 24 & 12 & 30 & 6 & 5 \\
\hline 41 & 30 & 24 & 24 & 10 & 29 & 5 & 5.5 \\
\hline 42 & 29 & 26 & 17 & 6 & 26 & 5 & 5 \\
\hline 43 & 24 & 21 & 17 & 0 & 19 & 4 & 5 \\
\hline 44 & 25 & 17 & 16 & 0 & 21 & 4.5 & 4 \\
\hline 45 & 30 & 30 & 23 & 6 & 29 & 6 & 6 \\
\hline 46 & 30 & 22 & 16 & 9 & 25 & 5 & 5 \\
\hline 47 & 30 & 27 & 25 & 6 & 30 & 5 & 5.5 \\
\hline 48 & 30 & 30 & 28 & 9 & 30 & 6 & 6 \\
\hline 49 & 28 & 27 & 21 & 11 & 28 & 6.5 & 7.5 \\
\hline 50 & 29 & 26 & 18 & 5 & 26 & 4.5 & 5.5 \\
\hline 51 & 30 & 27 & 25 & 12 & 28 & 3 & 6 \\
\hline 52 & 28 & 22 & 18 & 9 & 18 & 5 & 5 \\
\hline 53 & 30 & 25 & 27 & 14 & 28 & 6.5 & 5.5 \\
\hline 54 & 29 & 27 & 17 & 3 & 26 & 3.5 & 6 \\
\hline 55 & 30 & 29 & 24 & 0 & 27 & 6 & 5.5 \\
\hline 56 & 30 & 30 & 29 & 25 & 30 & 7 & 6.5 \\
\hline 57 & 29 & 29 & 27 & 15 & 28 & 6.5 & 6 \\
\hline 58 & 29 & 29 & 21 & 6 & 29 & 5.5 & 6 \\
\hline 59 & 30 & 30 & 26 & 13 & 30 & 6 & 6 \\
\hline 60 & 30 & 29 & 27 & 7 & 30 & 6.5 & 6 \\
\hline 61 & 30 & 28 & 28 & 20 & 30 & 8.5 & 6.5 \\
\hline 62 & 29 & 29 & 26 & 11 & 28 & 5.5 & 6.5 \\
\hline
\end{tabular}




\section{Appendix 8 Writing prompts}

- Appendix 8A Writing prompt 1

- Appendix 8B Writing prompt 2

- Appendix 8C Writing prompt 3

- Appendix 8D Writing prompt 4

- Appendix 8E Writing prompt 5

- Appendix 8F Writing prompt 6

- Appendix 8G Writing prompt 7

- Appendix 8H Writing prompt 8

- Appendix 8I Writing prompt 9 


\section{Appendix 8A Writing prompt 1}

\section{Welcome to the Blogging among In-Service Teachers research project! I am very pleased to be working with you.}

We have met face to face during my visit to Indonesia. I would like to reinforce some of the information I have given you during our meetings and provide a bit of new information as well.

Our group blog can be found on www.blogger.com. This is the place where you will find information about the course, assignments, and reading and videos. We will also use this site for our class discussions. You will soon be getting an email with an attached handout for instructions on how to: 1) get your assignments, 2) draft your blog posts, 3) post your ideas and 4) give comment to your friends' posts.

There are many resources and a lot of information on the site, and we will continue to build and add to it as the term goes along.

Please read the handout carefully and set up your blogger account as soon as possible so that you can join our course site, and meet our first task deadline by Thursday, Oct 24 (Pacific Standard Time). If you have any difficulty at any point in the process, please let me know as soon as possible, so that I can get you what you need.

One of the most effective ways to participate in a distance course of this nature is to check in regularly. Check your email and the blogger course site daily if possible to learn what other participants are saying and to make your own contributions. It can sometimes be uncomfortable getting started because it may be a new means of communication for many of you, but I am eager to hear from you and start getting to know you, so please don't hesitate to jump in. 


\section{Appendix 8B Writing prompt 2}

This is the first week of October. You must have been waiting for the results of the pre-tests and the coming tasks. For the results of the pre-tests, I could not give you the results for the moment. I have just done a quick check on the reading task. I might be some time for you to be able to receive the whole results. Do not worry about them.

Now, talking about the first task. The first task that I would like you to do is to post a self-introduction in the group blog that I have created for you. The main task for this month will come on the second week after you all introduce yourself to others.

Also a quick word about response time: in general I will get back to your emails as soon as possible, but definitely within 48 hours, barring unforeseen circumstances. Also, weekend (Saturday and Sunday) response time will likely be longer, with Sunday being a low or no response day. I realise that which days constitute the weekend vary throughout the world and you may be trying to complete class work in your off time, but please be aware that there may be slower response lags and don't panic if you don't hear back from me immediately.

If you have any questions or problems, please let me know! 


\title{
Appendix 8C Writing prompt 3
}

\begin{abstract}
Each month there will be a checklist of items required for the month. This will include readings, posting ideas in the group blog, and assignments related to the final projects.
\end{abstract}

You may consider downloading month's the articles and other files onto a flash drive or your desktop, to read at your leisure. For those who have limited or inconsistent internet connections, this is the best recommendation. This month's checklist includes the following:

1) Post a self-introduction on the course group blog (bloggingamongteachersa.blogspot.com or bloggingamongteachersb.blogspot.com) on Oct 14th at midnight, Pacific Standard Time.

2) Read the introductory article "Less Teaching, More Learning" (http://www.kaganonline.com/free_articles/dr_spencer_kagan/294/Teach-LessLearn-More)

3) Visit the two links on the introduction to Project-Based Learning (PBL): http://www.gsn.org/web/pbl/ and http://www.bie.org/

4) **OPTIONAL** view the videos of what PBL is and an example of the project.

a. http://www.bie.org/videos/video/project_based_learning_explained

b. http://www.bie.org/videos/video/learning_to_act_as_women_and_men

5) Post a response in the form of essay ( 250 to 500 words) to the article by answering the related questions by Monday, Oct 28th at midnight (PST).

The questions are:

* Do you agree with the idea of 'Less Teaching, More Learning' or/and ProjectBased Learning (PBL)? Please provide reasons why you agree or disagree to the idea.

* What might prevent the idea to be implemented in the Indonesian teaching and 
learning context?

* What might support the implementation in the Indonesian schools?

* If you have other opinion, please do not hesitate to share it with all of us.

Hopefully this addresses the question of how to proceed when you visit the blog. As usual, if you have any problems, questions or confusion, please do not hesitate to let me know!

Good luck, and we look forward to "meeting" you online! (1) Do you agree with the idea of 'Less Teaching, More Learning' and/or Project-Based Learning (PBL)? Please provide reasons why you agree or disagree with the idea, (2) What might prevent the idea to be implemented in the Indonesian teaching and learning context?, (3) What might support the implementation in the Indonesian schools?, and (4) If you have other opinions, please do not hesitate to share them with all of us. 


\section{Appendix 8D Writing prompt 4}

\section{Hi everyone!}

Thank to those of you who posted their self-introductions in the blog in October. It would be great to hear from the rest of you in November. When working in online groups like this one, a little bit of personal information and a photo makes a big difference! It was very exciting to see the first blog entries with your reflections on the article about "Less Teaching, More Learning". I can't wait to see the rest of your introductory posts and comments on the readings soon!

Since you are now in the middle of the semester, it must be almost time for midterm tests. This makes your next reading by Dave Dodgson very relevant, as it discusses the issue of how a test may be more of a hindrance rather than a help (http://www.davedodgson.com/2011/12/another-failure-for-exam-basedsystem.html).

In this article, Dave was talking about one of his students, ${ }^{*}$ Sarah (not her real name). She was upset and told her parents that she did not want to do her English homework anymore. She believed that she was not doing well in her English class. Why did she feel that way? What did Dave do to overcome the situation? What did he learn from the incident?

Note: Please read the full article from the link provided

Sounds familiar, isn't it? It will be great to have your thoughts and comments on this article. Please post them in the next two weeks. Once you have written your own blog post, please read other posts on the topic and continue the discussion by adding comments, or even creating another blog post. Let's get blogging!

Please remember that your active participation in this blog will be used to issue a certificate of participation at the end of the study. You also go in the draw to win 
one of four autographed-books by Professor Paul Nation - a world-renowned TESOL scholar. The first book will be drawn at the end of November. 


\section{Appendix 8E Writing prompt 5}

Kia ora tatou/greetings to everyone

I am writing to you because I'm interested in vocabulary teaching and learning in your context. I thought it might make an interesting discussion for your blogs. I think vocabulary is one of the most important aspects of learning another language - you could say vocabulary is a passion of mine.

I have found a text about vocabulary and language education written by Professor Paul Nation - one of our professors here at Victoria University of Wellington, New Zealand. In this short article, he discusses learning and teaching vocabulary through different kinds of classroom tasks and from different approaches. For your blogs, I would like you to read the article and comment on Nation's ideas and their connection to your classroom, your learners, and your context. For example, you might like to comment on the five principles he outlines later in the article, or you might like to discuss aspects of vocabulary such as fluency, learning through listening, and learner responsibility. Please visit this link:

http://www.victoria.ac.nz/lals/about/staff/publications/paul-nation/2006Language-education-vocabulary.pdf

Another thing you could try is Nation's Vocabulary Size Test - take the 20,000 version on this link - http://my.vocabularysize.com/. You could test your own vocabulary size and consider your results, and then perhaps test some of your students and see how they do. How useful is this vocabulary size test in your context? Do you think a bilingual Indonesian/English vocabulary size test might be more useful? Why/Why not?

Best wishes and I look forward to your discussion. 


\section{Appendix 8F Writing prompt 6}

This January I would like you to read (and listen to) an article about vocabulary: http://www.beeoasis.com/archives/15228. Please also read an online debate generated by the post. "Vocabulary acquisition, input, and extensive reading: A conversation". Follow this link: http://jalt-publications.org/tlt/articles/3152vocabulary-acquisition-input-and-extensive-reading-conversation and download the article.

After reading both articles please share your views in a blog post. What do you think about deliberate vocabulary learning and learning from reading? Do you that extensive reading (ER) is enough to increase L2 vocabulary?

How do you teach vocabulary at school? Does the approach you use work well? Why do you think so?

I really appreciate to those who posted in December. It would be great to hear from the rest of you this January. I am looking forward to seeing your posts and comments on the readings soon!

Your active participation in this blog is essential for the study. You are also still in for the draw to win one of four autographed-books by Professor Paul Nation - a world-renowned TESOL scholar. The first book has been drawn at the end of November. The next draw is at the end of February 2014. 


\section{Appendix 8G Writing prompt 7}

This month we are going to look at involving students in creating rubrics. Please visit the link: http://www.teachersfirst.com/lessons/rubrics/involvingstudents.cfm.

What would you say to the idea of involving students in creating rubrics? Please discuss both advantages and disadvantages of student generated assessment rubrics.

Please remember that another book will be drawn in the end of this month. Be ready for the prize! 


\section{Appendix 8H Writing prompt 8}

This March we will talk about listening skills. Nunan (2002) mentioned that listening was the Cinderella skill in second language learning. He explained that listening (just like Cinderella) had usually been overlooked by its elder sister speaking. I will send the article through your email.

Regarding Nunan's idea, how do you teach listening skills to your students? What are your challenges? I believe that listening is one of the skills tested in the National Examination (NE) for high school students in Indonesia. Do you teach listening skills to help the students to understand all kinds of listening materials or to assist them to be able to do the NE? Please provide reasons for your ideas.

I really appreciate those who posted in February. It would be great to hear from the rest of you this March. I am looking forward to seeing your posts and comments on the readings soon!

One more thing - congratulations to the winner of the book draw! The prize goes to Pak Hamdan. Once again, congratulations.

Reference:

Nunan, D. (2002). Listening in language learning. Methodology in Language Teaching: An Anthology of Current Practice, 238-241. 


\section{Appendix 8I Writing prompt 9}

(1) What do you think about teaching or learning writing using graphic organisers?

(2) Do you also think that graphic organisers help you to teach writing better? and

(3) Do you find graphic organisers helpful for learners? 


\section{Appendix 9 Seven guidelines for second language teacher institutional professional development}

\begin{tabular}{|c|c|}
\hline Guideline & Note \\
\hline $\begin{array}{l}\text { Determine the needs of both } \\
\text { the institution and its } \\
\text { teachers }\end{array}$ & $\begin{array}{l}\text { For the institutional needs, the judgment may go } \\
\text { to the head of schools, senior teachers and the } \\
\text { school management. For the individual needs, } \\
\text { they suggest that the decision is made based on } \\
\text { formal or informal conversation with teachers or } \\
\text { survey to teachers and school staff. }\end{array}$ \\
\hline $\begin{array}{l}\text { Set goals prior to the } \\
\text { administration of } \\
\text { professional development }\end{array}$ & $\begin{array}{l}\text { These goals should be based on the needs } \\
\text { analysis in the first guideline to keep the goals } \\
\text { realistic and practical to be achieved. }\end{array}$ \\
\hline Select the participants & $\begin{array}{l}\text { Becomes crucial because some teachers might } \\
\text { already have expertise in self-observation, team } \\
\text { teaching or journal writing. Clear procedures to } \\
\text { decide who should participate or not to } \\
\text { participate have to be considered carefully. }\end{array}$ \\
\hline $\begin{array}{l}\text { Consider principles of adult } \\
\text { learning }\end{array}$ & $\begin{array}{l}\text { For example, teachers as adult learners learn } \\
\text { through active involvement and their learning } \\
\text { must connect with their current understanding } \\
\text { (Richards \& Farrell, 2005: 19). The implication } \\
\text { of this principle is that there is a need for the } \\
\text { administrators to correlate what to learn and } \\
\text { what the teachers have known. }\end{array}$ \\
\hline $\begin{array}{l}\text { Support from the } \\
\text { institutions and from peers }\end{array}$ & $\begin{array}{l}\text { To ensure that the institutional and personal } \\
\text { goals are achieved, supports should be available } \\
\text { from institutions and from peers. The supports } \\
\text { can take many forms including financial } \\
\text { supports or non-financial support such as } \\
\text { allowing teachers to be away for seminar, }\end{array}$ \\
\hline
\end{tabular}


conference, training or visiting other schools.

Evaluate what has been $\quad$ By evaluating, it means that administrators and

learned teachers should be able to describe, justify and

improve their activities.

\begin{tabular}{ll}
\hline Share the results of the & $\begin{array}{l}\text { Sharing knowledge achieved from the activities } \\
\text { professional development }\end{array}$ \\
with their fellow teachers or wider audience will \\
help teachers to understand what they learned \\
better and other people can also learn from them.
\end{tabular}




\section{Appendix 10 Seven guidelines for second language teacher personal professional development}

\begin{tabular}{|c|c|}
\hline Guideline & Note \\
\hline $\begin{array}{l}\text { Decide what to learn about } \\
\text { their teaching and their } \\
\text { field }\end{array}$ & $\begin{array}{l}\text { The idea is for teacher not to stop learning after } \\
\text { they acquire their professional qualifications. } \\
\text { They need to decide their short-term and long- } \\
\text { term goals that correspond to their interest and } \\
\text { field they want to know more }\end{array}$ \\
\hline $\begin{array}{l}\text { Identify a strategy to } \\
\text { explore the topic they are } \\
\text { interested in }\end{array}$ & $\begin{array}{l}\text { Strategies refer to different activities the teachers } \\
\text { can do to facilitate the professional development. } \\
\text { They suggest that teachers start with some simple } \\
\text { activity such as self-monitoring to more complex } \\
\text { activity such as classroom action research. }\end{array}$ \\
\hline $\begin{array}{l}\text { Talk to people who have } \\
\text { taken part in a professional } \\
\text { development activity }\end{array}$ & $\begin{array}{l}\text { Having conversation with people who participated } \\
\text { in professional development and sharing ideas } \\
\text { about what they have been doing, what lessons } \\
\text { they learned from it and how to be able to gain the } \\
\text { most out of it is beneficial for self-reflection and } \\
\text { self-development }\end{array}$ \\
\hline $\begin{array}{l}\text { Decide what kind of } \\
\text { support they will need. }\end{array}$ & $\begin{array}{l}\text { Some activities such as writing journal or self- } \\
\text { monitoring may not need support from other } \\
\text { teacher or institutions. However, activities such as } \\
\text { peer-observation or team teaching will benefit } \\
\text { from getting support from other teachers and the } \\
\text { institutions where they work. }\end{array}$ \\
\hline $\begin{array}{l}\text { Select a colleague or } \\
\text { colleagues to work with }\end{array}$ & $\begin{array}{l}\text { This is especially true for collaborative teacher } \\
\text { development such as peer-coaching, team } \\
\text { teaching, or discussion group. }\end{array}$ \\
\hline $\begin{array}{l}\text { Set realistic goals and } \\
\text { establish a time frame }\end{array}$ & $\begin{array}{l}\text { Realistic goals refer to achievable and doable } \\
\text { goals for the teachers as individuals or groups to }\end{array}$ \\
\hline
\end{tabular}


accomplish in correlation to the time they have and dedicate into the professional development.

Evaluate what they have learned and share the results with others.
Stepping back and reviewing what hinders and supports the implementation of teacher development helps teachers to understand what works and does not work in the programme. Sharing the success stories and challenges of teacher development allows other teachers to learn from it and to give suggestion of how to improve or modify it for a better future implementation. 


\section{Appendix 11 Questions on teacher development for teachers}

\begin{tabular}{|c|c|c|}
\hline Questions & Teachers & Stakeholders \\
\hline $\begin{array}{l}\text { 1. What do you know about a professional } \\
\text { development (PD) programme? What is it? }\end{array}$ & $\sqrt{ }$ & $\sqrt{ }$ \\
\hline $\begin{array}{l}\text { 2. Tell me, what PD programmes are } \\
\text { available for EFL teachers in your district? }\end{array}$ & $\sqrt{ }$ & $\sqrt{ }$ \\
\hline $\begin{array}{l}\text { 3. What views do you have on PD } \\
\text { programmes? }\end{array}$ & $\sqrt{ }$ & $\sqrt{ }$ \\
\hline $\begin{array}{l}\text { 4. What do you think are their } \\
\text { goals/objectives? }\end{array}$ & $\sqrt{ }$ & $\sqrt{ }$ \\
\hline $\begin{array}{l}\text { 5. How are those objectives implemented, in } \\
\text { your experience? }\end{array}$ & $\sqrt{ }$ & -- \\
\hline $\begin{array}{l}\text { 6. What indicators are used to measure their } \\
\text { success? }\end{array}$ & $\sqrt{ }$ & $\sqrt{ }$ \\
\hline 7. Have you taken part in a PD programme? & $\sqrt{ }$ & $\sqrt{ }$ \\
\hline What was/were these programme/s? & & \\
\hline $\begin{array}{l}\text { 8. Is L2 proficiency maintenance is included } \\
\text { in PD programmes or not? }\end{array}$ & $\sqrt{ }$ & $\sqrt{ }$ \\
\hline $\begin{array}{l}\text { 9. (If not) Why not? What do you usually do } \\
\text { on PD programmes? Please describe the } \\
\text { activities. How effective and efficient are the } \\
\text { programmes? }\end{array}$ & $\sqrt{ }$ & $\sqrt{ }$ \\
\hline $\begin{array}{l}\text { 10. (If yes) How would you describe the } \\
\text { programme? What is like? How effective and } \\
\text { efficient are the programmes? }\end{array}$ & $\sqrt{ }$ & $\sqrt{ }$ \\
\hline 11. Do you know what I mean by Computer & $\sqrt{ }$ & $\sqrt{ }$ \\
\hline
\end{tabular}


Mediated Communication (CMC)? Is CMC

training offered to EFL teachers in the PD

programmes you've participated in?

12. What are the strengths and weaknesses of

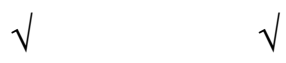

the training related to EFL teaching?

13. In your opinion, what are the challenges

$\sqrt{ }$

$\sqrt{ }$

of teacher education in the future?

14. What are the roles of PD in the teachers'

$--\sqrt{ }$

career progress?

15. Is there any format for PD? What is it

like? Or why there is no format?

16. What should/shouldn't the teacher do in a

$\begin{array}{lll}-- & \sqrt{ }-1 \\ \end{array}$

PD programmes? Are there any rules?

17. Before we finish, what questions or

$\sqrt{ }$

$\sqrt{ }$

comments do you have for me? 


\section{Appendix 12 Ethics Approval}

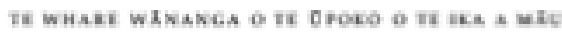

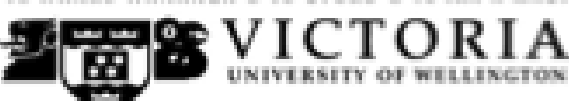

MEMORANDUM

Phane 04-4635076

Fax 04-4635009

Email Aliscnkirkmanînuwacne

\begin{tabular}{l|l}
\hline TO & Arik Wulyani \\
\hline COPY TO & Irina Elgort \\
\hline FROM & Dr Allison Kirkman, Corvener, Human Ettics Cormmittee \\
\hline
\end{tabular}

\begin{tabular}{l|l}
\hline DATE & 4 July 2013 \\
\hline PAGES & 1 \\
\hline
\end{tabular}

SUBJECT Ethics Approval: 19800

Blogging among in-service teachers

Thank you for your appication for ethical apgroval, which has now been considered by the Standing Commitee of the Human Ethics Committee.

Your application has been approved from the abowe date and this approval cantinues unt1 30 June 2015. If your data collection is not completed by this date you should apply to the Human Ethics Committee for an extension to this approval.

Best wishes with the research.

Alison Kirkman

Human Ethics Committee 